\title{
MASTER
}

\section{COMPENDIUM OF GAS AUTOCLAVE ENGINEERING STUDIES}

\author{
Y-12 Engineering Division \\ Edited by C. E. Muzzall
}

RELEASED FOR ANNOUNCBMENT

IN NUCLEAR SCIENCE ABSTRACTS

\author{
Y-12 PLANT \\ Oak Ridge, Tennessee
}

\section{UNION CARBIDE \\ UNION CARBIDE CORPORATION NUCLEAR DIVISIUN}

Operating the

OAK RIDGE GASEOUS DIFFUSION PLANT OAK RIDGE Y.12 PI ANT
- OAK RIDGE NATIONAL LABORATORY

- PADUCAH gaseous diffusion PLANT 


\section{DISCLAIMER}

This report was prepared as an account of work sponsored by an agency of the United States Government. Neither the United States Government nor any agency Thereof, nor any of their employees, makes any warranty, express or implied, or assumes any legal liability or responsibility for the accuracy, completeness, or usefulness of any information, apparatus, product, or process disclosed, or represents that its use would not infringe privately owned rights. Reference herein to any specific commercial product, process, or service by trade name, trademark, manufacturer, or otherwise does not necessarily constitute or imply its endorsement, recommendation, or favoring by the United States Government or any agency thereof. The views and opinions of authors expressed herein do not necessarily state or reflect those of the United States Government or any agency thereof. 


\section{DISCLAIMER}

Portions of this document may be illegible in electronic image products. Images are produced from the best available original document. 
Printed in USA. Price $\$ 6.00$. Available from the Clearinghouse for Federal Scientific and Technical Information, National Bureau of Standards,

U.S. Department of Commerce, Springfield, Virginia

\section{LEGAL NOTICE}

This report was prepared as an account of Government sponsored work. Neither the United States, nor the Commission, nor any person acting on behalf of the Commission:

A. Makes any warranty or representation, expressed or implied, with respect to the accuracy, completeness, or usefulness of the information contained in this report, or that the use of any information, apparatus, method, or process disclosed in this report may not infringe privately owned rights; or

B. Assumes any liabilities with respect to the use of, or for damages resulting from the use of any information, apparatus, method, or process disclosed in this report.

As used in the above, "person acting on behalf of the Commission" includes any employee or contractor of the Commission, or employee of such contractor, to the extent that such employee or contractor of the Commission, or employee of such contractor prepares, disseminates, or provides access to, any information pursuant to his employment or contract with the Commission, or his employment with such contractor. 
Date issued: August 23, 1965

Report Number Y-1478.

Engineering and Equipment

TID-4500 (37th Edition)

\section{UNION CARBIDE CORPORATION}

Nuclear Division

$$
\text { Y-12 PLANT }
$$

Contract W-7405-eng-26

With the US Atomic Energy Commission

\section{'COMPENDIUM OF GAS AUTOCLAVE ENGINEERING STUDIES \\ Y-12 Engineering Division \\ Edited by C. E. Muzzall}


Distribution:

Report Number Y-1478

Engineering and Equipment TID-4500 (37th Edition)

Bailey, E. W.

Baker, W. E. (SRI-San Antonio)

Ballenger, H. F. (2)

Bell, B. B.

Bernander, N.K.

Boyer, C. B. (Battelle-Columbus)

Burkhart, L. E.

Center, C. E. (ORGDP)

Christman, A. M.

Cowen, D. D. (ORNL)

Culler, F. L. (ORNL)

Ebert, J.W.

Evans, G.W.

Fortenbery, M. J.

Gambill, W. R. (ORNL)

Gorsline, G. W. (Pantex)

Griess, J. C. (ORNL)

Grim, M. S.

Gritzner, V. B.

Gwaltney, R. C. (ORNL)

Harding, J. E.

Harwell, W. L. (ORGDP)(5)

Heckert, W. E.

Hemphill, L. F.

Hensley, C. E.

Hoffman, H. W. (ORNL)

Huber, A. P. (ORGDP)

Huddleston, R.L.

Hulme, R. E.

Hunter, A. H.

Isham, G. E.

Jackson, V.C.

Jennings, D. A.

Johnson, C. E.

Jury, S. H. (ORNL)

Keller, C. A. (AEC-ORO)(4)

Lambert, F. J.

Levey, R. P.

Lewis, F. O. (ORGDP)

Little, J. C.

Long, $P$. J.

Lyon, R. N. (ORNL)

McLendon, J. D.

Mitchel, G. W.

Muzzall, C. E. (15)

Neeley, A. C.

Newhall, D. H. (Harwood-Walpole, Mass)

Patton, F. S.

Perry, A.E.

Pohto, H. A.

Rader, D. H.

Ross, W. D.

Schwenn, M. F.

Smith, W. T.

Sommerfeld, K. W.

St. Onge, C. D.

Sturm, R. G. (Huntsville)

Thomas, F. W.

Thompson, J. C.

Tilson, $F$. V.

Trotman, C. A.

Trotter, T. C.

Valentine, C. K.

Vavalides, S. P.

Waters, J. L.

Whitson, W. K.

Williams, J. L.

Williams, R. D.

Williamson, R. A.

Winkel, R. A. (Paducah)

Witt, F. J. (ORNL)

Yaggi, W. J.

Zurcher, $E$.

$Y-12$ Central Files (5)

$Y-12$ Central Files ( $Y-12 R C)$

In addition, this report is distributed in accordance with the category Engineering and Equipment, as given in the "USAEC Standard Distribution Lists for Unclassified Scientific and Technical Reports", TID-4500 (37th Edition), December 1, 1964. 


\section{ABSTRACT}

A compendium of nine articles on engineering studies has been prepured by the Engineering Division of the Oak Ridge $\mathrm{Y}-12$ Plant. These studies deal with two basic objectives: (1) the modification of an existing isostatic pressure vessel to permit the use of heatedargon gas as the pressure fluid, and (2) the choice of design parameters for a new future facility which will include a large pressure vessel to be operated as a gas autoclave. 


\section{THIS PAGE}

WAS INTENTIONALLY

LEFT BLANK 


\section{CONTENTS}

PREFACE ........................... 7

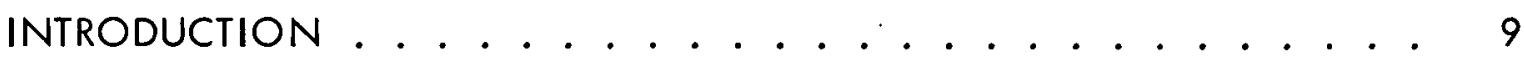

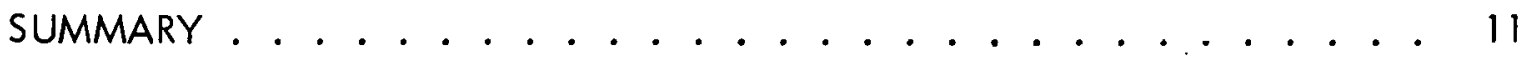

PART 1 - HAZARDS PERTAINING TO THE CONVERTED THIRTYINCH PRESSURE VESSEL . . . . . . . . . . . .

PART 2 - BLAST RESISTANT DESIGN .............. . . 55

PART 3 - MODIFIED NEWMARK ANALYTICAL METHOD FOR BLAST-RESISTANT CALCULATIONS . . . . . . . . . . 99

PART 4 - MECHANICAL DESIGN CRITERIA AND ANALYSES FOR CONVERTING PV-2 TO A GAS AUTOCLAVE . . . . . . 133

PART 5 - STRAIN GAGE TEST TO DETERMINE STRESSES AT THE ROOT OF THE INTERNAL THREADS OF CLOSURE ON A THIRTYYINCH PRESSURE VESSEL .......... 185

PART 6 - INTERPRETAIION ON THE EXPECTED FATIGUE LIFE OF A THIRTY-INCH PRESSURE VESSEL WITH THREADED CLOSURE . . . . . . . . . . . . 201

PART 7 - HEAT LOSS EVALUATION FOR Y-12 DEVELOPMENT FURNACE . . . . . . . . . . . . . 217

PART 8 - GAS AUTOCLAVE FACILITY DESIGN LIMITATIONS . . . . 239

PART 9 - SAFETY ANALYSIS FOR THE GAS AUTOCLAVE FACILITY . . . 253 


\section{THIS PAGE}

\section{WAS INTENTIONALLY}

\section{LEFT BLANK}




\section{PREFACE}

The information gathered in this compendium has resulted from a coordinated effort of many people over a two-year period. Nationally recognized experts and specialists, considered to be the most authoritative in the fields of ballistics, high-pressure te chnology, blast and shock effects, and other related disciplines, were consulted for data and guidance. The best qualified technical personnel in the $Y-12$ Plant and the Oak Ridge area were engaged in the investigations represented by this series of studies. We feel that the net result, as presented herein, is a worthwhile contribution to the engineering technology specifically required to present a logical solution to this type of problem. 
THIS PAGE

WAS INTENTIONALLY

LEFT BLANK 


\section{INTRODUCTION}

In late 1962, Union Carbide Management at the Oak Ridge Y-12 Plant became interested in developing facilities for high-pressure, high-temperature treatment of cermets, powder-metallurgy compacts, and other materials. It was visualized that 20,000 to 30,000 psi would be a practical working pressure level and that temperatures up to $2000^{\circ} \mathrm{C}$ could be achieved. A series of economic studies indicated that the initial step to be taken should be the modification of an existing isostatic pressure vessel for high-pressure, high-temperature service. It was immediately recognized that certain inherent features of the existing vessel would only permit it to operate at the lower end of the desired pressure range and at temperatures somewhat less than $2000^{\circ} \mathrm{C}$. The second step toward full capability under conditions of maximum desired pressure and temperature will require a completely new facility, designed on the basis of new criteria.

For identification purposes, the modification of an existing system is described as the "Thirty-Inch Pressure Vessel Conversion", and the new facility is identified as the "Gas Autoclave Facility".

It will be observed that the term "autoclave" used in this report has a restrictive meaning at variance with the conventional application of the word which normally suggests devices used for sterilizing and cooking by superheated steam under pressure. It has become accepted terminology among high-pressure industries to use the term "autoclave" to describe the devices which employ an inert gas such as helium or argon as the pressure medium in high-pressure, high-temperature processing.

During the early stages of engineering, UCC investigated the safety aspects of operating an existing thirty-inch pressure vessel, code $\mathrm{PV}-2$, as a gas autoclave. This vessel was designed to operate with a light mineral oil as the pressure medium.

The relative incompressibility of oil limits its energy of compression, whereas the compressibility of a gas permits the storage of a formidable amount of potential energy; however, the possibility of vessel rupture while under elevated gas pressure constitutes an explosion hazard literally of bomb proportions. Hence, the problems of barricading against expanding-gas shock waves and missile fragments be came paramount in importance. The first approach to the explosion hazard involved an accurate estimate of the releasable energy of rapidly expanding gas. This was a basic problem in thermodynamics which is treated in detail in Parts 1 and 9. Following a conventional simplifying assumption employed by ballistics laboratories, the expansion energy was translated into an equivalent amount of high explosive, such as pentolite, and the possible effects of the latter quantity were evaluated-effects such as shock wave and missile damage.

The principal components of a gas autoclave system include a pressure vessel, preferably with a quick-opening closure, a pressure-building system (called an intensification system), a cooling liner on the inside diameter of the vessel for protection of the 
vessel wall from heat damage, and a furnace mounted within the vessel cavity and insulated to minimize heat loss to the cooling liner. Modification of the existing PV-2 includes the provision for a new argon-gas intensification system, a new hightemperature furnace with power supply and controls, the installation of a cooling liner, the installation of two new "mushroom" seals, and modifications of the vessel containment cell to provide additional blast resistance. The argon intensifier will be a unit built by the Cosmodyne Corporation, Hawthorne, California and will consist of a piston-type compressor for pressurizing liquid argon to 20,000 psi at the rate of about $1.8 \mathrm{gpm}$ and an electric vaporizer which converts liquid argon to the gas phase at full pressure at the rate of $200 \mathrm{scfm}$.

The Gas Autoclave Facility has passed the conceptual engineering phase as a project and is awaiting AEC approval. If the project materializes, UCC will design a major part of the equipment, auxiliaries, and containment structures. The remainder of the design will be assigned to architect engineers and design specialists. An outline of the design parameters for the project is given in Part 8.

Acknowledgement is extended to the many sources and authorities given in the reference listings at the end of each part in this compendium. Special appreciation is expressed to the following institutions and individuals who have been particularly helpful in providing assistance to UCC: Battelle Memorial Institute, Columbus, Ohio; Ballistic Research Laboratories, Aberdeen Proving Ground, Maryland; Bettis Atomic Power Laboratories, Pittsburgh, Pennsylvania; Dr. Wilfred E. Baker, Aircraft Armaments, Incorporated, Cockeysville, Maryland; C. B. Boyer, Battelle Memorial Institute; Dr. Stanley H. Jury, The University of Tennessee, Knoxville, Tennessee; and Dr. R. G. Sturm, Huntsville, Alabama.

One purpose of this document is to acquaint other government contractors with $Y-12$ 's efforts in the high-pressure, high-temperature field. $Y-12$ will welcome comments or questions from any organization in regard to either the information in these studies or to related technical aspects not covered here. 


\section{SUMMARY}

Parts 1 through 7 are related to certain modifications and additions of an existing thirty-inch-ID isostatic pressure-vessel facility. This vessel was originally designed and equipped to operate at room temperature and at 30,000 psi with mineral oil as the pressure medium. The modifications, when completed, will permit operation with heated argon gas. A maximum temperature of $1500^{\circ} \mathrm{C}$ and a maximum pressure of $20,000 \mathrm{psi}$ are the limiting parameters for this vessel. For initial operations, the temperature limit will be $1000^{\circ} \mathrm{C}$.

The energy of compression stored in the gas will be much greater than the energy normally encountered with mineral oil. Hence, the hazard of a potential vessel rupture under gas pressure is much more severe than the hazard of a rupture with oil. Assessment of the new hazards associated with heated-gas pressurization is covered in Parts 1, 2, and 3. The impact of rupture upon barricading is evaluated and the effect of shock waves in air upon operating personnel is studied.

Part 4 is devoted to design problems of the mechanical modifications to the vessel itself. Parts 5 and 6 cover an evaluation of the life expectancy of the vessel on the basis of metal-fatigue studies. A study of heat-transfer phenomena in high-pressure argon is presented in Part 7, which serves as a guide for furnace design.

Parts 8 and 9 are devoted to a consideration of the design parameters and safety hazards of a proposed new Gas Autoclave Facility which centers around a forty-eightinch-ID pressure vessel. Maximum design operating conditions are set at 30,000 psi and $2000^{\circ} \mathrm{C}$. 


\section{THIS PAGE}

\section{WAS INTENTIONALLY LEFT BLANK}


PART 1

HAZARDS PERTAINING TO THE CONVERTED

THIRTY-INCH PRESSURE VESSEL

Walker T. Smith 
THIS PAGE

WAS INTENTIONALLY

LEFT BLANK 
CONTENTS

SUMMARY .................... 17

HAZARDS PERTAINING TO THE CONVERTED THIRTY-INCH

PRESSURE VESSEL . . . . . . . . . . . . 19

Background Information . . . . . . . . . . . . . 19

Introduction ................. . . 19

Existing Facility. . . . . . . . . . . . . . . . . 19

Proposed Operating Conditions . . . . . . . . . . . . 21

Statement of the Problem. . . . . . . . . . . . . . . . 22

Approach to the Problem. . . . . . . . . . . . . . . . . 22

Major Contributors to the Conclusions from the Study. . . . . . . . . . . . 24

Discussion of the Problem . . . . . . . . . . . . . . 25

Modes of Failure . . . . . . . . . . . . . . . . . 25

Experience in the Failure of Pressure Vessels . . . . . . . . . 26

Total Releasable Energy in the System . . . . . . . . . . . . 27

Maximum Blast Wave Condition . . . . . . . . . . . . . . 30

Missile Effect. . . . . . . . . . . . . . . . . . . . . 32

Strength of the Containment Cell . . . . . . . . . . 37

Modifications to be Made to the Existing Cell . . . . . . . . . . 37

Conclusions . . . . . . . . . . . . . . . 37

APPENDIX A $(S Y M B O L S) \ldots \ldots 43$

APPENDIX B (ENERGY-MASS RELATIONSHIP FOR MISSILES) . . . . . 47

APPENDIX C (BIBLIOGRAPHY)............... . . 53 


\section{THIS PAGE}

\section{WAS INTENTIONALLY LEFT BLANK}




\section{SUMMARY}

This report covers a study of the hazards involved in operating an existing pressure vessel (PV-2) in Building 9204-2, Y-12 Plant, after conversion to gas operation. A determination of the energy which would be released in case of vessel failure and the effect it would have on the surroundings has been made. It has been shown that the maximum energy release by the system is in the range of that released by a 40 to 50-pound TNT explosion, and that the containment cell walls are conservatively rated for personnel protection from incidents in the same range of energies. 
THIS PAGE

\section{WAS INTENTIONALLY \\ LEFT BLANK}




\section{HAZARDS PERTAINING TO THE CONVERTED \\ THIRTY-INCH PRESSURE VESSEL}

\section{BACKGROUND INFORMATION}

\section{Introduction}

The $Y-12$ Plant plans to convert a high-pressure vessel from use with mineral oil at 30,000 psi to argon at 20,000 psi. Although the pressure level is being lowered, the gas operation involves a much greater hazard because of the great compressibility of the argon relative to oil. Since the hazards connected with this type of operation are not very well understood, and in view of the failure of a pressure vessel in $Y-12$ in 1956, this study has been prepared to acquaint all interested personnel with the dangers involved, the methods of determination of the hazard, and the precautionary measures which will be taken to insure the safety of $Y-12$ personnel and equipment.

Existing Facility

The vessel to be converted is a screwed-plug unit (designated as $\mathrm{PV}-2$ ) and is very similar in design to an artillery piece (see Figure 1). The physical dimensions are:

Inside Diameter (in)

Inside Length (in)

Maximum Outside Diameter (in)

Outside Length (in)

Total Weight (lbs)

\section{Before Conversion}

30

120

70

237

186,000
After Conversion

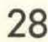

46

70

237

191,000

The wall is constructed of three individual sleeves shrunk together so that the inside sleeve is in compression when the internal pressure of the vessel is zero. The vessel has been completely disassembled, inspected and tested, and found to be in excellent condition. It was thus concluded that a safety factor of at least 1.5 exists in the vessel and that any failure is unlikely in 20,000-psi operation.

The vessel is mounted in a concrete containment cell at the northwest corner of Building 9204-2. The cell is approximately 16 by 16 by 45 feet high and is constructed of 12-inch-thick concrete walls (Figure 2). The concrete is reinforced with Size 5 bars on 10-inch centers, both horizontal and vertical, one inch in from each surface. The ronf slab is five-inches thick. A discussion of the changes to be made to this cell to further strengthen it is given under "Modifications to be Made to Existing Cell", Page 37.

A vessel very similar to this failed under a hydraulic pressure of approximately 28,500 psi in 1956. It was located in a containment cell identical to the one currently under discussion. The vessel failed by rupturing radially at the root of the 


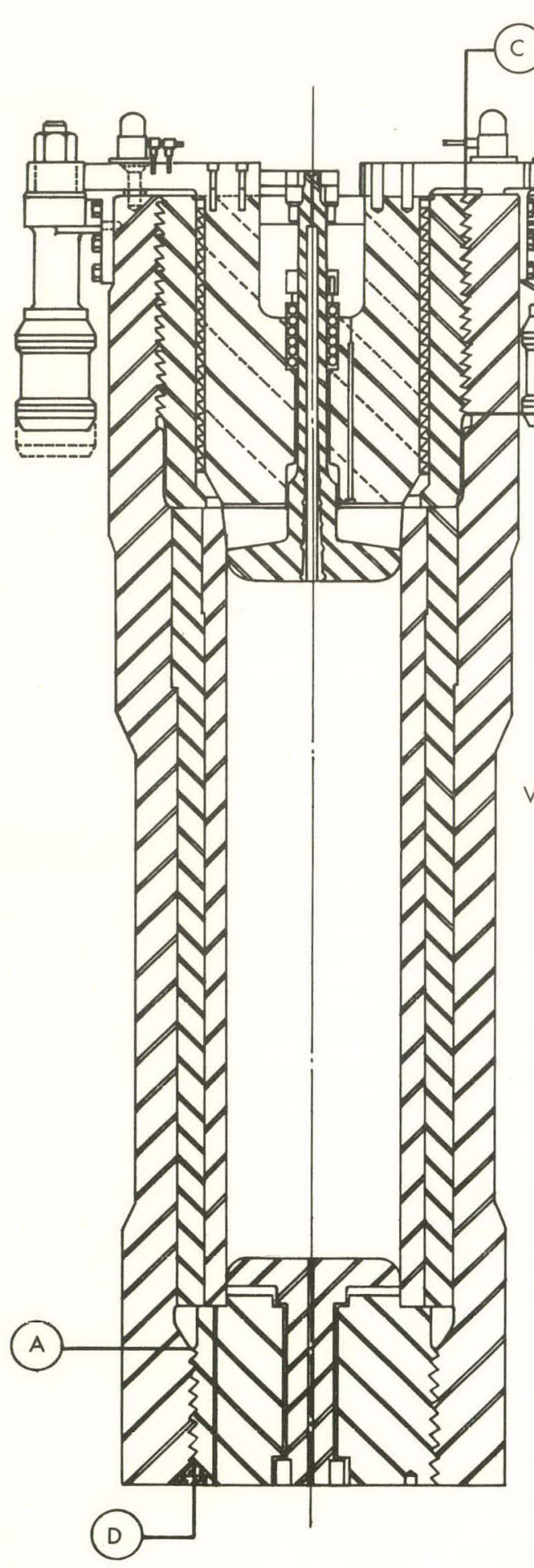

(A) Before Conversion

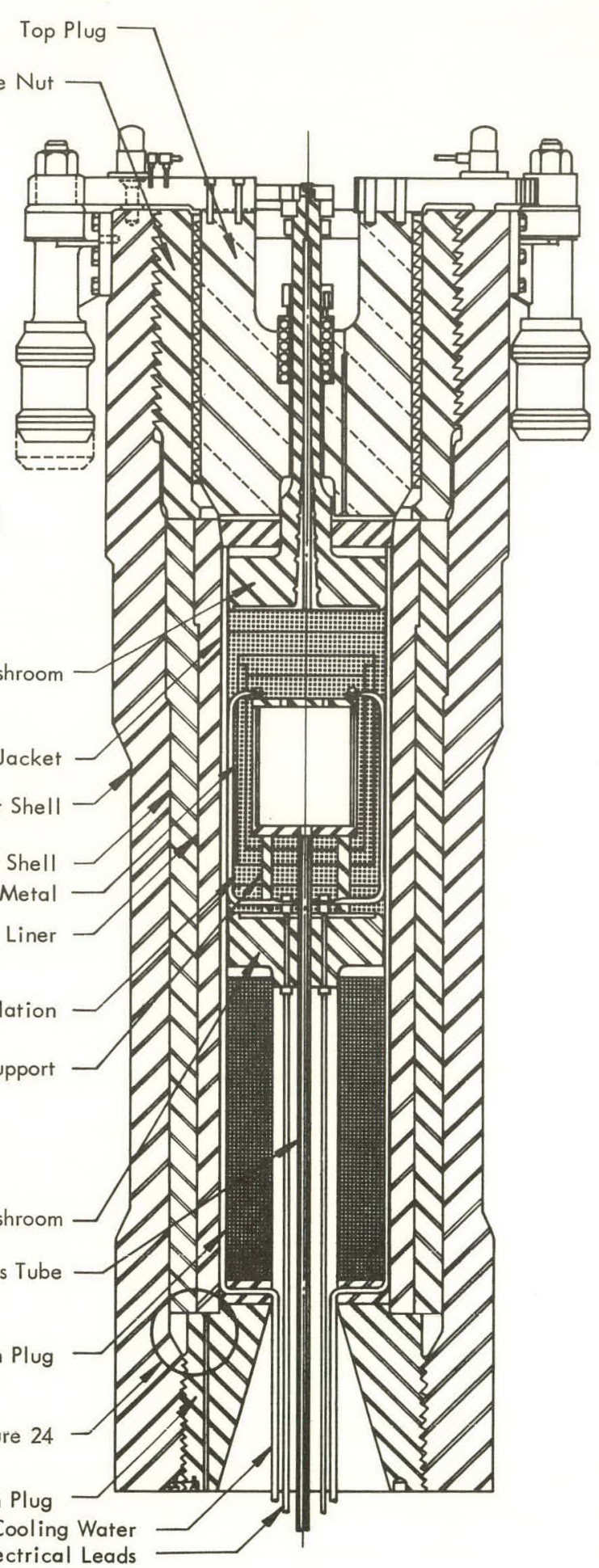

(B) After Conversion

Figure 1. PRESSURE VESSEL 2. (Before and After Conversion) 


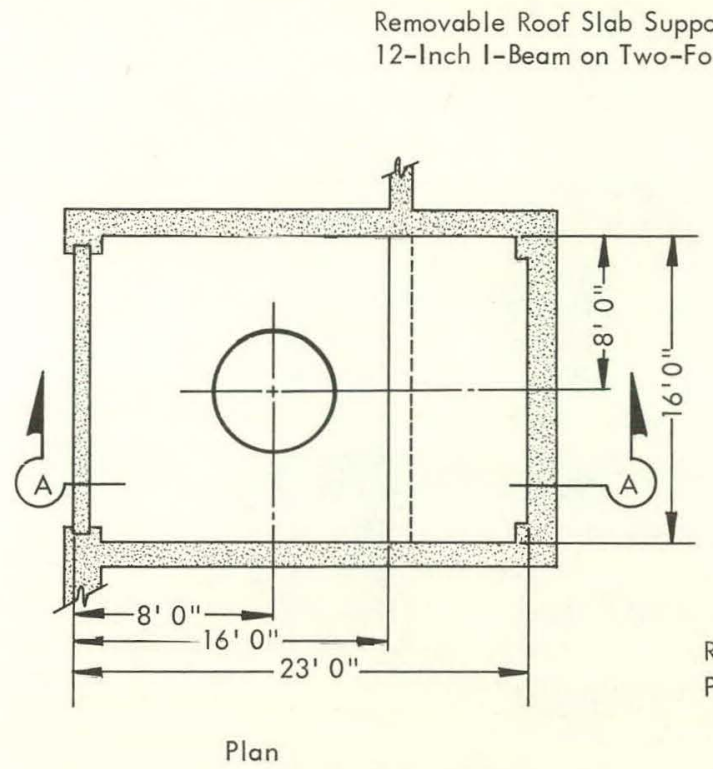

NOTES:

1. All walls are double-reinforced concrete, onefoot thick.

2. Removable roof slab is five-inches thick and stacked six-feet high with sand bags.

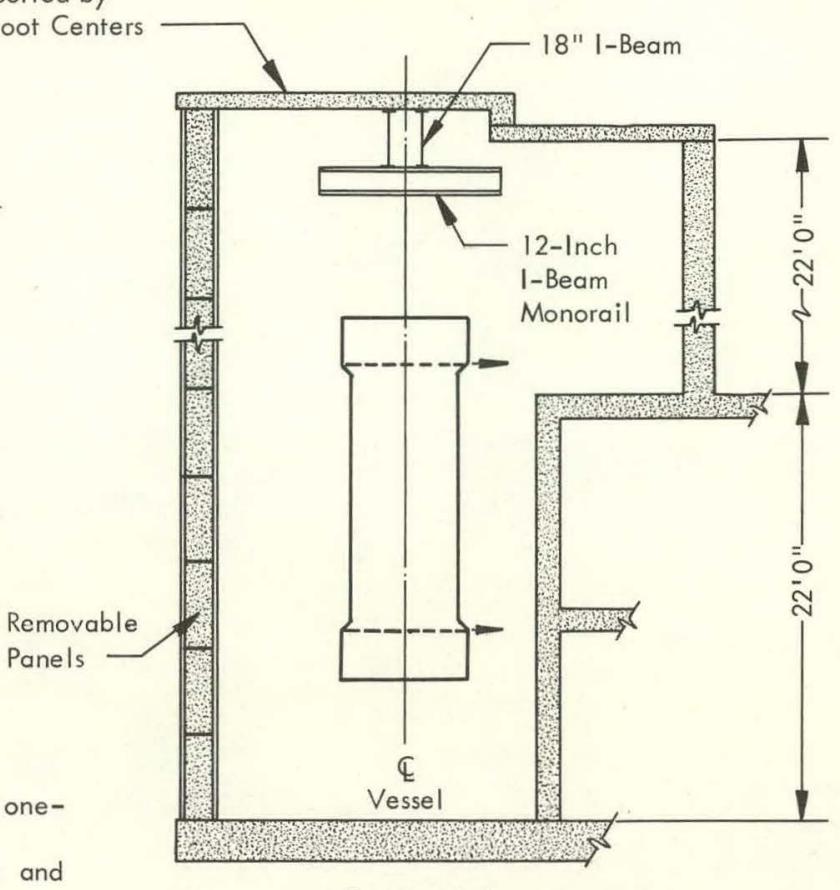

Sectional Elevation A-A

Figure 2. CONTAINMENT CELL FOR PRESSURE VESSEL 2.

first thread of the lower screwed closure, shown as Point $A$ in Figure 1(A). Upon failure, the main portion of the vessel was lifted up an unknown distance (probably about 18 inches) and fell back into the bottom of the cell. Although the vessel was completely fractured and the structural supports damaged extensively (Figure 3), no damage was incurred outside the cell and only very minor damage to the cell itself.

\section{Proposed Operating Conditions}

The vessel is to be fitted with a high-temperature furnace for treatment of a workpiece at a maximum pressure of $20,000 \mathrm{psi}$ and a maximum temperature of $1500^{\circ} \mathrm{C}$. The vessel will be operated at the same time that other pressure vessels in the area are in operation. All are controlled from a common control room. A typical operating cycle is as follows:

\section{Operation}

Time

Operation
Workpiece Loaded into Furnace and Vessel Closed
Vessel Evacuated and Purged
Vessel Pressurized and Heated
Soak Period
Cool Down
Workpiece Unloaded

(hrs) 


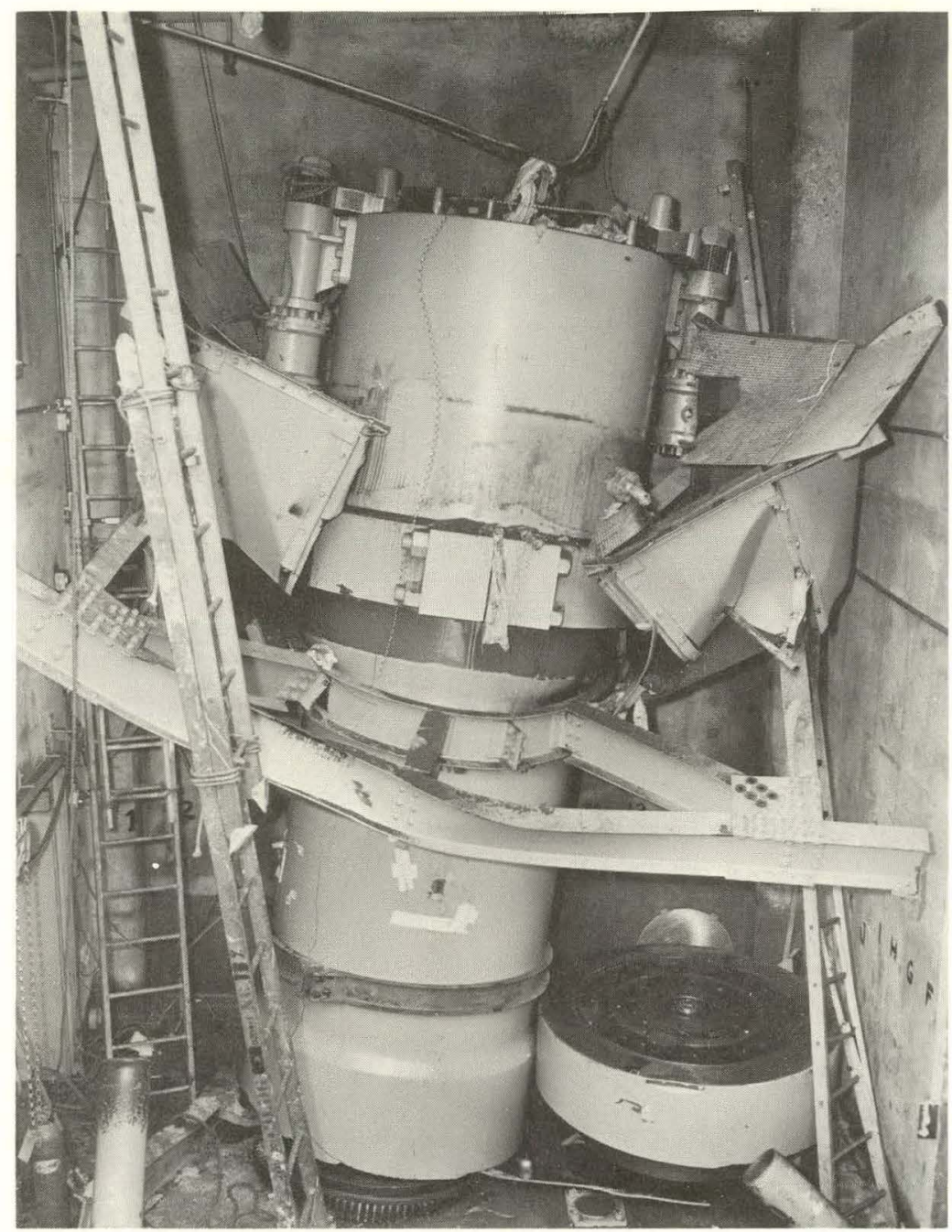

$13496 \mathrm{~A}(\mathrm{U})$

Figure 3. FAILED PRESSURE VESSEL SHOWING DAMAGE TO THE VESSEL AND TO THE CONTAINMENT CELL AREA.

The pressure intensification will be accomplished by pumping liquid argon to 20,000 psi and vaporizing it in electric vaporizersbefore introducing it into the vessel. The vessel will be kept cool by a flow of water through a cooling jacket inside the vessel wall.

\section{STATEMENT OF THE PROBLEM}

The major problem is concerned with determining the amount of energy available in case of a vessel failure and its most probable effect upon the surroundings. The energy released in the expansion of the gas from 1360 atmospheres to one atmosphere can be determined by assuming a thermodynamic path for the expansion and calculating the energy of such an explosion. The effect this energy would have on the 
surroundings, however, is difficult to determine directly. In practice, a comparison must be made with the energy release of some force, details of the effect of which are known. The energy level can be related to an equivalent weight of a chemical explosive such as TNT or pentolite, and the effects of these agentshave been studied at length by the US Army, USAEC, and others. As is well known, the effects of an explosion are to propel fragments or missiles and to form a blast or shock wave. The next problem then is to determine what proportions of the total releasable energy are used up in these two effects.

Once the size and velocity of probable missiles are determined and the strength of the blast calculated, it is necessary to determine the ability of the containment cell to resist these destructive forces.

It must be borne in mind that the remainder of the building must remain intact and operable in case of failure of this vessel. Furthermore, the vessel is located in close proximity to other buildings and heavily traveled streets. It is imperative then that the cell not only contain any explosion resulting from vessel failure but that it remain intact so that falling particles or flying concrete do not become secondary missiles and create additional hazards.

\section{APPROACH TO THE PROBLEM}

Since the overall problem was quite complicated and in a field not generally well known, a systematic approach was indicated. The method of attack is outlined in the sections that follow.

1. Determine the probability of various failure modes. Make an attempt at determining the weaker portions of the vessel through a complete stress analysis and experience gained from the previous failure.

2. Determine the experience of other installations. It was found that at least two other installations are using high-pressure gas vessels: Battelle Memorial Institute and the Bettis Atomic Laboratories of Westinghouse. In addition, a larger number of concerns have high-pressure liquid vessels, some of which are:

Battelle Memorial Institute

Westinghouse

General Electric

NASA

Livermore Radiation Laboratories

Pantex Ordnance Works
US Navy

Sylvania Elecilıic Cu

Monsanto Chemical Co

Autoclave Engineers

High Pressure Equipment Co

Southwest Research Institute

Several of these facilities were contacted and in some cases visited to determine their experiences In this field. 
3. Contact additional outside firms for assistance. In addition to the installation having similar equipment, other organizations having general knowledge of explosive effects were contacted; namely:

\author{
Aircraft Armaments, Inc \\ Ballistic Research Laboratories, US Army \\ Armour Research Foundation \\ Institute for Defense Analysis, USDOD \\ Union Carbide Corporation, Chemicals Division \\ The University of Tennessee \\ Harwood Engineering Co
}

4. Determine the releasable energy in the system. It was decided to have several eminent people in the fields of gas expansion and thermodynamics suggest their approach to this calculation. The consensus was that a reversible adiabatic was the best thermodynamic path to utilize, and that by utilizing this method, a conservative or higher-than-actual value would be obtained for the releasable energy.

5. Determine how the energy is utilized once the vessel fails. Dr. Wilfred Baker was interviewed and his services were secured to study this phase of the problem. His background with the US Army in the field of interior ballistics qualifies him as one of the outstanding authorities in this field.

6. Determine the effect of this energy release on its surroundings. Several outside contacts were made to evaluate this phase of the problem. Dr. Baker included his opinion in his report.

Others contacted were:

Dr. Joseph Sperrazza, Ballistic Research Laboratories, US Army Dr. Francis B. Porzell, Institute for Defense Analysis, US Department of Defense Mr. Gene Gorsline, Pantex Ordnance Works, USAEC

In addition to these outside contacts, an exhaustive literature search was made for experimental work done in this field.

\title{
MAJOR CONTRIBUTORS TO THE CONCLUSIONS FROM THE STUDY
}

The following people made significant contributions to the conclusions reached in this study:

1. Dr. Stanley H. Jury, Professor of Chemical Engineering, The University of. Tenessee, currently under consulting contract to the Oak Ridge National Laboratory for general chemical engineering and thermodynamic analysis. 
2. Dr. Wilfred E. Baker, Principal Design Engineer for Aircraft Armaments, Inc, Cockeysville, Md, formerly with the US Army Ballistics Research Laboratories, Aberdeen Proving Ground, Maryland. Dr. Baker has worked with the Interior and Terminal Ballistics Section for some 14 years and is considered an outstanding authority on explosive effects and containment structures.

3. Dr. Francis B. Porzell, Institute for Defense Analysis, US Department of Defense, Washington, DC, formerly with Armour Research Foundation and a consultant to the Los Alamos Scientific Laboratory on the Pacific Nuclear tests. Dr. Porzell is an authority in the field of blast physics, effects of atomic weapons, mechanics of strong shocks, and reactor containment.

4. Mr. Charles E. Boyer, Chief of Equipment Section, Advanced Materials Development Division, Battelle Memorial Institute, Columbus, Ohio. Mr. Boyer has been concerned with the operation of high-pressure gas vessels at Battelle since 1957 and is one of the pioneers in the field. He is currently operating several such vessels and has assisted in the design of similar installations at other places. $\mathrm{His}$ vast knowledge and experience in the field has been invaluable to this study.

5. The staff of Ballistics Research Laboratory, Aberdeen Proving Ground, Maryland, especially Dr. Joseph Sperrazza, Director. BRL has been concerned for many years with the interior conditions of pressure vessels (artillery barrels) and the effects of artillery shells at impact. This study includes barricading against the effects of same. Much basic research has been done and BRL reports were used extensively in this study.

6. Pantex Ordnance Plant, Amarillo, Texas, operated by Mason and Hanger, Silas Mason $\mathrm{Co}$, Inc. This plant has experience both in the pressure vessel (liquid) field and the field of chemical explosions. Studies made by personnel of that plant have proved valuable in determining overpressures resulting from explosions, and their designs of various containment cell features are considered superior.

\section{DISCUSSION OF THE PROBLEM}

Modes of Failure

There are various modes of failure which could occur in this vessel. The types of failure are listed in order of their probability and discussed in the paragraphs that follow. Figure $\mathrm{I}(\mathrm{A})$ shows the locations,

Radial Failure of the Vessel Wall at the Lower Closure (A) - The failures discussed in the following paragraph indicate that the most susceptible spot for failure is probably at the root of the first thread of a threaded closure. This failure consists of a brittle failure of the vessel wall completely around the circumference at the lower closure. It is considered as the most likely mode of failure. A missile 
consisting of the main vesse I wall and upper closure assembly weighing approximately 156,000 pounds would be propelled upward and the remainder of the energy would be used to form a shock wave.

Radial Failure of the Vessel Wall at the Upper Closure (B) - This is the same type failure as just describedbut occurring at the root of the first thread of the top sleeve nut. It is not as likely to occur since the stress level at the top is only $80 \%$ of that at the bottom.

Longitudinal Failure of the Vessel Wall - This mode of failure would constitute a split of the vessel wall with the end plugs remaining intact. No missiles would be formed and the total available energy would be dissipated in the form of a shock wave. This failure is very unlikely to occur, since the vessel wall is composed of three individual layers or laminations. For such a failure to occur, all three would have to fail simultaneously and at the same point.

Shear Failure of the Top Closure (C) - This failure will occur if the threads on either the sleeve nut or the top plug shear off allowing the plug assembly to be propelled out of the main vessel wall. This failure is considered very improbable since the shear stresses in the threads are very low (less than $3000 \mathrm{psi}$ ).

Shear Failure at the Bottom Closure (D) - Same as just discussed except that failure of the lower plug threads would occur.

Fragmentation of the Vessel into Small Missiles - This failure would be analogous to the explosion of a hand grenade in that the walls would break into small fragments and be scattered over a large area. Both missile damage and shock would be expected from this type of failure, but is considered very improbable. This failure could only occur if the elastic limit of the vessel material were exceeded in many places simultaneously. Since the only energy available is that in the gas, no sudden overpressures can occur, and this failure is not further considered.

Failure of Such Components as Fittings and Valves - This failure is perhaps more likely to occur than any other. It would not be catastrophic and could occur because of the improper assembly of piping, defective parts, or many other causes. Since any containment which will be adequate for safe operation of the vessel proper will be adequate for these small missiles, no further discussion of this hazard will be presented.

Experience in the Failure of Pressure Vessels

At least four high-pressure vessels have been known to fail catastrophically. Of these, three failed by brittle fracture of the vessel wall initiated from a crack or imperfection at the root of the first thread on the bottom closure. Metal fatigue is the suspected cause in all cases. The additional known failure was a shear failure of the threads of the top closure and was believed to be caused by poor fit of the 
closure to the vessel proper. No cases are known in which a vessel of this type has failed by total fragmentation although in at least one of the cases several small fragments spalled off from the outer layer of the vessel wall, forming small missiles.

Total Releasable Energy in the System

In order to determine the releasable energy in the system, the gas laws have been utilized and several basic assumptions have been made, all of which represent a conservative approach and tend to show the explosive hazard as being greater than it actually is. These assumptions are: (1) the argon behaves as a perfect gas; (2) the expansion of the gas upon failure of the vessel is reversible and adiabatic; and (3) when converting the available energy to equivalent weights of explosive, the heat of detonation alone is used rather than the total heat of formation.

The assumption of a reversible adiabatic expansion requires the expanding gas to follow the path:

$$
P_{v}^{k}=\text { Constant }^{(a)}
$$

where:

$P$ represents the pressure,

$\checkmark$ is the specific volume, and

$k$ is the ratio of the specific heats

from an initial state which is the operating condition of the vessel $\left(P_{i} v_{i} T_{i}\right)$ to a final state $\left(P_{f} \vee f(f)\right.$ dictated by pressure equilibrium with the surrounding atmosphere.

Now the energy available $(E)$ in this process may be represented by:

$$
\begin{aligned}
\frac{E_{i-f}}{W} & =\int_{i}^{f} P d v \\
& =c \int_{i}^{f} v^{-k} d v
\end{aligned}
$$

(a) A compilation of all general symbols used in this mathematical treatment is given in Appendix A. 


$$
\begin{aligned}
& \left.=c \frac{v^{1-k}}{1-k}\right]_{i}^{f} \\
& =c\left(\frac{v_{f}^{1-k}-v_{i}^{1-k}}{1-k}\right),
\end{aligned}
$$

and since

$$
\begin{aligned}
& C=P_{i} v_{i}^{k}=P_{f} v_{f}^{k} \\
&= \frac{\left(P_{i} v_{i}^{k}\right)\left(v_{i}^{1-k}\right)-\left(P_{f} v_{f}^{k}\right)\left(v_{f}^{1-k}\right)}{k-1} \\
&= \frac{P_{i} v_{i}-P_{f} v_{f}}{k-1}, \\
& E=\frac{W}{k-1}\left(P_{i} v_{i}-P_{f} v_{f}\right),
\end{aligned}
$$

where:

W represents the total weight of the gas in the process.

It is known that

$$
v=\frac{V}{W},
$$

therefore

$$
v_{i}=\frac{v_{i}}{W},
$$

and

$$
v_{f}=\frac{v_{f}}{W},
$$

where: 
$V$ is the total volume of gas.

Then,

$$
E=\frac{1}{k-1}\left(P_{i} V_{i}-P_{f} V_{f}\right)
$$

If Equation 3 is now divided by the initial volume $\left(V_{i}\right)$ of gas:

$$
\frac{E}{V_{i}}=\frac{1}{k-1}\left[P_{i}-P_{f}\left(\frac{V_{f}}{V_{i}}\right)\right] \text {. }
$$

And, since

$$
\begin{gathered}
\frac{V_{f}}{V_{i}}=\left(\frac{P_{i}}{P_{f}}\right)^{\frac{1}{k}}, \\
\frac{E}{V_{i}}=\frac{1}{k-1}\left[P_{i}-P_{f}\left(\frac{P_{i}}{P_{f}}\right)^{\frac{1}{k}}\right]
\end{gathered}
$$

represents the available work as a function of pressure and initial volume alone. The assumption of a perfect gas gives: $k=5 / 3$ for argon (a monatomic gas), and the resultant equation is:

$$
\frac{E_{i-f}}{V_{i}}=1.5\left[P_{i}-P_{f}\left(\frac{P_{i}}{P_{f}}\right)^{0.6}\right],
$$

where:
$E$ is expressed in foot pounds, and
$P$ is in pounds per square foot.

In order to utilize the work of Goodman $(b)$ to determine the shock wave pressure and impulse upon the cell walls, the releasable energy may now be compared to an

(b) BRL Report 1022, scc BIBLIOGRAPHY. 
equivalent weight of explosive by the relation: $1 \mathrm{lb}$ of explosive $=1,540,000 \mathrm{ft}$ lbs of energy. These explosive equivalent weights have been calculated for various operating pressures and are plotted in Figure 4 as a function of the free volume of the vessel.

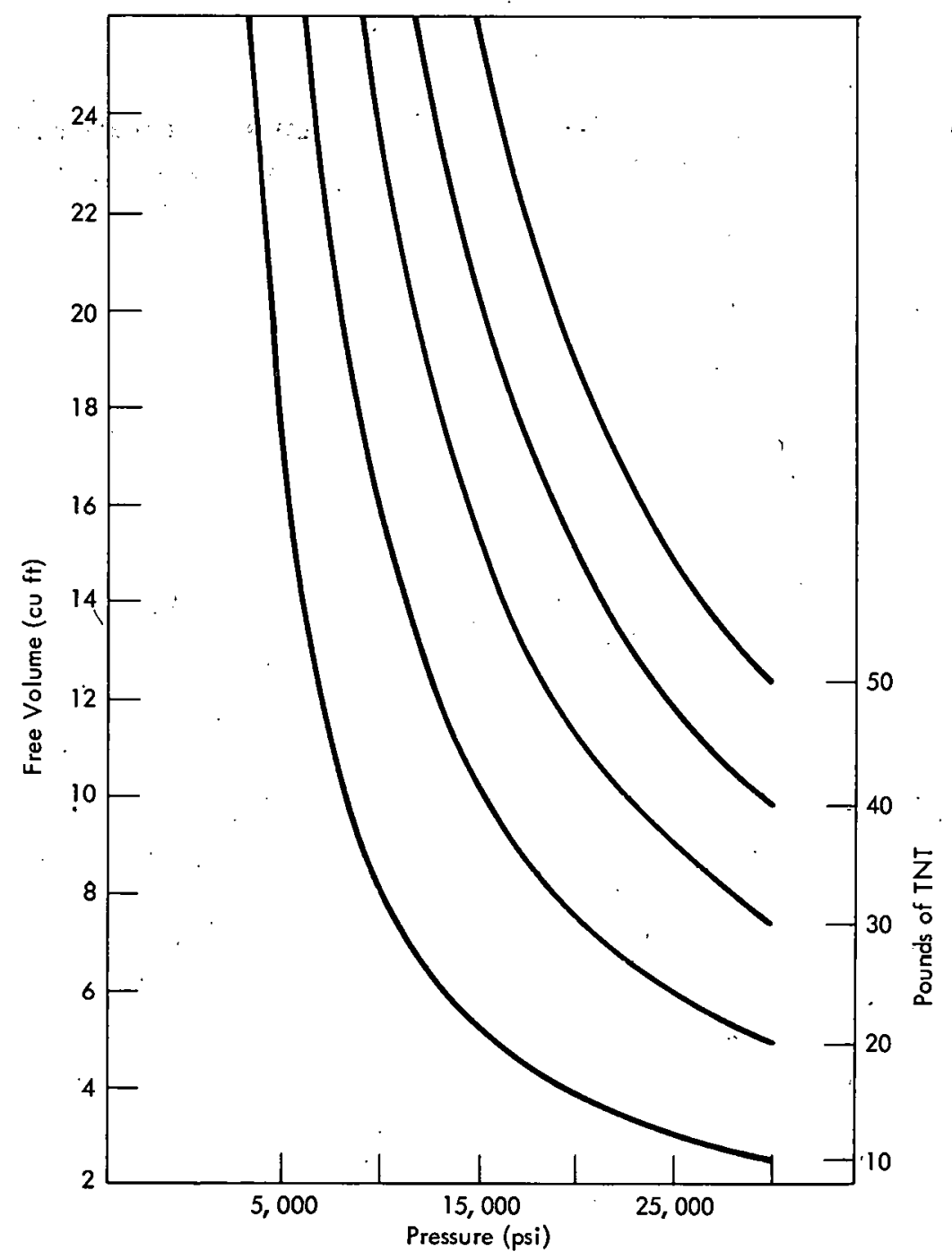

Figure 4. EQUIVALENT ENERGY VALUES FOR CONVERTED PRES. SURE VESSEL.

\section{Maximum Blast Wave Condition}

It is apparent that if the vessel fails at either end in a circumferential failure, a portion of the energy will be utilized to propel or at least dislodge a portion of the vessel. The energy utilized for this is then not available for formation of a shock wave. If the entire available energy is assumed to be available for formation of the shock wave, a worst condition will be considered, thus using a conservative approach. 
The pressures and impulse caused by this shock wave have been determined but the analytical methods of determining wall resistance to shock loads of very short duration are extremely unreliable and it was decided to utilize empirical information gathered from results of actual explosions. This information was gathered by the US Army Ballistics Research Laboratories, and confirmed by experiments at the Armour Research Foundation and Monsanto Chemical Co. A letter from a British chemical firm which has carried out similar experiments indicates agreement with this information. These data are presented in the form of a nomograph (Figure 5) from which one can easily determine the necessary concrete wall thickness necessary to provide protection to personnel from any weight TNT explosion at a given distance from the wall. This chart will be further discussed in a subsequent section (Page 37).

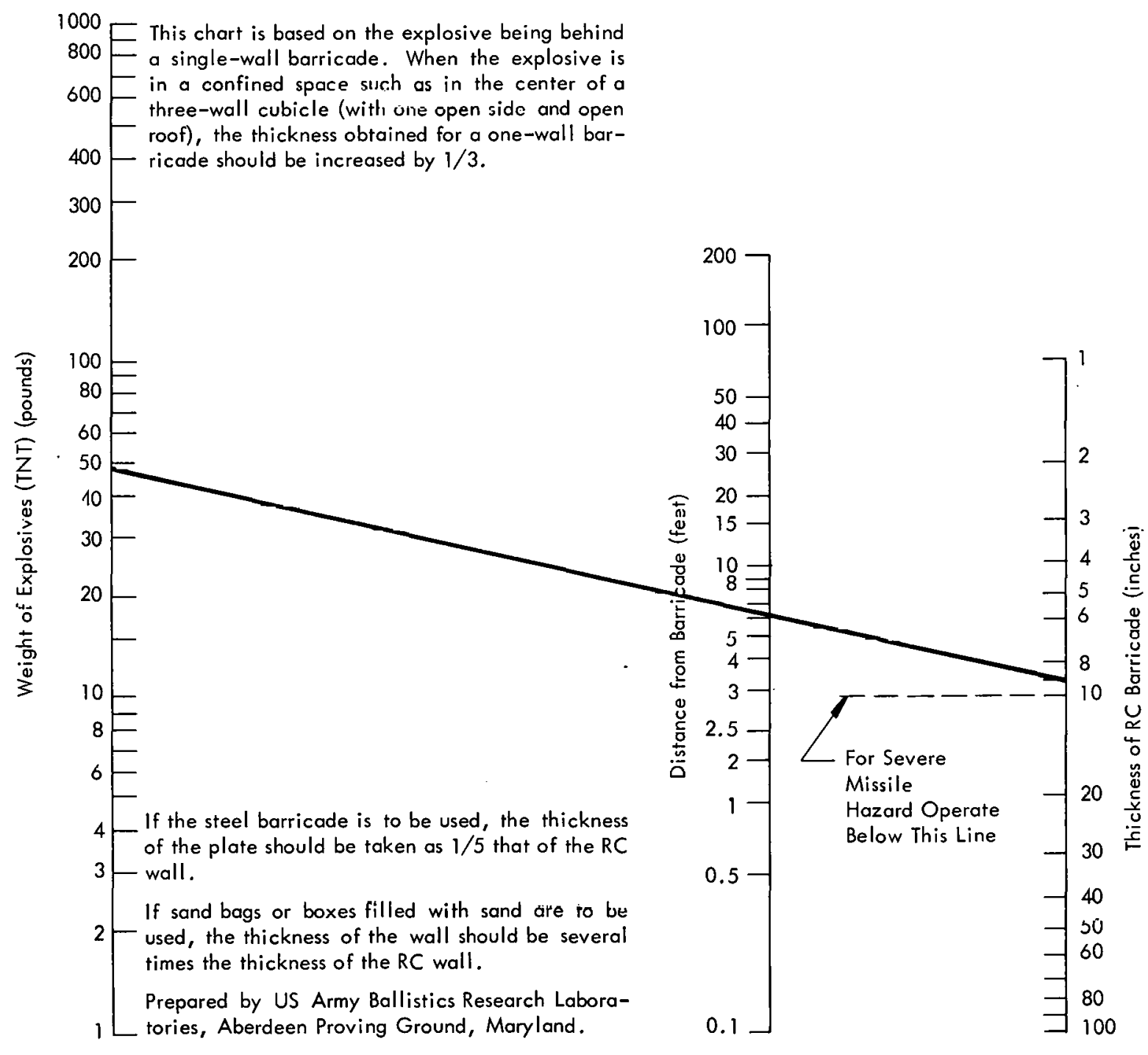

Figure 5. PROOF THICKNESS OF REINFORCED CONCRETE (RC) BARRICADES AGAINST INJURY TO PERSONNEL FROM HIGH.ORDER DETONATION. 
Missile Effect

It was stated in the preceding section that in case of a circumferential rupture there would probably be a portion of the vessel accelerated as a missile. It is well to investigate the three most probable missiles.

Top Closure - If the vessel breaks at the top closure the missile projected upward will consist of the following:

Vessel Component

Broken Portion of the Vessel Wall

Top Sleeve Nut

Top Plug

Top Mushroom

Attached Gear
Weight

(lbs)

19,400

13,400

13,850

1,250

$\underline{3,000}$

50,900

The remainder of the vessel will be projected downward. (The remaining weight is 140,000 pounds.) It can be shown that the energy imparted to the two masses by the expanding gas is inversely proportional to the mass or that:

$$
\frac{E_{1}}{E_{2}}=\frac{M_{2}}{M_{1}} \text { (see Appendix } B \text { for proof). }
$$

The total energy available for propelling the two masses is found by determining the energy released by the gas in expanding from the initial volume of the whole vessel to the volume contained in the ruptured vessel at the instant the two fragments part. In this case this distance of movement is some 16 inches $(c)$ and the volume added during this expansion is:

$$
V=\frac{(28)^{2} \frac{\pi}{(4)}}{1728}(16)=5.7 \mathrm{ft}^{3}
$$

Equation 3, Page 29 is:

(c) Approximate distance the mushroom must travel before it clears the ID of the cooling jacket. 


$$
E=\frac{1}{k-1}\left(P_{i} V_{i}-P_{f} V_{f}\right)
$$

Dividing by initial pressure, $\mathrm{P}_{\mathbf{i}}$ gives:

$$
\begin{aligned}
& \frac{E}{P_{i}}=\frac{1}{k-1}\left[V_{i}-V_{f}\left(\frac{P_{f}}{P_{i}}\right)\right] \text { and } \\
& \frac{E}{P_{i}}=\frac{1}{k-1}\left[V_{i}-V_{f}\left(\frac{V_{i}}{V_{f}}\right)^{k}\right],
\end{aligned}
$$

an expression for total work available as a function of volumes and initial pressure only. The final volume $\left(V_{f}\right)$ in this case is:

$$
V_{f}=V_{i}+5.7 \mathrm{ft}^{3}
$$

Combining Equations 5 and 5a gives:

$$
\frac{E}{P_{i}}=\frac{1}{k-1}\left[V_{i}-\left(V_{i}+5.7\right)\left(\frac{V_{i}}{V_{i}+5.7}\right)^{k}\right],
$$

or

$$
\frac{E}{P_{i}}=1.5\left[V_{i}-\left(V_{i}+5.7\right)\left(\frac{V_{i}}{V_{i}+5.7}\right)^{5 / 3}\right]
$$

With $16.5 \mathrm{ft}^{3}$ as the initial volume,

$$
\begin{aligned}
E & =\left(2.88 \times 10^{6}\right)(1.5)\left[16.5-22.2\left(\frac{16.5}{22.2}\right)^{1.67}\right] \\
& =1.275 \times 10^{7} \mathrm{ft} \mathrm{lbs} .
\end{aligned}
$$

Now since the energy imparted to the top part is inversely proportional to the masses and the total energy is known, the energy imparted to the missile and its velocity can be determined: 


$$
\frac{E_{u}}{E_{d}}=\frac{M_{d}}{M_{u}},
$$

and

$$
\begin{aligned}
E_{d} & =E_{t}-E_{u^{\prime}} \\
E_{u} & =E_{t}-E_{u}\left(\frac{M_{u}}{M_{d}}\right), \\
& =\frac{E_{t}}{1+\left(\frac{M_{u}}{M_{d}}\right)^{\prime}} \\
& =\frac{1.275 \times 10^{7}}{1+\frac{50,900}{140,100}}, \\
& =9.35 \times 10^{6} \mathrm{ft} \text { lbs. }
\end{aligned}
$$

To find the velocity $(U) E=1 / 2 M U^{2}$ is utilized to find that:

$$
\begin{aligned}
U & =\left(\frac{2 E}{M}\right)^{1 / 2}=\left(\frac{2 E g}{W}\right)^{1 / 2}, \\
& =\frac{(2)(32.2)\left(9.35 \times 10^{6}\right)}{50,900}, \\
& =109 \mathrm{ft} / \mathrm{sec} .
\end{aligned}
$$

Velocity at the roof - 18 feet after parting:

$$
\begin{aligned}
U_{r} & =\left(U_{i}^{2}-2 g h\right)^{1 / 2}, \\
& =\left[(109)^{2}-(2)(32.2)(18)\right]^{1 / 2}, \\
& =(10,740)^{1 / 2}, \\
& =103 \mathrm{ft} / \mathrm{sec} .
\end{aligned}
$$


To keep the roof from rising more than three feet, its mass will be increased so that it will absorb the energy within that distance. From the conservation of momentum law:

$$
M_{1} U_{1}=M_{2} U_{2}
$$

the velocity of the combined roof and plug mass is defined by:

$$
\begin{aligned}
U_{2} & =(2 g h)^{1 / 2}, \\
& =[(2)(32.2)(3)]^{1 / 2}, \\
& =13.9 \mathrm{ft} / \mathrm{sec} . \\
W_{u+r} & =W_{u}\left(\frac{U_{u}}{U_{2}}\right), \\
& =(59,900)\left(\frac{103}{13.9}\right), \\
& =378,000 \mathrm{lbs} .
\end{aligned}
$$

Since the plug weighs 50,900 pounds, the concrete mass must be $378,000-50,900$ or 327,100 pounds. This value constitutes a total concrete thickness of six feet for the entire cell roof.

Bottom Closure - If the vessel breaks at the bottom closure, the missile projected upward will consist of the following:

\begin{tabular}{lr}
\multicolumn{1}{c}{ Vessel Component } & $\begin{array}{c}\text { Weight } \\
\text { (lbs) }\end{array}$ \\
\cline { 3 - 3 } Failed Portion of the Outer Shell & 81,000 \\
Inner Shell & 26,830 \\
Liner & 17,165 \\
Top Plug & 13,850 \\
Top Sleeve Nut & 13,400 \\
Top Mushroom & 1,250 \\
Attached Gear & 3,000 \\
& \\
\multicolumn{1}{c}{ Total } & 156,495
\end{tabular}

The remainder of the vessel will be projected downward. The remaining weight is 35,400 pounds. Using the method described for the top closure and an expansion length of 80 inches, it is found that: 


$$
v_{f}=v_{i}+28.5 \mathrm{ft}^{3}
$$

With $16.5 \mathrm{ft}^{3}$ as the initial volume (from Equation 6a):

$$
\begin{aligned}
& E=\left(2.88 \times 10^{6}\right)(1.5)\left[16.5-45.0\left(\frac{16.5}{45.0}\right)^{1.67}\right], \text { or } \\
& E=3.5 \times 10^{6} \mathrm{ft} \text { lbs. }
\end{aligned}
$$

And, from Equation 7:

$$
\begin{aligned}
E_{u} & =\frac{3.5 \times 10^{7}}{5.43}, \\
& =6.5 \times 10^{6} \mathrm{ft} \mathrm{lbs} .
\end{aligned}
$$

Velocity will be (from Equation 8):

$$
\begin{aligned}
U & =\left[\frac{(64.4)\left(6.5 \times 10^{6}\right)}{156,500}\right]^{1 / 2}, \\
& =(2680)^{1 / 2}, \\
& =51.7 \mathrm{ft} / \mathrm{sec} .
\end{aligned}
$$

Velocity at the roof will be (from Equation 9):

$$
\begin{aligned}
& U_{r}^{2}=(51.7)^{2}-(2)(32.2)(18)=1510, \\
& U_{r}=39 \mathrm{ft} / \mathrm{sec} .
\end{aligned}
$$

From Equation 1 and considering three feet the maximum allowable rise for the roof:

$$
\begin{aligned}
W_{r+u} & =(156,500)\left(\frac{39}{13.9}\right), \\
& =438,000 \mathrm{lbs},
\end{aligned}
$$




$$
W_{r}=281,500 \mathrm{lbs} .
$$

Thus, the six-foot roof just calculated is more than adequate.

Accessory Equipment - A third possible source of missiles or fragments is the accessory equipment such as pipefittings, valves, or gages on the high-pressure lines. Although there is a definite possibility of such a failure, no danger is involved since the highpressure equipment will all be contained inside the containment cell which has walls adequate to stop any such missiles.

Strength of the Containment Cell

The existing containment cell was constructed in 1955 and has never been subjected to blast or other damaging forces. Close examination has revealed no visible cracks or other defects which would weaken the structure. The assumption is therefore made that it is sound.

Specific information concerning the failure point of concrete structures is extremely difficult to obtain. Several authorities in the field were contacted including the Portland Cement Association of America. Several analytical methods were explored but the most reliable information located was the nomograph prepared by the US Army Ballistics Research Laboratories from their many years' accumulation of empirical blast data. This nomograph is shown in Figure 5. The accuracy of this nomograph was verified by an experiment performed by Armour Research Foundation for Monsanto Chemical Co in which a full-scale cell was constructed of reinforced concrete and tested to destruction. The results indicate the nomograph to be completely safe in that a 12-inch wall reinforced approximately as the wall in question withstood a 50-pound TNT blast approximately two feet away. Since the nearest wall to the vessel is 6.17 feet, the chart shows (taking into consideration the additional thickness of $1 / 3$ indicated by the note) that the existing 12-inch wall is an adequate barricading for $\sim 48$ pounds of TNT. Conversation with Dr. Baker and with personnel at the Ballistics Research Labs indicates that the barricade thicknesses given by this chart are completely adequate for personnel protection. Additional safety is realized by the fact that the nearest operating personnel will be at least two feet from a wall which itself is 7.5 feet from the center of the vessel. Further, the two interior walls of the cell are reinforced and supported by two 12-inch concrete floors (elevations 955 and 966) and will have much more strength than the unsupported wall described by the nomograph.

Modifications to be Made to the Existing Cell

In order to add additional safety to the containment cell in case of vessel rupture, the following modifications are to be accomplished prior to operation of the converted pressure vessel. (Figure 6) 


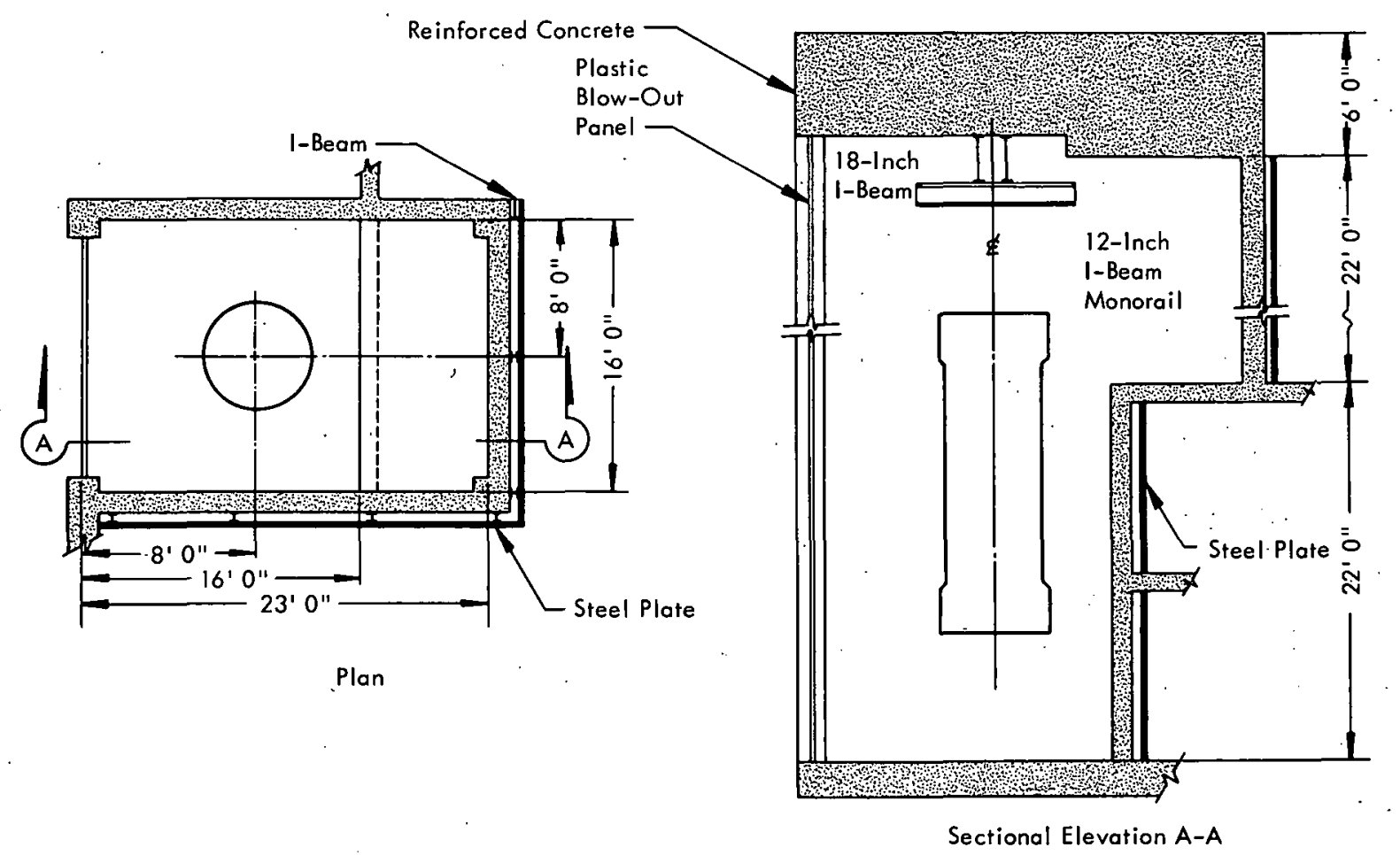

Figure 6. CONTAINMENT CELL MODIFICATIONS.

1. The interior walls between the control room and the cell, and between the equipment room and the cell, will be covered with separately supported 1/4-inch steel plate walls to prevent any concrete fragments from spalling from the walls (as a result of cracking) and striking personnel.

2. The existing five-inch roof slab will be built up to six feet as required by the calculation for the top closure to prevent vessel fragments from escaping.

3. Structural steel doors with strengths equal to or greater than the cell wall proper will replace the existing doors.

4. The existing west wall of the cell will be replaced with a light plastic wall to act as a blow-out panel.

5. A blasting mat woven of $7 / 8$-inch steel wire rope will be draped from the top to the bottom of the cell outside the west and north walls. The west mat will be eight feet from the wall. 


\section{CONCLUSIONS}

The following conclusions have been reached:

1. The vessel has an adequate safety factor for operation at 20,000 psi. (d)

2. The most probable type of failure is radial failure of the lower closure in which the blast effect would be approximately equal to a 21 -pound TNT explosion and the top portion of the vessel would be blown against the roof of the cell.

3. The most catastrophic failure that could occur would be a longitudinal failure of the vessel wall. This action would produce no missiles, but the blast effect would equal 10-45 pounds of TNT. The possibility of this failure is very remote.

4. The walls of the existing containment cell are adequate for an explosive force equal to $45-50$ pounds of TNT. However, to provide additional protection to cover contingent operational parameters it was decided to pour an additional one-foot-thick reinforced concrete wall outside and contiguous with the walls of the existing cell. The external surfaces of the new wall will be covered by a $1 / 4$-inch steel antispall plate.

5. The modified cell roof will not rise more than three feet in case of the worst possible vessel failure. This result could occur only if no steel beams were deformed by the missile prior to striking the roof. Since this could not occur, the energy of deformation absorbed by the massive beams in the structure would not be available to lift the roof.

6. Table 1 summarizes the failure information calculated in this report.

Table 1

TABULATION OF FAII.URE CALCULATION RESULTS

\begin{tabular}{|c|c|c|c|c|c|c|}
\hline \multirow[b]{2}{*}{ Failure } & \multicolumn{2}{|c|}{ Blast Wave Energy } & \multirow{2}{*}{$\begin{array}{l}\text { Energy Used } \\
\text { in Missile } \\
\text { Acceleration } \\
\left(\mathrm{ft} \mathrm{lbs} \times 10^{-6}\right)\end{array}$} & \multicolumn{2}{|c|}{ Velocity } & \multirow{2}{*}{$\begin{array}{l}\text { Height } \\
\text { of } \\
\text { Roof Rise } \\
\text { (ft) }\end{array}$} \\
\hline & $\left(\mathrm{ft}\right.$ lbs $\left.\times 10^{-6}\right)$ & $\begin{array}{c}\text { Equivalent } \\
\text { (lbs) }\end{array}$ & & $\begin{array}{l}\text { Initial } \\
(\mathrm{ft} / \mathrm{sec})\end{array}$ & $\begin{array}{l}\text { At Roof } \\
\text { Level } \\
\text { (ft/sec) }\end{array}$ & \\
\hline $\begin{array}{l}\text { Radial Failure } \\
\text { at the Lower } \\
\text { Closure }\end{array}$ & 32.7 & 21 & 35.0 & 51.7 & 39 & 2.46 \\
\hline $\begin{array}{l}\text { Radial Failure } \\
\text { at the Upper } \\
\text { C.losure }\end{array}$ & 55 & 36 & 12.75 & 109 & 103 & 3 \\
\hline $\begin{array}{l}\text { Longitudinal } \\
\text { Failure of the } \\
\text { Vessel Wall }\end{array}$ & 67.7 & 44 & 0 & 0 & 0 & 0 \\
\hline
\end{tabular}

(d) Following this report, strain gage tests were made on the vessel verifying this statement (see Parts 5 and 6). 
7. The modified facility is safe for operation under the following operating conditions:

$\begin{array}{lc}\text { Maximum Free Volume }\left(\mathrm{ft}^{3}\right) & 16.5 \\ \text { Maximum Temperature }\left({ }^{\circ} \mathrm{C}\right) & 1500 \\ \text { Maximum Pressure (psi) } & 20,000\end{array}$


APPENDIX A 


\section{THIS PAGE}

\section{WAS INTENTIONALLY}

\section{LEFT BLANK}




\section{SYMBOLS}

$$
\begin{aligned}
& E \text {. = Energy } \\
& U=\text { Velocity } \\
& E_{d}=\text { Energy directed downward } \\
& U_{f}=\text { Final velocity } \\
& E_{t}=\text { Total energy } \\
& U_{i}=\text { Initial velocity } \\
& E_{u}=\text { Energy directed upward } \\
& U_{r}=\text { Velocity of fragment at roof level } \\
& g=\begin{array}{l}
\text { Acceleration due to } \\
\text { gravity }=32.2 \mathrm{ft} / \mathrm{sec}^{2}
\end{array} \\
& U_{2}=\text { Velocity of fragment and roof } \\
& k=\text { Ratio of special heats } \\
& \checkmark=\text { Specific volume } \\
& M=\text { Mass } \\
& V=\text { Volume } \\
& M_{d}=\text { Mass moving downward } \\
& V_{f}=\text { Final volume } \\
& M_{u}=\text { Mass moving upward } \\
& V_{i}=\text { Initial volume } \\
& \mathrm{P} \quad=\text { Pressure } \\
& W=\text { Weight } \\
& P_{f}=\text { Final pressure } \\
& W_{r}=\text { Weight of roof } \\
& P_{i}=\text { Initial pressure } \\
& W_{u}=\begin{array}{l}
\text { Weight of fragment } \\
\text { propelled upward }
\end{array} \\
& T=\text { Temperature }-{ }^{\circ} \mathrm{R}
\end{aligned}
$$




\section{THIS PAGE \\ WAS INTENTIONALLY \\ LEFT BLANK}


APPENDIX B 
THIS PAGE

WAS INTENTIONALLY

LEFT BLANK 


\section{ENERGY-MASS RELATIONSHIP FOR MISSILES}

Consider a piston $\left(M_{1}\right)$ and a cylinder $\left(M_{2}\right)$ both unsupported and oriented as shown.

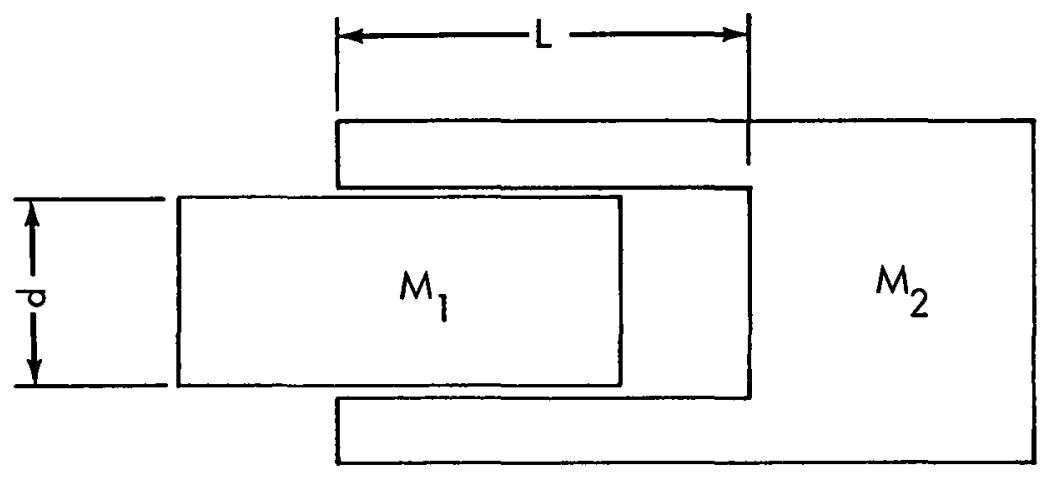

Let there be a given initial pressure $\left(P_{1}\right)$ in the chamber. The length $(L)$ is the distance one must travel in relation to the other to separate.

The force on each member of the system is equal to the product of pressure and the area of the piston face:

$$
\begin{aligned}
& A=\frac{\pi d^{2}}{4} \\
& F=\frac{P \pi d^{2}}{4} .
\end{aligned}
$$

To determine the work $(E)$ imparted to the members by an expansion of the gas the product of force and distance is determined or:

$$
E=F L=\int_{P_{2}}^{P_{1}} \frac{\pi d^{2} L}{4} d P,
$$

where $P_{2}$ is the pressure at the end of the stroke or

$$
E=\frac{\pi d^{2} L}{4}\left(P_{2}-P_{1}\right) \text {. }
$$

The expansion (considered adiabatic) is described by the expression

$$
P V^{k}=\text { Constant } \text {. }
$$


Thus:

$$
P_{1} v_{1}^{k}=P_{2} v_{2}^{k}
$$

and the final pressure $\left(P_{2}\right)$ is:

$$
P_{2}=P_{1}\left(\frac{V_{1}}{V_{2}}\right)^{k}
$$

It must now be assumed that there is an initial volume $\left(V_{1}\right)$, then the final volume is:

$$
V_{2}=V_{1}+\frac{\pi d^{2} L}{4}
$$

and the pressure equation becomes:

$$
P_{2}=P_{1}\left(\frac{V_{1}}{v_{1}+\frac{\pi d^{2} L}{4}}\right)^{k}
$$

The energy equation is now:

$$
E=\frac{\pi d^{2} L}{4}\left[P_{1}-P_{1}\left(\frac{v_{1}}{v_{1}+\frac{\pi d^{2} L}{4}}\right)^{k}\right]
$$

Since the force on each face of the chamber is equal and it will be used to accelerate the masses, it must be concluded that the absolute accelerations are proportional to the masses since:

$$
F=M a=M_{1} a_{1}=M_{2} a_{2}
$$

Thus, the acceleration of the piston $\left(M_{1}\right)$ is:

$$
a_{1}=a_{2}\left(\frac{M_{2}}{M_{1}}\right)
$$

Length of the stroke is defined by

$$
L=1 / 2 a t^{2} .
$$


Thus, the length is proportional to the acceleration and

$$
\frac{L_{1}}{L_{2}}=\frac{a_{1}}{a_{2}} \text {. }
$$

But, since $a_{1}=a_{2}\left(\frac{M_{2}}{M_{1}}\right)$, the length is inversely proportional to the mass:

$$
\frac{L_{1}}{L_{2}}=\frac{M_{2}}{M_{1}} \text {, }
$$

or

$$
L_{1}=L_{2}\left(\frac{M_{2}}{M_{1}}\right) \text {. }
$$

Since the relative length of the stroke $(L)$ is known and is equal to the total of $\left(L_{1}\right)$ and $\left(L_{2}\right)$ :

$$
\begin{aligned}
L & =L_{1}+L_{2}, \\
& =L_{2}\left(\frac{M_{2}}{M_{1}}\right)+L_{2}, \\
& =L_{2}\left(\frac{M_{2}}{M_{1}}\right)+1 .
\end{aligned}
$$

Or

$$
L_{2}=\frac{L}{\frac{M_{2}}{M_{1}}+1},
$$

and

$$
L_{1}=L-\frac{L}{\frac{M_{2}}{M_{1}}+1} \text {. }
$$


Hence the length of the stroke of the individual masses $\left(L_{1}\right.$ and $\left.L_{2}\right)$ is available in terms of the known length (L).

Returning to the energy imparted to each part:

$$
E_{1}=\frac{\pi d^{2}}{4}\left(L-\frac{L}{\frac{M_{2}}{M_{1}}+1}\right)\left[P_{1}-P_{1}\left(\frac{v_{1}}{v_{1}+\frac{\pi d^{2} L}{4}}\right)^{k}\right] \text {, }
$$

and

$$
E_{2}=\frac{\pi d^{2}}{4}\left(\frac{L}{\frac{M_{2}}{M_{1}}+1}\right)\left[P_{1}-P_{1}\left(\frac{V_{1}}{V_{1}+\frac{\pi d^{2} L}{4}}\right)^{k}\right] .
$$

Since the right side of these equations differ only in the second term:

$$
\frac{E_{1}}{E_{2}}=\frac{L-\frac{L}{M_{2}}+1}{\frac{L}{M_{2}}+1}=\frac{\left(\frac{M_{2}}{M_{1}}+1\right) L-L}{L},
$$

or

$$
\frac{E_{1}}{E_{2}}=\frac{M_{2}}{M_{1}} .
$$

Thus, energy imparted to each fragment is shown to be inversely proportional to its mass. 
APPENDIX C 
THIS PAGE

\section{WAS INTENTIONALLY \\ LEFT BLANK}




\section{BIBLIOGRAPHY}

Newmark, Nathan M.; "An Engineering Approach to Blast-Resistant Design", ASCE Transactions, Paper 2786; October 1953.

Jury, Stanley H.; An Investigation of Argon Expansion to Determine Maximum Work; Chemical Engineering Department, University of Tennessee; July 1963.

Browne, Howard C., Hileman, Harold, and Weger, Lowell C.; "Barricades for High Pressure Research", I and E Chemistry, 53 (10), p 52A; October 1961.

White, Clayton S.; "Biological Effect of Blast", Defense Atomic Support Agency Technical Progress Report 1271; December 1961.

Boyer, D. W., Brode, H. L., Glass, I. I., and Hall, J. G.; "Blast from a Pressurized Sphere ", UTIA Report 48, University of Toronto Institute of Aerophysics; January 1958.

Flynn, Paul D.; "Elastic Response of Simple Structures to Pulse Loading ", BRL Memorandum Report 525; Ballistic Research Laboratories, Aberdeen Proving Ground, Maryland; November 1951.

Tolch, N. A. and Bushkovitch, A. V.; "Penetration and Crater Volume in Various Kinds of Rocks as Dependent on Caliber, Mass, and Striking Velocity of Projectile", BRL Report 641; October 1947.

Allen, Frank J. and Rally, F.; "A Plastic-Rigid Theory of the Response of Beams to Air Blast Loading", BRL Memorandum Report 81 l; July 1954.

Goodman, H. J.; "Compiled Free-Air Blast Data on Bare Spherical Pentolite", BRL Report 1092; February 1960.

Hougen, Olaf A. and Watson, Kenneth M.; Chemical Process Principles, Part Two, Thermodynamics; John Wiley and Sons, New York (1947).

Porzel, F. B.; Comments on Explosive Rupture of Union Carbide Autoclave; Institute for Defense Analyses, Washington, DC; November 6, 1963.

Kaplan, M. F.; "Crack Propagation and the Fracture of Concrete", Journal of the American Concrete Institute; November 1961.

Concrete Reinforcing Steel Institute Handbook, Revised 1957.

Urquhart, L. C., O'Rourke, C. E., and Winter, George; Design of Concrete Structures, 6th Edition; McGraw-Hill Book Company, New York (1958). 
Weber, J. P., Savitt, Jacob, Krc, John, and Browne; H. C.; "Detonation Tests Evalvate High Pressure Cells", I and E Chemistry, 53 (11), pp 128A-133A; November 1961.

Shortley, George and Williams, Dudley; Elements of Physics, 2nd Edition; PrenticeHall, Inc (1955).

Baker, W.E.; Evaluation of Shock and Missile Hazards from a Bursting Pressure Vessel, Handwritten Report; Aircraft Armaments, Inc, Cockeysville, Maryland; August 14, 1963.

Baker, W.E.; Evaluation of Shock and Missile Hazards from a Bursting Pressure Vessel, Report ER-3192; Aircraft Armaments, Inc, Cockeysville, Maryland; August 1963.

Baker, W. E.; Evaluation of Shock and Missile Hazards from a Bursting Pressure Vessel, Addendum to AAl ER-3192; October 1963.

Rouse, Hunter; Fluid Mechanics for Hydraulic Engineers; McGraw-Hill Book Company, New York (1938).

Zemansky, Mark W.; Heat and Thermodynamics, 4th Edition; McGraw-Hill Book. Company, New York (1957).

Mooney, David A.; Introduction to Thermodynamics and Heat Transfer; PrenticeHall, Inc (1.956).

Getman; Frederick, H. and Daniels; Farrington; Outlines: of-Physical Chemistry; John Wiley and Sons; : Inc, New York (1943):

Courant, R. and Friedrichs, K. O.; Supersonic Flow and Shock Waves, Vol I; Interscience Püblishers, Inc, New York (1948).

Zeldovich, la. B. and Kompaneets, A. S.; Theory of Detonation; Academic Press, New York (1960).

Lewis, Gilbert Newton and Randall, Merle; Thermodynamics and the Free Energy of Chemical Substances, 1st Edition; McGraw-Hill Book Company, New York (1923).

McKee, K. E.; "Dynamic Characteristics of Structural Clay Masonry Walls", Blast Resistant Design-Phase Report IV, ARF K576; Armour Research Foundation of the Illinois Institute of Technology; October 1956. 
PART 2

\section{BLAST RESISTANT DESIGN}

Richard C: Gwaltney 
THIS PAGE

\section{WAS INTENTIONALLY LEFT BLANK}




\section{CONTENTS}

SUMMARY. . . . . . . . . . . . . . . . . . 59

BLAST RESISTANT DESIGN ..................... . . 61

Development of the Method .................... . . 61

Application to Resistant Design . . . . . . . . . . . . . . . 76

Coal City Test . . . . . . . . . . . . . . . . . . . 76

The PV-2 Containment Walls . . . . . . . . . . . . . 80

REFERENCES . . . . . . . . . . . . . . . . . . . . 97 
THIS PAGE

\section{WAS INTENTIONALLY \\ LEFT BLANK}


SUMMARY

An analytical method has been developed for calculating the stresses induced in reinforced concrete structures by impulsive loading such as shock waves in air. The underlying principle of the method is based upon calculating the deflection " $y$ " of the structure under shock loading and using this deflection to determine the magnitude of stresses acting in the structure.

Mathematically, the first procedural step was to solve the dynamic equation of motion in terms of displacement. The dynamic equation was then solved for the complete reaction of the structure during the pulse application and through the reflection phase of a triangular pulse loading. Similarly, the dynamic equation was solved for what is defined as an "initial impulse". In practice, this latter equation is applied in the case of shock waves emanating from conventional high explosives. The next step was to relate the maximized deflection to the stress level in the structure.

Application of the stress calculation method was made on a wall section of a concrete cell tested for resistance to explosives by the Armour Research Foundation at Coal City, lllinois. It was found that the most severe stress induced in a wall section only two feet away from a 50-pound charge was 4780 psi at the corner of the fixed edge. No damage occurred at this edge. The highest stress at the center of the wall panel was 2281 psi. A small crack resulted from this stress.

The stress method was also applied to the three walls of the existing containment cell which houses PV-2, the pressure vessel now being modified for gas autoclave service. The greatest stress calculated for the center of the wall section closest to the vessel was 870 psi and the greatest edge stress was 2420 psi. These values were based on impulsive loading from an assumed 50-pound (TNT) charge equivalent resulting from potential vessel rupture. Since the shock of a single 50-pound charge produced only minor damage to the Coal City cell, it is conjectured that damage from an equal charge equivalent would be no more severe in the PV-2 cell. This conclusion is borne out by stress levels of similar magnitude for each of the two cells. 


\section{THIS PAGE \\ WAS INTENTIONALLY \\ LEFT BLANK}




\section{BLAST RESISTANT DESIGN}

\section{DEVELOPMENT OF THE METHOD}

There are three approaches which can be employed to analyze the resistance of a structure to a blast-induced pressure pulse: (1) use of the deflection of a structure under impulsive loading to determine the stresses acting in the structure; (2) relating the energy introduced into the system by the impulsive loading to the induced stresses, and (3) use of the plastic-hinge concept to assess the maximum deflection which may be taken for calculating the stresses imposed in the structure.

The energy concept was first applied by Newmark $(1)$ in a generalized method for the analysis of a structure to blast loading. This method was derived for a simple spring mass system. Since no structure can be defined as a simple system, the Newmark method must be used with great care. However, the energy method can be applied properly to any system by using Newmark's technique for a simple system. Because of the fact that the maximum allowable deflection must be known or calculated for the energy method to be applied, it is simpler and preferable to use the deflection method in evaluating structural resistance. Furthermore, the Newmark method depends on the allowable deflection of a structure beyond the yield deflection. Reliable calculation methods for determining deflections beyond the yield deflection for structures have not been developed. No existing procedures are known for calculating the deflection of a structure after it has reached the plastic state or after it has developed a plastic hinge. These uncertainties lead to difficulties in selecting parameters to be used in the Newmark method.

An analysis of masonry slab walls using the plastic-hinge concept has been developed at the Armour Research Foundation of the Illinois Institute of Technology. (2) The inherent difficulty of calculating deflection at the plastic hinge weakens the effectiveness of this method. It is granted, however, that the Armour concept would provide the most economical method of design if there were available a satisfactory technique for calculating the plastic deflection.

It is considered that the deflection method of: stress evaluation is more amenable to blast-resistance application than the other procedures. Before initiating the deflection calculation, it is necessary to solve the dynamic problem of motion in terms of displacement so that the maximum displacement can be calculated. The general form of the dynamic equation of motion for a simplified system is given as:

$$
m \frac{d^{2} y}{d x^{2}}+K y=F(t)
$$

where: 
m. represents the mass of the system,

$\mathrm{K}$ is the spring constant of the mass,

$y$ is the displacement, and

$F(t)$ is the forcing function.

Dividing Equation 1 by $m$ gives:

$$
\frac{d^{2} y}{d x^{2}}+\frac{K y}{m}=\frac{F(t)}{m} .
$$

This equation can be rewritten in the form:

$$
D^{2} y+\omega_{n}^{2} y=\frac{F(t)}{m},
$$

where:

$$
\begin{aligned}
& D^{2} y \text { gives the second derivative of } y \text {, and } \\
& \omega_{n} \text { represents the natural frequency of the system. }
\end{aligned}
$$

Now the question arises: What is the form of the forcing function $F(t)$ ?

The forcing function is that force which causes the system to be set in motion. Since a blast gives off an impulsive pressure wave, the shape of the pressure wave is very important. The shape of the pressure wave given off by a nuclear explosion can be assumed to be triangular. $(1,2)$

Equation 3 can be solved for a triangular pressure pulse by the use of Laplace transformations. (3) $F(t)$ is equivalent to the force-time function which acts on the system or structure. The force-time relationship assumed for developing the deflection method is shown in Figure 7, where $P_{0}$ is the maximum pressure on the surface of the structure and $T$ is the duration of the pulse in time. It follows that:

$$
F_{0}=A P_{0}
$$

where:

$F_{0}$ gives the force acting on the structure, and

A is the surface area of the structure. 


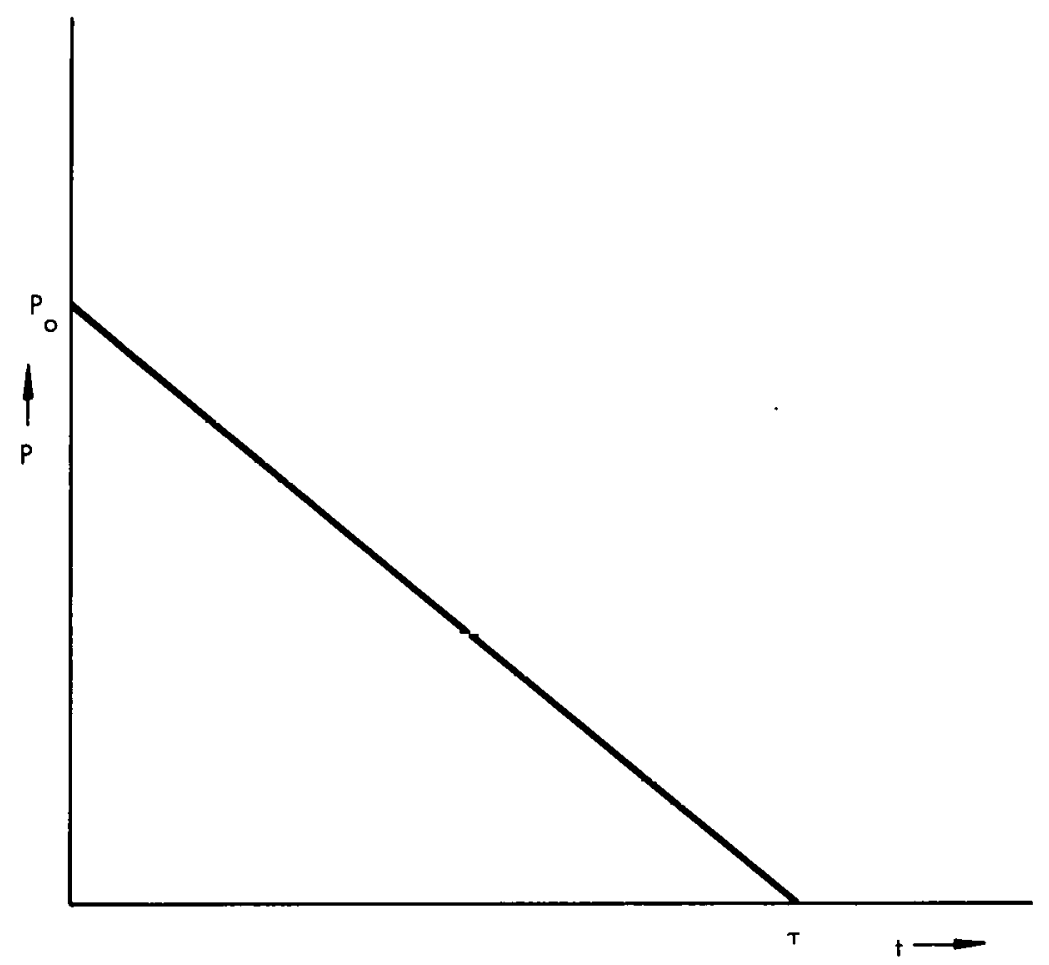

Figure 7. THE ASSUMED TRIANGULAR PULSE.

To solve Equation 3, the method of superposition of linear differential equations will be used. By using this method it is assumed that there are no nonlinear parameters in the system.

The assumption is made first that the structure has been subjected to a negative infinite triangular pulse, as shown in Figure 8 . The forcing function in this case can be written as:

$$
F(t)=\frac{-A P_{0} t}{T},
$$

where:

$t \quad$ is the time,

$\tau$ is the time at the end of the ussumed pulse,

$P_{0}$ is the maximum pressure, and

$A$ is the area of the surface of the structure.

Now Equation 3 can be rewritten in the form: 


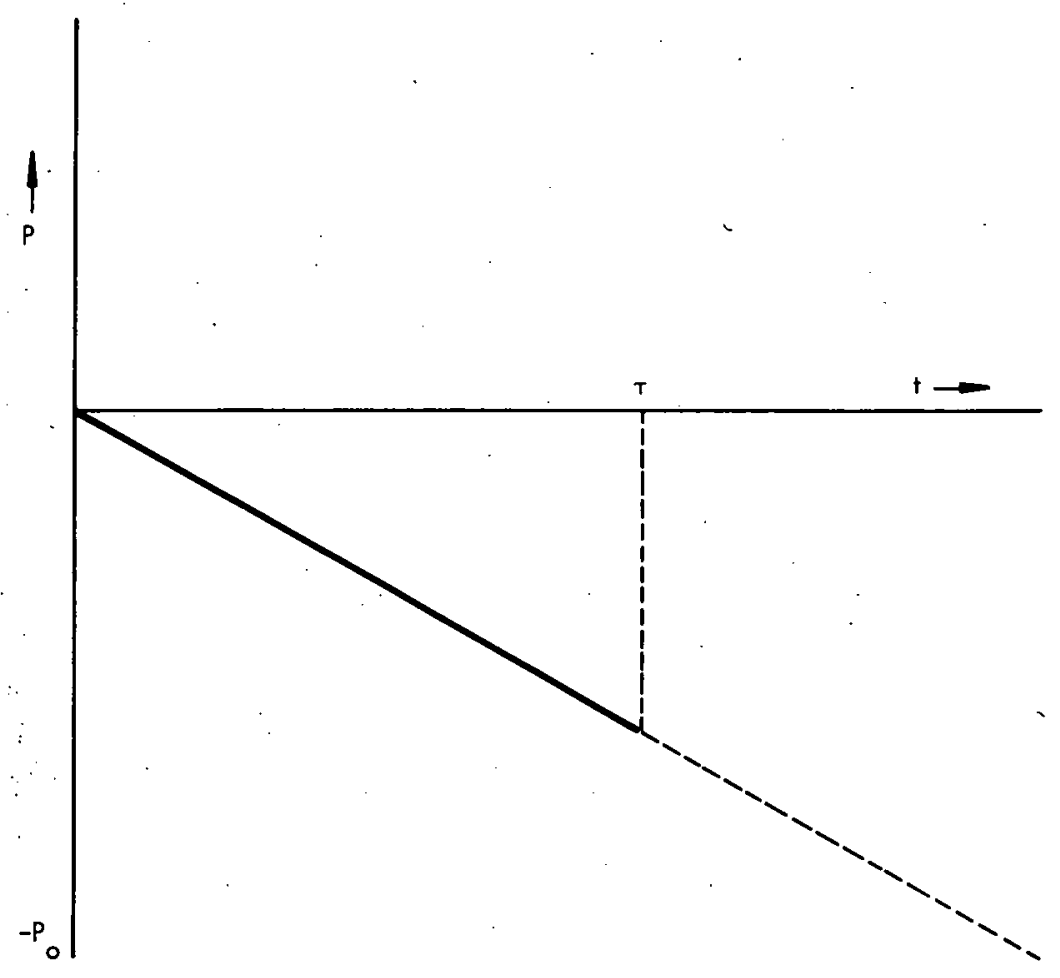

Figure 8. THE ASSUMED NEGATIVE INFINITE TRIANGULAR PULSE.

$$
D^{2} y+\omega_{n}^{2} y=-\frac{A P_{0} t}{m \tau}
$$

This equation can be solved by the use of Laplace transformation.

Transforming Equation 5 into the $S$ domain,

$$
\left[\left(s^{2}+\omega_{n}^{2}\right)\right] \text { y }(s)=-\left[\frac{A P}{m \cdot T}\right]\left[\frac{1}{s^{2}}\right],
$$

which, in turn, can be written as:

$$
y(s)=-\frac{A P_{0}}{m \tau}\left[\frac{1}{s^{2}\left(s^{2}+\omega_{n}^{2}\right)}\right] .
$$

Transformation back to the time domain yields:

$$
y=-\left[\frac{A P_{0}}{\tau m}\right]\left(\frac{1}{\omega_{n}^{3}}\right)\left(\omega_{n} \dagger-\sin \omega_{n} t\right) .
$$


Equation 6 is the solution to Equation 5 for the assumed pulse.

It may be assumed that a positive step pressure pulse is applied at the same time as the assumed infinite triangular pulse. The positive step pressure pulse is represented in Figure 9. The forcing function can be expressed as $F(t)=A P_{0}$, which, introduced in Equation 3, yields:

$$
D^{2} y+\omega_{n}^{2} y=\frac{A P_{0}}{m}
$$

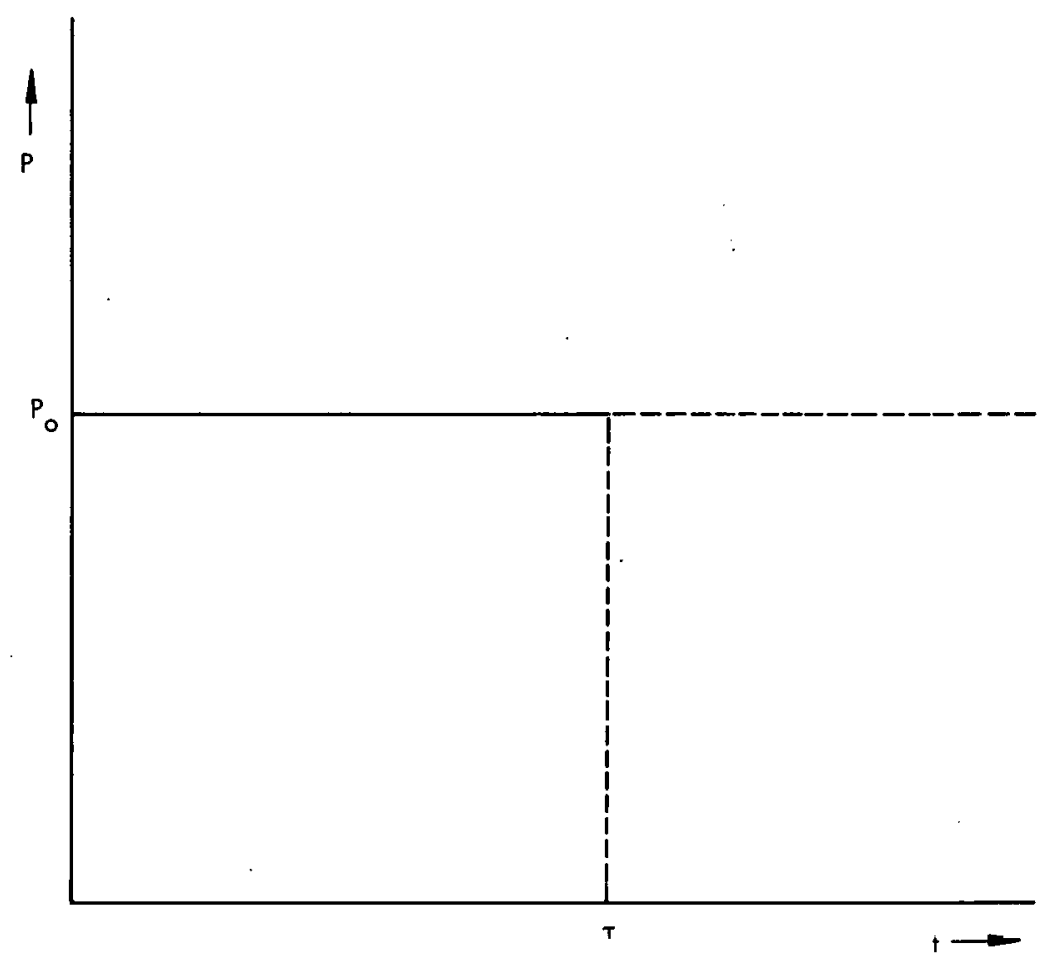

Figure 9. THE ASSUMED POSITIVE STEP PULSE.

Equation 7, transformed into the $S$ domain, yields:

$$
\left(S^{2}+\omega_{n}^{2}\right) y(s)=\frac{A P_{0}}{m S},
$$

which can be rewritten as:

$$
y(s)=\frac{A P_{0}}{m}\left[\frac{1}{S\left(s^{2}+\omega_{n}^{2}\right)}\right],
$$


and transformed back to the time domain as follows:

$$
y=\frac{A P_{0}}{m_{\omega} \omega_{n}^{2}}\left[1-\cos \omega_{n}{ }^{\dagger}\right]
$$

Equations 6 and 8 may be added to give the solution to Equation 3 for the case where the triangular pressure pulse is applied to the structure. Figure 10 illustrates that the addition of the positive step pulse and the negative infinite triangular pulse produces a positive triangular pulse, representing the application of the blast pulse to the structure. Therefore, the solution to Equation 3 becomes:

$$
y=\frac{A P_{0}}{m \omega_{n}^{2}}\left(1-\cos \omega_{n} t\right)-\left(\frac{A P}{\tau m}\right)\left(\frac{1}{\omega_{n}^{3}}\right)\left(\omega_{n} t-\sin \omega_{n} t\right)
$$

which can be reduced to the form:

$$
y=\left(\frac{A P_{0}}{m}\right)\left(\frac{1}{\omega_{n}^{2}}\right)\left[1-\cos \omega_{n} t-\frac{t}{T}+\frac{\sin \omega_{n} t}{T \omega_{n}}\right]
$$

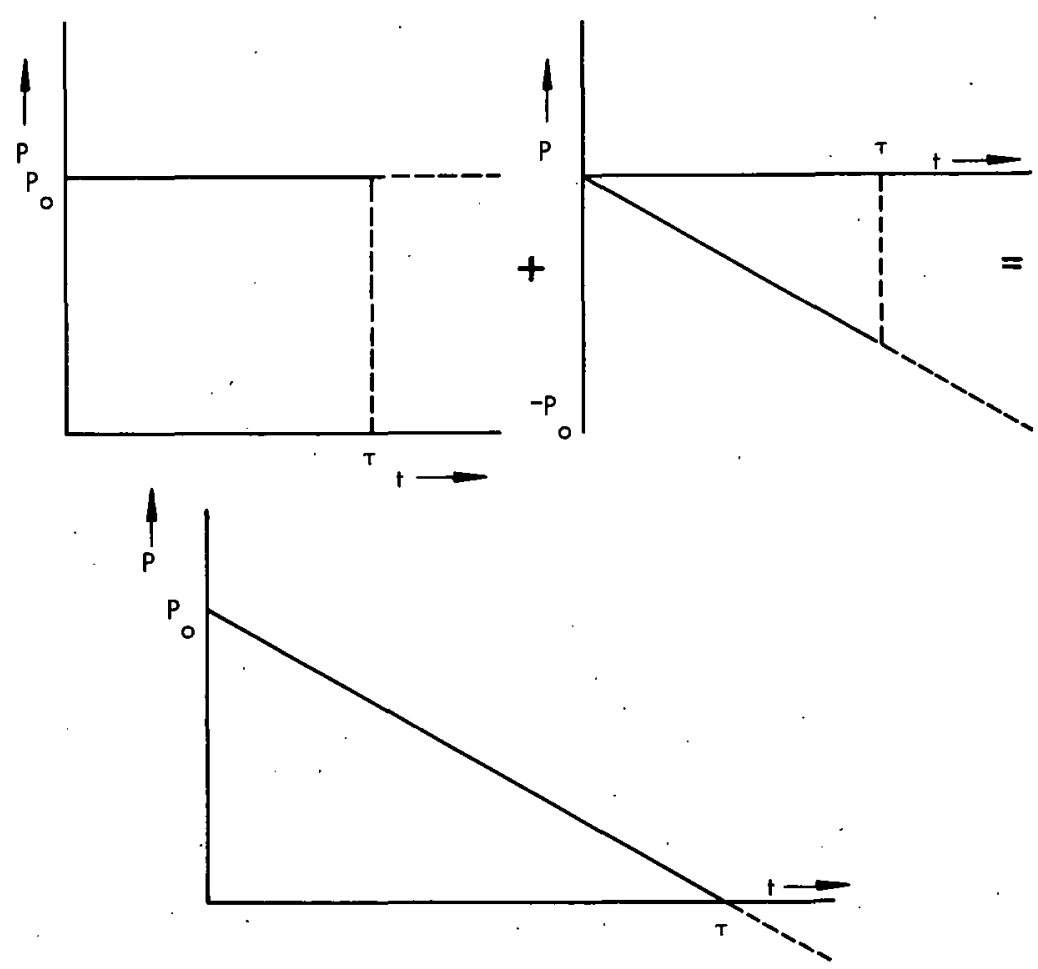

Figure 10. ADDITION OF THE TWO ASSUMED PULSES. 
Equation 9 is valid for the time interval $0 \leq t \leq \tau$.

Therefore, Equation 9 yields the response or displacement for the period when the blast pulse is being applied. At any time greater than $\tau$ this equation will not apply.

It is evident that the structure will continue to move (or deflect) after the pulse has been applied. From Figure 10 it is apparent that, for any time after $\tau$, the assumed pulse has a negative value. This assumed condition does not fit the physical case. To cover the response of the structure after the blast pulse has passed, a new equation must be derived. For the response after the pulse has passed it can be assumed that a positive infinite triangular pulse will be applied at the time $\tau$. This pulse can be added to that of the previous case. Figure 11 illustrates the positive infinite triangular pulse, while Figure 12 indicates that the summation of the three pulses is equivalent to the first assumed case. That is, the summation of the pulses shown in Figures 8,9 , and 11 takes the form of the pulse in Figures 7 or 12 .

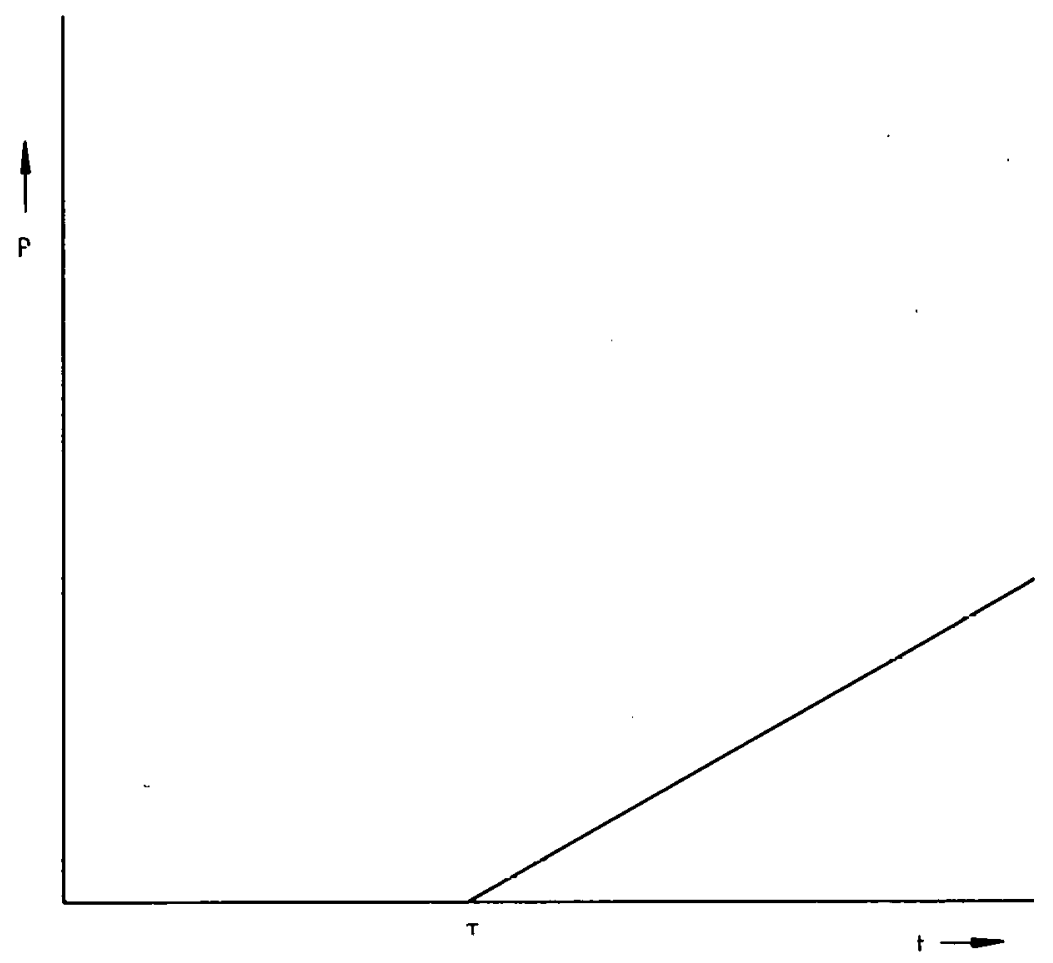

Figure 11. THE ASSUMED POSITIVE INFINITE TRIANGULAR PULSE.

The forcing function for the case for any time after $\tau$ is written as:

$$
F(t)=\frac{A P_{0}(t-\tau)}{\tau}, \quad \tau \leq t
$$




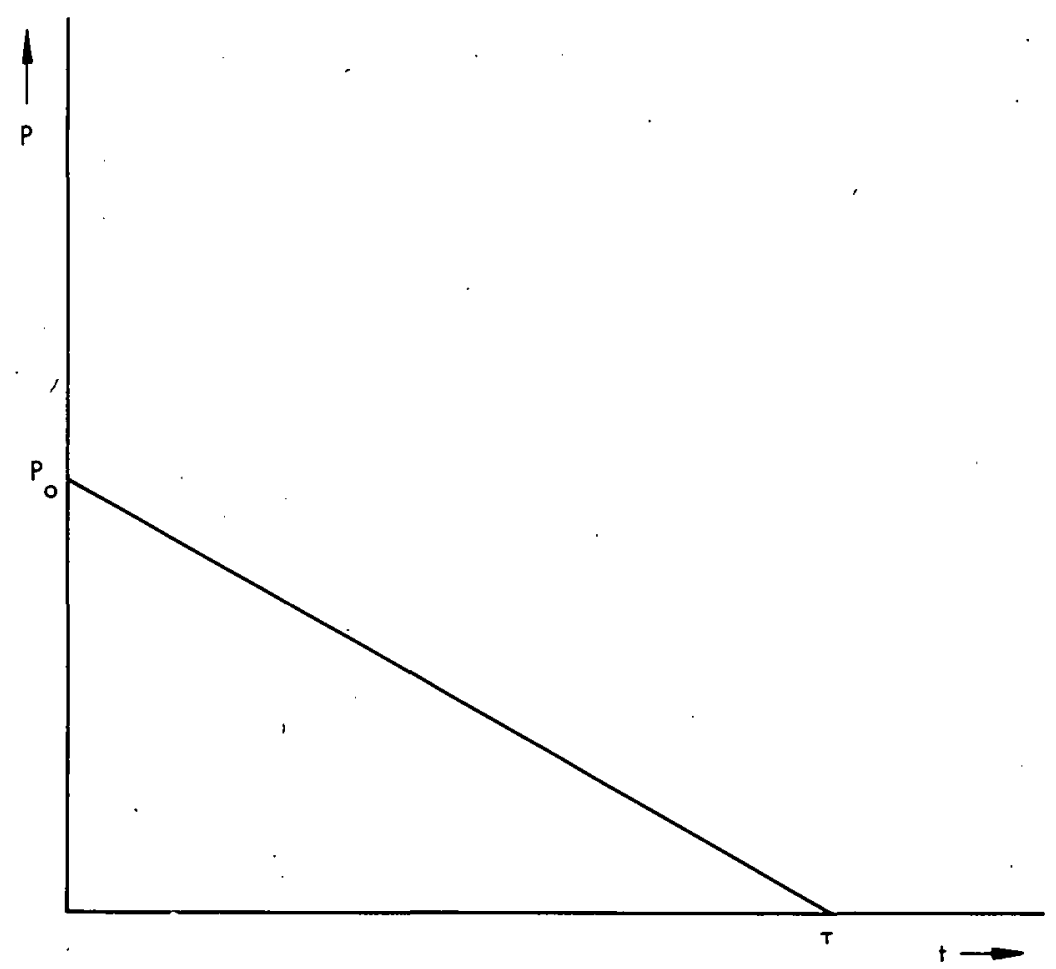

Figure 12. ADDITION OF THE THREE ASSUMED PULSES.

The response of the structure to this pulse is given by the equation:

$$
y=\left(\frac{A P}{\tau m}\right)\left(\frac{1}{\omega_{n}^{3}}\right)\left[\omega_{n}(t-\tau)-\sin \omega_{n}(t-\tau)\right] \text {. }
$$

The addition of Equation 10 to Equation 9 yields the solution to Equation 3 for the time after the pulse has passed, or has been reflected. The solution can be written as:

$$
\begin{aligned}
& y=\left(\frac{A P}{m}\right)\left(\frac{1}{2}\right)\left[1-\cos \omega_{n} t-\frac{t}{\tau}+\frac{\sin \omega_{n}{ }^{\dagger}}{\tau \omega_{n}}\right]+ \\
& \left(\frac{A P_{0}}{\tau m}\right)\left(\frac{1}{3}\right)\left[\omega_{n}(t-\tau)-\sin \omega_{n}(t-\tau)\right] .
\end{aligned}
$$

Equations 9 and 11 are the solutions to the dynamic equation of a simplified structure loaded by a triangular pulse. Equation 9 is to be used while the pulse is applied to the structure and Equation 11 after the pulse has passed or been reflected. In nuclear explosions or similar explosions, the values of $P_{0}$ and $\tau$ must be known. 
$P_{0}$ is known as the peak reflected pressure and $\tau$ is the duration of the pulse. The data for nuclear explosions are given in several sources. $(2,3)$

The shape of the pressure wave generated in a high-explosion blast can be treated as initial impulse since the duration of the blast wave is extremely short. (2) The shape of an initial impulse is shown in Figure 13. The physical concept of the initial impulse is that maximum pressure, $P_{O}$, approaches infinity while the duration, $T$, approaches zero. This relationship has been experimentally determined by certain Armour tests. (2)

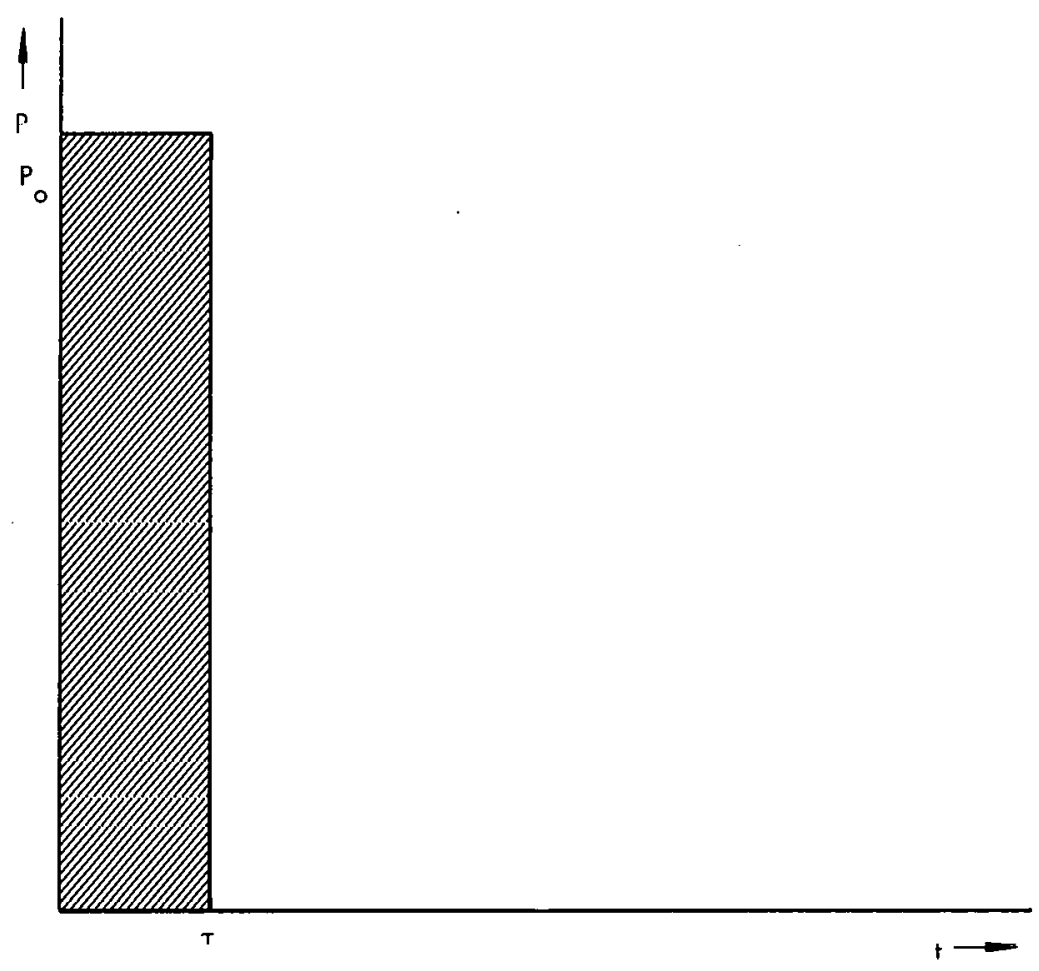

Figure 13. THE ASSUMED INITIAL PULSE.

To solve the dynamic equation for the interval when an initial impulse acts upon the structure, the forcing function is written as:

$$
F(t)=A l_{0}
$$

where:

A gives the area of the struck surface of the structure, and

$I_{0}$ is the initial impulse. 
With this forcing function, Equation 3 can be written as:

$$
D^{2} y+\omega_{n}^{2} y=\frac{A I_{0}}{m} .
$$

Transformation of Equation 12 in the $S$ domain yields:

$$
\left(s^{2}+\omega_{n}^{2}\right) \text { y }(s)=\frac{A l_{0}}{m},
$$

which can be rearranged to yield:

$$
y(s)=\frac{A I_{0}}{m}\left[\frac{1}{s^{2}+\omega_{n}^{2}}\right] .
$$

Transforming the equation back to the time domain results in:

$$
y=\left(\frac{A l_{0}}{m \omega_{n}}\right) \sin \omega_{n}+.
$$

Equation 14 is the solution to Equation 3 for an initial impulse. This solution can be employed with conventional high explosives below the energy level of nuclear explosions. Data which correlate the initial impulse with the weight of detonated high explosive can be found in a report from the Armour Research Foundation. (2)

Solution of the equation of motion for a simplified structure will not in itself permit the determination of maximum stress induced in a structure by a pressure pulse. It is necessary, after calculating maximum deflection, to relate the stress level in the structure to the deflection. Of primary significance in relating these two conditions is the type of structure under consideration.

The structure most commonly encountered in building construction is the flat wall. For a flat-wall structure designed for resistance to internal blast, it is normal to provide a blowout panel to vent the blast pressure. The venting action reduces reflection and repeated reflection which could, by cumulative effect, collapse the wall structure from inward forces.

As a simplifying assumption, the flat wall may be considered as a flat plate. The following derivation is taken from a standard classical. text on plates and shells. (4) Constants used in these calculations were taken from tables in the text. The edge conditions of the plate will indicate which table is to be used. The constant used to calculate the moment is chosen to give the maximum moment at any position in the plate. 
The maximum deflection of the plate is given by:

$$
y=\frac{a q a^{4}}{D}
$$

where:

a is the given constant from the tables, is the uniform pressure acting on the plate (sometimes $b$ - the longest
side - is used in this equation), and

D represents the flexural rigidity of the plate.

The flexural rigidity of the plate is given by the equation:

$$
D=\frac{E h^{3}}{12(1-\nu)} \text {, }
$$

where:

$E$ is the modulus of elasticity,

$h$ is the thickness of the plate, and

$\nu$ represents Poisson's ratio.

Substituting Equation 16 in Equation 15 yields:

$$
y=\frac{a q a^{4}(12)(1-1)}{E h^{3}} .
$$

Rearranging Equation 17 yields:

$$
q=\frac{y E h^{3}}{a a^{4}(12)(1-\nu)} .
$$

From Equation 18, the uniform pressure acting on the plate can be calculated. With the pressure, $q$, known, the maximum stress in the plate can be calculated. The stress in a plate caused by a moment can be calculated by the equation:

$$
\sigma=\frac{6 M}{h^{2}},
$$


where:

$M$ is the moment acting at any point in the plate.

The moment acting in a plate is given by the equation:

$$
M=\beta q a^{2}
$$

where:

$\dot{\beta}$ is the given constant from the tables (sometimes b - the longest side - is used in this equation instead of a).

Substituting Equation 20 into Equation 19 yields:

$$
\sigma=\frac{6 \beta q a^{2}}{h^{2}} .
$$

Substituting Equation 18 into Equation 21 gives:

$$
\sigma=\frac{6 \beta y E h}{a a^{2}(12)(1-\nu)} .
$$

By considering the type of blast the wall must resist, the deflection, $y$, can be calculated and substituted into Equation 22 to calculate the stress, $\sigma$. Using this procedure, the maximum stress in a plate of homogeneous material can be calculated. The walls of most buildings are constructed from inhomogeneous composite materials such as reinforced concrete. For calculation of the stresses in a reinforced concrete wall, Equation 22 must be rewritten. Before approaching the new stress equation for the flat-plate theory, it should be observed that bending is dependent upon the distance in the short direction as well as upon the edge conditions. This situation indicates that only a strip in the short direction bends at points situated away from the edges. Following this line of reasoning, a concept will be introduced into Equation 22 which employs the moment of inertia of the section perpendicular to the plane of bending. Figure 14 depicts the plane and axis used for calculating the moment of inertia.

For the rectangular section, the moment of inertia is:

$$
I=\frac{b h^{3}}{12}
$$

where: 


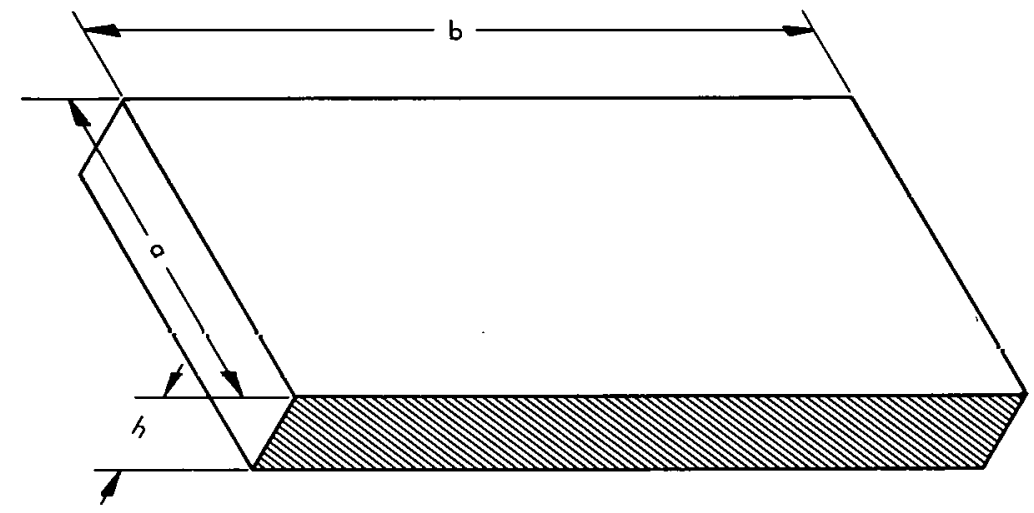

Figure 14. THE PLANE OF THE PLATE FOR WHICH THE MOMENT OF INERTIA IS USED.

b represents the length of the section, and

$h$ is the thickness.

The moment of inertia is introduced into Equation 22 as follows:

$$
\sigma=\frac{\sigma \beta y E}{a a^{2}(1-\nu) b h^{2}}\left(\frac{b h^{3}}{12}\right)
$$

or,

$$
\sigma=\frac{6 \beta Y E I}{\alpha a^{2}(1-\nu) b h^{2}}
$$

It is necessary to develop the equivalent moment of inertia for reinforced concrete sections for use in Equation 23a. The method of calculating "I" for a reinforced cuncrete beam is covered in standard texts on the design of concrete structures. (5) The moment of inertia developed in the following discussion is based upon the transformed section. The assumed wall section for the calculation is shown in Figure 15. The position of the neutral axis of the assumed section is given by:

$$
X=\sqrt{\frac{2 M N A\left(Y-Y^{\prime}\right)}{b}},
$$




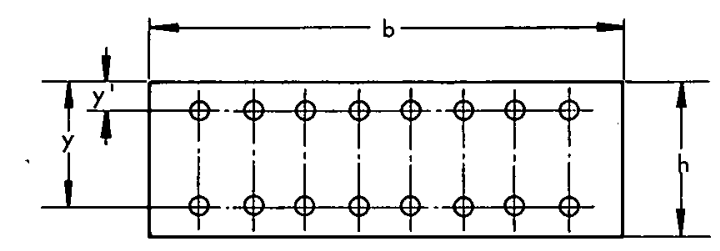

II $h=1$ foot
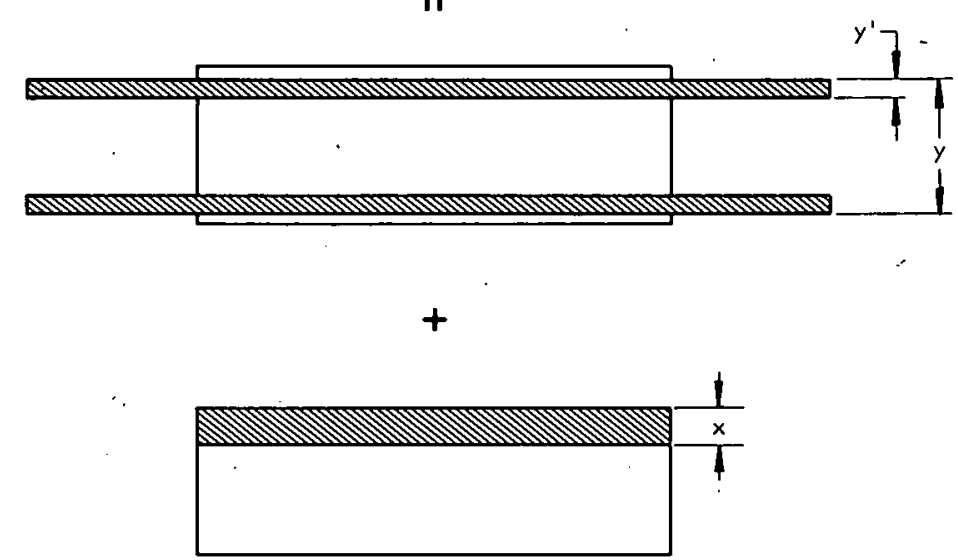

Figure 15. THE ASSUMED SECTION AND THE TRANSFORMED SECTIONS.

where:

$X$ 'is the distance from the top of plate to the neutral axis,

$M$ is the number of reinforcing rods per edge of the section,

$N$ is the ratio of the modulus of elasticity of the steel to the modulus of the concrete,

$Y$ is the distance from the top of the plate to the axis of the bottom reinforcing rods,

$Y^{\prime}$ is the distance from the top of the plate to the axis of the top reinforcing rods,

b is the width of the section, and

A is the cross sectional area of the rods.

"The moment of inertia of the section is given by:

$$
1=\frac{b X^{3}}{12}+\frac{b X^{3}}{4}+\operatorname{MNA}(Y-X)^{2}+\operatorname{MNA}\left(X-Y^{\prime}\right)^{2}
$$


With the use of Equations 23 and 25, the stress in a reinforced wall may be calculated.

At this point the significance of the stress values given by Equation 23 a should be discussed before proceeding to a calculation procedure. It should be observed that a building wall is not simply supported on all sides. Instead of the idealized peak stress build up at the center of the panel, the maximum stress will actually occur at one edge of the wall. In normal construction, walls are attached to support members by heavier reinforcement than that of the wall itself. Hence, there is greater strength at the positions of attachment than at points in the unsupported sections of the wall panel.

It is essential to determine the natural frequency of the walls in order to calculate the maximum wall deflection. Classical solutions for natural frequency of plates under specified edge or boundary conditions may be found in the literature. (3) For cases where natural frequency is not available in the literature, it is advisable to take a hypothetical beam formed from a unit strip of the plate, assuming the length of the beam to be the shortest side of the plate. The end conditions are assumed to be the same as the edge conditions of the plate on which the beam terminates.

After the boundary or edge conditions are assumed for the walls and the proper tables have been found in the literature, (4) the constants $\alpha$ and $\beta$ can be used in the stress equation. However, in most cases the tables are given for certain values of Poisson's ratio, $\nu$. Since Poisson's ratio affects the bending in a plate, the moment must be corrected for the proper Poisson's ratio. Timoshenko $(4)$ derives a method for this correction which is:

$$
\begin{aligned}
& M_{x}^{\prime}=\frac{1}{1-\nu^{2}}\left[\left(1-\nu \nu^{\prime}\right) M_{x}+\left(\nu^{\prime}-\nu\right) M_{y}\right] \text { and } \\
& M_{y}^{\prime}=\frac{1}{1-\nu^{\prime 2}}\left[\left(1-\nu \nu^{\prime}\right) M_{y}+\left(\nu^{\prime}-\nu\right) M_{x}\right],
\end{aligned}
$$

where:

$$
\begin{aligned}
& M_{X}^{\prime} \text { represents the corrected moment in the } X \text { direction, } \\
& M_{y}^{\prime} \text { gives the corrected moment in the } Y \text { direction, } \\
& \nu^{\prime} \quad \text { is the proper Poisson 's ratio, and } \\
& \nu \quad \text { is the Poisson's ratio for which the table was calculated. }
\end{aligned}
$$

Using the corrected moment, a new $\beta^{\prime}$ can be calculated by using Equation 20. Then the $\beta^{\prime}$ canbe used to replace the $\beta$ in the stress equation and the proper stress can be calculated using Equation 23a. 
Another physical condition concerning the natural period of the wall should be discussed. If the natural period of the wall is thirty times the duration $\tau$ in a nuclear explosion, the response of the wall may be treated in the same manner as a highexplosive response. This means that in the case of an assumed triangular pulse for the pressure wave, if the natural period of the wall is thirty times greater than the duration of the pulse, the pulse may be treated as an initial impulse. (6) This latter physical concept of the initial impulse will greatly reduce the necessary work to calculate the stress in a wall subjected to a triangular pulse.

The foregoing simplified stress calculation procedure provides more accuracy with less effort than the other techniques that were considered. It is significant that the method adopted for the following calculations permits a design to be drawn completely within the elastic range if the designer so desires.

\section{APPLICATION TO RESISTANT DESIGN}

It has been calculated that accidental failure of Pressure Vessel-2, which is being converted to a gas autoclave, would release the compressed gas with energy equivalent to the explosive force of 50 pounds of TNT. Since this energy release is at the level of the high-explosive range, Equation 14 may be used for calculating the blast response. In the stress Equation (Equation 23a), the maximum deflection of the structure is employed. Hence, the maximum value for deflection, as given in Equation 14, becomes:

$$
y=\frac{A l_{0}}{m W_{n}},
$$

since the maximum value for the sine of a function is unity. Having determined the maximum deflection, the stress at any position in the wall may be calculated.

The moment of inertia used in the stress equation is calculated on the basis of the steel reinforcement in the wall and does not include corner reinforcement or column reinforcement. The additional reinforcement in the corners is equivalent to increasing the wall thickness in the corner. This means that the actual stress will be lower than the calculated value for the corner sections.

Application of the analytical method discussed thus far has been made to two wall systems: (1) the PV-2 cell in the Y-12 Plant and (2) a special cell constructed and tested by the Armour Research Foundation at Coal City, Ill inois $(7)$. for Monsanto Chemical. Analysis of the latter wall structure will be presented first in the following calculations.

Coal City Test

The wall section chosen for analysis was a center partition located two feet away from the high explosives used in the test series. The wall section was assumed to 
have three sides fixed and one side free, as shown in Figure 16. The natural frequency could not be calculated by a classical solution so a beam of length "a " and fixed ends was assumed. The beam was chosen with a one-foot-square cross section for calculating the moment of inertia. Wall reinforcement of the test cell consisted of Number 4 bars on six-inch centers running both ways on each face.

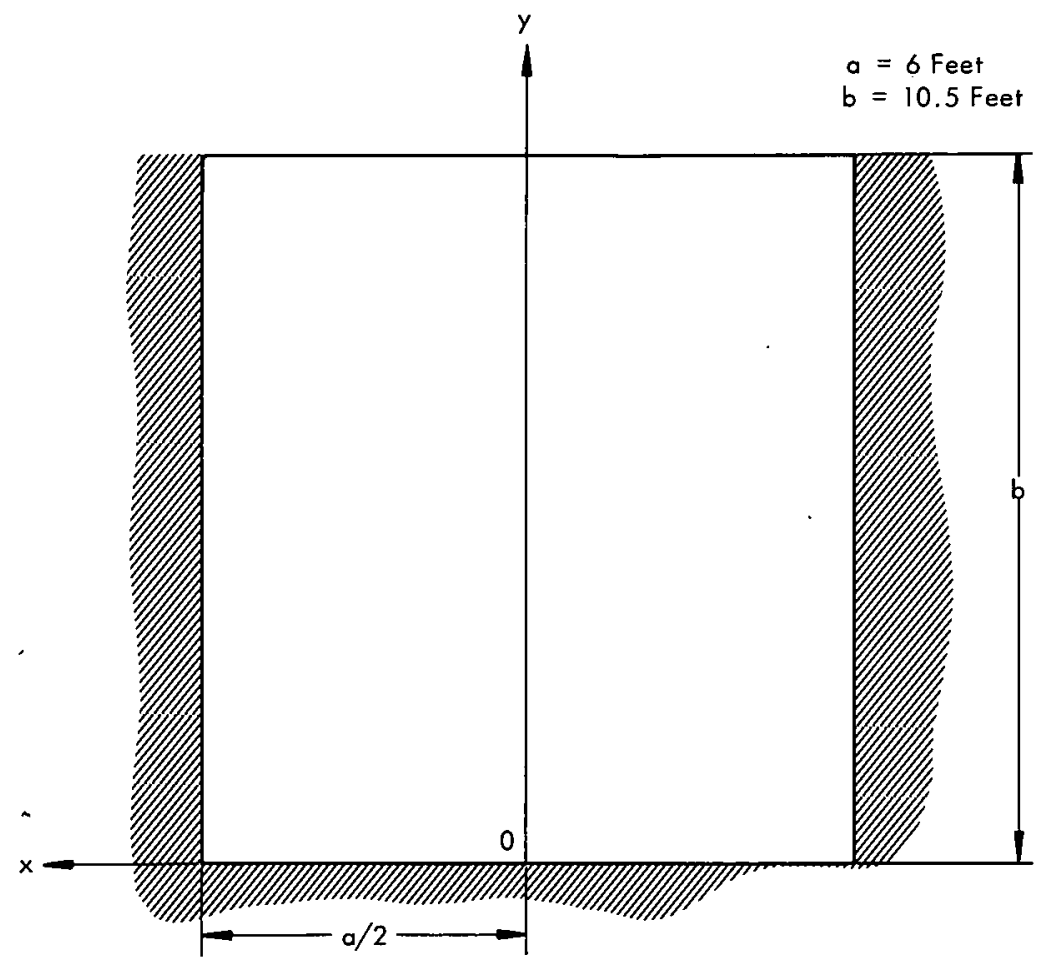

Figure 16. THE ASSUMED EDGE CONDITIONS FOR THE COAL CITY TEST.

The following calculations were made:

Moment of Inertia of the Beam (Equation 24) -

$$
\begin{aligned}
& X=\sqrt{\frac{2 M N A\left(Y-Y^{\prime}\right)}{b}}, \\
& X=\sqrt{\frac{(2)(2)(10)(0.20)(9)}{12}}=2.45 \text { inches, }
\end{aligned}
$$

when:

$M$ has a value of 2 ,

$\mathrm{N}$ has a value of 10 , 

A has a value of $0.20 \mathrm{in}^{2}$,
$Y$ has a value of $10.5 \mathrm{in}$,
$Y^{\prime}$ has a value of $1.5 \mathrm{in}$, and
b has a value of 12 .

Then by Equation 25:

$$
\begin{gathered}
I=\frac{b X^{2}}{12}+\frac{b X^{3}}{4}=\operatorname{MNA}(Y-X)^{2}+\operatorname{MNA}\left(X-Y^{\prime}\right)^{2} \\
I=\frac{12(2.45)^{3}}{12}+\frac{12(2.45)^{3}}{4}+2(10)(0.2)(8.06)^{2}+2(10)(0.2)(0.94)^{2}= \\
3.223 \times 10^{2} \mathrm{in}^{4} .
\end{gathered}
$$

Natural Frequency (see "Shock and Vibration Handbook", Pages 7-14)-

$$
\omega_{n}=K^{2} \sqrt{\frac{E I g}{a \rho}}
$$

where:

$$
\begin{aligned}
& \rho=8.68 \times 10^{-2} \mathrm{lb} / \mathrm{in}^{3}, \\
& g=386 \mathrm{in} / \mathrm{sec}^{2}, \text { and } \\
& \mathrm{aK}=4.730, \text { or } \\
& K=4.730 / \mathrm{a}=4.730 / 72=6.569 \times 10^{-2} .
\end{aligned}
$$

So:

$$
\omega_{n}=\left(6.569 \times 10^{-2}\right)^{2} \sqrt{\frac{\left(3 \times 10^{6}\right)\left(3.223 \times 10^{2}\right)\left(3.86 \times 10^{2}\right)}{\left(1.44 \times 10^{2}\right)\left(8.68 \times 10^{-2}\right)}}=744 \mathrm{radians} / \mathrm{sec} .
$$

Maximum Deflection (Equation 27)-

and

$$
y=\frac{A I_{0}}{m \omega_{n}}
$$




$$
m=\frac{a b h p}{g}=\frac{(72)(126)(12)(0.0868)}{386}=24.46 \mathrm{lb} \mathrm{sec}^{2} / \mathrm{in} .
$$

From page 34 of Armour's Phase Report: (2)

so:

$$
\mathrm{I}_{0}=0.500 \mathrm{psi}-\mathrm{sec} \text { at two feet from a blast of } 50 \text { pounds of TNT, }
$$

$$
y=\frac{(72)(126)(0.500)}{(24.46)(744)}=0.249 \text { inch }
$$

Stress (maximum stress occurs at the corner of the fixed and free edge) -

From "Theory of Plates and Shells", Page 215:

$$
\frac{b}{a}=1.75 \quad a=2.9 \times 10^{-3} \quad \beta=8.42 \times 10^{-2}
$$

Moment of Inertia for the Wall (Equation 25) -

$$
X=\sqrt{\frac{(2)(21)(10)(0.2)(9)}{126}}=2.44 \text { inches, }
$$

when:

$M$ has a value of 21 ,

$N$ has a value of 10 ,

A has a value of $0.2 \mathrm{in}$,

$Y$ has a value of $10.5 \mathrm{in}$,

$Y^{\prime}$ has a value of $1.5 \mathrm{in}$, and

b has a value of 126 .

$$
\begin{gathered}
I=\frac{(126)(2.44)^{3}}{12}+\frac{(126)(2.44)^{3}}{4}+(21)(10)(0.2)(8.06)^{2}+(21)(10)(0.2)(0.94)^{2}= \\
3.375 \times 10^{3} \mathrm{in}^{4} .
\end{gathered}
$$

Then, by Equation 23a:

$$
\sigma=\frac{6 \beta y E I}{a a^{2}(1-\nu) b h^{2}}
$$




$$
\sigma=\frac{(6)(8.42)\left(10^{-2}\right)(0.249)(3)\left(10^{6}\right)(3.375)\left(10^{3}\right)}{(2.9)\left(10^{-3}\right)(72)^{2}(0.9775)(126)(12)^{2}}=47.80 \mathrm{psi}
$$

when:

$\nu$ has a value of 0.15

Stress at the Center of the Wall -

$$
\sigma_{x}=\frac{(6)(4.02)\left(10^{-2}\right)(0.249)(3)\left(10^{6}\right)(3.375)\left(10^{3}\right)}{(2.9)\left(10^{-3}\right)(72)^{2}(0.9775)(126)(12)^{2}}=2281 \mathrm{psi}
$$

when:

$$
\begin{aligned}
& \beta_{x} \text { has a value of } 0.0402 \text {, and } \\
& \beta_{y} \text { has a value of } 0.0118 \text {. }
\end{aligned}
$$

And:

$$
\sigma_{y}=\frac{(6)(1.18)\left(10^{2}\right)(0.249)(3)\left(10^{6}\right)(3.375)\left(10^{3}\right)}{(2.9)\left(10^{-3}\right)(72)^{2}(0.9775)(126)(12)^{2}}=670 \mathrm{psi} \text {. }
$$

The only visible evidence of damage to the wall caused by the 50-pound blast was a vertical crack in the center of the wall. From photographic evidence it appeared that the initial 50-pound charge produced only minor damage to the cell structure. Later in the test series, repeated 50 and 70 -pound charges annihilated the cell.

\section{The PV-2 Containment Walls}

South Wall (elevation - 976 feet) - Wall reinforcement of the PV-2 containment cell consisted of Number 5 steel bars spaced on 10-inch centers running both ways on each face. The wall panel that was analyzed was assumed to have two sides simply supported with the other two edges fixed, as shown by Figure 17. The following calculations were made:

$$
\begin{aligned}
& \text { Moment of Inertia of the Wall } \\
& X=\sqrt{\frac{(2)(28.2)(10)(0.31)(10.5)}{282}}=2.55 \text { inches, }
\end{aligned}
$$

when: 


$$
\begin{aligned}
& a=18 \text { Feet } \\
& b=23.5 \text { Feet }
\end{aligned}
$$

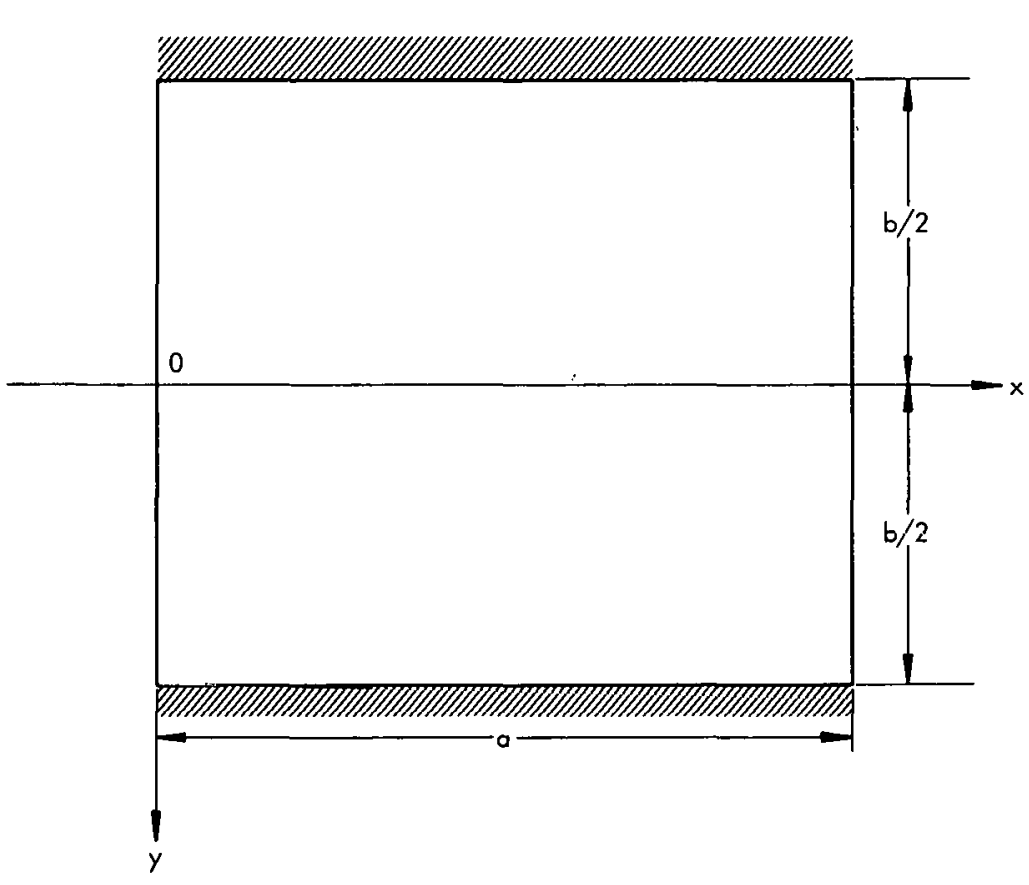

Figure 17. THE ASSUMED EDGE CONDITIONS FOR THE SOUTH WALL. (Elevation - 976 feet)

$M$ has a value of 28.2 ,

$\mathrm{N}$ has a value of 10 ,

A has a value of $0.31 \mathrm{in}^{2}$,

$Y$ has a value of $11.5 \mathrm{in}$,

$Y^{\prime}$ has a value of $0.75 \mathrm{in}$, and

b has a value of 282 .

$$
\begin{gathered}
I=\frac{(282)(2.55)^{3}}{12}+\frac{(282)(2.55)^{3}}{4}+(28.2)(10)(0.31)(8.7)^{2}+ \\
(28.2)(10)(0.31)(1.8)^{2}=8.459 \times 10^{3} \mathrm{in}^{4}
\end{gathered}
$$

Natural Frequency (see "Shock and Vibration Handbook", Pages 7-32)

$$
b / a=1.306
$$




$$
\begin{aligned}
W_{n} & =26.61 \sqrt{\frac{E h^{3} g}{12\left(1-\nu^{2}\right) \rho \cdot h a^{4} \cdot}}=\sqrt{\frac{E g}{\left(1-\nu^{2}\right) \rho}\left[\frac{1}{h a^{4} b}\right]}, \\
& =26.61 \sqrt{\left(1.365 \times 10^{10}\right)\left[\frac{1}{h a^{4} b}\right]}, \\
& =26.61 \cdot\left[\frac{(1.365)\left(10^{10}\right)(8.459)\left(10^{3}\right)}{(12)(216)^{4}(282)}\right]=103.247 \text { radians } / \mathrm{sec} . \\
m & =\frac{(216)(282)(12)(0.0868)}{386}=1.642 \times 10^{2} \mathrm{lb} \mathrm{sec} \mathrm{sec}^{2} / \mathrm{in} .
\end{aligned}
$$

From Page 34 of the Armour Phase Report:

$I_{0}=0.275$ psi sec at 8 feet from the center of the vessel for 34 pounds of TNT, so:

$$
y=\frac{(216)(282)(0.275)}{(1.642)\left(10^{2}\right)(103.247)}=0.987 \mathrm{in}
$$

Stress (maximum stress occurs at the middle of the fixed sides)

$$
\begin{gathered}
M_{y}=\beta q a^{2}, \\
M_{y}^{\prime}=\frac{\left(1-\nu \nu^{\prime}\right)_{y}}{1-\nu^{\prime 2}}=\left[\frac{1-0.045}{1-0.0225}\right] M_{y^{\prime}}
\end{gathered}
$$

when:

$\nu$ has a value of 0.3 and $\nu^{\prime}$ has a value of $0.15 ; M_{y}^{\prime}$ equals $0.977 M_{y}$ and $\beta^{\prime}$ equals $0.977 \beta$.

Also:

$$
\frac{b}{a}=\frac{282}{216}=1.306, \alpha=0.00388, \beta=0.0938 \text {. }
$$




$$
\begin{gathered}
\beta^{\prime}=0.977(0.0938)=0.0916 \\
\sigma=\frac{(6)(0.0916)(0.987)(3)\left(10^{6}\right)(8.459)\left(10^{3}\right)}{(0.00388)(216)^{2}(0.9775)(12)^{2}(282)}=1916 \mathrm{psi} . \\
\frac{\text { Stress at the Middle }}{\beta_{x}^{\prime}}=0.0436 \\
\beta_{x}=0.0446 \quad \beta_{y}^{\prime}=0.0416 \\
\beta_{y}=0.0426 \quad(1916)=911 \text { psi. } \\
\sigma_{x}=\frac{\beta_{x}^{\prime}}{\beta} \sigma=\frac{0.0436}{0.0916} \quad \beta_{y}^{\prime} \\
\sigma_{y}=\frac{0.0416}{\beta^{\prime}} \sigma=\frac{0.0916}{(1916)=870 \mathrm{psi} .}
\end{gathered}
$$

On the basis of the stress level $\left(\sigma_{y}=870 \mathrm{psi}\right)$ and the associated damage previously encountered with the Coal City cell, it can be assumed that only minor cracking would be expected for this wall section.

East Wall (elevation - 976 feet) - Wall reinforcement for this section was the same as that in the south wall. The wall was assumed to have three sides fixed and the other side simply supported, as shown in Figure 18. The natural frequency could not be calculated by the classical method so a beam of length "b", with one end fixed and the other end simply supported, was assumed for calculation. A beam of one foot square cross section was chosen. The following calculations were made:

$$
\begin{aligned}
& \text { Moment of Inertia of the Beam (by Equation 24) } \\
& \qquad x=\sqrt{\frac{(2)(2)(10)(0.31)(10.5)}{12}}=3.29,
\end{aligned}
$$

when:

$M$ has a value of 2 ,

$N$ has a value of 10 ,
A has a value of $0.31 \mathrm{in}^{2}$,
$Y$ has a value of $11.5 \mathrm{in}$,
$\mathrm{Y}^{\prime}$ has a value of $0.75 \mathrm{in}$, and
b has a value of $12 \mathrm{in.}$ 


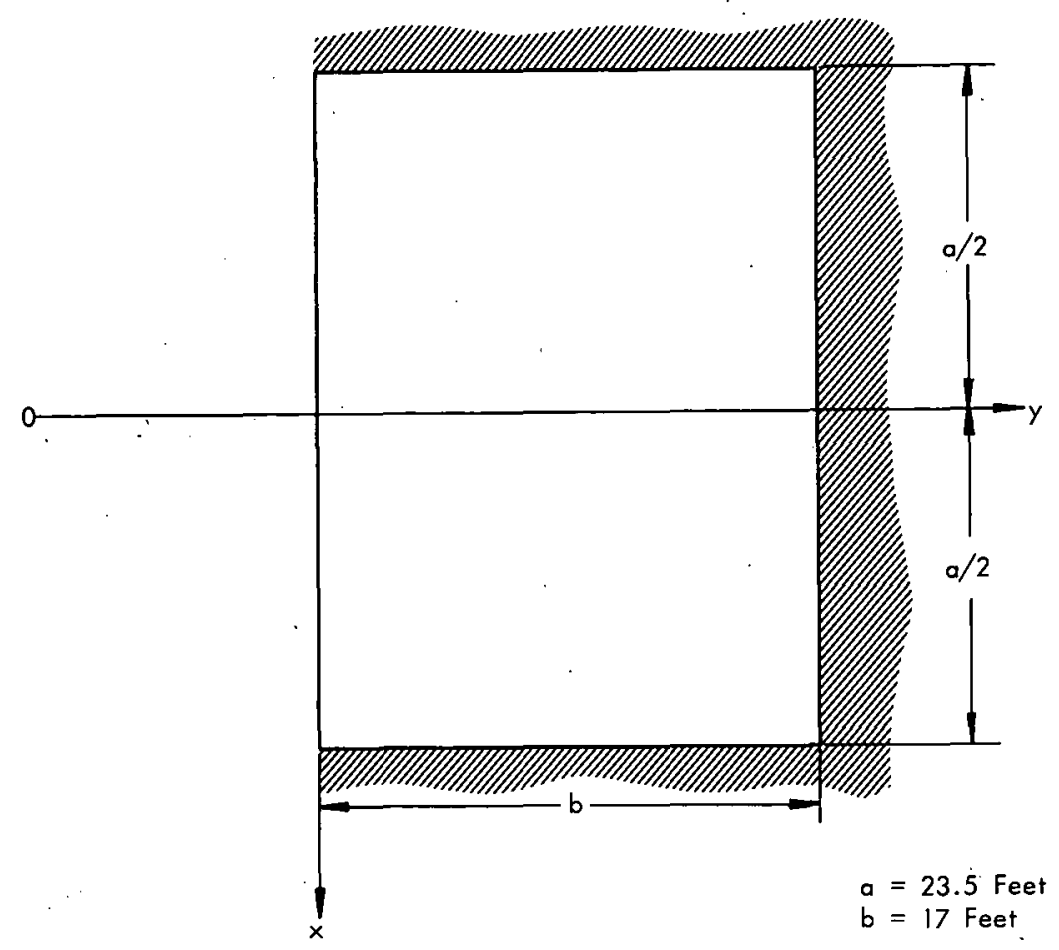

Figure 18. THE ASSUMED EDGE CONDITIONS FOR THE EAST WALL. (Elevation - 976 feet)

Then, by Equation 25:

$$
\begin{gathered}
I=\frac{(12)(3.29)^{3}}{12}+\frac{(12)(3.29)^{3}}{4}+(2)(10)(0.31)(7.96)^{2}+(2)(10)(0.31)(2.54)^{2}= \\
575.286 \mathrm{in}^{4} . \\
\frac{\text { Natural Frequency (see "Shock and Vibration Handbook ", Pages 7-14) }}{\omega_{n}=K^{2} \sqrt{\frac{E I g}{A P}} .}
\end{gathered}
$$

When:

$\rho$ has a value of $8.68 \times 10^{-2} \mathrm{lb} / \mathrm{in}^{3}$,

g has a value of $386 \mathrm{in} / \mathrm{sec}^{2}$,

bK has a value of 3.927 , so

$K$ becomes $\frac{3.927}{b}=\frac{4.730}{2.04 \times 10^{2}}=1.925 \times 10^{-2}$, 


$$
\begin{gathered}
\omega_{n}=\left(1.925 \times 10^{-2}\right) \sqrt{\frac{\left(3 \times 10^{6}\right)(575.286)(386)}{(144)\left(8.68 \times 10^{-2}\right)}}=85.609 \text { radians } / \mathrm{sec} . \\
\frac{\text { Maximum Deflection }}{g}=\frac{a b h p}{g}=\frac{(282)(204)(12)\left(8.68 \times 10^{-2}\right)}{386}=155.1 \mathrm{lb} \mathrm{sec}^{2} / \mathrm{in} .
\end{gathered}
$$

By Equation 27:

$$
y=\frac{A I_{0}}{m \omega n},
$$

where:

$I_{\circ}=0.180$ psi sec at 13.25 feet from the center of the vessel for 34 pounds of TNT.

Therefore:

$$
\begin{gathered}
y=\frac{(204)(282)(0.180)}{(155.1)(85.609)}=0.618 \text { inch. } \\
\frac{\text { Moment of Inertia for the Wall }}{X=} \\
\frac{\sqrt{2 \text { MNA }\left(Y-Y^{\prime}\right)}}{a}=2.55 \text { inches, }
\end{gathered}
$$

when:

$M$ has a value of 20.4 ,

$N$ has a value of 10 ,
A has a value of $0.31 \mathrm{in}$,
$Y$ has a value of $11.5 \mathrm{in}$,
$Y^{\prime}$ has a value of 0.75 , and
a has a value of 204 .

So: 
86

$$
\begin{aligned}
I= & \frac{a X^{3}}{12}+\frac{a X^{3}}{4}+\operatorname{NMA}(Y-X)^{2}+\operatorname{NMA}\left(X-Y^{\prime}\right)^{2} \\
= & \frac{(204)(2.55)^{3}}{12}+\frac{(204)(2.55)^{3}}{4}+(10)(20.4)(0.31)(8.7)^{2}+ \\
& (10)(20.4)(0.31)(1.8)^{2}=6.120 \times 10^{3} \mathrm{in}^{4} .
\end{aligned}
$$

Stress (maximum stress occurs at the middle of the long side - a)

From "Theory of Plates and Shells", Pages 207 and 244:

$$
\begin{aligned}
\frac{b}{a}=\frac{204}{282} & =0.723, a=0.00304, \beta=0.0877 . \\
M_{y}^{\prime} & =\frac{\left(1-\nu^{\prime}\right)}{\left(1-\nu^{2}\right)} M_{y^{\prime}}
\end{aligned}
$$

or

$$
M_{y}^{\prime}=\frac{(1-0.030)}{(1-0.0225)} M_{y}^{\prime}=0.992 M_{y^{\prime}}
$$

when:

$\nu$ has a value of 0.2 ,

$\nu$ ' has a value of 0.15 , and

$\beta^{\prime}$ equals $0.992 \beta$.

So:

$$
\beta^{\prime}=0.0870
$$

Therefore:

$$
\begin{aligned}
\sigma & =\frac{6 \beta^{\prime} y E I}{b^{2} h^{2} a \alpha\left(1-\nu^{2}\right)}, \\
& =\frac{(6)(0.0870)(0.618)\left(3 \times 10^{6}\right)\left(6.120 \times 10^{3}\right)}{(0.00304)(204)^{2}(12)^{2}(282)(0.9775)}=1180 \mathrm{psi} .
\end{aligned}
$$


Stress at the Center of the Wall

$$
\begin{aligned}
& \beta_{x}=0.0270 \quad \beta_{y}=0.0392 \\
& \sigma_{x}=\frac{\beta_{x}}{\beta} \sigma=\frac{0.0270}{0.0877}(1180)=360 \mathrm{psi} \\
& \sigma_{y}=\frac{\beta_{y}}{\beta} \sigma=\frac{0.0392}{0.0877}(1180)=450 \mathrm{psi} .
\end{aligned}
$$

This low stress level indicates that any damage to this wall section would probably be inconsequential. Some cracking on the outer surface of the wall might occur.

North Wall (elevation - 976 feet) - With reinforcement identical to that of the previous cases, the wall is assumed to be fixed on all four sides, as shown by Figure 19.

$$
\begin{gathered}
\text { Moment of Inertia of the Wall } \\
X=2.55 \text { inches, and } \\
I=8.459 \times 10^{3} \text { in }^{4}
\end{gathered}
$$

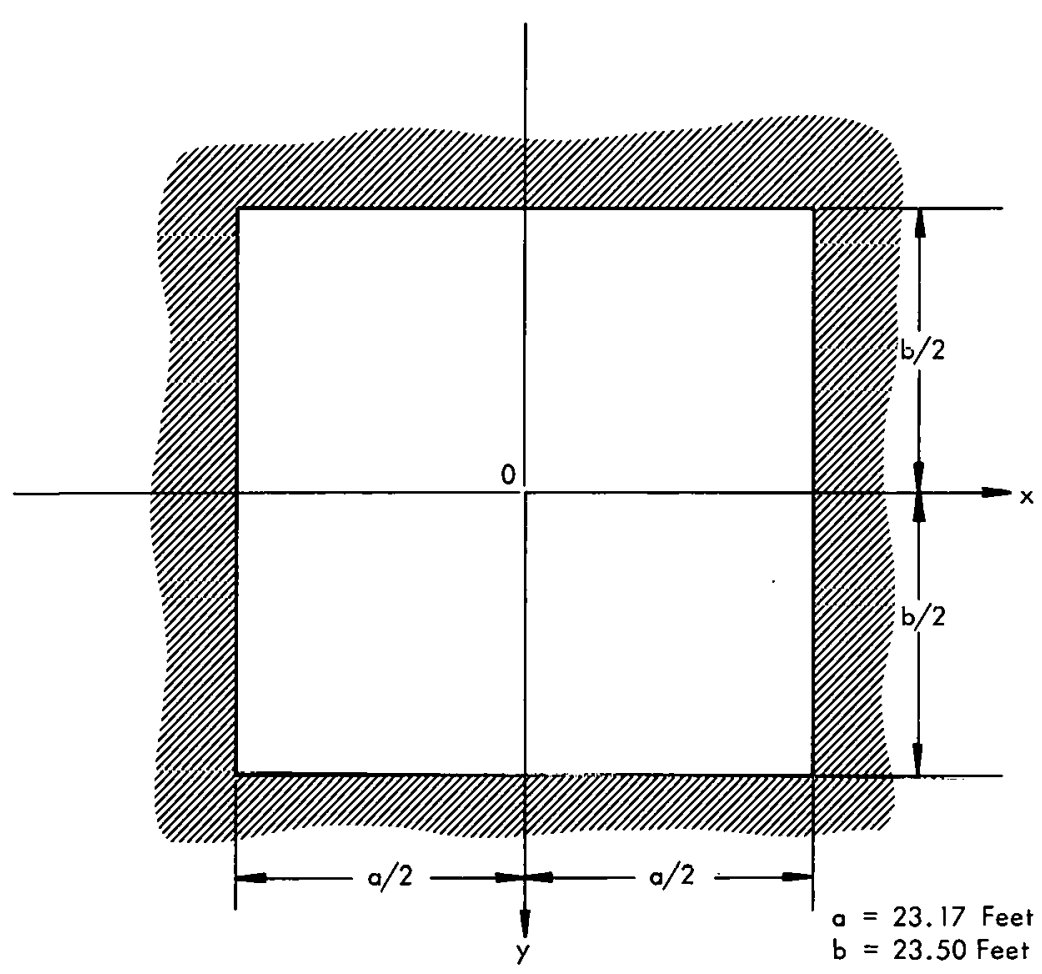

Figure 19. THE ASSUMED EDGE CONDITIONS FOR THE NORTH WALL. (Elevation - 976 feet) 
when:

$M$ has a value of 28.2 ,

$\mathrm{N}$ has a value of 10 ,

A has a value of $0.31 \mathrm{in}^{2}$,

$Y$ has a value of $11.5 \mathrm{in}$,

$Y^{\prime}$ has a value of $0.75 \mathrm{in}$, and

b has a value of 282 .

Natural Frequency (see "Shock and Vibration Handbook", Pages 7-32)

$$
\begin{gathered}
\frac{b}{a}=\frac{282}{277}=1.018 \\
\omega_{n}=19.74 \sqrt{\frac{\left(1.365 \times 10^{10}\right) 1}{h a^{4} b}} ; \\
=19.74 \sqrt{\frac{\left(1.365 \times 10^{10}\right)\left(8.459 \times 10^{3}\right)}{(1.2)\left(2.77 \times 10^{2}\right)\left(2.82 \times 10^{2}\right)}}=150.419 \text { radians } / \mathrm{sec} . \\
m=\frac{(277)(282)\left(8.68 \times 10^{-2}\right)(12)}{386}=2.106 \times 10^{2} \mathrm{lb} \mathrm{sec} \mathrm{Maxim}^{2} / \mathrm{in} .
\end{gathered}
$$

From the Armour Phase Report, Page 34:

$I_{0}=0.280$ psi sec at 7.75 feet from the center of the vessel for 34 pounds of TNT,

so:

$$
y=\frac{(277)(282)(0.280)}{\left(2.106 \times 10^{2}\right)(150.419)}=0.619 \mathrm{inch}
$$

Stress (maximum stress occurs at the middle of the longest side)

$$
\beta^{\prime}=0.977 \beta
$$




$$
\frac{b}{a}=1.018, a=0.00130, \beta=0.0525,
$$

therefore:

$$
\begin{gathered}
\beta^{\prime}=0.977(0.0525)=0.0513 \text {, and } \\
\sigma=\frac{(6)(0.0513)(0.691)\left(3 \times 10^{6}\right)\left(8.459 \times 10^{3}\right)}{(0.0013)(12)^{2}(277)(9.9775)(282)}=1360 \mathrm{psi} . \\
\frac{\text { Stress at the Center of the Wall }}{\beta_{x}=0.0237 \quad \beta_{y}=0.0231} \\
\sigma_{x}=\frac{\beta_{x}}{\beta} \sigma=\frac{0.0237}{0.0525}(1360)=613 \mathrm{psi} . \\
\sigma_{y}=\frac{\beta_{y}}{\beta} \sigma=\frac{0.0231}{0.0525}(1360)=600 \mathrm{psi} .
\end{gathered}
$$

No serious damage can be associated with this low stress level.

South Wall (elevation - 955 feet) - The reinforcement is the same as in previous cases. The wall section is assumied lo be fixed on all four sides, that is:

$$
\begin{aligned}
& a=12 \mathrm{ft}=144 \mathrm{in}, \\
& b=16.25 \mathrm{ft}=195 \mathrm{in}, \\
& h=1 \mathrm{ft}=12 \mathrm{in} .
\end{aligned}
$$

Moment of Inertia of the Wall

$$
X=2.55 \text { inches, and }
$$

$$
\begin{gathered}
I=\frac{(195)(2.55)^{3}}{12}+\frac{(195)(2.55)^{3}}{4}+(10)(19.5)(0.31)(8.7)^{2} \\
+(10)(19.5)(0.31)(1.8)^{2}=5.850 \times 10^{3} \mathrm{in}^{4}
\end{gathered}
$$

when:

M has a value of 19.5 ,

$N$ has a value of 10 , 
A has a value of $0.31 \mathrm{in}^{2}$,

$Y$ has a value of $11.5 \mathrm{in}$,

$Y^{\prime}$ has a value of $0.75 \mathrm{in}$, and

b has a value of 195 .

Natural Frequency (see "Shock and Vibration Handbook", Pages 7-32)

$$
\begin{gathered}
\frac{b}{a}=\frac{195}{144}=1.354 \\
\omega_{n}=29.62 \sqrt{\frac{1.365 \times 10^{10}}{h a^{4} b}}= \\
29.62 \sqrt{\frac{\left(1.365 \times 10^{10}\right)\left(5.85 \times 10^{3}\right)}{(12)(144)^{4}(195)}}=263.914 \text { radians } / \mathrm{sec} . \\
\frac{\text { Maximum Deflection }}{m=\frac{(144)(195)(12)\left(8.68 \times 10^{-2}\right)}{386}}=7.567 \times 10^{2} \mathrm{lb} \mathrm{sec}^{2} / \mathrm{in} .
\end{gathered}
$$

From the Armour Phase Report, Page 34:

$I_{0}=0.200$ psi sec at 7.75 feet from the center of the vessel for 21 pounds of TNT,

so:

$$
y=\frac{(144)(195)(0.20)}{(75.67)(263.914)}=0.281 \text { inch }
$$

Stress (maximum stress occurs at the center of the longest side)

$$
\begin{gathered}
\beta^{\prime}=0.977 \beta \\
\frac{b}{a}=1.354, \alpha=0.00200, \beta=0.0708,
\end{gathered}
$$

therefore:

$$
\begin{gathered}
\beta^{\prime}=0.977(0.0708)=0.0692 \\
\sigma=\frac{(6)(0.0692)(0.281)\left(3 \times 10^{6}\right)\left(5.850^{-} \times 10^{3}\right)}{(0.002)(12)^{2}(144)^{2}(0.9775)(195)}=1800 \mathrm{psi}
\end{gathered}
$$




$$
\begin{aligned}
& \text { Stress at the Center of the Wall } \\
& \beta_{x}=0.0339 \quad \beta_{y}=0.0217 \\
& \sigma_{x}=\frac{\beta}{\beta} \sigma=\frac{0.0339}{0.0708}(1800)=860 \mathrm{psi} . \\
& \sigma_{y}=\frac{y}{\beta} \sigma=\frac{0.0217}{0.0708}(1800)=550 \mathrm{psi} .
\end{aligned}
$$

This indicates that there will probably be some cracking damage on the outer surface.

East Wall (elevation - 955 feet) - The wall is assumed to be fixed on all four sides; that is:

$$
\begin{aligned}
& a=10 \mathrm{ft}=120 \mathrm{in}, \\
& b=15.667 \mathrm{ft}=188 \mathrm{in}, \\
& h=1 \mathrm{ft}=12 \mathrm{in} .
\end{aligned}
$$

Moment of Inertia of the Wall

$$
X=2.55 \text { inches and }
$$

$$
\begin{gathered}
I=\frac{(188)(2.55)^{3}}{12}+\frac{(188)(2.55)^{3}}{4}+(18.8)(10)(0.31)(8.7)^{2}+ \\
(18.8)(10)(0.31)(18)^{2}=5.667 \times 10^{3} \mathrm{in}^{4}
\end{gathered}
$$

when:

$M$ has a value of 18.8 ,

$N$ has a value of 10 ,

A has a value of $0.31 \mathrm{in}^{2}$,

$Y$ has a value of $11.5 \mathrm{in}$,

$Y^{\prime}$ has a value of $0.75 \mathrm{in}$, and

b has a value of $188 \mathrm{in.}$ 
Natural Frequency (see "Shock and Vibration Handbook", Page 7-32)

$$
\begin{gathered}
\frac{b}{a}=\frac{188}{120}=1.567 \\
\omega_{n}=26.674 \sqrt{\frac{\left(1.365 \times 10^{10}\right) 1}{h a^{4} b}} \\
=26.674 \sqrt{\frac{\left(1.365 \times 10^{10}\right)\left(5.667 \times 10^{3}\right)}{(12)(120)^{4}(188)}}=341.96 \text { radians } / \mathrm{sec} . \\
\frac{\text { Maximum Deflection }}{m}=\frac{(120)(188)(12)\left(8.68 \times 10^{-2}\right)}{386}=6.084 \times 10^{2} \mathrm{lb} \mathrm{sec}^{2} / \mathrm{in} .
\end{gathered}
$$

From the Armour Phase Report, Page 34:

$I_{0}=0.250$ psi sec at 6.25 feet from the center of the vessel for 21 pounds of TNT, so:

$$
y=\frac{(188)(120)(0.25)}{(60.84)(341.96)}=0.271 \text { in }
$$

Stress (maximum stress occurs at the middle of the longest side at the edge)

$$
\begin{gathered}
\beta^{\prime}=0.977 \beta \\
\frac{b}{a}=1.567, \alpha=0.00227, \beta=0.0772,
\end{gathered}
$$

therefore:

$$
\begin{gathered}
\beta^{\prime}=0.977(0.0772)=0.0754 \\
\sigma=\frac{(6)(0.0754)(0.271)\left(3 \times 10^{6}\right)\left(5.667 \times 10^{3}\right)}{(0.00227)(12)^{2}(120)^{2}(0.9775)(188)}=2420 \mathrm{psi}
\end{gathered}
$$

This relatively high stress is at an edge position analagous to the Coal City point where $\sigma=4780$ psi and where no damage occurred. 


$$
\begin{aligned}
& \text { Stress at the Center of the Wall } \\
& \beta_{x}=0.0377 \quad \beta_{y}=0.0196 \\
& \sigma_{x}=\frac{\beta_{x}}{\beta} \sigma=\frac{0.0377}{0.0772}(2420)=1180 \mathrm{psi} . \\
& \sigma_{y}=\frac{\beta_{y}}{\beta} \sigma=\frac{0.0196}{0.0772}(2420)=620 \mathrm{psi} .
\end{aligned}
$$

Again, the damage would be restricted to minor cracking.

North Wall (elevation - 995 feet) - The wall is assumed to be fixed on all four sides; that is:

$$
\begin{aligned}
& a=16.25 \mathrm{ft}=195 \mathrm{in}, \\
& b=22.5 \mathrm{ft}=270 \mathrm{in}, \\
& h=1 \mathrm{ft}=12 \mathrm{in} .
\end{aligned}
$$

$$
\begin{aligned}
& \frac{\text { Moment of Inertia of the Wall }}{X=2.55 \text { inches and }} \\
& I=\frac{(270)(2.55)^{3}}{12}+\frac{(270)(2.55)^{3}}{4}+(10)(27)(0.31)(8.7)^{2}+ \\
& (10)(27)(0.21)(1.8)^{2}=8.099 \times 10^{3} \mathrm{in}^{4},
\end{aligned}
$$

when:

$M$ has a value of 27 ,

$N$ has a value of 10 ,

A has a value of $0.31 \mathrm{in}^{2}$,

$Y$ has a value of 11.5 in,

$Y^{\prime}$ has a value of 0.75 , and

b has a value of 270 . 


$$
\begin{aligned}
& \frac{\text { Natural Frequency (see "Shock and Vibration Handbook", Pages 7-32) }}{\frac{b}{a}=\frac{270}{195}=1.385} \\
& \omega_{n}=29.06 \sqrt{\frac{\left(1.365 \times 10^{10}\right) 1}{h a^{4} b}}, \\
& =29.06 \sqrt{\frac{\left(1.365 \times 10^{10}\right)\left(8.099 \times 10^{3}\right)}{(12)(195)^{4}(270)}}=141.232 \text { radians } / \mathrm{sec}^{-} \\
& \frac{\text { Maximum Deflection }}{386}
\end{aligned}
$$

From the Armour Phase Report, Page 34:

$I_{0}=0.200$ psi sec at 7.75 feet from the center of the vessel for 21 pounds of TNT,

so:

$$
y=\frac{(195)(270)(0.200)}{\left(1.419 \times 10^{4}\right)(141.232)}=0.525 \mathrm{in} .
$$

Stress (maximum stress occurs at the middle of the longest side)

$$
\begin{gathered}
\beta^{\prime}=0.977 \beta \\
\frac{b}{a}=1.385, a=0.00205, \beta=0.0720,
\end{gathered}
$$

therefore:

$$
\begin{gathered}
\beta^{\prime}=0.977(0.072)=0.0703 \\
\sigma=\frac{(6)(0.0703)(0.525)\left(3 \times 10^{6}\right)\left(8.099 \times 10^{3}\right)}{(0.00205)(12)^{2}(195)^{2}(0.9775)(270)}=1820 \mathrm{psi}
\end{gathered}
$$


Stress at the Center of the Wall

$$
\begin{aligned}
& \beta_{x}=0.0346 \quad \beta_{y}=0.0213 \\
& \sigma_{x}=\frac{\beta_{x}}{\beta} \sigma=\frac{0.0346}{0.072}(1820)=870 \mathrm{psi} . \\
& \sigma_{y}=\frac{\beta_{y}}{\beta} \sigma=\frac{0.0213}{0.072}(1820)=538 \mathrm{psi} .
\end{aligned}
$$

Again, the stress level lies in the innocuous range and the damage would be restricted to harmless cracking with a minimum of spallation. Reference should be made to Part 1 of this compendium for details on the explosive equivalents for various cases of vessel rupture. It should be pointed out, in conclusion, that the method of analysis presented in this paper contains the conservative assumption that the initial pulse at its maximum value was applied uniformly over the wall surface. Only the wall section at the closest proximity to the vessel centerline would receive the maximum pulse. In consideration of the low stress levels encountered on the basis of the assumptions used, it should be considered that the only protection necessary for the wall structure of the PV-2 cell is the installation of antispall plates, as directed in Part 1. 
THIS PAGE

\section{WAS INTENTIONALLY LEFT BLANK}




\section{REFERENCES}

(1) Newmark, Nathan M.; "An Engineering Approach to Blast-Resistant Design", ASCE Tranșactions, Paper 2786; October 1953.

(2) McKee, K. E.; "Dynamic Characteristics of Structural Clay Masonry Walls", Blast Resistant Design-Phase Report IV, ARF K576; Armour Research Foundation. of the IIlinois Institute of Technology; October 1956.

(3) Harris, Cyril M. and Crede, Charles E., (editors); Shock and Vibration Handbook; McGraw-Hill Book Company, Inc, New York (1961).

(4) Timoshenko, S. and Woinowsky-Krieger, S.; Theory of Plates and Shells; Mc GrawHill Book Company, Inc, New York (1959).

(5) Urquhart, L. C., O'Rourke, C. E., and Winter, George; Design of Concrete Structures; 6th Edition, McGraw-Hill Book Company, Inc, New York (1958).

(6) MacDuff, J. N. and Curreri, J. R.; Vibration Control, p 183; McGraw-Hill Book Company, Inc (1958).

(7) Weber, J. P., Savitt, Jacob, Krc, John, and Browne, H. C.; "Detonation Tests Evaluate High Pressure Cells", I and E Chemistry, 53 (11), pp 128A-133A; November 1961. 
THIS PAGE

\section{WAS INTENTIONALLY LEFT BLANK}




\section{PART 3}

MODIFIED NEWMARK ANALYTICAL METHOD FOR BLAST-RESISTANT CALCULATIONS

C. E. Muzzall 
THIS PAGE

\section{WAS INTENTIONALLY LEFT BLANK}




\section{CONTENTS}

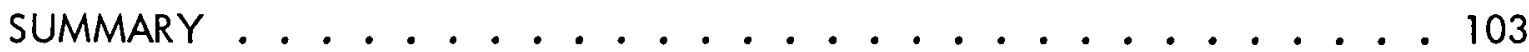

MODIFIED NEWMARK ANALYTICAL METHOD FOR BLASTRESISTANCE CALCULATIONS. . . . . . . 105

REFERENCES ................... 111

APPENDIX A (NEWMARK EMPIRICAL RELATIONS DEVELOPED

BY Y-12 ENGINEERS) . . . . . . . 115

APPENDIX B (NEWMARK EQUATION FOR IMPULSE EFFECT) . . . . 121

APPENDIX C (CALCULATION OF THE NATURAL PERIOD OF VIBRATION FOR PV-2 EAST CELL WALL) . . . . 125

APPENDIX D (CALCULATION OF THE NATURAL PERIOD OF VIBRATION OF THE CELL WALL TESTED BY ARMOUR RESEARCH FOUNDATION) ....... 131 
THIS PAGE

\section{WAS INTENTIONALLY LEFT BLANK}




\section{SUMMARY}

The original Newmark method of analysis, which involves the calculation of a staticequivalent pressure for a shock wave in terms of peak pressure and duration, has been modified for calculation in terms of impulse. This refinement permits a more accurate estimate of the static-equivalent pressure for high-explosive blasts.

The modified Newmark equation has been applied to the $Y-12$ Plant's PV-2 cell structure for comparison with a similar analysis by the Armour Research Foundation at its Coal City, Illinois test cell. 
THIS PAGE

\section{WAS INTENTIONALLY LEFT BLANK}




\section{MODIFIED NEWMARK ANALYTICAL METHOD FOR}

BLAST-RESISTANCE CALCULATIONS

Blast-resistance evaluation of the PV-2 cell in the $\mathrm{Y}-12$ Plant, in connection with the pressure vessel conversion has been performed by the $Y-12$ Engineering Division using four methods. Dr. Nathan M. Newmark (1) of the University of Illinois has developed one of the techniques. Following a personal contact with Dr. Newmark, a modified equation was developed which should be of interest to those who apply the Newmark static equivalent in the cell analysis. The new equation and the significance of its application are explained in the discussion that follows.

Before proceeding to the new equation and for orientation purposes, the Newmark method should be briefly reviewed. In Newmark's approach, the blast-wave characteristics are evaluated in terms of peak pressure and duration based on the magnitude of the energy release. Then a static force, equivalent to the integrated effect of the shock force, is calculated. This is done in the following manner: If the maximum work done by the pressure and by the resistance of the wall is considered, it becomes evident that the work and the resistance must be equal if the mass of the structure is initially at rest, because the structure also stops temporarily at its position of maximum displacement. Also, since the pressure is applied very quickly as an impulse, the work done by the pressure is equal to the kinetic energy of motion of the structure after the external forces have ceased and before the internal resistances have developed. From these concepts, Newmark developed the following relation to be applied for very small values of $t_{1}$ :

$$
\frac{P_{\text {max }}}{q_{e}}=\frac{(2 \mu-1)^{0.5} T}{\pi{ }^{t}} .
$$

Trials with various combinations of the equation led to the following generally applicable empirical result:

$$
\frac{P_{\text {max }}}{q_{e}}=\frac{T}{\pi t_{1}} \sqrt{2 \mu-1}+\frac{1-\frac{1}{2 \mu}}{1+0.7 \frac{T}{t_{1}}}
$$

where:

$$
\begin{aligned}
& P_{\text {max }} \text { is the peak blast pressure, } \\
& \mathrm{q}_{e} \quad \text { is the static equivalent, }
\end{aligned}
$$


T is the natural period of vibration of the wall,

$t_{1}$ is the shock wave duration, and

$\mu$ is the ductility factor or the ratio of the maximum deflection, $X_{\mathrm{m}^{\prime}}$ to the yield deflection, $x_{e}$.

Having the static equivalent, $q_{e}$, from Equations 1 and 2, the static resistance of the wall is calculated and then compared with $q_{e}$. A mathematical development of the Newmark equations is given in Appendix $A$.

In the discussion with Newmark it was observed that both Equations 1 and 2 take into account the peak pressure and the duration of the shock wave but not the actual impulse value. Such a procedure is satisfactory for atomic blasts (for which the method was originated) but is conservative for high-energy chemical explosives. The pressure decay curve for atomic shocks is gradual compared to that of a high-explosive detonation, as seen by comparing the two curves in Figure 20.

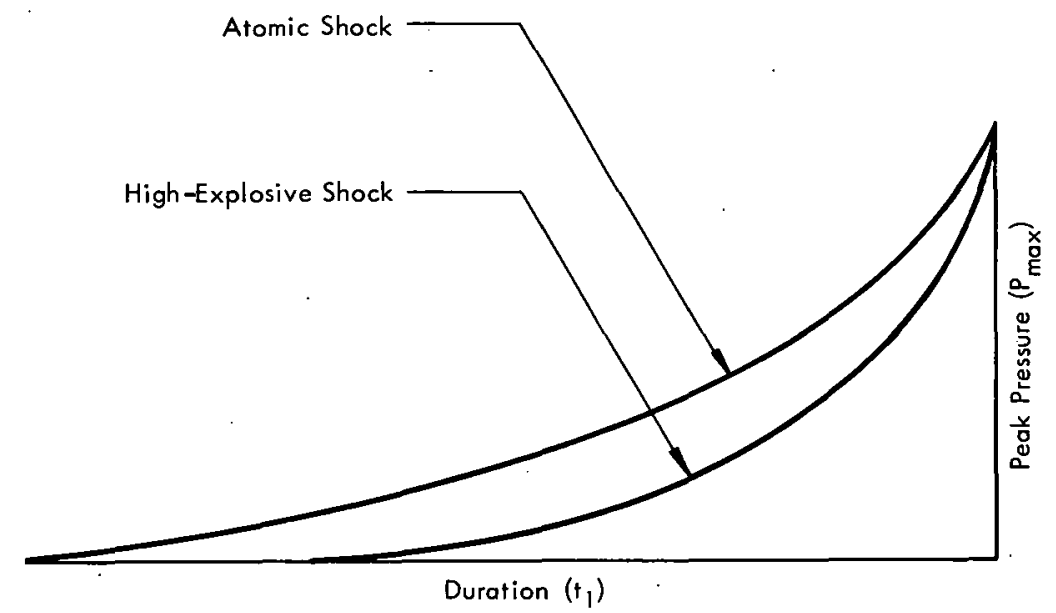

Figure 20. COMPARISON BETWEEN THE HIGH-EXPLOSIVE AND ATOMIC SHOCKS.

The area under the curve (impulse or pressure $x$ time) is greater for the atomic shock compared with the high-explosive shock even though the peak pressure and duration are the same in the case described.

Newmark agreed that the most realistic approach for high-explosive calculations would be to derive a relationship for $q_{e}$ involving impulse. Following his instructions, $Y-12$ engineers developed an equation for $q_{e}$ in terms of $T, 1$ (impulse), and $\mu$ : 


$$
q_{e}=\frac{\sqrt{2} 1 \pi}{T \sqrt{\mu-0.5}} .
$$

A mathematical development of this equation is given in Appendix $B$.

The natural period of vibration, $T$, which appears in Equations 1, 2, and 3 can be determined by several analytical methods. Two procedures are illustrated in Appendixes $C$ and $D$. The example taken for calculation in Appendix $C$ involved the PV-2 east wall panel shown at position W-I on Figure 21. The other case in Appendix $D$ involved the inner partition of the cell tested by the Armour Research Foundation for Monsanto Chemical Company. $(2,3)$ This wall section is shown on Monsanto Drawing D-03-CE-43. With regard to the period of the PV-2 panel (W-1), $\mathrm{Dr}$. Newmark gave a rough approximation of 0.025 second which compares favorably with the computed value of 0.018 and with a measured value of 0.020 . The latter value was determined in the field using an MB Vibrator-Exciter, Model $\mathrm{C}-11$, and a Raydata Vibrator-Analyzer with CEC velocity pickup.

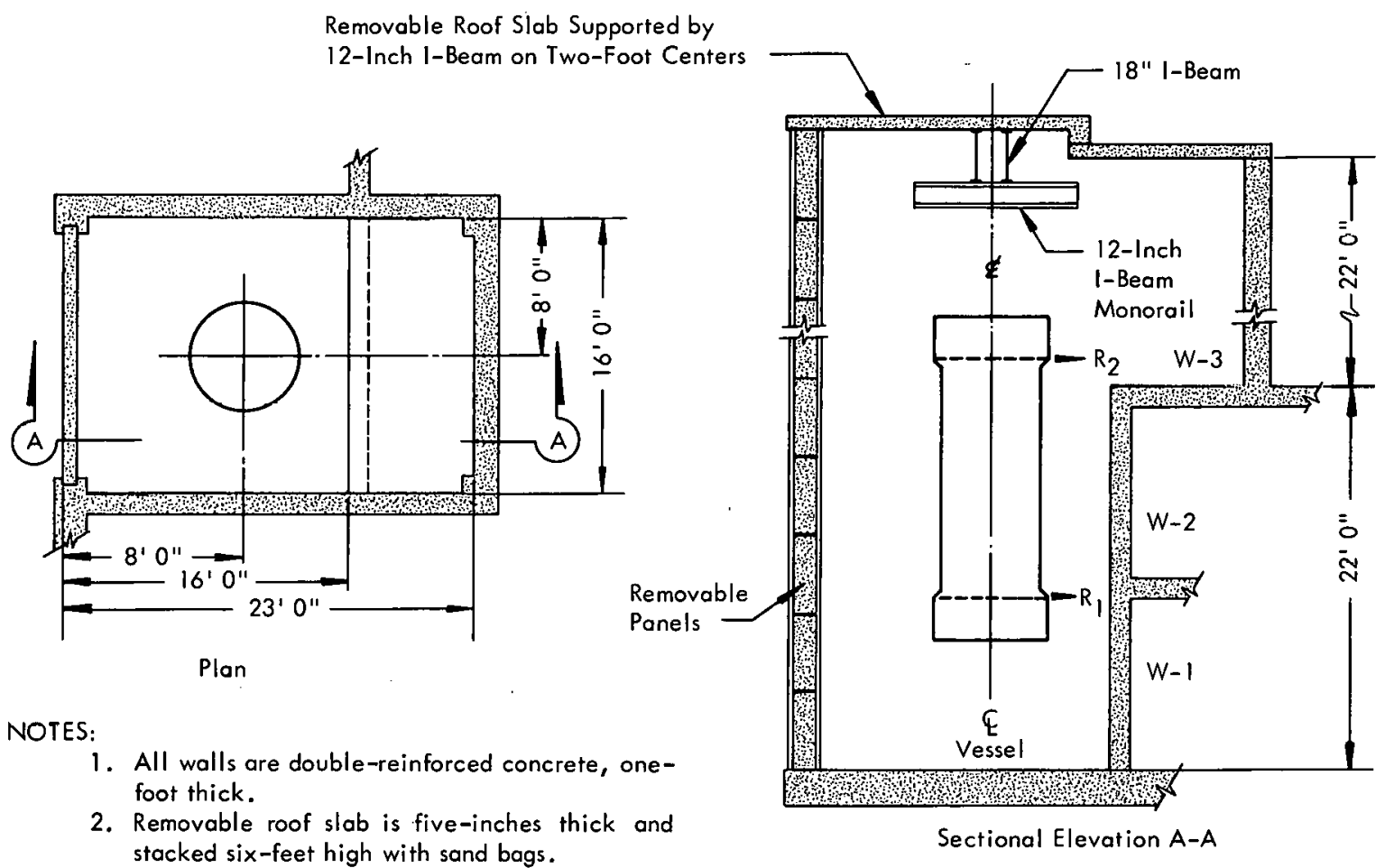

Figure 21. CONTAINMENT CELL FOR PRESSURE VESSEL 2 SHOWING PANELS W-1, W-2, AND W-3.

The other element of Equation 3 which must be evaluated is the ductility factor, $\mu$, or the ratio of the maximum deflection to the yield deflection, $X_{m} / X_{e}$. Several attempts were made unsuccessfully to calculate this ratio. Guidance for estimating $\mu$ 
is given in the Newmark paper mentioned previously. (1) In the contact with Dr. Newmark he stated that a value for $\mu$ of 20 could be used for the PV -2 concrete wall on the basis of near-failure limits although he would recommend a value of $6-7$ for conservative design purposes if a new wall were to be constructed.

Table 2 presents pertinent data from the hazards analysis of PV-2. From this table the blast-wave equivalent values were taken for the vessel failure cases at the lower and upper closures. These cases (the positions being shown as $R_{1}$ and $R_{2}$, Figure 21) were analyzed by the Newmark impulse equation (Equation 3 ) and tabulated in Table 3. For simplicity, the $q_{e}$ calculations were determined at various distances from the vessel centerline using the same values for $\mu$ and $T$ at each point. It is recognized that the period of the upper panel $(W-3)$ will be longer than that for $W-1$. Hence, use of the shorter value for the upper case (36 lbs TNT) results in larger qe values. A separate calculation from the period of Panel W-3 was not made for this study and the qe values in Table 3 are consequently on the high side.

Table 2

TABULATION OF CALCULATED EFFECTS OF VESSEL FAILURE

\begin{tabular}{|c|c|c|c|c|c|}
\hline Failure Location & $\begin{array}{c}\text { Blast Wave } \\
\text { Equivalent } \\
\text { (lbs TNT) }\end{array}$ & $\begin{array}{l}\text { Energy Applied } \\
\text { to Missile } \\
\text { Acceleration } \\
\text { (Ibs TNT) }\end{array}$ & $\begin{array}{c}\text { Initial Velocity } \\
\text { of Missiles } \\
(\mathrm{ft} / \mathrm{sec})\end{array}$ & $\begin{array}{l}\text { Velocity } \\
\text { of Missiles } \\
\text { at Roof } \\
(\mathrm{ft} / \mathrm{sec})\end{array}$ & $\begin{array}{c}\text { Height } \\
\text { of Rise } \\
\text { of Roof } \\
(\mathrm{ft})\end{array}$ \\
\hline $\begin{array}{l}\text { Radial Crack at } \\
\text { Lower Closure }\end{array}$ & 21 & 23 & 51.7 & 39 & 2.46 \\
\hline $\begin{array}{l}\text { Radial Crock at } \\
\text { Upper Closure }\end{array}$ & 36 & 8 & 109 & 103 & 3 \\
\hline $\begin{array}{l}\text { Longitudinal } \\
\text { Crack of } \\
\text { Vessel Wall }\end{array}$ & 44 & 0 & 0 & 0 & 0 \\
\hline
\end{tabular}

A superficial glance at the $q_{e}$ values in Table 3 would lead to the conclusion that the wall panels of the cell would fail catastrophically on the basis that structural calculations of the wall resistance gave a value of 5 psi. Incidentally, Newmark estimated casually that the PV-2 cell wall would have a resistance of about 5-6 psi. However, test results of the Armour-Monsanto cell experiment at Coal City, Illinois in February-March 1960, indicate that high-explosive shocks are actually less destructive than these theoretical calculations signify. The wall panel, the period for which is calculated in Appendix $D$, was situated about two feet from the charge in the Coal City test series. From photographic evidence, this wall withstood the effects of 16 pounds of $50 \%$ ditching dynamite ( 15.4 lbs TNT) with practically no damage to the cell. The structure also withstood 50 pounds of dynamite. (48 lbs TNT) with considerably less than catastrophic results. At a distance of two feet and using Equation 3, the inner wall panel was subjected to $q_{e}$ 's as follows: 
Table 3

BLAST EQUIVALENT, IMPULSE AND STATIC EQUIVALENT

\begin{tabular}{|c|c|c|c|c|}
\hline $\begin{array}{l}\text { Distance } \\
(\mathrm{ft})\end{array}$ & $\begin{array}{c}\text { Impulse } 1(1) \\
\text { (psi sec) }\end{array}$ & $\begin{array}{c}\text { Newmark (2) } \\
q \text { e } \\
\text { (psi) }\end{array}$ & $\begin{array}{c}\text { Impulse } 1 /(3) \\
(p s i \text { sec) }\end{array}$ & $\begin{array}{c}\text { Newmark(2) } \\
q e \\
(p s i)\end{array}$ \\
\hline 5 & 0.380 & 15.3 & 0.240 & 9.7 \\
\hline 7 & 0.310 & 12.5 & 0.195 & 7.9 \\
\hline 8 & 0.255 & 10.3 & 0.165 & 6.6 \\
\hline 9 & 0.220 & 8.9 & 0.140 & 5.6 \\
\hline 10 & 0.190 & 7.7 & 0.122 & 4.9 \\
\hline 11 & 0.167 & 6.7 & & \\
\hline 12 & 0.150 & 6.0 & & \\
\hline 13 & 0.135 & 5.4 & & \\
\hline 13.5 & 0.127 & 5.1 & & \\
\hline 14 & 0.122 & 4.9 & & \\
\hline
\end{tabular}

These values were calculated from the equation:

where:

$$
q_{e}=\frac{\sqrt{2} 1 \pi}{T \sqrt{\mu-0.5}}=\frac{1.4141 \pi}{(0.025) \sqrt{20-0.5}}=40.25 \mathrm{l}
$$

$$
\begin{aligned}
& T=0.025, \text { and } \\
& \mu=20 .
\end{aligned}
$$

Impulse values were taken from test data by the Ballistic Research Laboratory, Aberdeen, Maryland.

(1) Based on 36 pounds of TNT.

(2) Based on impulse.

(3) Based on 21 pounds of TNT.

For $15.4 \mathrm{lbs}$ TNT:

$$
q_{e}=\frac{\sqrt{2} \pi 1}{T \sqrt{\mu-0.5}}=\frac{(1.414) \pi(0.350)}{(0.008) \sqrt{20-0.5}}=44 \text { psi. }
$$

Fór 48 lbs TNT:

$$
q_{e}=\frac{(1.414) \pi(0.480)}{(0.008) \sqrt{20-0.5}}=65 \text { psi. }
$$

Note: These impulse values, expressed in units of psi sec, were taken from Armour data. (4)

Since the resistance of this wall panel is roughly in the same range as that of the PV-2 cell walls, namely $5-10$ psi, it is apparent that the Newmark qe cannot be interpreted literally to mean that failure will result if the resistance fails to match the qe. 
On the basis of the foregoing calculations, it can be assumed that if the PV-2 cell walls are subjected io a maximum Newmark qe of 15.3 psi (see Table 3), a safety factor in the range of 2 to 4 is available for the existing PV-2 cell. At least there is no positive evidence that the present cell walls are insufficient for exposure to a 36-pound (TNT) blast on the basis of Newmark's analysis.

It is not surprising that calculated resistances and blast equivalents are conservative. Even if a resistance is postulated on the so-called ultimate strength of material, it is seldom that a structure will fail exactly at the ultimate threshold. In the first place, "ultimates "are normally taken at the lower limit of a statistical range of "ultimates". In the case of the PV-2 cell it is desirable to ascertain that some reasonable factor of safety exists beyond the actual point of structural collapse. It is not essential to provide a sufficiently wide margin so that no cracks or spalling will occur. The antispall plates, which will be installed on the operating side of the walls, are expected to stop relatively massive debris of spallation.

Three other methods of theoretical analysis have been applied which involve physical principles as logical as the Newmark method. These procedures involved applications by: (1) Paul D. Flynn; (2) John N. MacDuff, John R. Curreri, Cyril M. Harris, and Charles E. Crede; and (3) K. E. McKee. It can be stated that all of the applied theoretical approaches are conservative. It follows that the best way to ascertain the true limit of structural failure is through physical testing, not theoretical calculation. Of course, in the absence of test results, the only alternative would be to accept the conservatism of theory. For PV-2, the Coal City tests, in addition to the vast amount of test data from the Ballistic Research Laboratory, are available for study.

Whereas the theoretical calculations were valuable and interesting, it is recommended that calculations based on a comparison of the PV-2 cell with tested structures be accepted as the most economical evaluation, within the limits of acceptable safety. The latter calculations indicate that the existing PV-2 cell structures will withstand the postulated maximum energy release from a vessel rupture at 20,000 psi, with an operating free volume of 16.5 cubic feet at any temperature between 20 and $1500^{\circ} \mathrm{C}$. 


\section{REFERENCES}

(1) Newmark, Nathan M.; "An Engineering Approach to Blast-Resistant Design", ASCE Transactions, Paper 2786; October 1953.

(2) Browne, Howard C., Heleman, Harold, and Weger, Lowell C.; "Barricades for High Pressure Research", I and E Chemistry, 53 (10), p 52A; October 1961.

(3) Weber, J. P., Savitt, Jacob, Krc, John, and Browne, H. C.; "Detonation Tests Evaluate High Pressure Cells", 1 and E Chemistry, 53 (11), pp 128A-133A; November 1961 .

(4) McKee, K. E.; "Dynamic Characteristics of Structural Clay Masonry Walls", Phase Report IV "Blast Resistant Design", ARF K576; Armour Research Foundation of Illinois Institute of Technology; October 1956. 
THIS PAGE

\section{WAS INTENTIONALLY LEFT BLANK}


APPENDIX A 
THIS PAGE

\section{WAS INTENTIONALLY LEFT BLANK}




\section{NEWMARK EMPIRICAL RELATIONS DEVELOPED BY Y-12 ENGINEERS}

If the pressure is of infinitely long duration, the external work done is equal to the internal energy absorbed at maximum deflection. Then:

$$
P_{\max } X_{m}=q_{e}\left(X_{m}-0.5 X_{e}\right),
$$

(Note: the substraction of $0.5 \mathrm{X}_{\mathrm{e}}$ contributes a safety factor.)

or:

$$
\frac{p_{\text {max }}}{q_{e}}=\frac{x_{m}}{x_{m}}-\frac{\dot{u} \cdot 5 x_{e}}{x_{m}} .
$$

But,

$$
\mu=\frac{X_{m}}{X_{e}} \text { by definition, }
$$

so:

$$
\frac{p_{\text {max }}}{q_{e}}=1-\frac{0.5}{\mu} \text {. }
$$

On the other hand, if the pressure lasts a very short time, the positive impulse of the pressure is $0.5 p_{\max }+1$, and the initial kinetic energy of the mass is $12 / 2 \mathrm{~m}=0.25$ $p_{\text {max }}^{2} t_{1} 2 / 2 m$. However, this energy is equal to the stored energy at maximum deflection. Hence:

$$
K E=\frac{0.25 p_{\text {max }}^{2} t_{1}^{2}}{2 m}=q_{e}\left(x_{m}-0.5 x_{e}\right) .
$$

But,

$$
\mathrm{k}=\frac{\mathrm{F}}{\delta} ; \mathrm{F} \cong \mathrm{q}_{\mathrm{e} ; \delta} \cong \mathrm{X}_{\mathrm{e}^{\prime}}
$$

so:

$$
k=\frac{q_{e}}{x_{e}}
$$




$$
T=1 / f=\frac{2 \pi}{\omega_{n}}=\frac{2 \pi}{\sqrt{\frac{k}{m}}}=2 \pi \sqrt{\frac{m}{k}},
$$

or,

$$
T=2 \pi \sqrt{\frac{m x_{e}}{q_{e}}} .
$$

Solving for $m$ in Equation 9:

$$
T^{2}=\frac{4 \pi^{2} m x_{e}}{q_{e}} ; m=\frac{q_{e} T^{2}}{4 \pi^{2} x_{e}} .
$$

Substituting for $m$ in Equation 5:

$$
\begin{aligned}
& \frac{0.25 \cdot p_{\text {max }}^{2} t_{1}^{2}}{2\left(\frac{q_{e}^{T^{2}}}{4 \pi^{2} X_{e}}\right)}=q_{e}\left(X_{m}-0.5 X_{e}\right) \text {, or } \\
& \frac{0.5 p_{\text {max }}^{2} t_{1}^{2} \pi^{2}}{q_{e} T^{2}}=q_{e}\left[\left(\frac{x_{m}}{X_{e}}\right)-0.5\right] \text {, or } \\
& q_{e}^{2}=\frac{0.5 p_{\text {max }}^{2} t_{1}^{2} \pi^{2}}{T^{2}(\mu-0.5)} \text {, or } \\
& q_{e}=\frac{P_{\text {max }}{ }^{\dagger} 1^{-\pi}}{T} \sqrt{\frac{1 / 2}{\mu-1 / 2}} \text {, or } \\
& \frac{p_{\text {max }}}{q_{e}}=\frac{T}{\pi t_{1}} \sqrt{\frac{2 \mu-1}{2(1 / 2)}} \text {, or } \\
& \frac{p_{\text {max }}}{q_{e}}=\frac{T}{\pi t_{1}} \sqrt{2 \mu-1} .
\end{aligned}
$$


Equation 16 applies when ${ }^{\dagger} l$ is very small and Equation 4 when $t_{l}$ is very large. Trials by Newmark with various combinations of the equations led to the following generally applicable empirical result:

$$
\frac{P_{\max }}{q_{e}}=\frac{T}{\pi t_{1}} \sqrt{2 \mu-1}+\frac{1-\frac{1}{2 \mu}}{1+0.7 \frac{T}{t_{1}}} .
$$

He states that Equation 17 is in error by less than $5 \%$ over the whole range of values of $t_{1}$ from zero to infinity and of $\mu$ from one to infinity. 
THIS PAGE

\section{WAS INTENTIONALLY LEFT BLANK}


APPENDIX B 
INSTRUCTIONS: This form should accompany each UNCLASS IFIED document the first time it is submitted to the

USAEC Division of Technical Information Extension, Post Office Box 62, Oak Ridge, Tennessee.

Document Title Cómpendium of Gas Autoc lave Engineering Stgdies Document_August 23, 1965

Author(s). Edited by C. E. Muzzal1 Contract No. W-7405-èng-26

1. X] Research and Development Report Enclosed is a TID-4500 Standard Distribution Report as defined in

- AEC Manual Chapter 3202. No Journal Publication or Oral Presentation is Intended. (Use. Section II or III below if Journal Publication is Intended or Section IV if Oral 'Presenfätion is Intended.)

1. $X$ Complete TID-4500 distribution has been made, including copies to the Clearinghouse for Federal Scientific and Technical Information, National Bureau of Standards (formerly OTS) (Federal Clearinghouse sale price is $\$ \underline{6}, 00$ The number of copies specified in TID-4500 has been forwarded to the Division of Technical Information Extension for stock and for further distribution to domestic and foreign depository libraries, foreign exchange organizations, etc., and for announcement in Nuclear Science Abstracts.

2. $\square$ Document has been printed but complete TID-4500 distribution has not been made. Copies are being furnished for the Division of Technical Information Extension to:
a. $\square$ Make complete TID-4500 distribution including copies to Federal Clearinghouse (sale price is \$ itory libraries, etc.
b. Make distribution to Federal Clearinghouse and depository libraries, etc. AEC and other Government agency distribution has been made in accordance with TID -4500 (Federal Clearinghouse sale price is $\$$ ).
c. $\square$ Other. Please specify

3. $\square$ No copies have been printed for TID -4500 and Federal Clearinghouse distribution. DTI may reproduce from copy enclosed and make TID-4500 distribution, including copies to Federal Clearinghouse for public sale, depository libraries, etc.

Enclosure is:
a. $\square$ Printed copy
b. $\square$ Typed copy

(Up to '2b copies will be furnished to authors if desired. Indicate number
4. $\square$ This document, previously distributed as a classified report, has been declassified with $\square$ without $\square$ deletions.

c. $\square$ Reproducible or multilith plates

DTI may reproduce from the ir master copy and make TID-4500 distribution, including copies to Federal Clearinghouse for public sale, and to depository libraries, etc.

(Up to 25 copies will be furnished to authors if desired. Indicate number

.)

11. $\square$ Document Enclosed is a TID-4500 Standard Distribution Report which is also intended for Journal Publication:

1. $\square$ TID -4500 (AEC) distribution has been made. Copies are enclosed for DTI to make single copy distribution to Federal Clearinghouse and to the domestic depository libraries, and for announcement in NSA

i. $\square$ Copies are being furnished DTI to make TID -4500 (AEC) distribution, and single copy distribution to Federal Clearinghouse and to the domestic depository libraries, and for announcement in NSA.

3. $\square$ From the copy enclosed, DTI is requested to reproduce in Microcard form and make TID-4500 (AEC) distribution, domestic depository library distribution and send 1 full size copy to Federal Clearinghouse, and announce in $\underline{\text { NSA }}$.

Document enclosed has or will be submitted for publication in the following scientific journal:

(Name of Journal)

(Expected date of issuance)

11I. $\square$ Document enclosed is intended for publication in a journal whose publication policy precludes advance distribution within the AEC and single copy distribution to Federal Clearinghouse and to domestic depository libraries.

1. Paper has been or will be submitted for publication in the following scientific journal:

(NOTE: DTI will hold this document for internal use and will not announce in NSA. No further distribution will be made except in unique circumstances when the report is required by present work of another AEC Contractor in advance of the paper's appearance in the jourual. Such further distribution by DTI will be limited to specific requests for this information.) 
IV. $\square$ Document enclosed is intended for Oral Presentation.

Name, Location, Sponsor of Meeting

Date

Publication plans arc:

1. $\square$ This paper will be included in the published proceedings of the meeting.

2. $\square$ This paper will not be included in published proceedings. After the date indicated above:

a. $\square$ DTI is requested to reproduce and make TID-4500 distribution, including copies to Federal Clearinghouse, depository libraries and announce in NSA.

b. $\square$ We (originator) will make TID -4500 distribution, including copies to Federal Clearinghouse. (Note: When printed, please transmit copies to DTI with a new PRF appropriately checked in Section I.)

c. $\square$ Paper will be submitted for journal publication. (NÖTE: When paper is submitted for journal publication, please submit to DTI a new PRF appropriately checked in either Section II or III.)

V. $\square$ Document enclosed is an internal or informal report not intended for TID-4500 Standard Distribution, Journal Publication or Oral Presentation.

AEC Manual Chapter 3202 requires that informal reports generally be given TID-4500 distribution, and that technical information contained in internal reports also appear in a distributable document which receives appropriate distribution.

Chapter 3202 does recognize that issuing organizations may wish to recommend distribution limitations for informal reports and internal reports (subse quently distributed externally) under certain conditions. It also provides for negotiation between DTI and the originator, or DTI and the cognizant AEC Program Division if distribution limitations specified by the originator appear questionable to Federal Clearinghouse.

Recommendations are:

1. DTI is $\square$ is not $\square$ to make selected positive distribution to certain AEC contractors as appropriate.

2. DTI is $\square$ is not $\square$ to fill requests for this document from AEC contractors.

3. DTI is $\square$ is not $\square$ to selectively distribute and fill requests for this document from other Government agencies.

4. DTI is $\square$ is not $\square$ to make a single copy available to Federal Clearinghouse and announce in NSA.

IF DISTRIBUTION LIMITATIONS ARE INDICATED ABOVE, LIST JUSTIFICATION OR REASONS AS REQUIRED BY AEC MANUAL CHAPTER 3202.

Patent clearance for the document cited in this Publication Release Form has $\mathrm{x}$ has not $\square$ been obtained.

WLH :DSN :0

Distribution:

R. A. Charpie

H. E. Hennas

R. C. Dreyer

Attn: Corum Scott

C. E. Muzzal1
This release is submitted by

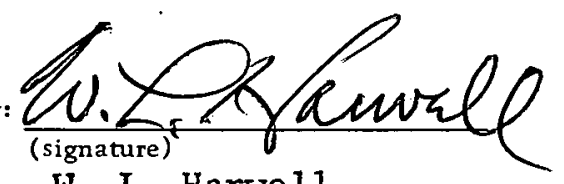

W. L. Harwe 11

(name typed)

Organization Union Carbide Corp., Nuclear Div.

Date

August 25, 1965

If it is desired that correspondence concerning this document be directed to an individual other than the name above, please indicate 
121

NEWMARK EQUATION FOR IMPULSE EFFECT

Take:

$$
V=\frac{1}{m} ; \quad K E=1 / 2 m V^{2} \text {. }
$$

Then:

$$
K E=\frac{m l^{2}}{2 m^{2}}=\frac{1^{2}}{2 m} \text {. }
$$

Setting KE equal to $q_{e}$ times maximum displacement, as discussed in Appendix A:

$$
q_{e}\left(x_{m}-0.5 x_{e}\right)=\frac{1^{2}}{2 m} \text {. }
$$

But,

$$
m=\frac{q_{e} T^{2}}{4 \pi^{2} x_{2}}(\text { see Appendix A, Equation 10) }
$$

So,

$$
\begin{aligned}
& q_{e}\left(x_{m}-0.5 X_{e}\right)=\frac{1^{2}}{2\left[\frac{q_{e} T^{2}}{4 \pi^{2} X_{2}}\right]}, \text { or } \\
& q_{e}\left(x_{m}-0.5 x_{e}\right)=\frac{21^{2} \pi^{2} X_{e}}{q_{e} T^{2}}, \text { or } \\
& q_{e}\left[\frac{x_{m}}{X_{e}}-0.5\right]=\frac{21^{2} \pi^{2}}{q_{e} T^{2}, \text { or }}
\end{aligned}
$$




$$
\begin{aligned}
& q_{e}^{2}=\frac{21 \pi^{2}}{(\mu-0.5) T^{2}}, \text { or } \\
& q_{e}=\frac{\pi \sqrt{2} 1}{T \sqrt{\mu-0.5}} .
\end{aligned}
$$




\section{APPENDIX C}


THIS PAGE

\section{WAS INTENTIONALLY LEFT BLANK}




\section{CALCULATION OF THE NATURAL PERIOD OF VIBRATION FOR PV-2 (EAST CELL WALL)}

\section{A FIXED EDGE SLAB (Wall Has Four Sides Fixed)}

Note: Natural frequency calculation derived from a paper by R. F. S. Hearman.

Given that:

$$
\frac{b}{a}=1.567,
$$

$\frac{\omega_{n}}{\sqrt{\frac{D g}{\gamma^{4} a^{4}}}}=26.674=C$ (from table by Hearman),

$\sqrt{\frac{D g}{\gamma h a^{4}}}=\frac{E h^{3}}{\left(1-v^{2}\right)(12)}$, and $I=\frac{b h^{3}}{12}$.

Therefore:

$$
\begin{aligned}
& \sqrt{\frac{E h^{3} g}{12\left(1-v^{2}\right) \gamma h a^{4}}}=\sqrt{\frac{E g}{\left(1-v^{2}\right) \gamma h a^{4} b}\left[\frac{b h^{3}}{12}\right]} \\
& =\sqrt{\frac{E g}{\left(1-v^{2}\right) \gamma}\left[\frac{1}{h a^{4} b}\right]} .
\end{aligned}
$$

But:

$$
\frac{E g}{\left(1-v^{2}\right) \gamma}=\frac{\left(3 \times 10^{6}\right)\left(3.86 \times 10^{2}\right)}{(0.9775)\left(8.68 \times 10^{-2}\right)} \text {, and } \gamma=8.68 \times 10^{-2} \mathrm{lb} / \mathrm{in}^{3}
$$

Therefore:

$$
\frac{E g}{\left(1-v^{2}\right) \gamma}=\frac{1.158 \times 10^{9}}{8.485 \times 10^{-2}}=1.365 \times 10^{10}
$$

And: 


$$
\omega_{n}=C \sqrt{\left(1.365 \times 10^{10}\right) \frac{1}{h a^{4} b}}=C \sqrt{\frac{\left(1.365 \times 10^{10}\right)\left(5.667 \times 10^{3}\right)}{(1.2 \times 10)\left(1.2 \times 10^{2}\right)\left(1.88 \times 10^{2}\right)}} \text {, or }
$$

(See Middle of Page for Calculation of 1)

$$
\begin{aligned}
& \omega_{n}=c \sqrt{\left(1.365 \times 10^{10}\right)\left[\frac{5.667 \times 10^{3}}{4.678 \times 10^{11}}\right]}=C \sqrt{\left(1.365 \times 10^{10}\right)\left(1.21 \times 10^{-8}\right)}, \text { or } \\
& \omega_{n}=C \sqrt{1.653 \times 10^{2}}=(26.674)(12.82)=341.96 \text { radians } / \mathrm{sec} .
\end{aligned}
$$

And:

$$
f=\frac{\omega_{n}}{2}=\frac{341.96}{2 \pi}=54.452 \text { cycles } / \text { sec. }
$$

And:

$$
T=\frac{l}{f}=\frac{1}{5.445 \times 10}=0.01837 \text { second per cycle. }
$$

CALCULATION OF I (from Design of Concrete Structures, Urquihart)

Given that:

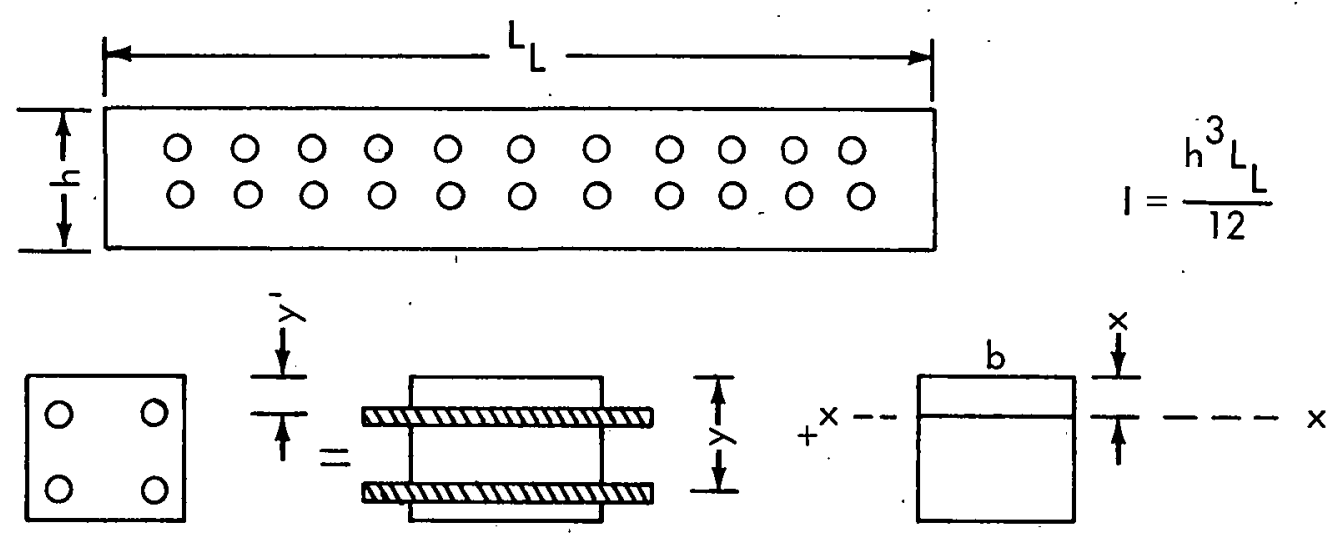

So:

$$
\begin{gathered}
n=\frac{E_{s}}{E_{c}}=\frac{3 \times 10^{7}}{3 \times 10^{6}}=10, \\
A_{c e}=\frac{E_{s}}{E_{c}} \text { As, }
\end{gathered}
$$




$$
\begin{gathered}
y^{\prime} n A+b x \frac{x}{2}=y n A, \\
b x \frac{x}{2}=y n A-y^{\prime} n A=n A\left(y-y^{\prime}\right), \\
y=11.25^{\prime \prime} ; y^{\prime}=0.75^{\prime \prime}, \\
b=L_{L}=15^{\prime} 8^{\prime \prime}=188^{\prime \prime}, \text { and } \\
A=(18.8)(0.31) \text { (number of bars } x \text { area of Number } 5 \text { bar). }
\end{gathered}
$$

Therefore:

$$
\begin{aligned}
& \frac{b x^{2}}{2}=n A\left(y-y^{\prime}\right)= \\
& \qquad \begin{aligned}
188 \frac{x^{2}}{2} & =6.119 \times 10^{2}, \text { or } \\
x^{2} & =6.510, \text { or } \\
x & =2.55 \text { inches. }
\end{aligned}
\end{aligned}
$$

For I:

$$
\begin{aligned}
& I=\frac{b x^{3}}{12}+b x\left[\frac{x}{2}\right]^{2}+n A(y-x)^{2}+n A\left(x-y^{\prime}\right)^{2}, \text { or } \\
& I=\frac{188(2.55)^{3}}{12}+\frac{188(2.55)^{3}}{4}+(3.1)(8.7)^{2}(1.88 \times 10)+ \\
& I=\frac{(3.1)(1.8)^{2}(1.88 \times 10) \text {, or }}{12}+\frac{31.174 \times 10^{2}}{4}+4.411 \times 10^{3}+1.907 \times 10^{2} \text {, or } \\
& I=5.667 \times 10^{3} \mathrm{in}^{4} .
\end{aligned}
$$


THIS PAGE

\section{WAS INTENTIONALLY LEFT BLANK}


APPENDIX D 
THIS PAGE

\section{WAS INTENTIONALLY LEFT BLANK}




\section{CALCULATION OF THE NATURAL PERIOD OF VIBRATION OF THE CELL WALL TESTED BY ARMOUR RESEARCH FOUNDATION}

Note: Data taken from Vibration Handbook, Harris and Crede.

The method of Hearman does not cover this case.

Assume the slab is a beam with fixed end. Wall has three sides fixed; one side free.

Given:

$$
k l=4.730 \text { and } l=6 \mathrm{ft} \text {. }
$$

Therefore:

$$
k=\frac{4.7 .30}{l}=\frac{4.730}{7.2 \times 10}=6.569 \times 10^{-2} \text {. }
$$

\section{CALCULATION OF I}

Using same nomenclature as for I in Appendix C,

$$
\frac{b x^{2}}{2}=n A\left(y-y^{\prime}\right) .
$$

Wall data:

$$
\begin{gathered}
b=12^{\prime \prime}, n=10, A=2 \times 0.2 \text { (number of bars } x \text { area of Number } 5 \text { bar), } \\
y=10.5, \text { and } y^{\prime}=1.5 .
\end{gathered}
$$

Therefore:

$$
\begin{gathered}
12 \frac{x^{2}}{2}=(10)(2)\left(2 \times 10^{-1}\right)(10.5-1.5), \text { or } \\
x^{2}=6, \text { or } \\
x=2.45 \text { inches. }
\end{gathered}
$$

So: 


$$
\begin{aligned}
& I=\frac{b x^{3}}{12}+b x\left[\frac{x}{2}\right]^{2}+n A(y-x)^{2}+n A\left(x-y^{\prime}\right)^{2} \text {, or } \\
& I=\frac{12(2.45)^{3}}{12}+\frac{12(2.45)^{3}}{4}+(10)(2)(0.2)(8.05)^{2}+ \\
& \quad(10)(2)(0.2)(0.95)^{2} \text {, or } \\
& I=3.223 \times 10^{2} \mathrm{in}^{4} .
\end{aligned}
$$

And:

$$
\begin{aligned}
& \omega_{n}=k^{2} \sqrt{\frac{E I g}{A \gamma}}=\left(6.569 \times 10^{-2}\right) \sqrt{\frac{\left(3 \times 10^{6}\right)\left(3.223 \times 10^{2}\right)\left(3.86 \times 10^{2}\right)}{\left(144 \times 10^{2}\right)\left(8.68 \times 10^{-2}\right)}} \text {, or } \\
& \omega_{n}=\left(4.315 \times 10^{-3}\right)\left(1.725 \times 10^{5}\right) \text {, or } \\
& \omega_{n}=744 \text { radians } / \mathrm{sec} .
\end{aligned}
$$

And:

$$
T=\frac{1}{f}=\frac{2 \pi}{\omega_{n}}=\frac{2 \pi}{744}=0.008441 \text { second per cycle. }
$$


PART 4

MECHANICAL DESIGN CRITERIA AND ANALYSES FOR CONVERTING PV-2 TO A GAS AUTOCLAVE

H. A. Pohto

C. D. St. Onge 
THIS PAGE

\section{WAS INTENTIONALLY LEFT BLANK}




\section{CONTENTS}

SUMMARY ................... 137

MECHANICAL DESIGN CRITERIA AND ANALYSES FOR CONVERTING PV-2 TO A GAS AUTOCLAVE . . . . . 139

Introduction ................... 139

Design Criteria . . . . . . . . . . . . . . . . . . . 139

Design Summaries . . . . . . . . . . . . . . . . . . . 140

Cooling Jacket. . . . . . . . . . . . . . . . . 140

Mushrooms. . . . . . . . . . . . . . . . . 142

Design Calculations .. . . . . . . . . . . . . . 143

Stress Calculations on the Cooling Jacket . . . . . . . . . 143

Stress Calculations on the Upper Mushroom . . . . . . . . . . . 152

Stress Calculations on the Lower Mushroom . . . . . . . . . . . . . 160

Water Requirements for the Top Mushroom Cooling Plate . . . . . . . 167

Water Requirements for the Cooling Jacket. . . . . . . . . . 173

Water Requirements for the Lower Mushroom Cooling Plate . . . . . . 177

REFERENCES .................. 183 
THIS PAGE

\section{WAS INTENTIONALLY LEFT BLANK}




\section{SUMMARY}

A gas autoclave facility with a relatively large capacity is to be provided at the $Y-12$ Plant for processing materials at high pressures and elevated temperatures. To acquire such a facility expeditiously and at a reasonable cost it was decided to modify an existing pressure vessel held in standby. This report deals with the major mechanical design modification criteria and analyses, but excludes instrumentation, the furnace design, and the pressurization system. 
THIS PAGE

\section{WAS INTENTIONALLY LEFT BLANK}




\section{MECHANICAL DESIGN CRITERIA AND ANALYSES FOR \\ CONVERTING PV-2 TO A GAS AUTOCLAVE}

\section{INTRODUCTION}

The existing pressure vessel (PV-2) to be modified has the inside dimension of 30inches ID, and is 120 inches deep (closed), and is of the forged steel multiwall, threaded-plug or breech type (see Figure IA, Page 20).

The previous maximum allowable operating pressure, using mineral oil as the pressing medium, was established at 22,500 psi. This pressure has been reduced from the original design operating pressure of 30,000 psi after the catastrophic failure of a pressure vessel of the same size and similar design in $1956(P V-1)$.

This existing vessel hashad over 1550 operating cycles. The bottom first three thread roots of the vessel (the first thread root was the point of rupture of $P V-1$ ) have been experimentally analyzed by strain gages using a mineral oil pressure medium before any modification. These experimental data were comparable to the photoelastic calculated results and reflect a safe operating pressure at 20,000 psi for an adequate equipment life (see Part 6, "Interpretation on the Expected Fatigue Life of a ThirtyInch Pressure Vessel with Threaded Closure").

Dr. R. G. Sturm, Huntsville, Alabama, was engaged as a consultant on pressurevessel design and stress analysis. W. R. Gambill, ORNL, was consulted on heat transfer. Dr. M. G. Fontana, Ohio State University and John C. Griess, ORNL were consulted regarding corrosion and stress corrosion of various alloys.

\section{DESIGN CRITERIA}

The design criteria for the modification are as follows:

20,000 psi maximum operating pressure with argon gas, $1500^{\circ} \mathrm{C}$ maximum furnace temperature, $300 \mathrm{kw}$ maximum heat loss, and

$200^{\circ} \mathrm{F}$ maximum inside surface temperature of the inner sleeve of the existing pressure vessel.

The depth of the work cavity, to house the furnace, is to be limited to 48 inches.

This volume will restrict the potential energy level of the compressed gas to a value that is small enough to permit the existing cell housing (with a slight modification) to be used to hold the converted assembly at the present site (see Part 1, "Hazards Pertaining to the Converted Thirty-Inch Pressure Vessel"). 
Dr. R. G. Sturm calculated the combined stresses resulting from the the rmal stresses, due to temperature gradients of the vessel walls, and the operating pressure load stress. At an inner sleeve temperature of about $240^{\circ} \mathrm{F}$, the stress in the outer sleeve wouldreach a critical level. He recommends that the inside wall temperature of the vessel be limited to $200^{\circ} \mathrm{F}$. This criterion makes it necessary to cool the inside wall by a cooling liner inserted into the vessel. If a cooling jacket were placed on the outside of the vessel, the thickness of the shells and their interfaces would make heat transfer inadequate and the critical condition would still exist.

W. R. Gambill made a heat-loss study and surface-temperature calculations of a furnace having the necessary criterion (see Part 7, "Heat Loss Evaluation for $Y-12$ Development Furnace").

The existing vessel structure lends itself best to a coolantinlet and outlet through the lower plug into the cooling jacket since:

1. Lateral holes through the walls of the pressure vessel would create stresses, particularly in the outer shell, beyond the safe operating limit.

2. The operating mechanism of the top plug would make it impractical and nearly impossible to make an effective coolant seal for a coolant inlet and/or outlet through the top plug.

3. Adding coolant holes in the upper threaded liner would weaken the liner to a critical level at operating pressures.

Gambill's heat-loss calculation indicated that it is necessary to cool the upper and lower mushrooms for the following reasons:

1. The mushroom seal pads required cooling to assure proper sealing.

2. Although the mushroom material is of high-strength steel, the stresses are high, and the heat must be kept from affecting the material strength.

3. To be able to use the proposed method of potting the electrical wires through the mushroom, the epoxy must be kept below $200^{\circ} \mathrm{F}$.

\section{DESIGN SUMMARIES}

Cooling Jacket

The following points were determined concerning the design of the cooling jacket:

1. The ID of the existing pressure vessel varies 0.016 inch from maximum to minimum. 
2. The most practical method to install the cooling jacket into the vessel is at the site with a slip fit (clearance) between the vessel ID and jacket OD. The minimum average allowable clearance was determinedas 0.020 inch on the diameter.

3. The sum of the allowable clearance (0.020") and the vessel expansion (0.034") gives a maximum average diametral expansion of the cooling jacket of 0.054 inch at the operating pressure.

At the maximum operating pressure, a steel cooling jacket (with a modulus of elasticity of 30 million psi) would result in a maximum stress of 129,000 psi in its outer shell. An aluminum alloy cooling jacket (with a modulus of elasticity of 10.3 million psi) would result in a maximum stress of 44,000 psi.

The maximum compressive load on the lands between the grooves of the cooling, jacket would be 33,300 psi at the operating pressure.

4. To eliminate the possibility of corrosion of the existing pressure vessel inner liner surface due to a coolant, a double-sleeve cooling jacket was the selected design.

5. High-strength Kaiser Aluminum Alloy 7039 was selected as the material for the cooling jacket because of: (1) the presence of high stresses, (2) the need to reduce the possibility of corrosion, (3) the desire to have a weldable alloy, and (4) cost comparisons.

Preliminary fabrication bids on a high-strength steel jacket versus a Type 7039 aluminum jacket indicated that the aluminum jacket would cost only about half that of steel fabrication, and with faster delivery.

Commercially available Kaiser Alloy 7039 was selected over the comparable Alcoa X7139 or X7106 alloy (still experimental). Alcoa did not recommend their alloys for this application at this time.

6. Neither Kaiser nor Alcoa had any applicable stress-corrosion data on these alloys, although Kaiser indicated considerable confidence in their Alloy 7039.

Kaiser Alloy 7039 has a minimum tensile of 55,000 psi (T-61 condition) with excellent welding and heat-treating properties.

The welding and heat-treating specifications are essentially those recommended by Kaiser. The T-61 temper was selected because of better ductility and better resistance to stress corrosion.

7. Using a 300-kw heat loss as a criterion in the design of the cooling jacket, the water passages were sized to allow a maximum coolant temperature rise of $15^{\circ} \mathrm{F}$, using tap water at a pressure of 80 psi maximum (without a pump). This pressure 
would give a maximum total flow rate of $137 \mathrm{gpm}$ (approximately $20 \mathrm{gpm}$ per passage group).

At this flow rate, and using the heat losses derived by Gambill, the cooling capacity of the jacket would be about five times that required.

Mushrooms

The following points were determined concerning the design of the mushrooms:

1. The maximum calculated combined stress of the lower mushroom is 82,000 psi and of the upper mushroom-86,000 psi. High-strength forged alloy steel with a yield strength of 150,000 psi, ultimate strength of 165,000 psi, and an impact value of $20 \mathrm{ft} \mathrm{lbs}$ at a minus $65^{\circ} \mathrm{F}$ are the specifications for the material of fabrication.

2. Because of a three-zone furnace, six power leads are required for entry into the vessel.

The most practical location for entry of the power leads is through the lower mushroom. This location eliminates the operator area congestion and disconnect problem that would be present if the leads entered through the upper mushroom.

3. The entryand exit of argon gas at high pressure is provided best through the lower mushroom. This location would permit preferred fixed piping, (particularly at high pressures) and would more readily accommodate the required cooling of the piping and fittings as a result of the hot exit gas.

4. All thermocouple leads (32) required for data and control are designed to enter through the upper mushroom plug.

This location is preferred to that of the lower mushroom because it eliminates electrical interference from the power leads and prevents further weakening of the lower mushroom by additional holes.

The manual manipulation of the thermocouple Amphenol connectors will be no real problem to the operator since this will be done in the "open" position. The wire bundles will be not unlike a telephone cord. The wire leads will be "epoxy potted" in the upper mushroom to prevent pressure leaks.

5. The mushroom inner surface is cooled by a plate grooved for coolant passage and attached to the mushroom surface by a threaded retainer ring.

A flow rate of $6.8 \mathrm{gpm}$ through each mushroom cooling plate, at an $80 \mathrm{psi}$ tap water pressure, will give a cooling capacity at the mushroom four times that required, calculated from the surface temperatures derived by Gambill. 


\section{DESIGN CALCULATIONS}

Stress Calculations on the Cooling Jacket

The calculations are based on a slip fit of the jacket into the vessel. Calculations are made for the inside of both the inner and outer sleeve of the cooling jacket. (a)

The maximum stress will occur at the inside of the outer sleeve and will be a summation of the following stresses:

1. Stress due to clearance between jacket and vessel wall.

2. Stress due to internal pressure on the jacket.

3. Stress due to shrinking the sleeves of the cooling jacket together.

Stress in the Cooling Jacket when the Jacket Gains External Support from the Vessel Wall Assembly - The bore of the vessel assembly was measured every six inches with the following results:

\begin{tabular}{|c|c|}
\hline Measurement & $\begin{array}{l}\text { Dimensior } \\
\text { (inches) }\end{array}$ \\
\hline Minimum Inside Diameter & 29.979 \\
\hline Maximum Inside Diameter & 29.995 \\
\hline Average Inside Diameter & 29.090 \\
\hline
\end{tabular}

The lower tolerance on the $O D$ of the cooling jacket was used to give the maximum clearance between the vessel ID and the cooling jacket $O D$. A radial clearance of 0.010 inch between the vessel ID and the cooling jacket OD was used.

\section{Pressure on Cooling Jacket $(1)$}

The pressure on the cooling jacket can be calculated from:

$$
U_{c}=\frac{1-\mu}{E}\left[\frac{a^{2} P_{i}-b^{2} P_{o}}{b^{2}-a^{2}}\right] r+\left[\frac{1+\mu}{E}\right]\left[\frac{a^{2} b^{2}\left(P_{i}-P_{o}\right)}{\left(b^{2}-a^{2}\right) r}\right],
$$

(a) The following drawings and specifications were used in these calculations: UCC Drawings E-M-52689, E-M-51001, and E-M-51002; UCC Specification Y-S1369, and Fabricator Drawings 201430 and 201409. 
where:

b represents the outside radius of the jacket (14.98 inches),

a is the inside radius of the jacket (13.75 inches),

$U_{c}$ gives the radial clearance between the jacket and the vessel $(0.010$ inch),

$\mu$ gives the Poisson's ratio for the jacket $(0.36)$,

E is the modulus of elasticity for the jacket $\left(10.3 \times 10^{6} \mathrm{psi}\right)$,

$P_{0}$ represents the pressure on the OD of the jacket $(0)$,

$P_{i}$ gives the pressure on the ID of the jacket (to be solved), and

$r \quad$ is the radius at which $U_{c}$ is calculated (14.98 inches).

Substituting in Equation 1 gives:

$$
\begin{gathered}
0.010=\left[\frac{1-0.36}{10.3 \times 10^{6}}\right]\left[\frac{(189.1)\left(P_{i}\right)-0}{224.5-189.1}\right][14.98]+ \\
{\left[\frac{1.36}{10.3 \times 10^{6}}\right]\left[\frac{(224.5)(189.1) P_{i}}{(224.5-189.1)(14.98)}\right] .}
\end{gathered}
$$

Solving for $\mathrm{P}_{\mathbf{i}}$ gives:

$\mathrm{P}_{\mathrm{i}}=644 \mathrm{psi}=$ the initial pressure required to push the cooling jacket against the wall.

$$
\text { Stress at the Inner Wall (2) }
$$

The stress at the inner wall can be calculated from:

$$
\sigma_{t}(\max )=P_{i}\left[\frac{b^{2}+a^{2}}{b^{2}-a^{2}}\right]=644\left[\frac{224.5+189.1}{224.5-189.1}\right]=7530 \text { psi }
$$

where:

$\sigma_{\dagger}(\max )$ is the maximum tangential stress,

$P_{i} \quad$ is the internal pressure, 
a is the inside radius of the jacket, and

b is the outside radius of the jacket.

Stress at the Inside of the Outer Sleeve (2)

The stress at the inside of the outer sleeve can be calculated from:

$$
\sigma_{t}=P_{i}\left[\frac{a^{2}}{b^{2}-a^{2}}\right]\left[\frac{b^{2}}{p^{2}}+1\right],
$$

where:

$\rho$ is the radius at the point that the stress is calculated.

Using the values previously given:

$$
\sigma_{\dagger}=644\left[\frac{189.1}{224.5-189.1}\right]\left[\frac{224.5}{214}+1\right]=7050 \text { psi. }
$$

Stress in the Jacket Due to an Internal Pressure of 20,000 psi and Externally Supported by the Vessel Assembly -

$$
\text { Radial Movement of the Inside Radius (1) }
$$

The stress in the jacket due to the internal pressure can be calculated from:

where:

$$
U_{r_{1}}=\frac{r_{1} P_{i}}{E}\left[\frac{r_{1}{ }^{2}+r_{2}{ }^{2}}{r_{2}{ }^{2}-r_{1}{ }^{2}}+\mu\right],
$$

$U_{r_{1}}$ is the radial movement of the inside radius of the vessel under the as-

$r_{1}$ sumed value of 17,250 psi (to be solved),

$r_{1}$ is the inside radius of the vessel (15 inches),

$r_{2}$ is the outside radius of the vessel ( 31 inches),

$\mu$ represents Poisson's ratio for the vessel (0.26),

E is the modulus of elasticity for the vessel $\left(29 \times 10^{6} \mathrm{psi}\right)$, and

$P_{i}$ gives the internal pressure of the vessel (assumed to be 17,250 psi; will be checked later). 
Solving gives:

$U_{r_{1}}=\frac{15(17,250)}{29 \times 10^{6}}\left[\frac{961+225}{961-225}+0.26\right]=0.017=$ radial movement outward of the ID of the vessel.

\section{Radial Movement of the Outside Radius}

The radial movement outward of the outside radius can be calculated from:

$$
U_{i}=\frac{1-\mu}{E}\left[\frac{a^{2} P_{i}-b^{2} P_{0}}{b^{2}-a^{2}}\right] r+\frac{1+\mu}{E}\left[\frac{a^{2} b^{2}\left(P_{i}-P_{o}\right)}{\left(b^{2}-a^{2}\right) r}\right],
$$

where:

$U_{i}$ represents the radial movement outward of the outside radius (to be solved),

$P_{i}$ is the pressure on the inside diameter of the jacket $(19,356 . \mathrm{psi})$, and

$P_{0}$ gives the external pressure on the jacket $(0)$.

Solving gives:

$$
\begin{gathered}
U_{i}=\frac{1-0.36}{10.3 \times 10^{6}}\left[\frac{(189.1)(19,356)-0}{224.5-189.1}\right](14.98)+ \\
\frac{1+0.36}{10.3 \times 10^{6}}\left[\frac{(189.1)(224.5)(19,356)}{(224.5-189.1) 14.98}\right]=0.300 \text { inch, which gives the radial dis- }
\end{gathered}
$$

tance the jacket would expand without support of the vessel assembly.

\section{External Pressure on the Cooling Jacket ${ }^{(1)}$}

The radial interference due to the vessel assembly can be determined by:

$$
\delta=\frac{P_{s} b}{E}\left[\frac{b^{2}+a^{2}}{b^{2}-a^{2}}-\mu\right],
$$

where: 
$\delta$ is the radial interference due to the vessel assembly $(0.300-0.017=$ 0.283 ), and

$P_{S}$ is the interfacial pressure between the jacket and the vessel.

Solving gives:

$$
0.283=\frac{P_{s}(14.98)}{10.3 \times 10^{6}}\left[\frac{224.5+189.1}{224.5-189.1}-0.36\right]
$$

Therefore:

$$
\begin{aligned}
P_{\mathrm{S}}= & 17,150 \mathrm{psi} \text {, which is the external pressure on the cooling jacket that is } \\
& \text { required to keep the OD of the jacket from expanding } 0.283 \text { inch radi- } \\
& \text { ally. }
\end{aligned}
$$

To check on $P_{S}$ which should equal the $P_{i}$ of the vessel:

$$
U_{i}=\frac{1+\mu}{E}\left[\frac{a^{2} P_{i}-b^{2} P_{s}}{b^{2}-a^{2}}\right] r+\frac{1+\mu}{E}\left[\frac{a^{2} b^{2}\left(P_{i}-P_{s}\right)}{\left(b^{2}-a^{2}\right) r}\right],
$$

where:

$$
\begin{aligned}
& U_{i} \text { represents the radial expansion of the outside radius of the jacket, } \\
& P_{i} \text { equals } 19,356 \mathrm{psi} \text {, and } \\
& P_{S} \text { equals } P_{i} \text { (vessel). }
\end{aligned}
$$

Solving gives:

$$
\begin{aligned}
0.017= & \frac{1-0.36}{10.3 \times 10^{6}}\left[\frac{189.1(19,356)-224.5 P_{s}}{224.5-189.1}\right](14.98)+ \\
& \frac{1+0.36}{10.3 \times 10^{6}}\left[\frac{(224.5)(189.1)\left(19,356-P_{s}\right)}{(224.5-189.1)(14.98)}\right] .
\end{aligned}
$$

Therefore:

$$
\begin{aligned}
P_{S}= & 17,250 \text { psi, the external pressure on the cooling jacket due to the vessel } \\
& \text { assembly. }
\end{aligned}
$$

Since $P_{S}$ is within $1 \%$ when calculated by both methods, the value of 17,250 psi will be used. 
Stress at the Inside Wall of the Jacket $(\rho=a){ }^{(2)}$

The maximum tangential stress at the inside wall of the jacket can be calculated from:

$$
\sigma_{t}=\frac{P_{i} a^{2}-P_{s} b^{2}+\left(\frac{a^{2} b^{2}}{p^{2}}\right)\left(P_{i}-P_{s}\right)}{b^{2}-a^{2}} .
$$

Using the appropriate values and solving gives:

$$
\begin{gathered}
\sigma_{t}=\frac{(19,356)(189.1)-(17,250)(224.5)+\left[\frac{(189.1)(224.5)}{189.1}\right](19,356-17,250)}{224.5-189.1}= \\
7070 \text { psi . }
\end{gathered}
$$

Stress at the Inside of the Outer Sleeve $(p=14.625)$

The maximum tangential stress at the inside wall of the outer sleeve can be calculated from:

$$
\sigma_{t}=\frac{P_{i} a^{2}-P_{s} b^{2}+\left(\frac{a^{2} b^{2}}{p^{2}}\right)\left(P_{i}-P_{s}\right)}{b^{2}-a^{2}}
$$

Using the appropriate values and solving gives:

$$
\begin{gathered}
\sigma_{t}=\frac{(19,356)(189.1)-(17,250)(224.5)+\left[\frac{(189.1)(224.5)}{214}\right](19,356-17,250)}{224.5-189.1}= \\
5650 \text { psi . }
\end{gathered}
$$

Stresses Due to Shrinking the Outer Sleeve over the Inner Sleeve on the Jacket -

$$
\text { Interfacial Pressure Between Sleeves }\left(P_{s}\right)(2)
$$

The interfacial pressure between the sleeves can be calculated from: 


$$
P_{s}=\frac{E \delta_{r}}{2 r_{2}^{3}}\left[\frac{\left(r_{3}^{2}-r_{2}{ }^{2}\right)\left(r_{2}{ }^{2}-r_{1}{ }^{2}\right)}{\left(r_{3}{ }^{2}-r_{1}{ }^{2}\right)}\right],
$$

where:

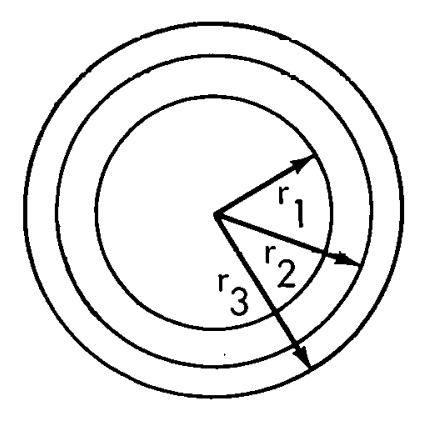

$r_{1}$ has a value of 13.75 (or $r_{1}{ }^{2}=189.1$ ),

$r_{2}$ has a value of 14.625 (or $r_{2}{ }^{2}=213.9$ ),

$r_{3}$ has a value of 14.984 (or $r_{3}^{2}=224.5$ ), $\delta_{r}$ has a value of 0.010 which is the max-
imum radial interference.

Solving gives:

$$
P_{S}=\frac{\left(10.3 \times 10^{6}\right)(0.010)}{(2)(3128)}\left[\frac{(224.5-213.9)(213.9-189.1)}{(224.5-189.1)}\right]=122 \mathrm{psi} .
$$

Stress on the Inside of the Outer Sleeve ${ }^{(2)}$

The stress on the inside of the outer sleeve can be calculated from:

$$
\sigma_{t}=P_{s}\left[\frac{r_{3}{ }^{2}+r_{2}{ }^{2}}{r_{3}^{2}-r_{2}{ }^{2}}\right]
$$

Solving gives:

$$
\sigma_{t}=122\left[\frac{224.5+213.9}{224.5-213.9}\right]=5050 \text { psi. }
$$

\section{Stress on the Inside of the Inner Sleeve ${ }^{(2)}$}

The stress on the inside of the inner sleeve can be calculated frum:

$$
\sigma_{t}=-2 P_{s}\left[\frac{r_{2}^{2}}{r_{2}^{2}-r_{1}^{2}}\right] \text {. }
$$


Solving gives:

$$
\sigma_{t}=-(2)(122)\left[\frac{213: 9}{213.9-189.1}\right]=-2100 \mathrm{psi} .
$$

Bearing Stress between Lands on the Grooves and the Outer Sleeve of the Jacket -

The following data are used to determine the bearing stress on the lands between the grooves:

$O D$ of the inner jacket at the grooves $=29.25$ inches,

circumference at the groove diameter $=91.9$ inches,

84 grooves at $1 / 2$-inch each $=42$ inches removed,

$\frac{49.9}{91.9}=54.3 \%$ of the material left on the circumference.

Assume $\sigma_{r}$ varies as a straight line function across jacket ( $\sigma_{r}$ is the radial stress), outer shell thickness is 0.375 inch, and total jacket thickness is 1.25 inches.

So:

$$
\frac{0.375}{1.25}(100)=30 \%
$$

And:

$$
\begin{aligned}
& P_{i}-P_{s}=19,356-17,250=2,106 \mathrm{psi}, \\
& 644(0.30)=193 \mathrm{psi}, \\
& 2,106(0.30)=632 \mathrm{psi}, \\
& \sigma_{b}=17,250+632+193=18,075 \text { psi bearing stress (without grooves), and }
\end{aligned}
$$




$$
\sigma_{b}=\frac{18,075}{0.543}=33,300 \text { psi }=\text { bearing stress on lands between grooves }
$$

Summation of Stresses - Stresses can be summed by the following considerations:

$$
\text { Maximum Stress on the Inside of the Outer Sleeve }{ }^{(1)}
$$

Maximum stress on the inside of the outer sleeve can be found by:

$$
2 \sigma_{o}^{2}=\left(\sigma_{t}-\sigma_{r}\right)^{2}+\left(\sigma_{r}-\sigma_{f}\right)^{2}+\left(\sigma_{f}-\sigma_{f}\right)^{2},
$$

where:

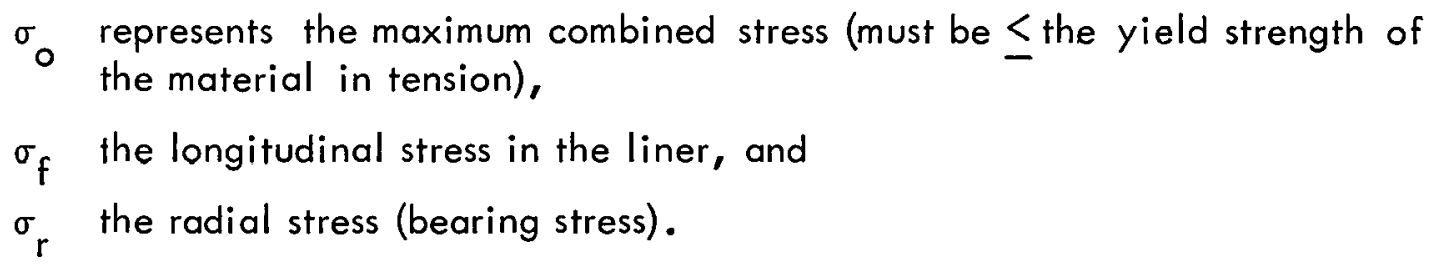

If:

$$
\begin{aligned}
\Sigma \sigma_{t} & =7050+5650+5050=17,750 \mathrm{psi}, \text { and } \\
\sigma_{r} & =-33,300 \mathrm{psi},
\end{aligned}
$$

then:

$\sigma_{f}=\mu\left(\sigma_{r}+\sigma_{f}\right)=0.36(-33,300+17,750)=-5580$ psi, and the maximum stress on the cooling jacket is:

$$
\sigma_{\circ}=44,300 \text { psi. }
$$

By using Mohr's circle relationship for stresses, the maximum shear stress was found to be 25,500 psi.

Stress on the Inside of the Inner Sleeve

The stress on the inside of the inner sleeve can be determined by the following:

$$
2 \sigma_{o}-\left(\sigma_{t}-\sigma_{r}\right)^{2}+\left(\sigma_{r}-\sigma_{f}\right)^{2}+\left(\sigma_{f}-\sigma_{t}\right)^{2}
$$

If:

$$
\begin{aligned}
\Sigma \sigma_{t} & =7530+7070-2100=12,500 \text { psi, then } \\
\sigma_{t} & =(12,500) K \text { (where } K=2.0 \text { due to grooves), or }
\end{aligned}
$$




$$
\begin{aligned}
& \sigma_{t}=25,000 \mathrm{psi}, \text { and } \\
& \sigma_{r}=-20,000 \mathrm{psi} .
\end{aligned}
$$

Then:

$$
\sigma_{f}=\mu\left(\sigma_{r}+\sigma_{f}\right)=0.36(-20,000+25,000)=1750 \mathrm{psi},
$$

and:

$$
\sigma_{\circ}=39,000 \text { psi. }
$$

Again, by using Mohr's circle relationship for stresses, the maximum shear stress was found to be 23,000 psi .

Check the Cooling Jacket for Buckling when no Pressure is in the Vessel(3) - To determine the water pressure that is necessary to buckle the inner sleeve with no pressure. in the vessel:

$$
P_{c r}=\frac{1}{4}\left[\frac{E}{1-\mu^{2}}\right] \frac{t^{3}}{r^{3}} .
$$

If:

$r$ has a value of 14 , and

t has a value of 0.625 ,

then:

$P_{c r}=\frac{1}{4}\left[\frac{10.3 \times 10^{6}}{1-0.14}\right] \frac{0.244}{2750}=266 \mathrm{psi}$. This is the water pressure in the grooves required to buckle the inner sleeve with no pressure in the vessel.

Stress Calculations on the Upper Mushroom

The stresses in the upper mushroom are calculated for a maximum pressure of 20,000 psi in the vessel. (b) The stress will be calculated at three points (in inches) in the mushroom as follows: (1) at $r=0$ - center of the mushroom, (2) at $r=2$ - center of the $1 / 2$-inch-diameter hole, and (3) at $r=4.5$ - at the large radius.

(b) The following drawings and specifications were used in these calculations: UCC Drawings $E-M-52380$ and $E-M-53213$, and UCC Specifications $Y-S-1379$. 
The formulas for flat plates are usedbut are superimposed to give the correct loading as applied to the mushroom in the vessel. In the calculations, the stem portion of the mushroom is neglected, but stress concentration factors are considered.

If the upper mushroom is loaded by a 20,000-psi internal pressure, the following forces are considered in the problems pertaining to the mushroom:

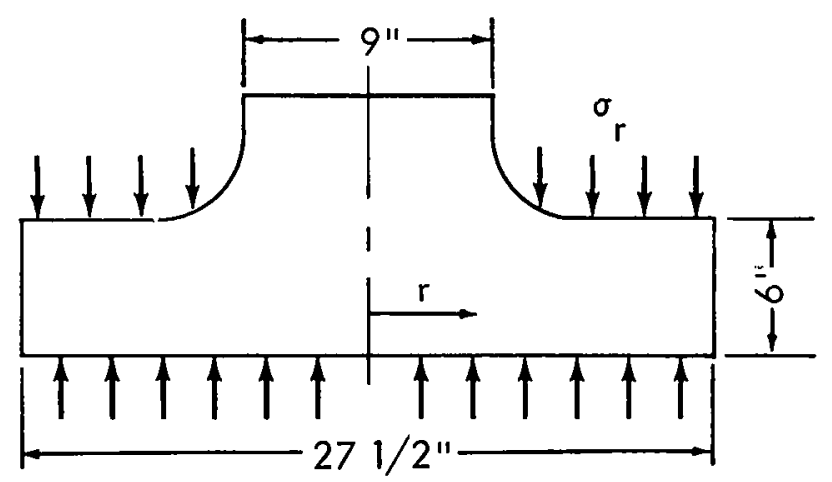

where:

$$
\sigma_{p}=20,000 \text { psi (internal pressure) }
$$

$$
\begin{aligned}
\sigma_{p} A_{p} & =\sigma_{r} A_{r^{\prime}} \text { or } \\
(20,000)(594) & =\sigma_{r}(594-64) .
\end{aligned}
$$

Therefore:

$$
\sigma_{r}=22,400 \mathrm{psi}=\text { the pressure on the rubber pad. }
$$

The following symbols will be used:

t the mushroom thickness,

$m$ the reciprocal of Poisson's ratio,

a the radius of the mushroom,

$S_{r}$ the radial stress at the top and bottom of the flat plate,

$S_{f}$ the tangential stress at the top and bottom of the flat plate,

$r$ the radius to the point at which the stress is calculated, and 
w. the total load (lbs).

Stress at a Radius of 4.5 Inches $(3)$ - To find the stress $\left(S_{r}\right)$ at a radius of 4.5 inches:

Case A:

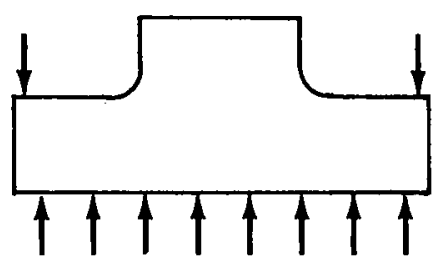

$20,000 \mathrm{psi}$

$$
S_{r}=-\frac{3 w}{8 \pi m t^{2}}\left[(3 m+1)\left(1-\frac{r^{2}}{a^{2}}\right)\right] .
$$

If:

+ has a value of 6.0 inches,

$\mathrm{m}$ has a value of $\frac{1}{0.26}=3.84$,

a has a value of 13.75 inches, and

$w$ has a value of $(20,000)(594)$,

then:

$$
S_{r}=-\frac{(3)(20,000)(594)}{(8)(3.14)(3.84)(36)}\left[(12.5)\left(1-\frac{20.25}{189}\right)\right]=-114,000 \text { psi }
$$

The tangential stress becomes:

$$
\begin{aligned}
& S_{t}=-\frac{3 w}{8 \pi m t^{2}}\left[(3 m+1)-(m+3) \frac{r^{2}}{a^{2}}\right], \text { or } \\
& S_{t}=-\frac{(3)(20,000)(594)}{(8)(3.14)(3.84)(36)}\left[(12.5)-6.84 \frac{20.25}{189}\right]=-120,000 \text { psi. }
\end{aligned}
$$


Case B:

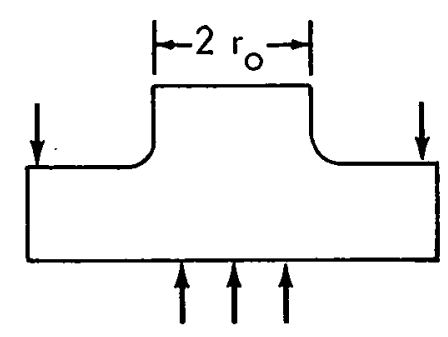

$$
22,400 \text { psi }
$$

$S_{r}=-\frac{3 w}{2 \pi m t^{2}}\left[m+(m+1) \log \frac{a}{r_{0}}-(m-1) \frac{r_{0}^{2}}{4 a^{2}}-(3 m+1) \frac{r^{2}}{4 r_{0}^{2}}\right]$.

If:

$r_{0}$ has a value of 4.5 inches, and

w has a value of 22,400 (64),

then:

$$
\begin{gathered}
S_{r}=-\frac{(3)(22,400)(64)}{(2)(3.14)(3.84)(36)}\left[3.84+(4.84) \log \frac{13.75}{4.5}-(2.84) \frac{20.25}{4(189)}-\right. \\
\left.(12.5) \frac{20.25}{4(20.25)}\right]=-30,000 \text { psi. }
\end{gathered}
$$

The tangential stress becomes:

$$
\begin{gathered}
S_{t}=-\frac{3 w}{2 \pi m t^{2}}\left[m+(m+1) \log \frac{a}{r_{0}}-(m-1) \frac{r_{0}^{2}}{4 a^{2}}-(m+3) \frac{r^{2}}{4 r_{0}^{2}}\right] \text {, or } \\
S_{t}=-\frac{(3)(22,400)(64)}{(2)(3.14)(3.84)(36)}\left[3.84+4.84 \log \frac{13.75}{4.5}-(2.84) \frac{20.25}{4(189)}-\right. \\
\left.(6.84) \frac{20.25}{4(20.25)}\right]=-37,000 \text { psi. }
\end{gathered}
$$


Case C:

$$
S_{r}=\frac{3 w}{8 \pi \mathrm{mt}^{2}}\left[(3 m+1)\left(1-\frac{r^{2}}{a^{2}}\right)\right] \text {. }
$$

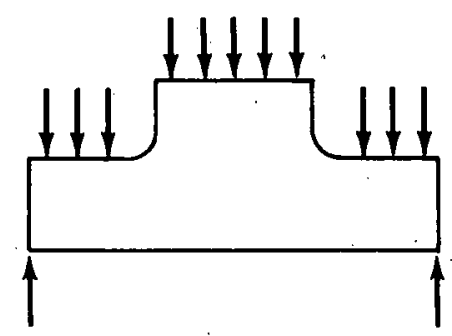

If:

w has a value of $(22,400)(594)$,

then:

$$
S_{r}=\frac{(3)(22,400)(594)}{(8)(3.14)(3.84)(36)}\left[(12.5)\left(1-\frac{20.25}{189}\right)\right]=128,500 \mathrm{psi}
$$

The tangential stress becomes:

$$
\begin{aligned}
& S_{t}=\frac{3 w}{8 \pi \mathrm{mt}^{2}}\left[(3 m+1)-(m+3) \frac{r^{2}}{a^{2}}\right], \text { or } \\
& S_{t}=\frac{(3)(22,400)(594)}{(8)(3.14)(3.84)(36)}\left[(12.5)-6.84 \frac{20.25}{189}\right]=133,500 \text { psi. }
\end{aligned}
$$

Summation of stresses:

$$
S_{r}=-114,000 \text { psi }-30,000 \text { psi }+128,500 \text { psi }=-15,500 \text { psi. }
$$

And:

$$
S_{t}=-120,000 p s i-37,000 p s i+133,500 p s i=-23,500 p s i:
$$

Stress at a Radius of Zero - To find the stress $\left(\mathrm{S}_{\mathrm{r}}\right)$ at a zero radius: 
Case A:

$$
\begin{aligned}
& S_{r}=S_{t}=-\frac{3 w}{8 \pi \mathrm{mt}^{2}}(3 \mathrm{~m}+1), \text { or } \\
& S_{r}=S_{t}=-\frac{(3)(20,000)(594)}{(8)(3.14)(3.84)(36)}(12.5)=-128,000 \mathrm{psi} .
\end{aligned}
$$

Case B:

$$
\begin{gathered}
S_{r}=S_{t}=-\frac{3 w}{2 \pi m t^{2}}\left[m+(m+1) \log \frac{a}{r_{0}}-(m-1) \frac{r_{0}^{2}}{4 a^{2}}\right] \text {, or } \\
S_{r}=S_{t}=-\frac{(3)(22,400)(64)}{(2)(3.14)(3.84)(36)}\left[3.84+4.84 \log \frac{13.75}{4.5}-\right. \\
\left.(2.84) \frac{20.25}{4(189)}\right]=-45,300 \text { psi. }
\end{gathered}
$$

Case C:

$$
\begin{aligned}
& S_{r}=S_{t}=\frac{3 w}{8 \pi \mathrm{mt}^{2}}(3 \mathrm{~m}+1), \text { or } \\
& S_{r}=S_{t}=\frac{(3)(22,400)(594)}{(8)(3.14)(3.84)(36)}(12.5)=142,000 \mathrm{psi} .
\end{aligned}
$$

Summation of stresses:

$$
S_{r}=S_{t}=-128,000 \text { psi }-45,300 \text { psi }+142,000 \text { psi }=-31,300 \text { psi }
$$

Stress at a Radius of Two Inches - To find the stress $\left(S_{r}\right)$ at a radius of 2 inches:

Case A:

$$
S_{r}=-\frac{3 w}{8 \pi m t^{2}}\left[(3 m+1)\left(1-\frac{r^{2}}{a^{2}}\right)\right] .
$$

Then:

$$
S_{r}=-\frac{(3)(20,000)(594)}{(8)(3.14)(3.84)(36)}\left[(12.5)\left(1-\frac{4}{189}\right)\right]=-126,000 \text { psi }
$$


The tangential stress becomes:

$$
\begin{aligned}
& S_{f}=-\frac{3 w}{8 \pi m t^{2}}\left[(3 m+1)-(m+3) \frac{r^{2}}{a^{2}}\right], \text { or } \\
& S_{f}=-\frac{(3)(20,000)(594)}{(8)(3.14)(3.84)(36)}\left[(12.5)-6.84 \frac{4}{189}\right]=-127,000 \text { psi. }
\end{aligned}
$$

\section{Case B:}

$$
S_{r}=-\frac{3 w}{2 \pi m t^{2}}\left[m+(m+1) \log \frac{a}{r_{0}}-(m-1) \frac{r_{0}^{2}}{4 a^{2}}-(3 m+1) \frac{r^{2}}{4 r_{0}^{2}}\right] .
$$

Then:

$$
\begin{aligned}
S_{r}=-\frac{(3)(22,400)(64)}{(2)(3.14)(3.84)(36)}[3.84+ & \left.4.84 \log \frac{13.75}{4.5}-2.84 \frac{20.25}{4(189)}-\frac{(12.5)(4)}{4(20.25)}\right]= \\
& -42,300 \text { psi. }
\end{aligned}
$$

The tangential stress becomes:

$$
\begin{gathered}
S_{t}=-\frac{3 w}{2 \pi m t^{2}}\left[m+(m+1) \log \frac{a}{r_{0}}-(m-1) \frac{r_{0}^{2}}{4 a^{2}}-(m+3) \frac{r^{2}}{4 r_{\circ}^{2}}\right] \text {, or } \\
S_{t}=-\frac{(3)(22,400)(64)}{(2)(3.14)(3.84)(36)}\left[3.84+4.84 \log \frac{13.75}{4.5}-2.84 \frac{20.25}{4(189)}-\right. \\
\left.6.84 \frac{4}{4(20.25)}\right]=-43,800 \text { psi. }
\end{gathered}
$$

Case C:

$$
S_{r}=\frac{3 w}{8 \pi m t^{2}}\left[(3 m+1)\left(1-\frac{r^{2}}{a^{2}}\right)\right]
$$

Then:

$$
S_{r}=\frac{(3)(22,400)(594)}{(8)(3.14)(3.84)(36)}\left[(12.5)\left(1-\frac{4}{189}\right)\right]=141,000 \text { psi. }
$$


The tangential stress becomes:

$$
\begin{aligned}
& S_{t}=\frac{3 w}{8 \pi m t^{2}}\left[(3 m+1)-(m+1) \frac{r^{2}}{a^{2}}\right] \text {, or } \\
& S_{t}=\frac{(3)(22,400)(594)}{(8)(3.14)(3.84)(36)},\left[(12.5)-4.84 \frac{4}{189}\right]=142,000 \mathrm{psi} .
\end{aligned}
$$

Summation of stresses:

$$
S_{r}=-126,000 \text { psi }-42,300 \text { psi }+141,000 \text { psi }=-27,300 \text { psi, }
$$

and:

$$
S_{t}=-127,000 \text { psi }-43,800 \text { psi }+142,000 \text { psi }=-28,800 \text { psi } .
$$

Stress Concentration Factors $(7)$ - The following stress concentration factors were used (figure numbers are from the reference):

For 2 1/2-inch Radius - K = 1.35 (from Figure 65).

For 1-Inch-Diameter Hole $-K=2.75$ (from Figure 86).

For 1/2-Inch-Diameter Hole - K $=2.90$ (from Figure 86).

Maximum Stress - The maximum stress in the upper mushroom is 86,075 psi and occurs at the center. The increase of the stress concentration factor at $r=2$ inches from 2.90 to 2.95 is due to a slight compounding of the concentration factors. The sign convention on stresses was used only to keep the signs straight. The back side of the mushroom is in tension and the pressure side is in compression.

The following data summarize the findings:

$$
\begin{aligned}
& \text { At } r=0 ; S_{r}=S_{\dagger}=31,300(2.74)=86,075 \mathrm{psi} . \\
& \text { At } r=2 ; S_{\dagger}=28,800(2.95)=84,960 \mathrm{psi} \\
& \text { At } r=4.5 ; S_{\dagger}=23,500(1.35)=31,725 \mathrm{psi}
\end{aligned}
$$


Stress Calculations on the Lower Mushroom

The stresses in the lower mushroom are calculated for a maximum pressure of 20,000 psi in the vessel.(c) The stress will be calculated at four points (in inches) in the mushroom as follows: (1) at $r=0$ - center of the mushroom, (2) at $r=1.5$ - center of the $1 / 2$-inch-diameter hole, (3) at $r=2.75$ - center of the $11 / 8$-inch-diameter hole, and (4) at $r=5.5$ - at the large radius.

The formulas for flat plates are used but are superimposed to give the correct loading as applied to the mushroom in the vessel. In the calculations, the stemportion of the mushroom is neglecied, but stress concentration factors are considered.

If the lower mushroom is loaded by a 20,000-psi internal pressure, the following forces are considered in the problems pertaining to the mushroom:

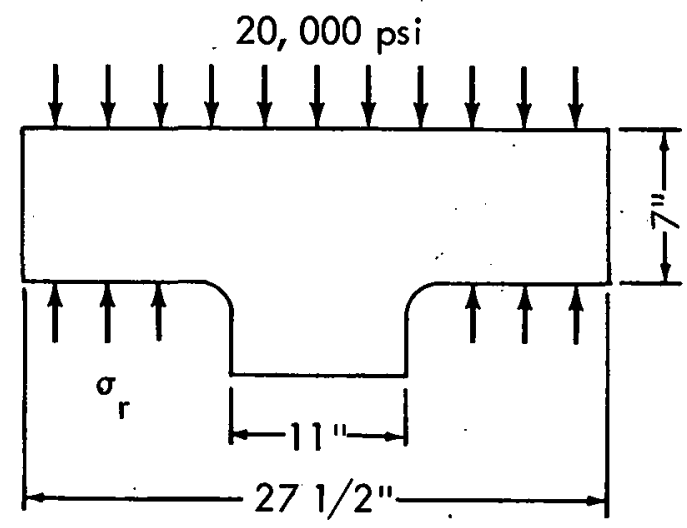

where:

$$
\begin{aligned}
& \sigma_{p} A_{p}=\sigma_{r} A_{r}, \text { or } \\
& (20,000)(594)=\sigma_{r}(594-95) . \sigma_{p}=20,000 \mathrm{psi} \text { (internal pressure). }
\end{aligned}
$$

Therefore:

$$
\sigma_{r}=23,800 \mathrm{psi}=\text { the pressure on the rubber pad. }
$$

The symbols and cases of loading are the same as for the upper mushroom, so will not be repeated here.

(c) The following drawings and specifications were used in these calculations: UCC Drawings E-M-53169 and E-M-53213, and UCC Specification Y-S-1379. 
Stress at a Radius of 5.5 Inches $(3)$ - To find the stress $\left(S_{r}\right)$ at a radius of 5.5 inches:

Case A:

$$
\begin{aligned}
& S_{r}=-\frac{3 w}{8 \pi t^{2}}\left[(3 m+1)\left(1-\frac{r^{2}}{a^{2}}\right)\right], \text { or } \\
& S_{r}=-\frac{(3)(20,000)(594)}{(8)(3.14)(3.84)(49)}\left[(12.5)\left(1-\frac{30.2}{189}\right)\right]=-79,000 \text { psi. }
\end{aligned}
$$

The tangential stress becomes:

$$
\begin{aligned}
& S_{t}=-\frac{3 w}{8 \pi \mathrm{mt}^{2}}\left[(3 m+1)-(m+3) \frac{r^{2}}{a^{2}}\right], \text { or } \\
& S_{t}=-\frac{(3)(20,000)(594)}{(8)(3.14)(3.84)(49)}\left[(12.5)-(6.84) \frac{30.2}{189}\right]=-85,800 \text { psi. }
\end{aligned}
$$

Case B:

$$
\begin{gathered}
S_{r}=-\frac{3 w}{2 \pi m t^{2}}\left[m+(m+1) \log \frac{a}{r_{0}}-(m-1) \frac{r_{0}^{2}}{4 a^{2}}-(3 m+1) \frac{r^{2}}{4 r_{0}^{2}}\right] \text {, or } \\
S_{r}=-\frac{(3)(23,800)(95)}{(2)(3.14)(3.84)(49)}\left[(3.84)+(4.84) \log \frac{13.75}{5.5}-(2.84) \frac{30.2}{4(189)}-\right. \\
\left.\frac{12.5}{4}\right]=-28,900 \text { psi. }
\end{gathered}
$$

The tangential stress becomes:

$$
\begin{gathered}
S_{t}=-\frac{3 w}{2 \pi m t^{2}}\left[m+(m+1) \log \frac{a}{r_{0}}-(m-1) \frac{r_{0}^{2}}{4 a^{2}}-(m+3) \frac{r^{2}}{4 r_{0}^{2}}\right], \text { or } \\
S_{t}=-\frac{(3)(23,800)(95)}{(2)(3.14)(3.84)(49)}\left[(3.84)+(4.84) \log \frac{13.75}{5.5}-(2.84) \frac{30.2}{4(189)}-\right. \\
\left.\frac{6.84}{4}\right]=-37,000 \text { psi. }
\end{gathered}
$$


Case C:

$$
\begin{aligned}
& S_{r}=\frac{3 w}{8 \pi m t^{2}}\left[(3 m+1)\left(1-\frac{r^{2}}{a^{2}}\right)\right], \text { or } \\
& S_{r}=\frac{(3)(23,800)(594)}{(8)(3.14)(3.84)(49)}\left[(12.5)\left(1-\frac{30.2}{189}\right)\right]=94,000 \text { psi. }
\end{aligned}
$$

The tangential stress becomes:

$$
\begin{aligned}
& S_{t}=\frac{3 w}{8 \pi \mathrm{mt}^{2}}\left[(3 m+1)-(m+3) \frac{r^{2}}{a^{2}}\right], \text { or } \\
& S_{t}=\frac{(3)(23,800)(594)}{(8)(3.14)(3.84)(49)}\left[(12.5)-(6.84) \frac{30.2}{189}\right]=102,500 \mathrm{psi} .
\end{aligned}
$$

Summation of stresses:

$$
S_{r}=-79,000 \text { psi }-28,900 \text { psi }+94,000 \text { psi }=-13,900 \text { psi. }
$$

And:

$$
S_{t}=-85,800 \text { psi }-37,000 \text { psi }+102,500 \text { psi }=-20,300 \text { psi. }
$$

Stress at a Radius of 2.75 Inches - To find the stress $\left(S_{r}\right)$ at a radius of 2.75 inches:

Case A:

$$
\begin{aligned}
& S_{r}=-\frac{3 w}{8 \pi m t^{2}}\left[(3 m+1)\left(1-\frac{r^{2}}{a^{2}}\right)\right] \text {, or } \\
& S_{r}=-\frac{(3)(20,000)(594)}{(8)(3.14)(3.84)(49)}\left[(12.5)\left(1-\frac{7.55}{189}\right)\right]=-90,400 \text { psi. }
\end{aligned}
$$

The tangential stress becomes:

$$
\begin{aligned}
& S_{t}=-\frac{3 w}{8 \pi m t^{2}}\left[(3 m+1)-(m+3) \frac{r^{2}}{a^{2}}\right], \text { or } \\
& S_{t}=-\frac{(3)(20,000)(594)}{(8)(3.14)(3.84)(49)}\left[(12.5)-(6.84) \frac{7.55}{189}\right]=-92,700 \text { psi. }
\end{aligned}
$$


Case B:

$$
\begin{gathered}
-S_{r}=-\frac{3 w}{2 \pi m t^{2}}\left[m+(m+1) \log \frac{a}{r_{0}}-(m-1) \frac{r^{2}}{4 a^{2}}-(3 m+1) \frac{r^{2}}{4 r_{o}^{2}}\right] \text {, or } \\
S_{r}=-\frac{(3)(23,800)(95)}{(2)(3.14)(3.84)(49)}\left[(3.84)+(4.84) \log \frac{13.75}{5.5}-(2.84) \frac{30.2}{4(189)}-\right. \\
\left.\frac{(12.5)(7.55)}{4(30.2)}\right]=-42,300 \text { psi. }
\end{gathered}
$$

The tangential stress becomes:

$$
\begin{gathered}
S_{t}=-\frac{3 w}{2 \pi m t^{2}}\left[m+(m+1) \log \frac{a}{r_{0}}-(m-1) \frac{r_{0}^{2}}{4 a^{2}}-(m+3) \frac{r^{2}}{4 r_{0}^{2}}\right] \text {, or } \\
S_{t}=-\frac{(3)(23,800)(95)}{(2)(3.14)(3.84)(49)}\left[(3.84)+(4.84) \log \frac{13.75}{5.5}-(2.84) \frac{30.2}{4(189)}-\right. \\
\left.\frac{(6.84)(7.55)}{4(30.2)}\right]=-44,300 \text { psi. }
\end{gathered}
$$

Case C:

$$
\begin{aligned}
& S_{r}=\frac{3 w}{8 \pi \mathrm{mt}^{2}}\left[(3 m+1)\left(1-\frac{r^{2}}{a^{2}}\right)\right], \text { or } \\
& S_{r}=\frac{(3)(23,800)(594)}{(8)(3.14)(3.84)(49)}\left[(12.5)\left(1-\frac{7.55}{189}\right)\right]=108,700 \mathrm{psi} .
\end{aligned}
$$

The tangential stress becomes:

$$
\begin{aligned}
& S_{t}=\frac{3 w}{8 \pi m t^{2}}\left[(3 m+1)-(m+3) \frac{r^{2}}{a^{2}}\right], \text { or } \\
& S_{t}=\frac{(3)(23,800)(594)}{(8)(3.14)(3.84)(49)}\left[(12.5)-(6.84) \frac{7.55}{189}\right]=109,700 \text { psi. }
\end{aligned}
$$

Summation of stresses: 


$$
S_{r}=-90,400 \text { psi }-42,300 \text { psi }+108,700 \text { psi }=-24,000 \text { psi }
$$

And:

$$
S_{f}=-92,700 \text { psi }-44,300 \text { psi }+109,700 \text { psi }=-27,300 \text { psi } .
$$

Stress at a Radius of 1.50 Inches - To find the stress $\left(S_{r}\right)$ at a radius of 1.5 inches:

Case A:

$$
\begin{aligned}
& S_{r}=-\frac{3 w}{8 \pi m t^{2}}\left[(3 m+1)\left(1-\frac{r^{2}}{a^{2}}\right)\right] \text {, or } \\
& S_{r}=-\frac{(3)(20,000)(594)}{(8)(3.14)(3.84)(49)}\left[(12.5)\left(1-\frac{2.25}{189}\right)\right]=-93,200 \text { psi. }
\end{aligned}
$$

The tangential stress becomes:

$$
\begin{aligned}
& S_{t}=-\frac{3 w}{8 \pi m t^{2}}\left[(3 m+1)-(m+3) \frac{r^{2}}{a^{2}}\right], \text { or } \\
& S_{t}=-\frac{(3)(20,000)(594)}{(8)(3.14)(3.84)(49)}\left[(12.5)-(6.84) \frac{2.25}{189}\right]=-93,700 \mathrm{psi} .
\end{aligned}
$$

Case B:

$$
\begin{gathered}
S_{r}=-\frac{3 w}{2 \pi m t^{2}}\left[m+(m+1) \log \frac{a}{r_{0}}-(m-1) \frac{r_{0}^{2}}{4 a^{2}}-(3 m+1) \frac{r^{2}}{4 r_{0}^{2}}\right], \text { or } \\
S_{r}=-\frac{(3)(23,800)(95)}{(2)(3.14)(3.84)(49)}\left[(3.84)-(4.84) \log \frac{13.75}{5.5}-(2.84) \frac{30.2}{4(189)}-\right. \\
\left.\frac{(12.5)(2.25)}{4(302)}\right]=-45,400 \text { psi. }
\end{gathered}
$$

The tangential stress becomes:

$$
S_{t}=-\frac{3 w}{2 \pi m t^{2}}\left[m+(m+1) \log \frac{a}{r_{0}}-(m-1) \frac{r_{0}^{2}}{4 a^{2}}-(m+3) \frac{r^{2}}{4 r_{0}^{2}}\right] \text {, or }
$$




$$
\begin{gathered}
S_{f}=-\frac{(3)(23,800)(95)}{(2)(3.14)(3.84)(49)}\left[(3.84)+(4.84) \log \frac{13.75}{5.5}-2.84 \frac{30.2}{4(189)}-\right. \\
\left.\frac{(6.84)(2.25)}{4(30.2)}\right]=-46,100 \text { psi. }
\end{gathered}
$$

Case C:

$$
\begin{aligned}
& S_{r}=\frac{3 w}{8 \pi m t^{2}}\left[(3 m+1)\left(1-\frac{r^{2}}{a^{2}}\right)\right] \text {, or } \\
& S_{r}=\frac{(3)(23,800)(594)}{(8)(3.14)(3.84)(49)}\left[(12.5)\left(1-\frac{2.25}{189}\right)\right]=111,000 \text { psi. }
\end{aligned}
$$

The tangential stress becomes:

$$
\begin{aligned}
& S_{t}=\frac{3 w}{8 \pi \mathrm{mt}^{2}}\left[(3 m+1)-(m+3) \frac{r^{2}}{a^{2}}\right], \text { or } \\
& S_{t}=\frac{(3)(23,800)(594)}{(8)(3.14)(3.84)(49)}\left[(12.5)-(6.84) \frac{2.25}{189}\right]=111,500 \mathrm{psi} .
\end{aligned}
$$

Summation of stresses:

$$
S_{r}=-93,200 \text { psi }-45,400 p s i+111,000 \text { psi }=-27,600 \text { psi. }
$$

And:

$$
S_{\dagger}=-93,700 \text { psi }-46,100 \text { psi }+111,500 \text { psi }=-28,300 \text { psi. }
$$

Stress at a Radius of Zero - To find the stress $\left(S_{r}\right)$ at a zero radius:

Case A:

$$
\begin{aligned}
& S_{r}=S_{t}=-\frac{3 w}{8 m m 1^{2}}(3 m+1), \text { or } \\
& S_{r}=S_{t}=-\frac{(3)(20,000)(594)}{(8)(3.14)(3.84)(49)}(12.5)=-94,200 \text { psi. }
\end{aligned}
$$

Case B: 


$$
\begin{aligned}
S_{r}=S_{t}=-\frac{3 w}{2 \pi m t^{2}}\left[m+(m+1) \log \frac{a}{r_{0}}-(m-1) \frac{r_{0}^{2}}{4 a^{2}}\right], \text { or } \\
S_{r}=S_{t}=-\frac{(3)(23,800)(95)}{(2)(3.14)(3.84)(49)}\left[(3.84)+(4.84) \log \frac{13.75}{5.5}-\frac{(2.84)(30.2)}{4(189)}\right]= \\
-46,800 \text { psi. }
\end{aligned}
$$

Case C:

$$
\begin{aligned}
& S_{r}=S_{t}=\frac{3 w}{8 . \pi \mathrm{mt}^{2}}(3 \mathrm{~m}+1), \text { or } \\
& S_{r}=S_{t}=\frac{(3)(23,800)(594)}{(8)(3.14)(3.84)(49)}(12.5)=112,100 \text { psi. }
\end{aligned}
$$

Summation of stresses:

$$
S_{r}=S_{t}=-94,200 p s i-46,800 p s i+112,100 \text { psi }=-28,900 \text { psi } .
$$

Stress Concentration Factors $(7)$ - The following stress concentration factors were used (figure numbers are from the reference):

For 2 1/2-Inch Radius - K = 1.40 (from Figure 65).

For 1-Inch-Diameter Hole $-K=2.75$ (from Figure 86).

For 1/2-Inch-Diameter Hole $-K=2.90$ (from Figure 86).

For 1 1/8-Inch-Diameter Hole $-K=2.70$ (from Figure 86).

Maximum Stress - The maximum stress in the lower mushroom is 82,000 psi and occurs at a radius of 1.50 inches. The back side of the mushroom is in tension and the pressure side is in compression.

The following data summarize the findings:

$$
\begin{aligned}
& \text { At } r=0 ; S_{r}=S_{t}=28,900(2.75)=79,500 \text { psi. } \\
& \text { At } r=1.5 ; S_{t}=28,300(2.9)=82,000 \text { psi. } \\
& \text { At } r=2.75 ; S_{t}=27,300(2.7)=73,700 \text { psi. } \\
& \text { At } r=5.5 ; S_{t}=20,300(1.4)=28,400 \text { psi. }
\end{aligned}
$$


Water Requirements for the Top Mushroom Cooling Plate

Maximum Condition - The cooling plate is to be designed to remove $25 \mathrm{kw}$. (d) Calculations are based on a maximum $\Delta t$ of $25^{\circ} \mathrm{F}$ for the cooling water. Calculations have been made in three parts:

Flow in the Inlet and Outlet Pipes

Flow in the Grooves

Flow in the Manifold

The following symbols are used throughout:

Q represents the heat flow in Btuss/hr,

$w$ is the flow in lbs/hr,

C represents the specific heat at constant pressure in Btus $/(\mathrm{Ib})\left({ }^{\circ} \mathrm{F}\right)$, and

$\Delta t$ represents the temperature rise in ${ }^{\circ} \mathrm{F}$.

Therefore: ${ }^{(4)}$

$$
Q=w C \Delta t \text {, or }
$$

$$
\begin{aligned}
(25)(3413) & =w(1) 25, \text { or } \\
w & =3413 \mathrm{lbs} / \mathrm{hr}, \text { or } \\
w & =6.85 \mathrm{gals} / \mathrm{min} .
\end{aligned}
$$

Flow in the Inlet and Outlet Pipes - Flow in the inlet and outlet pipes can be found by:

$$
\begin{gathered}
w=1.53 \times 10^{-2} \mathrm{ft}^{3} / \mathrm{sec} \text {, the flow in each pipe. } \\
w=a v, \text { or }
\end{gathered}
$$

$$
1.53 \times 10^{-2}=\frac{0.196}{144} \mathrm{ft}^{2}(\mathrm{v}) \quad\left(0.196 \mathrm{in}^{2}=\text { area of } 3 / 8 \text {-inch pipe }\right)
$$

$v=11.2 \mathrm{ft} / \mathrm{sec}$, the velocity in the inlet and outlet pipes.

(d) The following drawings and report were used in these calculations: UCC Drawings $E-M-52379$ and $E-M-52380$, and Part 7 "Heat Loss Evaluation for $Y-12$ Development Furnace". 
The Reynolds number, $\mathrm{N}_{\mathrm{Re}^{\prime}}$ is:

$$
N_{\operatorname{Re}}=\frac{D_{e} v \rho}{\mu},
$$

where:

$\checkmark$ represents the velocity $(11.2 \mathrm{ft} / \mathrm{sec})$,

$\rho \quad$ is the density $\left(62.34 \mathrm{lbs} / \mathrm{ft}^{3}\right)$,

$\mu \quad$ is the viscosity $(2.71 \mathrm{lbs} / \mathrm{ft}-\mathrm{hr})$, and

$D_{e}$ is the equivalent diameter $(0.500 \mathrm{in})$.

From the chart on the relation between friction factor $(f=0.022)$ and Reynolds number for smooth pipes,

pressure loss $(\Delta p)$ can be found from:

$$
\Delta p=f \frac{L \rho v^{2}}{D_{e}{ }^{2 g}} .
$$

If the following additional constants are used:

$$
\begin{aligned}
& f=\text { friction factor }(0.022), \\
& L=\text { equivalent length including turns }(7.1 \mathrm{ft}), \text { and } \\
& g_{c}=\text { gravitational constant }\left(32.17 \mathrm{ft} / \mathrm{sec}^{2}\right) .
\end{aligned}
$$

Then:

$$
\Delta p=\frac{(0.022)(7.1)(62.34)(11.2)^{2}(1.2)}{(0.50)(2)(32.17)}=454 \mathrm{lbs} / \mathrm{ft}^{2}=3.15 \mathrm{lbs} / \mathrm{in}^{2} .
$$

Flow in the Grooves - Since all of the grooves are in parallel, the pressure drop across each path will be the same. Also, since the flow paths are symetrical about the manifold, only one half shall be calculated.

If $Q_{f}$ represents the total flow required for the cooling plate: 
169

$$
\frac{Q_{t}}{2}=Q_{1}+Q_{2}+Q_{3}+Q_{4}+Q_{5^{\prime}}
$$

where:

$Q_{1}$ through $Q_{5}$ represent the flow in each groove with Groove 1 on the outside. So the pressure drop across each path will be found by:

$$
\Delta p_{1}=\Delta p_{2}=\Delta p_{3}=\Delta p_{4}=\Delta p_{5}=f \frac{L \rho v^{2}}{D e^{2 g}}
$$

All velocities shall be calculated in terms of $v$ (the velocity in the oustide groove). A friction factor of 0.025 shall be assumed and checked later.

So:

$$
\begin{aligned}
& \Delta p=f \frac{L \rho v^{2}}{D_{e}{ }^{2 g} c}, \text { and } \\
& v=\left(\frac{\Delta p D_{e} 2 g_{c}}{L f \rho}\right)^{1 / 2} .
\end{aligned}
$$

For groove $\mathrm{l}\left(\mathrm{L}_{1}=10.3 \mathrm{ft} ; \mathrm{D}_{\mathrm{e}}=0.19 \mathrm{in}\right)$ :

$$
\frac{v_{1}}{\sqrt{\Delta p}}=\left[\frac{D_{e} 2 g_{c}}{f L_{1} \rho}\right]^{1 / 2}=\left[\frac{(0.19)(2)(32.17)}{(12)(0.025)(10.3)(62.34)}\right]^{1 / 2}=0.252
$$

For Groove $2\left(\mathrm{~L}_{2}=7.95 \mathrm{ft} ; \mathrm{D}_{\mathrm{e}}=0.19 \mathrm{in}\right)$ :

$$
\frac{v_{2}}{\sqrt{\Delta p}}=\left[\frac{D_{e}{ }^{2 g_{c}}}{f L_{2} p}\right]^{1 / 2}=\left[\frac{(0.19)(2)(32.17)}{(12)(0.025)(7.95)(62.34)}\right]^{1 / 2}=0.287
$$

For Groove $3\left(\mathrm{~L}_{3}=6.5 \mathrm{ft} ; \mathrm{D}_{\mathrm{e}}=0.188 \mathrm{in}\right)$ :

$$
\frac{v_{3}}{\sqrt{\Delta p}}=\left[\frac{D_{e} 2 g_{c}}{f L_{3} p}\right]^{1 / 2}=\left[\frac{(0.188)(2)(32.17)}{(0.025)(12)(6.5)(62.34)}\right]^{1 / 2}=0.316
$$


For Groove $4\left(\mathrm{~L}_{4}=5.08 \mathrm{ft} ; \mathrm{D}_{\mathrm{e}}=0.188 \mathrm{in}\right)$ :

$$
\frac{v_{4}}{\sqrt{\Delta p}}=\left[\frac{D_{e} 2 g_{c}}{f L_{4} p}\right]^{1 / 2}=\left[\frac{(0.188)(2)(32.17)}{(0.025)(12)(5.08)(62.34)}\right]^{1 / 2}=0.357 .
$$

For Groove $5\left(\mathrm{~L}_{5}=4.04 \mathrm{ft} ; \mathrm{D}_{\mathrm{e}}=0.156 \mathrm{in}\right)$ :

$$
\frac{v_{5}}{\sqrt{\Delta p}}=\left[\frac{D_{e} 2 g_{c}}{f L_{5} p}\right]^{1 / 2}=\left[\frac{(0.156)(2)(32.17)}{(0.025)(4.04)(12)(62.34)}\right]^{1 / 2}=0.365 .
$$

Since $\Delta p_{1}=\Delta p_{2}=\Delta p_{3}=\Delta p_{4}=\Delta p_{5}$

$$
\begin{aligned}
& \sqrt{\Delta p_{1}}=\sqrt{\Delta p_{2}}=\sqrt{\Delta p_{3}}=\sqrt{\Delta p_{4}}=\sqrt{\Delta p_{5}} . \\
& \sqrt{\Delta p}=\frac{v_{1}}{0.253}=\frac{v_{2}}{0.287} \text { or } v_{2}=1.135 v_{1} .
\end{aligned}
$$

All velocities are now calculated in terms of $v$ as follows:

$$
\begin{aligned}
v_{2} & =1.135 v_{1}, \\
v_{3} & =1.25 v_{1}{ }^{\prime} \\
v_{4} & =1.41 v_{1} \text {, and } \\
v_{5} & =1.44 v_{1} \cdot \\
\frac{Q t}{2} & =7.65 \times 10^{-3} \mathrm{ft}^{3} / \mathrm{sec}=a_{1} v_{1}+a_{2} v_{2}+a_{3} v_{3}+a_{4} v_{4}+a_{5} v_{5} \text { or }
\end{aligned}
$$

$7.65 \times 10^{-3} \frac{\mathrm{ft}^{3}}{\mathrm{sec}}=\frac{1}{144}\left[0.038 v_{1}+0.038\left(1.135 v_{1}\right)+0.031\left(1.25 v_{1}\right)+0.031\right.$

$$
\left.\left(1.41 v_{1}\right)+0.025\left(1.44 v_{1}\right)\right] \text {. }
$$

So:

$$
v_{1}=5.52 \mathrm{ft} / \mathrm{sec},
$$




$$
\begin{aligned}
& v_{2}=6.26 \mathrm{ft} / \mathrm{sec}, \\
& v_{3}=6.90 \mathrm{ft} / \mathrm{sec}, \\
& v_{4}=7.78 \mathrm{ft} / \mathrm{sec}, \text { and } \\
& v_{5}=7.95 \mathrm{ft} / \mathrm{sec} .
\end{aligned}
$$

Thus, the Reynolds number for each of the grooves is:

Groove $1(f=0.031)$ :

$$
N_{\operatorname{Re}}=\frac{D_{e} v_{1} \rho}{\mu}=\frac{(0.19)(5.52)(3600)(62.34)}{(12)(2.71)}=7.38 \times 10^{3},
$$

and:

$$
\begin{gathered}
\Delta p=f \frac{L_{1} \rho v_{1}^{2}}{D_{e}{ }^{2 g_{c}}}=\frac{(0.031)(10.3)(62.34)(30.5)(12)}{(0.19)(2)(32.17)}=595 \mathrm{lbs} / \mathrm{ft}^{2} \text { or } \\
4.13 \mathrm{lbs} / \mathrm{in}^{2} .
\end{gathered}
$$

Groove $2(f=0.031)$ :

$$
N_{\operatorname{Re}}=\frac{\mathrm{D}_{e v_{2}}}{\mu}=\frac{(0.19)(6.26)(3600)(62.34)}{(12)(2.71)}=8.2 \times 10^{3}
$$

and:

$$
\begin{gathered}
\Delta p=f \frac{L_{2} \rho v_{2}^{2}}{D_{e}{ }^{2 g_{c}}}=\frac{(0.031)(12)(7.95)(62.34)(39.2)}{(0.19)(2)(32.17)}=590 \mathrm{lbs} / \mathrm{ft}^{2} \text { or } \\
4.1 \mathrm{lbs} / \mathrm{in}^{2} .
\end{gathered}
$$

Groove $3(f=0.031)$ :

$$
N_{\operatorname{Re}}=\frac{D_{e} v_{3} \rho}{\mu}=\frac{(0.188)(6.9)(3600)(62.34)}{(12)(2.71)}=8.8 \times 10^{3}
$$

and: 


$$
\Delta p=f \frac{L_{3} \rho v_{3}^{2}}{D_{e} 2 g_{c}}=\frac{(0.031)(6.5)(62.34)(47.6)(12)}{(0.188)(2)(32.17)}=595 \mathrm{lbs} / \mathrm{ft}^{2} \text { or }
$$

$$
4.13 \mathrm{lbs} / \mathrm{in}^{2} \text {. }
$$

Groove $4(f=0.0305)$ :

$$
N_{\operatorname{Re}}=\frac{D_{e} v_{4} \rho}{\mu}=\frac{(0.188)(7.78)(62.34)(3600)}{(12)(2.71)}=1 \times 10^{4},
$$

and:

$$
\begin{gathered}
\Delta p=f \frac{L_{4} \rho v_{4}^{2}}{D_{e} 2 g_{c}}=\frac{(0.0305)(5.08)(62.34)(60.5)(12)}{(0.188)(2)(32.17)}=580 \mathrm{lbs} / \mathrm{ft}^{2} \text { or } \\
4.02 \mathrm{lbs} / \mathrm{in}^{2} .
\end{gathered}
$$

Groove $5(f=0.031)$ :

$$
N_{\operatorname{Re}}=\frac{D_{e} v_{5} \rho}{\mu}=\frac{(0.156)(7.95)(3600)(62.34)}{(12)(2.71)}=8.55 \times 10^{3},
$$

and:

$$
\begin{gathered}
\Delta p=f \frac{L_{5} \rho v_{5}{ }^{2}}{D_{e} 2 g_{c}}=\frac{(0.031)(4.04)(62.34)(63.1)(12)}{(0.156)(2)(32.17)}= \\
588 \mathrm{lbs} / \mathrm{ft}^{2} \text { or } 4.08 \mathrm{lbs} / \mathrm{in}^{2} .
\end{gathered}
$$

The friction factor (f) is higher than the assumed value but is close enough that the velocities would not be appreciably changed.

Flow in the Manifold - If $D_{e}=0.344 \mathrm{in}, a=0.124 \mathrm{in}^{2}$, and

$$
\begin{aligned}
& w=a v \text {, then } \\
& 1.53 \times 10^{-2}=\frac{0.124}{144} \mathrm{ft}^{2} v \text {, or }
\end{aligned}
$$




$$
v=17.8 \mathrm{ft} / \mathrm{sec} .
$$

The Reynolds number would be:

$$
N_{\operatorname{Re}}=\frac{D_{e} v \rho}{\mu}=\frac{(0.344)(17.8)(3600)(62.34)}{(12)(2.71)}=4.22 \times 10^{4} .
$$

The drop in pressure would be $(f=0.022)$ :

$$
\begin{gathered}
\Delta p=f \frac{L \rho v^{2}}{D_{e} 2 g_{c}}=\frac{(0.022)(1.5)(62.34)(317)(12)}{(0.344)(2)(32.17)}=354 \mathrm{lbs} / \mathrm{ft}^{2} \text { or } 2.46 \mathrm{lbs} / \mathrm{in}^{2} . \\
\text { Total } \Delta p=6.30 \mathrm{lbs} / \mathrm{in}^{2}+4.13 \mathrm{lbs} / \mathrm{in}^{2}+2.45 \mathrm{lbs} / \mathrm{in}^{2}=12.9 \mathrm{lbs} / \mathrm{in}^{2} .
\end{gathered}
$$

The surface coefficient $\left(h_{c}\right)$ for water grooves from the chart by Kern $(6)$ is: 1350 Btus/ $(h r)\left(\mathrm{ft}^{2}\right)(\circ \mathrm{F})$.

Flow Requirements for the First Furnace (see Part 7, "Heat Loss Evaluation for Y-12 Development Furnace") - The flow requirements for the first furnace can be calculated from:

$$
Q=w C \Delta t \text {. }
$$

Substituting gives:

$$
\text { (6.1)(3413) Btus } / \mathrm{hr}=3413 \mathrm{lbs} / \mathrm{hr} \times 1 \mathrm{Btu} /(\mathrm{lb})(\circ \mathrm{F}) \Delta \mathrm{t} \text {, or }
$$

$$
\Delta t=6.1^{\circ} \mathrm{F} \text {. }
$$

Water Requirements for the Cooling Jacket

Maximum Condition - The cooling jacket is to be designed to remove $300 \mathrm{kw}$. (e) Calculations are based on a maximum $\Delta \mathrm{t}$ of $15^{\circ} \mathrm{F}$ for the cooling water. Calculations have been made in two parts:

Flow in Each Passage

Flow in Inlet and Outlet Tubes

The following symbols are used throughout:

Q represents the heat flow in Btus/hr,

(e) The following drawings, specifications, and report were used in these calculations: UCC Drawings E-M-52689, E-M-51001, and E-M-51002; UCC Specification Y-S-1369, and Part 7 "Heat Loss Evaluation for Y-12 Development Furnace". 
$w$ is the flow in $\mathrm{lbs} / \mathrm{hr}$,

C represents the specific heat at constant pressure in Btus $/(\mathrm{Ib})\left({ }^{\circ} \mathrm{F}\right)$, and $\Delta t$ represents the temperature rise in ${ }^{\circ} \mathrm{F}$.

Therefore: (4)

$$
Q=w C \Delta t, \text { or }
$$

$(300)(3413)=w(1) 15$, or

$w=6.82 \times 10^{4} \mathrm{lbs} / \mathrm{hr}$, or

$\mathrm{w}=137 \mathrm{gals} / \mathrm{min}$ which gives the total flow required for maximum condition.

Flow in Each Passage - The flow in each passage can be found from:

$$
\begin{aligned}
& w=\frac{6.82 \times 10^{4}}{42}=1.62 \times 10^{3} \mathrm{lbs} / \mathrm{hr}, \text { or } \\
& w=0.00724 \mathrm{ft}^{3} / \mathrm{sec} .
\end{aligned}
$$

Area of $1 / 2$-diameter semicircle $=0.0982 \mathrm{in}^{2}$, so:

$$
\begin{gathered}
w=a v, \text { or } \\
0.00724 \mathrm{ft}^{3} / \mathrm{sec}=\frac{0.0982}{144} \mathrm{ft}^{2}(v), \text { or } \\
v=10.6 \mathrm{ft} / \mathrm{sec}^{2}=\text { velocity in each passage. }
\end{gathered}
$$

The equivalent diameter can be found from:

$$
D_{e}=\frac{4 a}{p}
$$

where:

a is the cross sectional area, and

$p$ is the perimeter of the area.

Therefore: 


$$
D_{e}=\frac{(4)(0.0982)}{1.285}=0.306 \text { inch. }
$$

The Reynolds number ${ }^{(5)}$ would be:

$$
N_{R e}=\frac{D_{e} v p}{\mu},
$$

where;

$\checkmark$ represents the velocity $(10.6 \mathrm{ft} / \mathrm{sec})$,

$p \quad$ is the density $\left(62.31 \mathrm{lbs} / \mathrm{ft}^{3}\right)$,

$\mu \quad$ is the viscosity $(2.71 \mathrm{lbs} / \mathrm{ft}-\mathrm{hr})$, and

$D_{e}$ is the equivalent diameter $(0.306 \mathrm{in})$.

So:

$$
N_{\operatorname{Re}}=\frac{(0.306)(10.6)(62.34)(3600)}{(12)(2.71)}=2.24 \times 10^{4}
$$

From the chart on the relation between friction factor $(f=0.026)$ and Reynolds number for smooth pipes, $(5)$ pressure loss $(\Delta p)$ can be found from:

$$
\Delta p=f \frac{L \rho v^{2}}{D_{e} 2 g_{c}} .
$$

If the following additional constants are used:

$$
\begin{aligned}
& L=\text { equivalent length including turns }(23.4 \mathrm{ft}), \\
& v=\text { velocity, and } \\
& g_{c}=\text { gravitational constant }\left(32.17 \mathrm{ft} / \mathrm{sec}^{2}\right),
\end{aligned}
$$

then:

$$
\Delta p=\frac{(0.026)(23.4)(62.34)(10.6)^{2}(12)}{(0.306)(2)(32.17)}=2600 \mathrm{lbs} / \mathrm{ft}^{2}=18 \mathrm{lbs} / \mathrm{in}^{2}
$$

The surface coefficient $\left(h_{c}\right)$ for water passages from the chart by Kern $(6)$ is: 1800 Btus $/(h r)\left(f t^{2}\right)\left({ }^{\circ} \mathrm{F}\right)$. 
Flow in Inlet and Outlet Tubes - Flow in the inlet and outlet tubes can be found by:

$$
\begin{aligned}
& w=0.0435 \mathrm{ft}^{3} / \mathrm{sec} \text {, the flow in each tube. } \\
& w=a v \text {, or } \\
& 0.0435 \mathrm{ft}^{3} / \mathrm{sec}=\frac{0.601}{144} \mathrm{ft}^{2}(\mathrm{v}) \text {, or } \\
& v=10.4 \mathrm{ft} / \mathrm{sec} \text {, the velocity in the inlet and outlet tubes. }
\end{aligned}
$$

The Reynolds number, $\mathrm{N}_{\mathrm{Re}}$ is:

$$
N_{\operatorname{Re}}=\frac{D_{e} v p}{\mu}
$$

If:

$$
D_{e}=0.750 \text { inch, }
$$

then:

$$
N_{\operatorname{Re}}=\frac{(0.750)(10.4)(62.34)(3600)}{(12)(2.71)}=5.38 \times 10^{4}
$$

Pressure loss can be found from:

$$
\Delta p=f \frac{L \rho v^{2}}{D_{e} 2 g_{c}}(L=8 f t) .
$$

So:

$$
\Delta p=\frac{(0.020)(8)(62.34)(10.4)^{2}(12)}{(0.750)(2)(32.2)}=268 \mathrm{lbs} / \mathrm{ft}^{2}=1.86 \mathrm{lbs} / \mathrm{in}^{2}
$$

The total pressure loss through the cooling jacket would be $19.86 \mathrm{lbs} / \mathrm{in}^{2}$.

Flow Requirements for the First Furnace (see Part 7 "Heat Loss Evaluation for $Y-12$ Development Furnace ") - The flow requirements for the first furnace would be:

$Q=65 \mathrm{kw}=2.22 \times 10^{5} \mathrm{Btus} / \mathrm{hr}$, or

$2.22 \times 10^{5} \mathrm{Btus} / \mathrm{hr}=6.82 \times 10^{4} \mathrm{lbs} / \mathrm{hr} \times 1 \mathrm{Btu} /(\mathrm{lb})\left({ }^{\circ} \mathrm{F}\right) \Delta \mathrm{t}$, or 


$$
\Delta t=3.25^{\circ} \mathrm{F} .
$$

$\Delta t$ was calculated using a total flow of $137 \mathrm{gals} / \mathrm{min}$.

Water Requirements for the Lower Mushroom Cooling Plate

Maximum Condition - The cooling plate is to be designed to remove $25 \mathrm{kw}$. (f) Calculations are based on a maximum $\Delta t$ of $25^{\circ} \mathrm{F}$ for the cooling water. Calculations have been made in three parts:

Flow in the Inlet Pipe

Flow in the Givuves

Flow in the Outlet Pipe

$w($ water flow $)=6.85 \mathrm{gals} / \mathrm{min}$.

Total heat flow, $Q_{+}$, will be the same as for the top cooling plate.

Flow in the Inlet Pipe - The pressure loss $(\Delta p)$ in the inlet pipe can be found by:

$$
\Delta p=f \frac{L p v^{2}}{D_{e} 2 g_{c}} .
$$

From previous calculations of the top plate:

$$
\begin{aligned}
& v=11.2 \mathrm{ft} / \mathrm{sec}, \\
& N_{\operatorname{Re}}=3.86 \times 10^{4}, \\
& f=0.022 \text {, and } \\
& L=11.1 \mathrm{ft} .
\end{aligned}
$$

Therefore:

$$
\Delta p=\frac{(0.022)(11.1)(62.34)(125.5)(12)}{(0.50)(2)(32.2)}=712 \mathrm{lbs} / \mathrm{ft}^{2}=4.95 \mathrm{lbs} / \mathrm{in}^{2} .
$$

(f) The following drawings and report were used in these calculations: UCC Drawings $E-M-5.3383$ and $E-M-53169$, and Part 7 "Heat Loss Evaluation for $Y-12$ Development Furnace". 
Flow in the Grooves - The velocities and pressure losses through the grooves will be calculated in the same manner as for the upper plate:

$$
\frac{Q_{1}}{2}=Q_{1}+Q_{2}+Q_{3}+Q_{4}
$$

Since the first four grooves are identical to those of the top plate, the following relationships hold:

$$
\begin{aligned}
& v_{2}=1.135 v_{1}, \\
& v_{3}=1.25 v_{1}, \text { and } \\
& v_{4}=1.41 v_{1} . \\
& \frac{Q_{t}}{2}=7.65 \times 10^{-3} \mathrm{ft}^{3} / \mathrm{sec}=a_{1} v_{1}+a_{2} v_{2}+a_{3} v_{3}+a_{4} v_{4} \text { or } \\
& 7.65 \times 10^{-3} \mathrm{ft}^{3} / \mathrm{sec}=\frac{1}{144}\left[0.038 v_{1}+0.038\left(1.135 v_{1}\right)+0.031\left(1.25 v_{1}\right)\right. \\
&\left.\quad+0.031\left(1.41 v_{1}\right)\right] .
\end{aligned}
$$

So:

$$
\begin{aligned}
& v_{1}=6.73 \mathrm{ft} / \mathrm{sec}, \\
& v_{2}=7.64 \mathrm{ft} / \mathrm{sec}, \\
& v_{3}=8.41 \mathrm{ft} / \mathrm{sec} \text {, and } \\
& v_{4}=9.48 \mathrm{ft} / \mathrm{sec} .
\end{aligned}
$$

Thus, the Reynolds number for each of the grooves is:

Groove $1(f=0.031)$ :

$$
N_{R e}=\frac{D_{e} v_{1} \rho}{\mu}=\frac{(0.19)(6.73)(3600)(62.34)}{(12)(2.71)}=8.82 \times 10^{3},
$$

and: 


$$
\begin{gathered}
\Delta p=f \frac{L_{1} \rho v_{1}^{2}}{D_{e}{ }^{2 g_{c}}}=\frac{(0.031)(10.3)(62.34)(45.2)(12)}{(0.19)(2)(32.17)}= \\
890 \mathrm{lbs} / \mathrm{ft}^{2} \text { or } 6.18 \mathrm{lbs} / \mathrm{in}^{2} .
\end{gathered}
$$

Groove $2(f=0.0307)$ :

$$
N_{\operatorname{Re}}=\frac{D_{e} v_{2} \rho}{\mu}=\frac{(0.19)(7.64)(3600)(62.34)}{(12)(2.71)}=1 \times 10^{4},
$$

and:

$$
\begin{gathered}
\Delta p=f \frac{L_{2} \rho v_{2}^{2}}{D_{e}{ }^{2 g} g_{c}}=\frac{(0.0307)(7.95)(62.34)(58.2)(12)}{(0.19)(2)(32.17)}= \\
870 \mathrm{lbs} / \mathrm{ft}^{2} \text { or } 6.04 \mathrm{lbs} / \mathrm{in}^{2} .
\end{gathered}
$$

Groove $3(f=0.0305)$ :

$$
N_{\operatorname{Re}}=\frac{D_{e} v_{3} \rho}{\mu}=\frac{(0.188)(8.41)(3600)(62.34)}{(12)(2.71)}=1.09 \times 10^{4}
$$

and:

$$
\begin{gathered}
\Delta p=f \frac{L_{3} \rho v_{3}^{2}}{D_{e}{ }^{2 g_{c}}}=\frac{(0.0305)(6.5)(62.34)(70.7)(12)}{(0.188)(2)(32.17)}= \\
867 \mathrm{lbs} / \mathrm{ft}^{2} \text { or } 6.02 \mathrm{lbs} / \mathrm{in}^{2} .
\end{gathered}
$$

Groove 4 ( $f=0.0295)$ :

$$
N_{\operatorname{Re}}=\frac{D_{e} v_{4} \rho}{\mu}=\frac{(0.188)(9.48)(3600)(62.34)}{(12)(2.71)}=1.23 \times 10^{4},
$$

and: 


$$
\begin{gathered}
\Delta p=f \frac{L_{4} \rho v_{4}^{2}}{D_{e} 2 g_{c}}=\frac{(0.0295)(5.08)(62.34)(89)(12)}{(0.188)(2)(32.17)}= \\
845 \mathrm{lbs} / \mathrm{ft}^{2} \text { or } 5.87 \mathrm{lbs} / \mathrm{in}^{2} .
\end{gathered}
$$

As previously stated, the friction factor ( $f$ ) is slightly higher than the assumed value. However, this difference will only slightly affect the velocities in the grooves.

Flow in the Outlet Pipe - If $D_{\dot{e}}=D_{2}-D_{1}=1.00-0.75=0.25$, and

$$
\begin{gathered}
w=a v \text {, then } \\
1.53 \times 10^{-2} \mathrm{ft}^{3} / \mathrm{sec}=\frac{0.343}{144} \mathrm{ft}^{2}(v), \text { or } \\
v=6.42 \mathrm{ft} / \mathrm{sec} .
\end{gathered}
$$

The Reynolds number would be:

$$
N_{\operatorname{Re}}=\frac{D_{e} \vee p}{\mu}=\frac{(0.25)(6.42)(62.34)(3600)}{(12)(2.71)}=1.1 \times 10^{4} .
$$

The drop in pressure would be $\left(\dot{f}=0.030 ; L_{t}=10.55 \mathrm{ft}\right)$ :

$$
\begin{aligned}
\Delta p=f \frac{L \rho v^{2}}{D_{e} 2 g_{c}} & =\frac{(0.030)(10.55)(62.34)(41.1)(12)}{(0.25)(2)(32.17)}= \\
& 603 \mathrm{lbs} / \mathrm{ft}^{2} \text { or } 4.18 \mathrm{lbs} / \mathrm{in}^{2} .
\end{aligned}
$$

The surface coefficient $\left(h_{c}\right)$. for water grooves from the chart by Kern $(6)$ is: 1500 Btus $/(\mathrm{hr})\left(\mathrm{ft}^{2}\right)\left({ }^{\circ} \mathrm{F}\right)$.

From previous calculations on the top cooling plate, the manifold $\Delta p$ would be 2.46 $\mathrm{lbs} / \mathrm{in}^{2}$.

$$
\begin{gathered}
\text { Total } \Delta p=4.95 \mathrm{lbs} / \mathrm{in}^{2}+6.18 \mathrm{lbs} / \mathrm{in}^{2}+4.18 \mathrm{lbs} / \mathrm{in}^{2}+2.46 \mathrm{lbs} / \mathrm{in}^{2}= \\
17.8 \mathrm{lbs} / \mathrm{in}^{2} .
\end{gathered}
$$


Flow Requirements for the First Furnace (see Part 7 "Heat Loss Evaluation for $Y-12$ Development Furnace") - The flow requirements for the first furnace can be calculated from:

$$
\text { , } Q=w C \Delta t \text {. }
$$

Substituting gives:

(8.65)(3413) Btus $/ \mathrm{hr}=3413 \mathrm{lbs} / \mathrm{hr} \times 1 \mathrm{Btu} /(\mathrm{lb})\left({ }^{\circ} \mathrm{F}\right) \Delta \mathrm{t}$, or $\Delta t=8.65^{\circ} \mathrm{F}$. 
THIS PAGE

\section{WAS INTENTIONALLY LEFT BLANK}




\section{REFERENCES}

(1) Timoshenko, S.; Strength of Materials, Part II Advanced Theory and Problems, Third Edition, pp 210, 454; D. Van Nostrand Co.

(2) Seely, Fred B.; Advanced Mechanics of Materials, Second Edition, pp 299, 300, 322; John Wiley and Sons, Inc.

(3) Roark, R. J.; Formulas for Stress and Strain, Third Edition, pp 194, 318; McGrawHill Book Co.

(4) Young, V. W. and Young, G. A.; Elementary Engineering Thermodynamics, Third Edition, p 48; McGraw-Hill Book Co.

(5) Brown, A. I. and Marco, S. M.; Introduction to Heat Transfer, Third Edition, pp 107, 108, 110, and 111; McGraw-Hill Book Co.

(6) Kern, D. W.; Process Heat Transfer, First Edition, p 835; McGraw-Hill Book Co.

(7) Peterson, R.E.; Stress Concentration Design Factors, Third Printing; John Wiley and Sons, Inc. 
THIS PAGE

\section{WAS INTENTIONALLY LEFT BLANK}


PART 5

STRAIN GAGE TEST TO DETERMINE STRESSES AT THE ROOT OF THE INTERNAL THREADS OF CLOSURE ON A THIRTY-INCH PRESSURE VESSEL

P. J. Ross

W. D. Long 
THIS PAGE

\section{WAS INTENTIONALLY LEFT BLANK}




\section{CONTENTS}

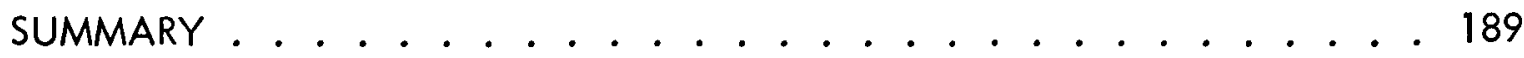

STRAIN GAGE TEST TO DETERMINE STRESSES AT THE ROOT OF THE INTERNAL THREADS OF CLOSURE ON A THIRTY-

INCH PRESSURE VESSEL . . . . . . . . . . 191

Introduction. .................... 191

Discussion .................... 191

Test Criteria . . . . . . . . . . . . . . . . . . . 192

Gage Installation Procedure . . . . . . . . . . . . . . 194

Test Procedure. . . . . . . . . . . . . . . . . . 196 
THIS PAGE

\section{WAS INTENTIONALLY LEFT BLANK}


A thirty-inch-ID isostatic pressure vessel (threaded-closure type) at the $\mathrm{Y}-12$ Plant, Oak Ridge, Tennessee will be modified from a liquid to a gas autoclave system. A strain-gage measurement technique has been developed to determine stress values at various operating pressures on selected internal closure threads. Measurements were performed to gain information needed to determine: (1) the useful operational life of the vessel at various pressure levels; (2) internal stress levels at various pressures; (3) the relationship to photoelastic studies made on models of a vessel of similar design; and (4) the design parameters for proposedalterations to the vessel and facility.

The largest strain reading at an internal pressure of 22,500 psi was 3470 microinches/ inch. Strains were recorded from each gage at the various pressure levels. Reliable readings were obtained on all of the installed gages, and the data obtained can be applied and used toward a better stress analysis of the vessel and in the determination of life expectancy. 
THIS PAGE

\section{WAS INTENTIONALLY LEFT BLANK}




\section{STRAIN GAGE TEST TO DETERMINE STRESSES AT THE ROOT OF THE INTERNAL THREADS OF CLOSURE ON A \\ THIRTY-INCH PRESSURE VESSEL}

\section{INTRODUCTION}

It has been determined that the most critical area of the vessel in question (a thirtyinch-ID pressure vessel) is located in the roots of the wall threads in the lower plug assembly.(a) The application of strain gages and strain-gage techniques to obtain actual readings at these critical locations under load conditions was chosen as the best approach to analyzing stress conditions and the life expectancy of the equipment.(b)

Since the original installation of the vessel there has been a substantial gain in strain-gage technology. This advancement has made available very small strain gages and the special accessories that are necessary for determining the strain in thread-root areas under actual load conditions. Measurements were obtained by utilizing metal film gages, having a gage length of 50 mils and a width of 44 mils, that were secured in the root of the threads with Eastman 910 cement. Gage installation was accomplished by using enameled AWG Size 34 wire which is small enough to fit in the annular clearance between the male and female closure threads. Conventional strain readout instrumentation was used. Results of the test indicate that reliable information can be obtained by this strain-measuring technique provided the installation of the gage and lead wire system is accomplished with exactness.

\section{DISCUSSION}

Physical installation of the strain gages posed a formidable problem. Figure 1A (Page 20) shows that the assembled plug and mushroom do not offer ready access to the area in question. The approach decided on was to use a small strain gage with fine wire leads as required to get a terminal circuit into the chamber immediately above the threads. In this area, larger leads were attached and passed through the bleeder passages, down through the plug, and out the bottom to the indicating equipment. Full advantage was taken of the clearance between the mating threads (see Figure 22). This clearance was slightly greater than 0.10 inch and this fact had a decided bearing on the gage size, number of gages, and wire size to be used. Figure 23 shows the mockup thread ring that was built to help train the technician in the proper installation of the gage and lead wires.

(a) Part 1, "Hazards Pertaining to the Converted Thirty-Inch Pressure Vessel ".

(b) Part 6, "Interpretation on the Expected Fatigue Life of a Thirty-Inch Pressure Vessel with Threaded Closure". 


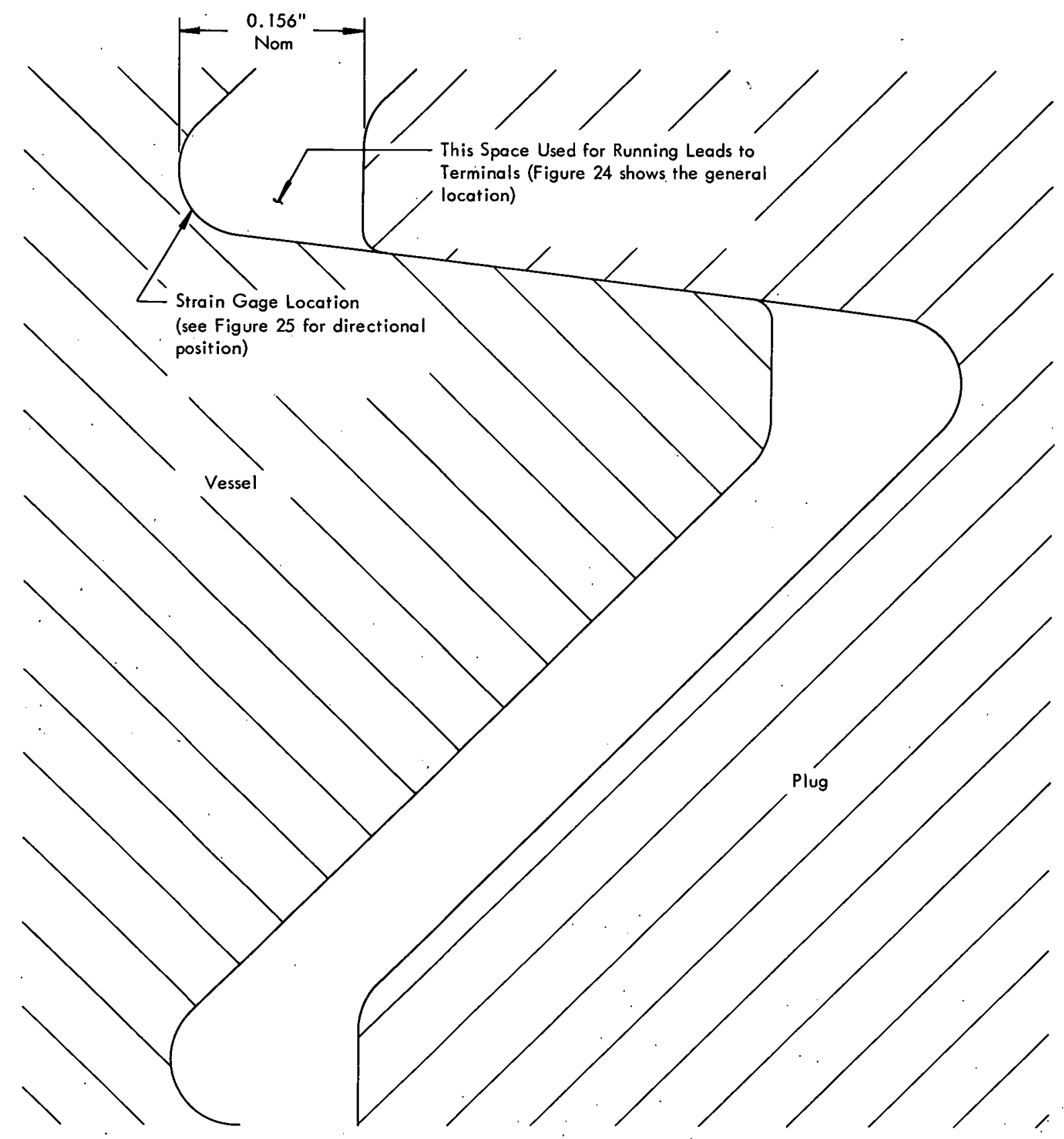

Figure 22. THREAD CROSS SECTION DETAIL.

\section{TEST CRITERIA}

After consultations between Dr. R. G. Sturm, $Y-12$ Engineering personnel, and representatives of the $Y-12$ Physical Testing Department, the following criteria were followed in performing the tests:

1. Because the size of the wire leads was a deciding factor in using up the available space, AWG 34 enameled copper wire was used. 


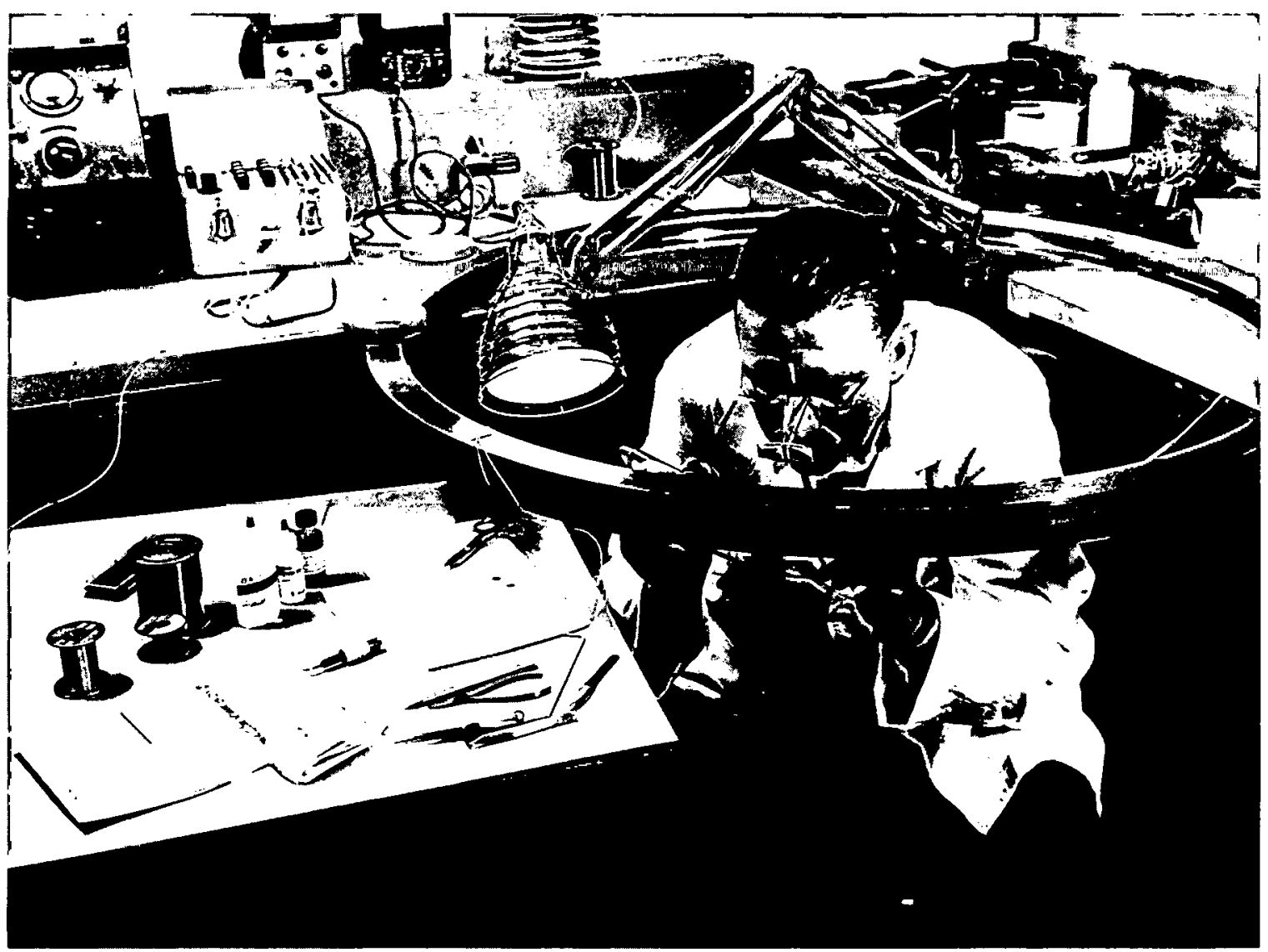

$112415(\mathrm{U})$

Figure 23. WORKING ON THE PRACTICE RING.

2. Due to the diameter of the wire and the fact that the wire was cemented into the root of the threads to make its exit into the cavity above the threads, a maximum of 40 leads were used, allowing a total of 20 gages. This number provided 10 locations for biaxial gages.

3. The gage had a grid length of approximately 50 mils and was as small physically as possible. Here, again, the major consideration was the area available in which to install the gage. A review of the literature on commercially available gages indicated that the Budd C6-1X1-M50 metal film gage was suited for this installation.

4. In order to obtain the most useful information possible, the gages were located in the first three threads of the vessel shell from the top of the threaded area (see Figures $\mathrm{I}(\mathrm{A})$ and 24$)$. It was felt that the first thread was the most critical and there should be five gage locations there. Of the five remaining gage locations, three were located in the second thread and two in the third thread (see Figures 24 and 25 ). 


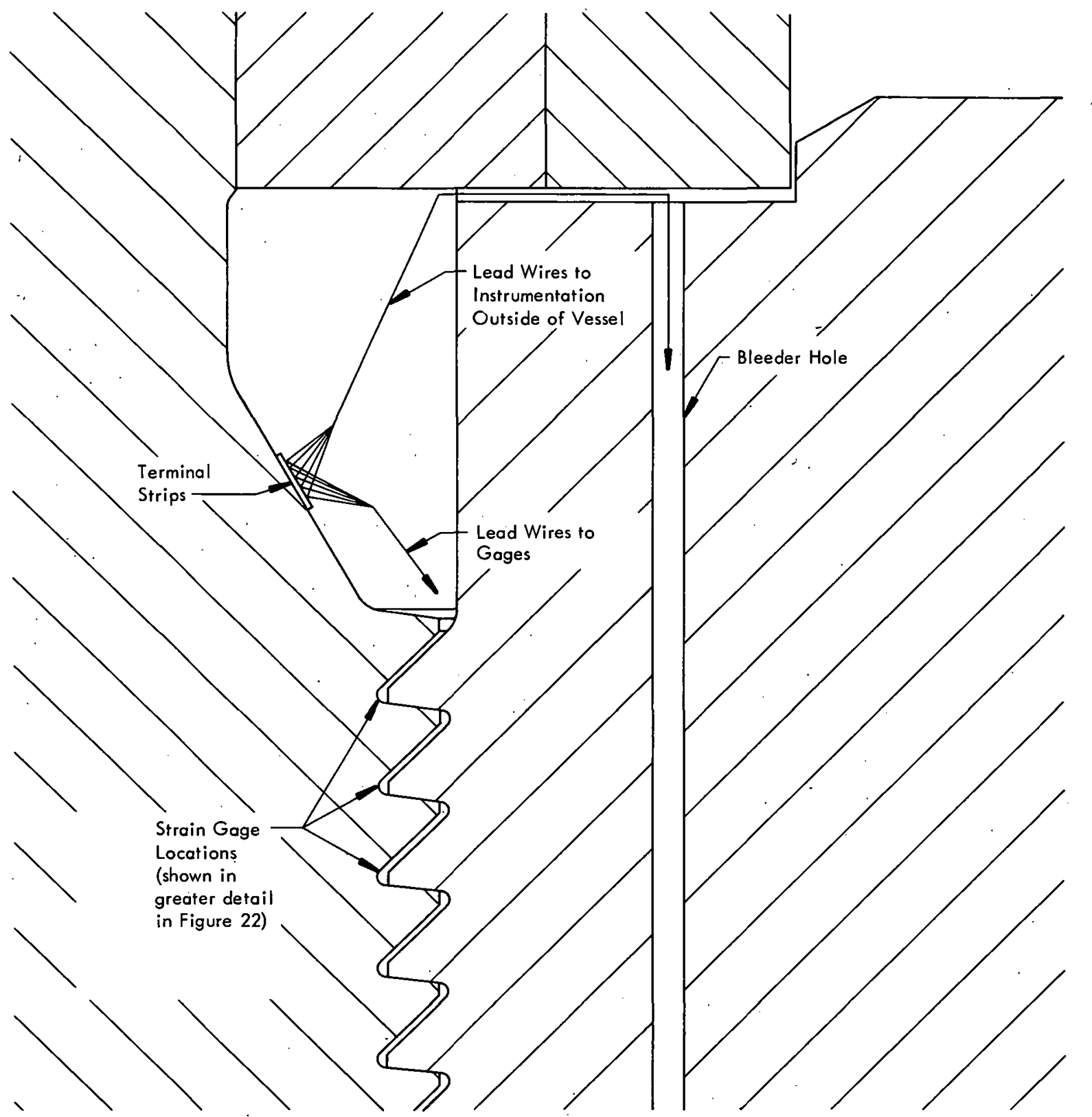

Figure 24. PLUG MATING TO THE END OF THE PRESSURE VESSEL.

\section{GAGE INSTALLATION PROCEDURE}

The following general procedure was observed during the installation of the gages:

1. Gages were cemented in place with Eastman 910 cement.

2. AWG 34 lead wires were attached to the gages. 

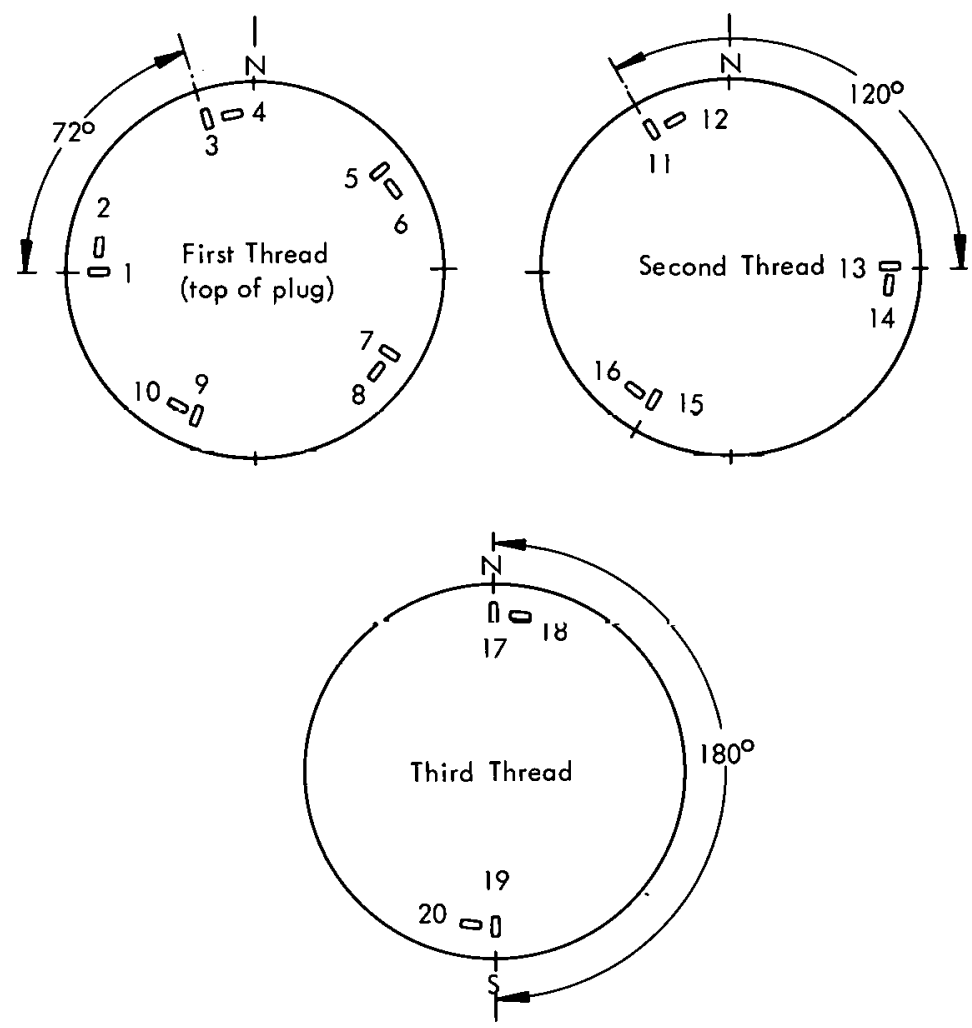

Figure 25. GAGE LOCATIONS IN THE THREE TEST THREADS. (Odd Numbers are Longitudinal Gages; Even Numbers are Circumferential Gages)

3. Lead wires were cemented into the roots of the threads, passing over succeeding gages, and picking up additional leads until all 40 leads made their exit into the cavity above the threads.

4. Leads were attached to terminals mounted in the cavity.

5. AWG 22 lead wire was attached to the terminals and was of sufficient length to reach outside the vessel.

6. The bottom vessel plug was inserted into the vessel until approximately three turns remained before sealing. This position left approximately 4.5 inches of curvily wük space.

7. At this point, external lead wires were wound around the plug in a way that they would unwind into the cavity as the plug was inserted the rest of the way into the vessel. The leads were fed out through the plug by way of the bleeder openings (4 each, 90 degrees apart) and cemented in place.

8. Installation of the plug was completed and the test was started. 
Figures 26 through 29 show details of the gage installation and some of the techniques and instruments that were used.

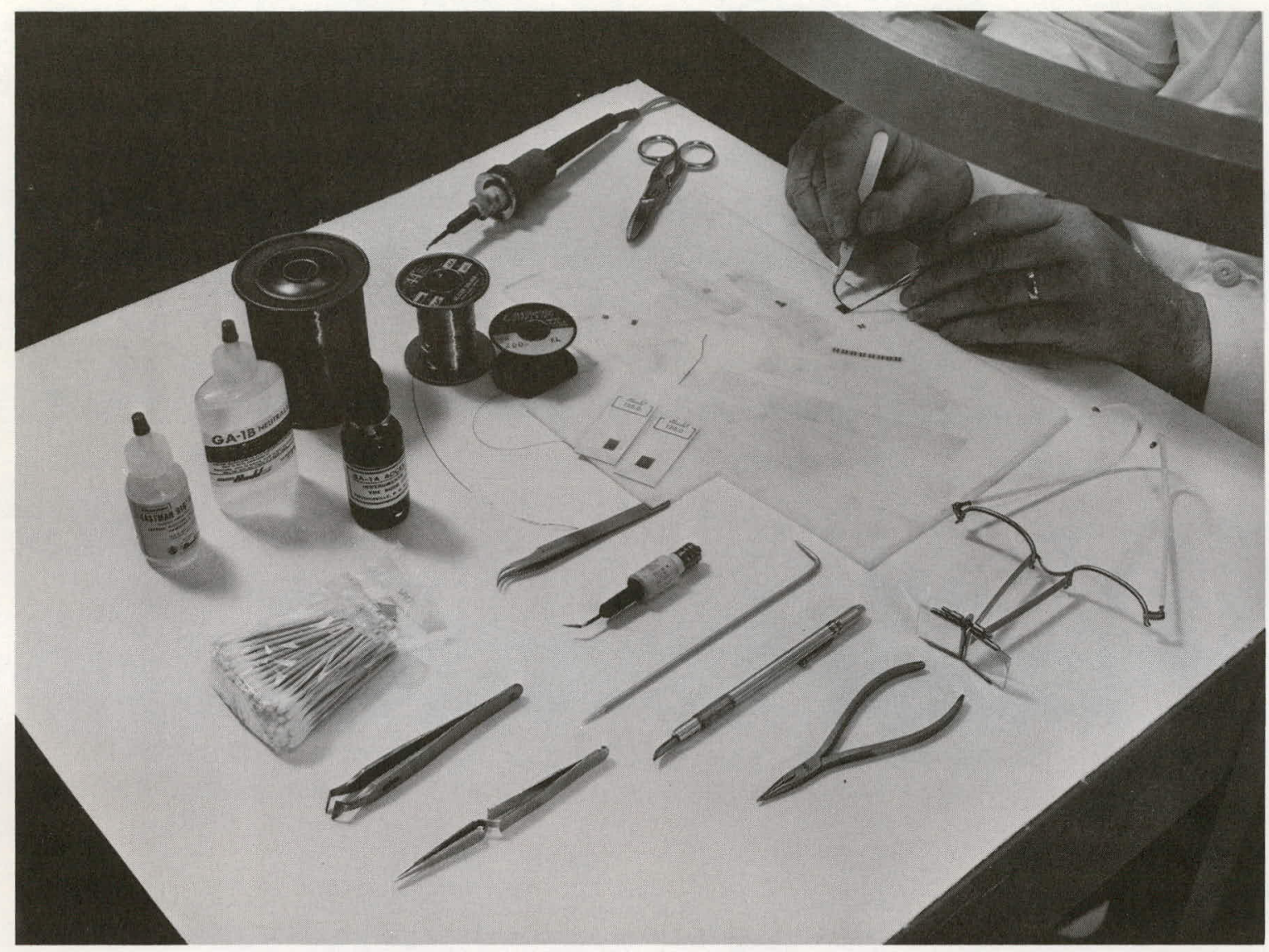

$112414(U)$

Figure 26. TOOLS AND MATERIALS THAT WERE USED FOR GAGE INSTALLATION.

\section{TEST PROCEDURE}

In order to obtain data over a wide pressure range, strain-gage readings were made in connection with the following pressure sequence:

1. Zero strain readings were taken at zero pressure.

2. Readings were taken at $5000 \mathrm{psi}$.

3. Readings were taken at $10,000 \mathrm{psi}$. 


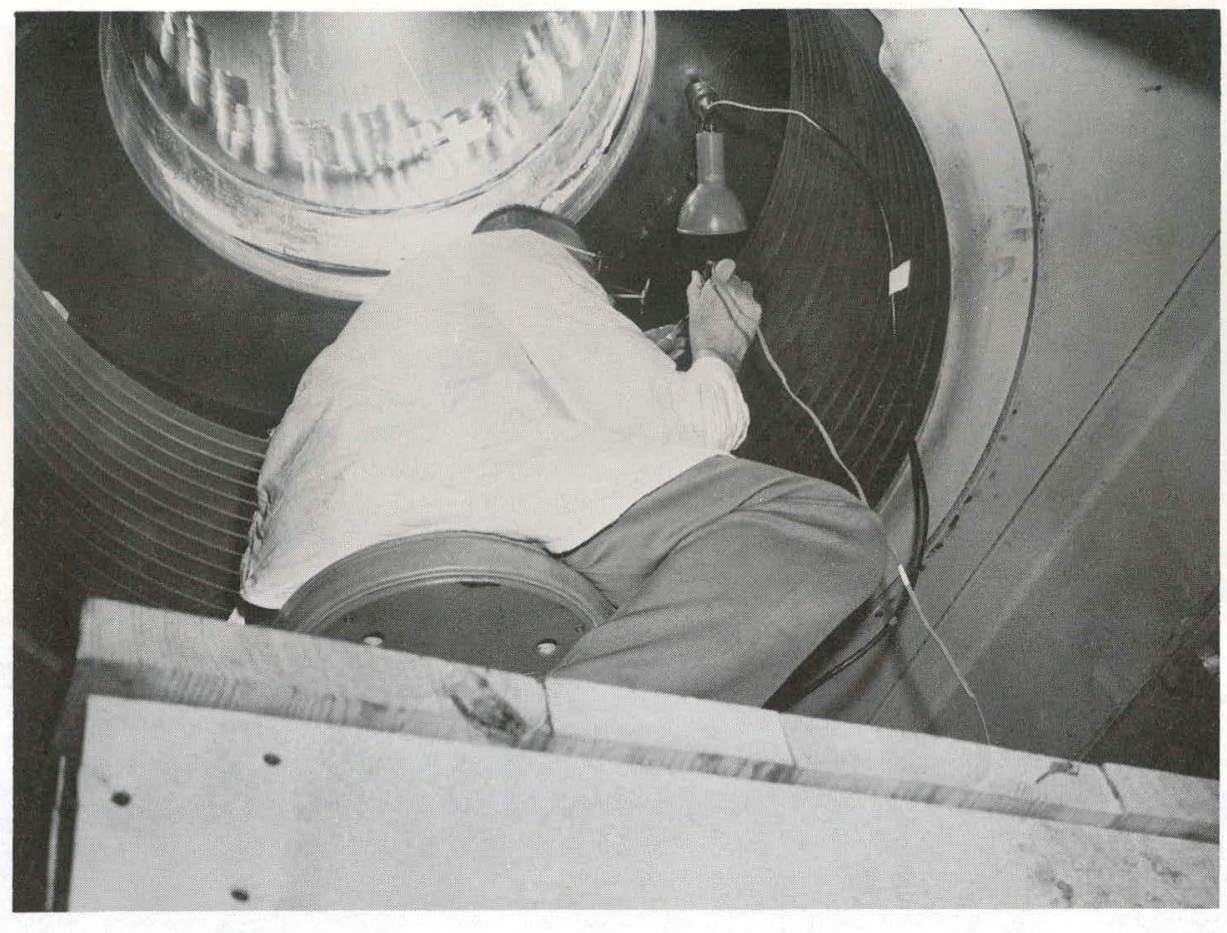

$112410(U)$

Figure 27. INSTALLING A GAGE IN THE PRESSURE VESSEL.

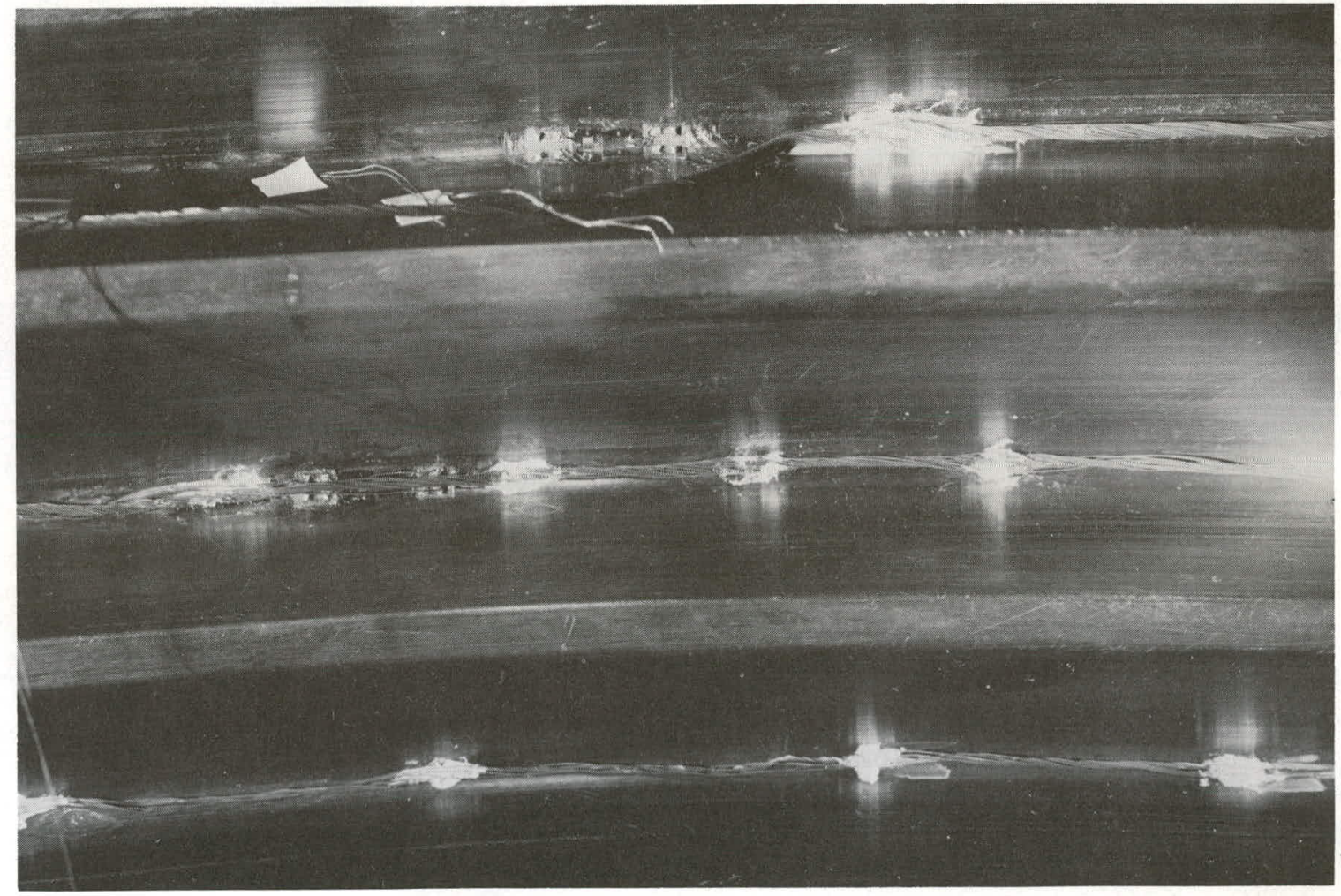

$112411(\mathrm{U})$

Figure 28. TYPICAL LEAD AND GAGE INSTALLATIONS. (View of All Three Threads) 


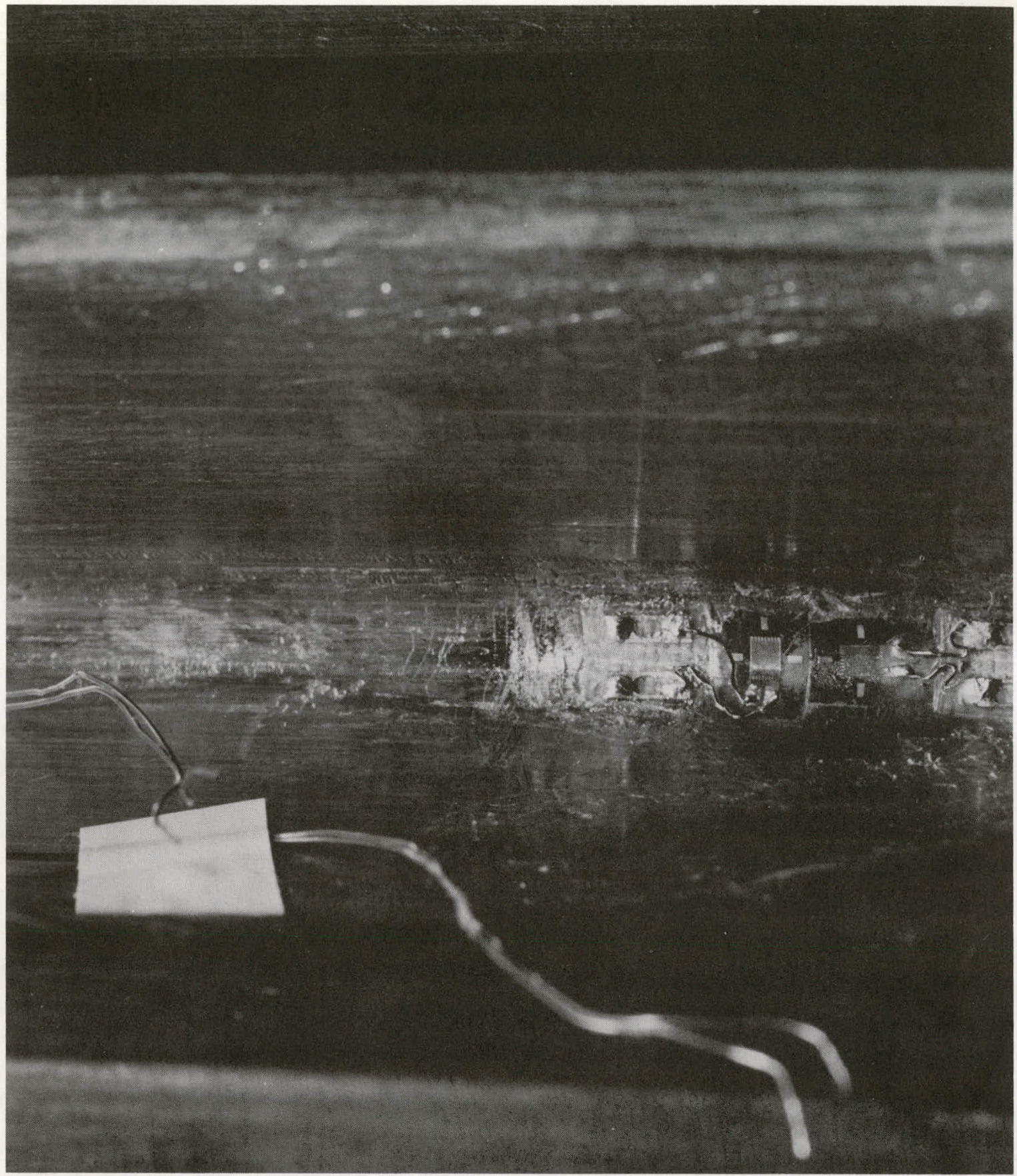

$112412(\mathrm{U})$

Figure 29. ENLARGED VIEW OF AN INSTALLED GAGE JUST PRIOR TO LEAD ATTACHMENT. ( $\sim 4 X)$

4. Again strain readings were taken at zero pressure.

5. Readings were taken at 5,000 and 10,000 psi, and then at every 2,000 psi up through 20,000 psi. Finally readings were taken at 21,000 and 22,500 psi . 
Table 4

RECDRDED STRAIN LEVELS ON THE THIRTY-INCH PRESSURE VESSEL

(A.ll Values are in Microinches/Inch)

\begin{tabular}{|c|c|c|c|c|c|c|c|c|c|c|c|c|c|c|c|c|}
\hline \multirow{2}{*}{\multicolumn{2}{|c|}{$\begin{array}{l}\text { Gage } \\
\text { Number }\end{array}$}} & \multicolumn{14}{|c|}{ Pressure Level (psi) } & \multirow{2}{*}{$\begin{array}{l}\text { Corrected } \\
\text { Maximum }\end{array}$} \\
\hline & & Zero & 5,000 & 10,000 & Zero & 5,000 & 10,000 & 12,000 & 14,000 & 16,000 & 18,000 & 20,000 & 21,000 & 22,500 & $\overline{\text { Zero }}$ & \\
\hline 1 & & 0 & 220 & 480 & 20 & 250 & 470 & 580 & 680 & 760 & 860 & 950 & 1,000 & 1,060 & -10 & 1,250 \\
\hline 2 & & 0 & 10 & 20 & 30 & -20 & 20 & 30 & 30 & 40 & 50 & 50 & 40 & 40 & -10 & 47 \\
\hline 3 & . & 0 & 920 & 1,490 & 10 & 860 & 1,500 & 1,740 & 2,020 & 2,190 & 2,430 & 2,660 & 2,770 & 2,940 & -30 & 3,470 \\
\hline 4 & & 0 & 0 & 20 & 20 & -20 & 10 & 30 & 30 & 40 & 40 & 40 & 50 & 40 & -10 & 47 \\
\hline 5 & & 0 & 510 & 1,080 & 10 & 530 & 1,070 & 1,320 & 1,600 & 1,780 & 2,010 & 2,260 & 2,370 & 2,540 & 0 & 2,995 \\
\hline 6 & & 0 & 10 & 30 & 20 & 0 & 30 & 40 & 50 & 60 & 50 & 60 & 60 & 60 & -10 & 70 \\
\hline 7 & & 0 & 560 & 1,130 & 10 & 590 & 1,130 & 1,400 & 1,710 & 1,870 & 2,110 & 2,380 & 2,500 & 2,670 & -10 & 3,150 \\
\hline 8 & & 0 & 60 & 90 & 70 & 0 & 80 & 90 & 100 & 100 & 110 & 110 & 110 & .110 & 0 & 130 \\
\hline 9 & & 0 & 960 & 1,400 & -10 & 990 & 1,400 & 1,590 & 1,760 & 1,880 & 2,020 & 2,170 & 2,240 & 2,340 & -20 & 2,760 \\
\hline 10 & . & 0 & -20 & 10 & -10 & -10 & 20 & 10 & 20 & 30 & 40 & 40 & 40 & 40 & 0 & 47 \\
\hline 11 & & 0 & -25 & 60 & 0 & -120 & 60 & 170 & 310 & 410 & 530 & 660 & 720 & 820 & 0 & 970 \\
\hline 12 & & 0 & -10 & $30^{-}$ & -10 & 10 & 40 & 40 & 50 & 50 & 60 & 60 & 60 & 70 & 0 & 83 \\
\hline 13 & & 0 & 580 & 840 & -10 & 620 & 860 & 960 & 1,070 & 1,150 & 1,250 & 1,350 & 1,400 & $1,470^{\circ}$ & 0 & 1,735 \\
\hline 14 & & 0 & -10 & 20 & -10 & 10 & 40 & 40 & 50 & 50 & 60 & 60 & 60 & 70 & 0 & 83 \\
\hline 15 & & 0 & -510 & -480 & -10 & 510 & 530 & 560 & 610 & 630 & 660 & 700 & 710 & 740 & -5 & 875 \\
\hline 16 & & 0 & -40 & 20 & -10 & 20 & 30 & 30 & 40 & 40 & 50 & 50 & 50 & 60 & 0 & 70 \\
\hline 17 & & 0 & 450 & 790 & 0 & 470 & 790 & 910 & 1,050 & 1,130 & 1,250 & 1,380 & 1,430 & 1,500 & -10 & 1,770 \\
\hline 18 & & 0 & 20 & 50 & 0 & 20 & 40 & 50 & 50 & 50 & 60 & 70 & 70 & 70 & -10 & 83 \\
\hline 19 & & 0 & 340 & 600 & 0 & 350 & 600 & 710 & 830 & 900 & 1,000 & 1,100 & 1,135 & 1,190 & -10 & 1,400 \\
\hline 20 & & 0 & 0 & 30 & 0 & 0 & 30 & 30 & 40 & 40 & 50 & 50 & 55 & 50 & -10 & 60 \\
\hline
\end{tabular}


6. Zero readings were taken after return to zero pressure.

The pressure-strain gage test was performed with commercially available equipment. Most of the equipment was available in the laboratory and consisted of two Baldwin SR-4-type strain indicators (a Model M and a Model N) and two ten-channel switching and balancing units (a Budd Company Model SW 1 and a Baldwin Model 225).

A check on the calibration of the system was made by installing gages on a standard deflection bar in a manner simulating the conditions encountered in the actual test and also in the normal manner. Table 4 lists the strains that were recorded from eact gage at the various pressure levels. Comparative readings indicated that a correction factor of 1.18 was required for the data taken during the test. 
PART 6

INTERPRETATION ON THE EXPECTED FATIGUE LIFE OF A THIRTY-INCH PRESSURE VESSEL WITH THREADED CLOSURE

H. A. Pohto

R. G. Sturm 
THIS PAGE

\section{WAS INTENTIONALLY LEFT BLANK}




\section{CONTENTS}

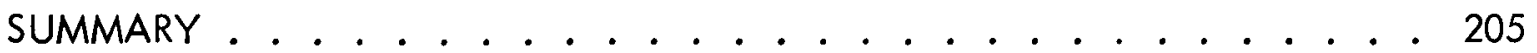

INTERPRETATION ON THE EXPECTED FATIGUE LIFE OF A

THIRTY-INCH PRESSURE VESSEL WITH

THREADED CLOSURE . . . . . . . . . . 207

Introduction. . . . . . . . . . . . . . . 207

Discussion . . . . . . . . . . . . . . . 207

REFERENCES ................. 215 
On the basis of strain-gage data from PV-2 and fatigue data from PV-1, it was determined that $29.9 \%$ of the life of the isostat has been used $-70.1 \%$ remains. At an internal pressure level of 22,500 psi, the life remaining is conservatively 9100 cycles; at 20,000 psi $-22,000$ cycles.

It is contemplated that the bore of the vessel will be modified by adding a liner with an inside diameter of 27.5 inches. The corresponding reduction in end thrust should increase the expected life at the intended normal operating pressure of 20,000 psi to 81,000 cycles, or at a maximum operating pressure of 22,500 psi to 42,000 cycles. 
THIS PAGE

\section{WAS INTENTIONALLY LEFT BLANK}




\section{INTERPRETATION ON THE EXPECTED FATIGUE LIFE OF A THIRTY-INCH PRESSURE VESSEL WITH THREADED CLOSURE}

\section{INTRODUCTION}

The thirty-inch isostat known as PV-2 at the $\mathrm{Y}-12$ Plant, Oak Ridge, Tennessee, is scheduled for further use and may involve hazardous pressures. In view of the fact that PV-1, a nearly identical vessel, failed in 1956 at 30,000 psi at a thread root of the bottom closure, a check of the expected fatigue life was desirable.

With the improvements since 1956 in the state of the art of stress analysis by straingage techniques, it was decided to use strain gages for finding the stresses in the root of the internal threads of the bottom closure of this pressure vessel. This report deals with the analysis of these findings and interpreting the expected fatigue life of this isostat.

\section{DISCUSSION}

Photoelastic analysis $(1,2)$ of the threads in the outer shell indicates that stresses slightly higher than 100,000 psi at the root of the first or second thread would result from an internal pressure of $22,500 \mathrm{psi}$. However, in view of the fact that the photoelastic studies were obtained on small plastic models and that three-dimensional photoelasticity methods cannot be assured to give results in general closer than $\pm 10 \%$, there was hope that the indicated stresses might be high.

In view of the fatigue data presented in the reports on $P V-1$, a very short life in terms of cycles may be expected at pressures producing over 100,000 psi tensile stress change at the root of the first thread or two in the outer shell at the bottom plug. While the test specimens were cut from vessel PV-1, the results are applicable for PV-2 because the material specifications were the same and the physical properties obtained from materials from both vessels are practically the same.

The photoelastic considerations emphasized the desirability of knowing more precisely the relation between the internal pressure and the maximum tensile stress change at the root of the threads. Consequently, bonded film strain gages were used to measure the stresses at the root of the first few threads at a series of internal pressures.

- The report of strain-gage tests by Long and Ross (3) describes the details of the test that was made on PV-2. For purposes of this report, the strains for one location (the location of greatest measured strains) are plotted in Figure 30. The strains plotted are those read on Longitudinal Gage 3 and on the corresponding Circumferential Gage 4. As could be expected, the circumferential strains were practically zero. 


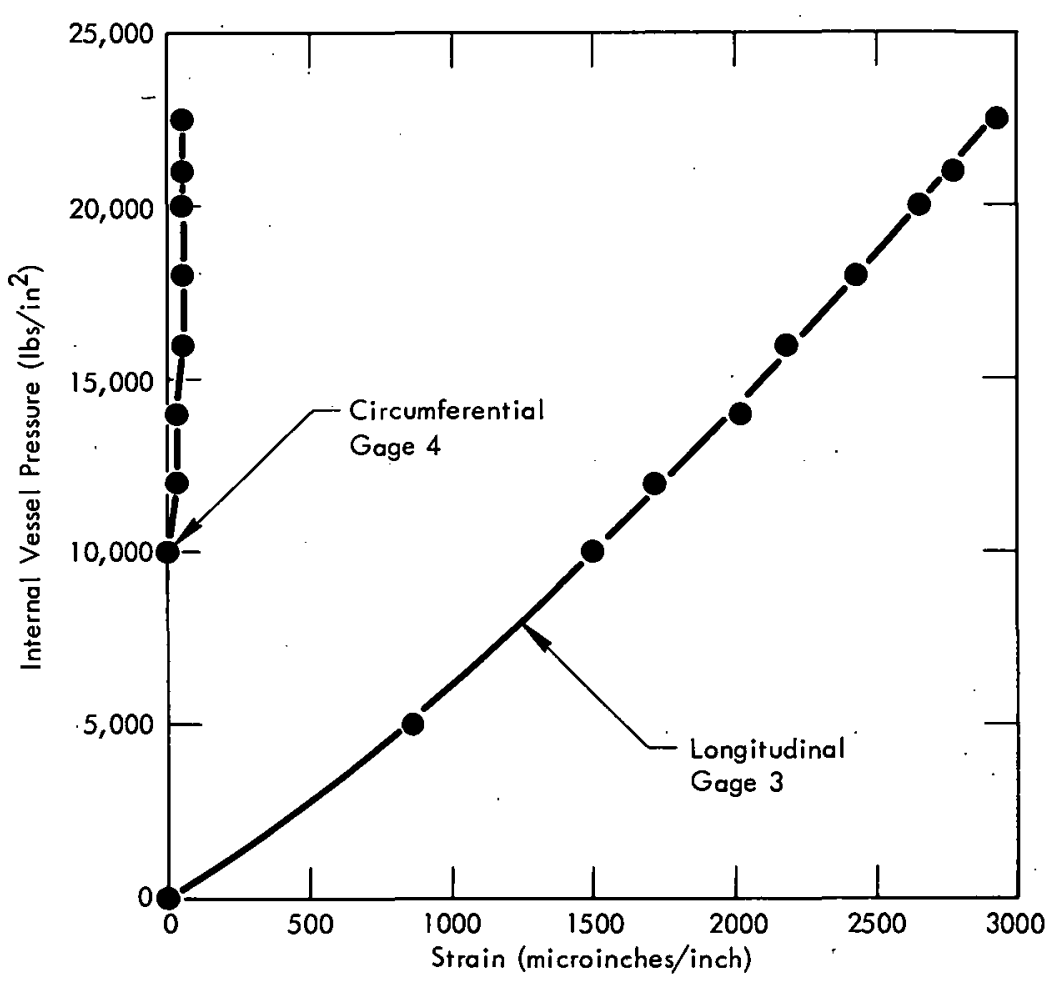

Figure 30. STRAINS AT THE BASE OF THE FIRST THREAD. (Lower Plug of Pressure Vessel 2)

The slight curvature at the foot of the curve for longitudinal strain is construed to indicate that as deformations took place, minute adjustments in the distribution of stress along the thread-as well as between threads-resulted. It is concluded, therefore, that strains, as measured, are real without any adjustment in values for zero shift. This conclusion is substantiated by the fact that the final zero readings were almost identical with the original zero readings.

There are, however, two small corrections to be applied to all readings. One is a correction for the "gage factor", and the other is for the very fine wire leads necessary for this test. As explained in the Long-Ross report, the corrected strains are 1.18 times the measured strains.

For Gage Lines 3 and 4, the corrected strains are:

$$
\Sigma_{L}=1.18 \times 2950=3400 \text { microinches per inch, }
$$

and

$$
\Sigma_{c}=1.18 \times 45=53 \text { microinches per inch, }
$$

where: 
$\Sigma_{L}$ is the longitudinal strain, and

$\Sigma_{c}$ is the circumferential strain.

The relations between stresses and strains in a biaxial state of stress are:

$$
\begin{aligned}
& S_{L}=\frac{E}{1-\mu^{2}}\left[\Sigma_{L}+\mu \Sigma_{c}\right] \ldots, \text { and } \\
& S_{C}=\frac{E}{1-\mu^{2}}\left[\Sigma_{c}+\mu \Sigma_{L}\right] \ldots,
\end{aligned}
$$

where:

$S_{L}$ represents the longitudinal stress,

$S_{c}$ represents the circumferential stress,

$E$ is the modulus of elasticity. $\left(30 \times 10^{6} \mathrm{psi}\right)$, and

$\mu \quad$ is Poisson's ratio $(0.30)$.

From these equations and the values of strain, it follows that:

$$
S_{L}=112,700 \text { psi tension, }
$$

and

$$
S_{c}=35,400 \text { psi tension. }
$$

It is emphasized that these are the changes in stress caused by the application of load. Locked-in stresses such as those caused by local plastic deformations must be considered along with the measured changes in stress.

The uniaxial stress equivalent to the biaxial state of stress may be found through the octohedronal shear stress invariant. (4) This is accomplished by equating the octohedronal shear stress invariant for the biaxial state of stress to the invariant for the uniaxial stress.

The octohedronal shear stress invariant for any state of stress is:

$$
\tau_{0}=\frac{1}{3} \sqrt{\left(\sigma_{1}-\sigma_{2}\right)^{2}+\left(\sigma_{1}-\sigma_{3}\right)^{2}+\left(\sigma_{2}-\sigma_{3}\right)^{2}} \ldots \text {, }
$$


where:

$$
\begin{array}{ll}
\tau_{0} & \text { represents the octohedronal shear stress, and } \\
\sigma_{1}, \sigma_{2} \text { and } \sigma_{3} & \begin{array}{l}
\text { are the principal stresses for the particular state of stress con- } \\
\text { sidered. }
\end{array}
\end{array}
$$

For an uniaxial stress, $\sigma$, either tension or compression, the principal stresses are (where $\sigma$ is the applied stress; $\sigma_{\cdot 1}=\sigma_{2} ;$ and $\sigma_{2}=\sigma_{3}=0$ ):

$$
\tau_{0}=\frac{\sqrt{2}}{3} \sigma=0.47 \sigma \ldots .
$$

For a state of plane strain, $(5)$ such as was found to exist at the root of the thread, the principal stresses are (where $\sigma_{1}=\sigma_{p} ; \sigma_{2}=\mu \sigma_{p} ;$ and $\sigma_{3}=0$ ):

$$
\tau_{0}=\sigma_{p} \frac{\sqrt{2}}{3} \sqrt{1-\mu+\mu^{2}}=0.42 \sigma_{p} \ldots \text {. }
$$

where:

$\sigma_{p}$ is the measured stress from the applied load.

Equating the value of $\tau_{0}$ from Equation 4 to that from Equation 5 gives:

$$
\begin{aligned}
& 0.47 \sigma=0.42 \sigma_{p^{\prime}} \text { or } \\
& \sigma_{p}=1.12 \sigma_{,} \text {or } \\
& \sigma=0.89 \sigma_{p} .
\end{aligned}
$$

In other words, for the restrained condition of plane strain for which the applied stress is $\sigma_{p}$, the equivalent uniaxial stress is only $0.89 \sigma_{p}$. It is this equivalent uniaxial stress that permits the comparison with fatigue data from simple round specimens. Surface conditions, however, may have a much greater effect than the state of stress for the particular problem at hand.

The fatigue strength of the material in PV-1 (which material has the same specification as the material in $P V-2$ ) was reported by the manufacturer and was included in the final report on $P V-1$. A confirmation of the tests on smooth specimens was obtained. Figure 31 shows a log-log plot of these data. 


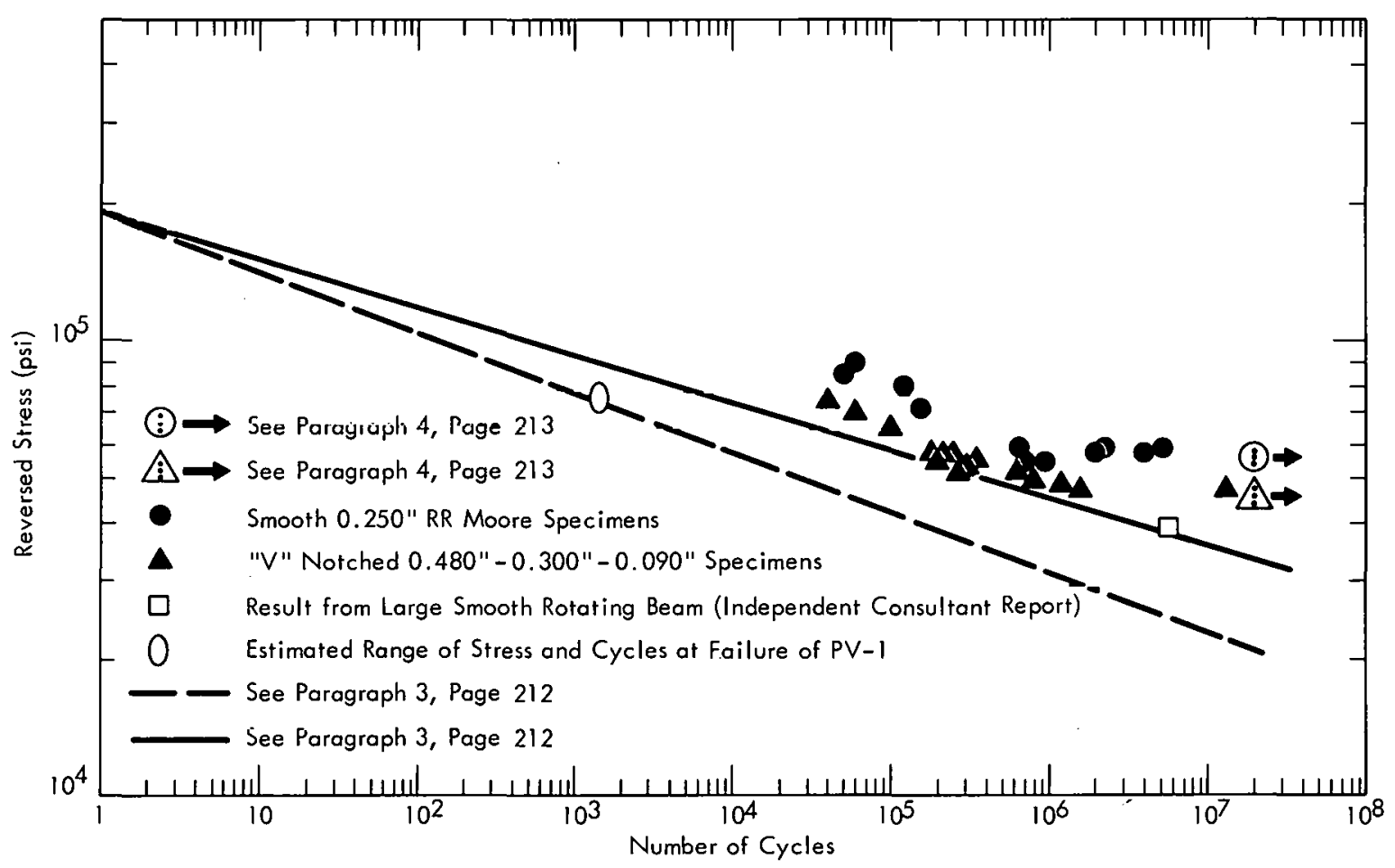

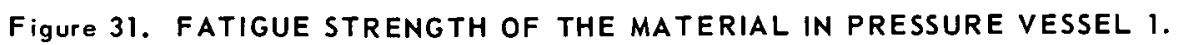

These data were obtained from rotating-beam fatigue testing machines. Under such test conditions, the total range of stress change is double the value in tension since the rotation of the loaded beam causes the stress to change from a tension to an equal compression each cycle. Attention is also called to the fact that the specimens tested were carefully machined, ground, and polished as is the custom for such tests. (a)

During the initial operation of the vessel at 30,000 psi internal pressure, the stress changes at the root of the threads would be on the order of the yield strength which would cause some plastic yielding. Such plastic yielding would gradually decrease as cycling proceeded; not because the stresses were less, but because the material

(a) The roots of the threads in the actual vessels were carefully machined, but were not ground and polished. A careful inspection with a magnifying glass revealed that tool marks were visible, and a tendency for an "orange peel "surface showed in the root areas of the first few threads. Such "orange peel" surface is usually caused by plastic deformation. At test pressures, the indicated stresses at the roots of the threads would cause considerable, but sharply localized, yielding. Subsequent release of the load would cause the massive surrounding material to force the localized yielded material to yield in the opposite direction to maintain the geometry. If the material would not yield, it would spall and crackwhich it did not do. 
would strain harden. The stress changes indicated by the strain gage measurements would be about 150,000 psi at a 30,000-psi applied pressure. Because of the gradual diminishing of the yielding it may be assumed that the actual stress range finally was approximately $+75,000$ psi to $-75,000$ psi; that is, a locked-in stress of about 75,000 psi.

The triangular point plots in Figure 31 represent the results from notched specimens subjected to a reversal of stress. This condition reasonably represents the conditions at the root of the threads except that the notches in the specimens would be smoother than the roots of the threads. Also, the state of stress at the root of the notcheswould be "plane strain" stresses, the same as for the root of the threads in the actual vessel. In this case, the octohedronal shear stresses are automatically the same.

Since the fatigue data were obtained at stresses below the nominal yield strength of the material, and the maximum stresses in the threads of the vessel were for a number of cycles in excess of the nominal yield strength, it will be necessary to extrapolate the fatigue-data to higher stresses. This step may be performed on a log-log plot by constructing a line for specimen failure as passing through the true strength at one cycle and asymptotic to the lower limit of the grouping of data points.

The true strength at fracture for any material is the load at fracture divided by the net area at fracture. From the usual tensile test data, this can be approximated by. multiplying the nominal tensile strength by a factor as follows:

$$
S_{\text {tu }}=S_{U} \frac{1}{1-0.8 R A^{\prime}}
$$

where:

$$
\begin{aligned}
& S_{\text {tu }} \text { is the true ultimate strength, } \\
& S_{U} \text { is the nominal ultimate strength, and } \\
& \text { RA represents the nominal reduction in area. }
\end{aligned}
$$

For the material under consideration, the longitudinal properties of the material may be averaged as:

$$
\begin{aligned}
Y S & =97,000 \text { psi, } \\
S_{U} & =116,000 \text { psi, and } \\
R A & =47 \% .
\end{aligned}
$$


On the basis of these values, the true ultimate strength of the material is:

$$
S_{\text {tu }}=116,000 \times \frac{1}{1-0.8 \times 0.47}=\frac{116,000}{0.624}=186,000 \text { psi. }
$$

This increase of true strength over nominal strength is consistent with the results of research in this field. (6)

In Figure 31 the true strength is plotted for one cycle and the corresponding lines drawn.

The solid line of Figure 31 represents the data and the dotted line the expected envelope for the material in the roots of the threads. A factor of 0.70 at $10^{6}$ cycles is used to account for the surface of the material at the root of the threads. (7)

For comparison purposes the stress in the root of the first thread for $\mathrm{PV}-1$ is plotted at 1500 cycles of 30,000 psi internal pressure. While no specific value of stress cycle was determined for $P V-1$, a range of $\pm 70,000$ to 80,000 psi apparently exists. This range is shown as the large oval in Figure 31 and falls between the two curves, indicating that the dotted line might be somewhat conservative.

The load life record of PV-2 up to date is given in Table 5.

Table 5

LOAD LIFE OF PRESSURE VESSEL-2

(To July' I, 1964)

\begin{tabular}{rccc}
$\begin{array}{c}\text { Number of } \\
\text { Cycles }\end{array}$ & $\begin{array}{c}\text { Pressure } \\
\left(\text { psi } \times 10^{-3}\right)\end{array}$ & $\begin{array}{c}\text { Estimate of Stress } \\
\left(\text { psi } \times 10^{-3}\right)\end{array}$ & $\begin{array}{c}\text { Equivalent Reversed Stress } \\
(p s i \times 10-3)\end{array}$ \\
\hline 1 & $45.0($ test $)$ & +110 to $-110><(1)$ & 110 \\
180 & 20.0 & +75 to -75 & 75 \\
1 & 28.5 & +70 to -75 & 72 \\
229 & 25.0 & +50 to -75 & 62 \\
22 & 23.5 & +43 to -75 & 59 \\
1551 & 22.5 & +37 to -75 & 56 \\
2 & 15.0 & -0 to -75 & 38 \\
1 & 11.0 & -47 to -75 & - \\
2 & 10.0 & -50 to -75 & - \\
1 & 6.0 & -60 to -75 & - \\
5 & 3.0 & -67 to -75 & -1 significant
\end{tabular}

(1) $><$ variable for first few cycles.

The cumulative fatigue damage may be determined as the sum of the percentages of available life used up for each stresslevel to which the material is subjected. Table $\sigma$ gives the equival cnt reversed stress, the number of cycles applied, the fatigue life at that stress, and the percent damage for the service life of PV-2. 
Table 6

DATA TO DETERMINE CUMULATIVE FATIGUE DAMAGE ON PRESSURE VESSEL-2

\begin{tabular}{crrr}
\hline $\begin{array}{c}\text { Equivalent Reversed Stress } \\
\text { (psi) }\end{array}$ & \multicolumn{2}{c}{ Number of Cycles } & \\
\cline { 2 - 4 } 110,000 & In Service & In Life & Percent Damage \\
75,000 & 1 & 70 & 1.4 \\
72,000 & 180 & 1,400 & 12.8 \\
62,000 & 1 & 1,900 & 0.1 \\
59,000 & 229 & 6,300 & 3.6 \\
56,000 & 22 & 9,000 & 0.2 \\
38,000 & 1551 & 13,000 & 11.9 \\
& 2 & 200,000 & 0.0 \\
\hline
\end{tabular}

Thus, $29.9 \%$ of the life of this vessel is indicated to be used. This leaves $70.1 \%$ remaining.

At a stress level of $\pm 56,000$ psi, the life is conservatively 13,000 cycles. Thus, the life still remaining for safe operation at $\pm 56,000$ psi or a stress change of $112,0.00$ psi corresponding to an internal pressure or 22,500 psi would be 9100 cycles $(70 \%$ of 13,000 cycles).

If the internal pressure is limited to 20,000 psi, the stress range will be 101,000 psi or an equivalent reversed stress of $\pm 50,000$ psi. The total life at $\pm 50,000$ psi is 32,000 cycles. Thus, 22,000 cycles remain ( $70 \%$ of 32,000 cycles).

It is contemplated that the modified bore of the vessel with an additional liner installed will be only 27.5 inches ID. The corresponding end thrust to be carried for a given internal pressure on the modified vessel will be $(27.5)^{2} /(30.0)^{2}=0.84$ times the end thrust for the original vessel at the same internal pressure. In such case, the maximum stress change at the root of the threads for 20,000 psi is 84,000 psi or an equivalent reversed stress of $\pm 42,000 \mathrm{psi}$. The estimated life of the material at $\pm 42,000$ psi is 115,000 cycles. The residual life of $P V-2$, as modified, is expected to be $70 \%$ of 115,000 or 81,000 cycles. At a 22,500 -psi internal pressure, the estimated life is 60,000 cycles, and the residual life $-42,000$ cycles. 


\section{REFERENCES}

(1) Report of Auburn Research Foundation, Oak Ridge Photoelasticity Studies; February $8,1958$.

(2) Letter Report from Timkin Roller Bearing Company; August 28, 1956.

(3) Long, P. J. and Ross, W. D.; Strain Gage Test at the Threaded Closure on a Thirty-Inch Pressure Vessel; Y-1471, Union Carbide Corporation-Nuclear Division, Y-12 Plant, Oak Ridge, Tennessee; November 20, 1964.

(4) Nadai, A.; Theory of Flow and Fracture of Solids, I, p 103; McGraw Hill Book Company (1950).

(5) Southwell, R. V.; Theory of Elasticity; p 366; Oxford Press (1936).

(6) Nadai, A.; op cit, p 76.

(7) Metals Engineering Design, p 100 et sequa; McGraw Hill Book Company (1953). 
THIS PAGE

\section{WAS INTENTIONALLY LEFT BLANK}


PART 7

HEAT LOSS EVALUATION FOR Y-I2 DEVELOPMENT FURNACE

W. R. Gambill 
THIS PAGE

\section{WAS INTENTIONALLY LEFT BLANK}




\section{CONTENTS}

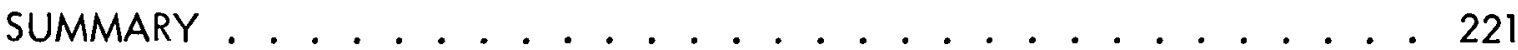

HEAT LOSS EVALUATION FOR Y-12 DEVELOPMENT FURNACE . . . . . 223

Introduction. . . . . . . . . . . . . . . . 223

Physical Properties. . . . . . . . . . . . . . . . 224

Solids. . . . . . . . . . . . . . . . 224

Gas ................... . . 225

Heat Flow Calculations. . . . . . . . . . . . . . . . . 227

Heat Flow Vertically Upward. . . . . . . . . . . . . . . . 229

Heat Flow Vertically Downward . . . . . . . . . . . . . 230

Heat Flow Radially Outward . . . . . . . . . . . . . . 230

Symbols . . . . . . . . . . . . . . . . . 235

Subscripts . . . . . . . . . . . . 236

REFERENCES ................... 237 
THIS PAGE

\section{WAS INTENTIONALLY LEFT BLANK}


The effectiveness of a furnace insulation system, designed for Pressure Vessel 2, has been determined. Numerical results were obtained for heater and heat-sink temperatures of 3000 and $40^{\circ} \mathrm{F}$, respectively.

It appears that the top and bottom coils providing $10 \mathrm{kw}$ each and a cylindrical coil rated at $100 \mathrm{kw}$ (all at a $3000^{\circ} \mathrm{F}$ operating temperature) would be more than adequate for steady-state operation. 
THIS PAGE

\section{WAS INTENTIONALLY LEFT BLANK}




\section{HEAT LOSS EVALUATION FOR Y-12 DEVELOPMENT FURNACE}

\section{INTRODUCTION}

The proposed design for the furnace is shown schematically in Figure 32. The geometry is cylindrical and the vertical limits of the furnace proper are indicated by Planes 1 and 2. A heat sink is provided by water coolant flowing in semicircular channels in the pressure vessel wall. The heater coils will be located $\sim 1 / 2$ inch from the inside surfaces of the alumina insulation. The spacing between adjacent alumina blocks will nominally be 0.160 inch in most cases, consisting of 0.060 inch of molybdenum canning plate and 0.100 inch of high-purity argon at a pressure of 20,000 psia.

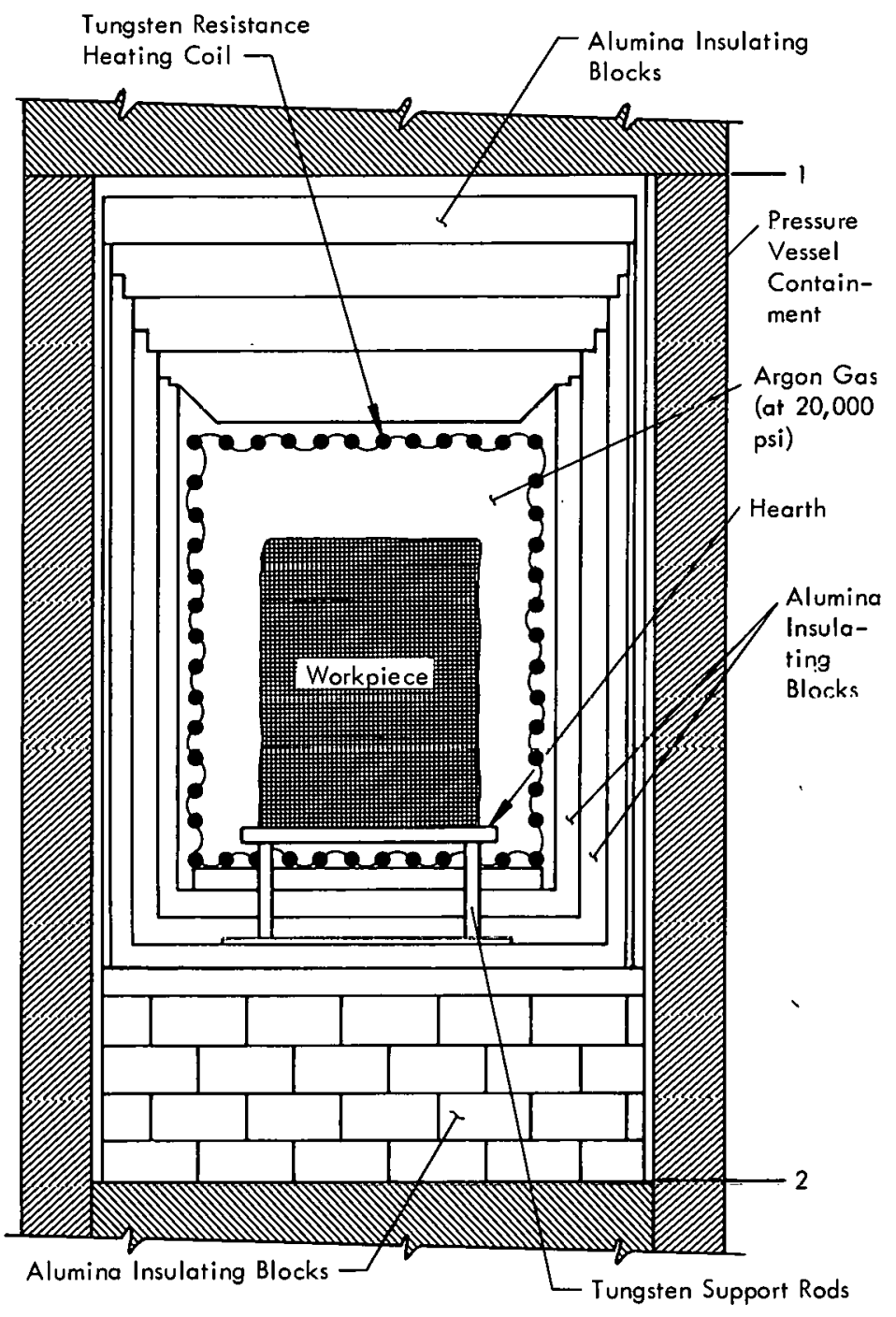

Figure 32. DEVELOPMENT ELECTRIC FURNACE. 
This report provides, for the record, an outline of the heat-loss calculations for a central-cavity argon temperature of $1500^{\circ} \mathrm{C}\left(2732^{\circ} \mathrm{F}\right)$.

\section{PHYSICAL PROPERTIES}

\section{Solids}

Pertinent physical properties of the dense alumina to be used were obtained from published sources $(1-3)$ and are plotted as a function of temperature in Figure 33. The density of the alumina is $\sim 3.8 \mathrm{gms} / \mathrm{cc}$ and the melting point, $\sim 3700^{\circ} \mathrm{F}$. The electrical resistivity at $2780^{\circ} \mathrm{F}$ is $\sim 300 \mathrm{ohm}-\mathrm{cm},(1)$ and the total linear thermal expansion at $2780^{\circ} \mathrm{F}$ with respect to room temperature is $\sim 1.50 \%$. (1)

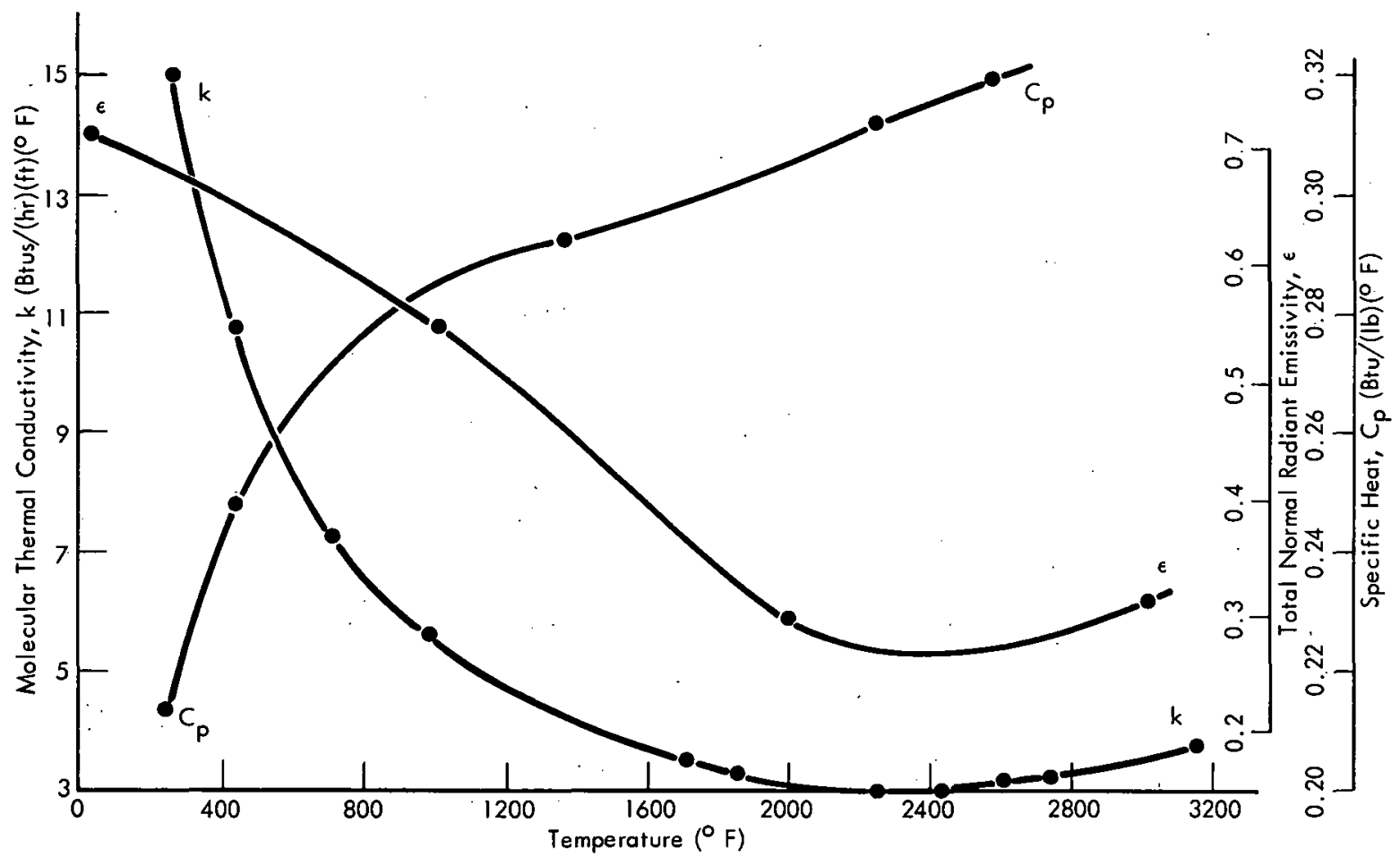

Figure 33. THERMAL PROPERTIES OF DENSE ALUMINA.

A radiant emissivity of 0.40 was taken for the tungsten heater and a value of 0.35 was used for the molybdenum canning plates. (1) If stainless steel is substituted for molybdenum in the lower-temperature regions, the radiant heat transmission will be reduced below that calculated since the emissivity of clean stainless steel is $\sim 2 / 3$ that of molybdenum.

Published emissivities for these solids are not in good agreement, but it is felt that the values chosen are conservatively characteristic of the materials to be used. 
$\underline{\text { Gas }}$

The critical pressure, temperature, and volume for argon are $48.0 \mathrm{~atm}$ abs, $151^{\circ} \mathrm{K}$, and $0.0302 \mathrm{ft} 3 / \mathrm{lb}$, respectively. The low-pressure heat capacity is essentially independent of temperature ${ }^{(4)}$ between 300 and $3000^{\circ} \mathrm{K}$ at $4.97 \mathrm{Btu} / \mathrm{lb}-\mathrm{mol}$. $\circ \mathrm{R}$, and examination of generalized correlations of the effect of pressure on heat capacity indicates a negligible pressure dependence. A constant value for the specific heat, $C_{p}$, of $0.125 \mathrm{Btu} / \mathrm{lb}$. O F was therefore used.

The density of argon at 20,000 psia was calculated using the Lydersen-chart compressibility factors, $(5)$ with the following results: (a)

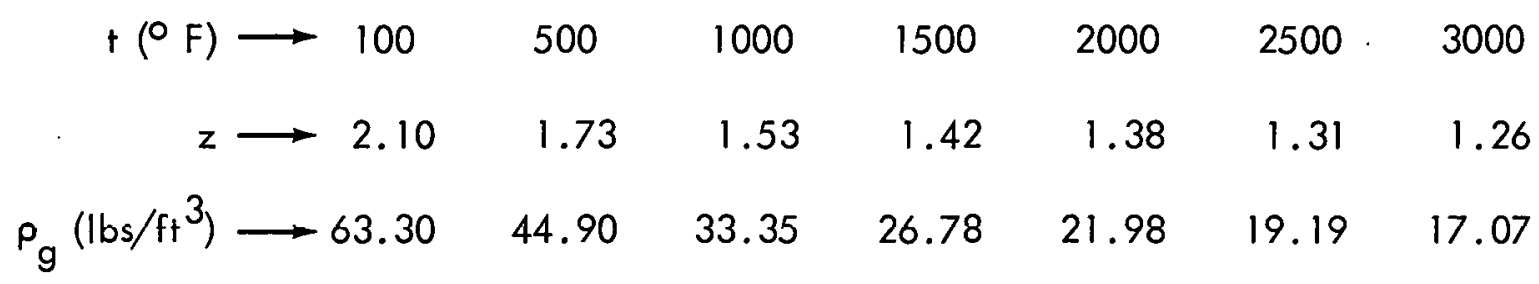

The volumetric coefficient of thermal expansion, $\beta$, which is needed for natural-convection, heat-transfer calculations, is defined by:

$$
\beta=\frac{1}{V}\left(\frac{\partial V}{\partial T}\right)_{P},
$$

and may be calculated from the plotted density curve with a finite-difference form of Equation 1:

$$
\beta=\frac{\rho_{1}{ }^{2}-\rho_{2}{ }^{2}}{2\left(t_{2}-t_{1}\right) \rho_{1} \rho_{2}},
$$

in which $\beta$ is the average coefficient for the indicated temperature range $t_{1}$ to $t_{2}$.

The thermal conductivity of argon was derived from the paper on generalized conductivities of the inert gases by Owens and Thodos. (6)

The low-pressure viscosity of argon was selected from the tables of the Thermophysical Properties Research Center at Purdue $(7)$ and was corrected for pressure with the graphical correlation of Ross and Brown, $(8)$ which extends to reduced temperatures of 100 and reduced pressures of 1000. The decreasing influence of pressure on $\mu$ with increasing temperature resulted in an almost flat viscosity curve, as shown in

(a) A list of symbols is given on Page 235 and applies throughout this report part. 
Figure 34, on which is also plotted the variation with temperature of the other properties.

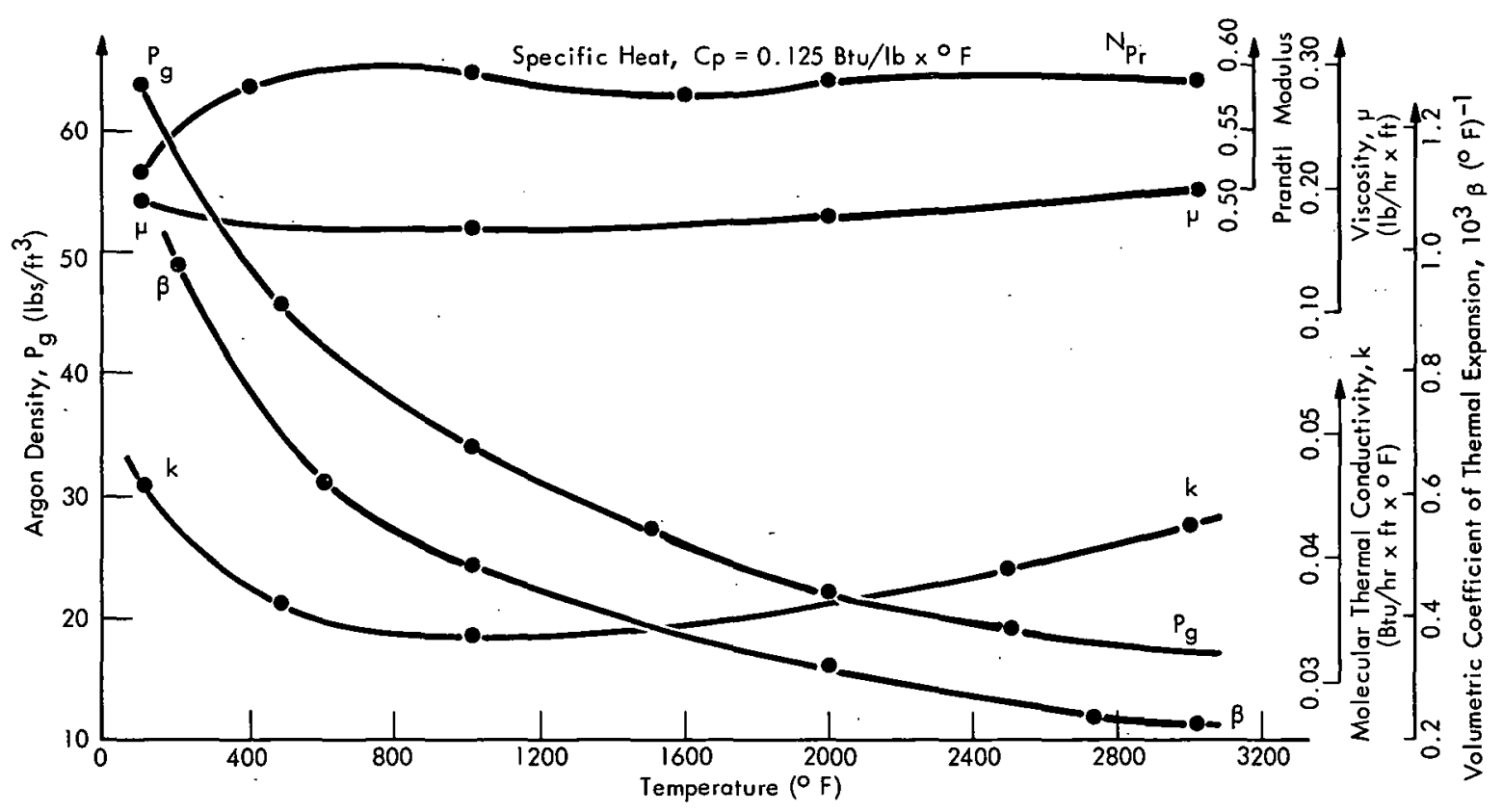

Figure 34. ESTIMATED PROPERTIES OF PURE ARGON AT 20,000 PSIA.

The Prandtl number, $C_{p} \mu / k$; was calculated from the previously determined values of specific heat, viscosity, and thermal conductivity.

The following approximations, which were used in the first trials of the iterative heat-transfer calculation, may be noted: 


$$
\begin{aligned}
& \mu=0.177 \mathrm{lb} / \mathrm{hr} \cdot \mathrm{ft} \text { for } 0<t<3200^{\circ} \mathrm{F}( \pm 14 \%), \\
& k=0.038 \mathrm{Btu} / \mathrm{hr} \cdot \mathrm{ft} \cdot{ }^{\circ} \mathrm{F} \text { for } 200<t<3200^{\circ} \mathrm{F}( \pm 13 \%), \\
& \beta \quad=0.73 / \mathrm{T}\left({ }^{\circ} \mathrm{R}^{-1}\right) \text { for } 200<t<3000^{\circ} \mathrm{F}( \pm 11 \%) \text {, and } \\
& N_{\operatorname{Pr}}=0.58 \text { for } 350<t<3200^{\circ} \mathrm{F}( \pm 2 \%) .
\end{aligned}
$$

\section{HEAT FLOW CALCULATIONS}

The heat flow mechanisms in the furnace consist of conduction (through the alumina blocks and molybdenum plates) in series with parallel natural convection and radiation (across the argon-filled gaps). The heat loss was independently evaluated for heat flow in three directions: (1) vertically upward, (2) vertically downward, and (3) radially outward. In reality, there will be heat flow between the three regions, probably by some conduction from the upper and lower horizontal layers into the vertical annular layers, but quantitative assessment would require a very extensive program of machine computation.

The natural-convection, heat-transfer rate was characterized by Kraussold's equation, as given by Grober, Erk, and Grigull. (9) The apparent or effective thermal conductivity of a vertical annular fluid-filled gap is given by:

$$
\frac{k_{e}}{k}=0.11\left(N_{R a}\right)^{0.29} \text {, }
$$

in which $k$ is the molecular thermal conductivity and $N_{R a}$ is the Rayleigh number (product of Grashof and Prandtl moduli). Equation 3 was proposed for $6 \times 10^{3}<$ $\mathrm{N}_{\mathrm{Ra}}<10^{6}$ for vertical annuli, but it actually correlates $(9)$ the maximum heat-transfer data for horizontal and vertical plane layers as well over the ranges $4 \times 10^{3}<\mathrm{NRa}<$ $\sim 2 \times 10^{7}, 0.010<\delta<11.2$ in, and $0.7<\mathrm{NPr}<4 \times 10^{3}$. The quantity $k_{e}$ is defined by the equation of heat conduction according to:

$$
q=\frac{k_{e} A \Delta t}{\delta}
$$

for a plane layer $(\delta=$ the gap), and according to:

$$
q=\frac{2 \pi k_{e} l \Delta t}{\ln \left(D_{o} / D_{i}\right)}
$$

for an annular gap. The ratio $k e / k$ therefore describes the relative increase in the heat-transfer rate caused by natural convection, as compared with pure conduction. 
Since the $N_{p r}$ is 0.58 , Equation 3 reduces to:

$$
k_{e}=0.094 k(G r)^{0.29} \text {. }
$$

For a given gap, the gap thickness and average values of $\mu$ and $k$ may be introduced into Equation 6 to yield:

$$
k_{e}=0.094 k\left(\frac{\delta^{3} g}{\mu}\right)^{0.29}\left(p^{2} \beta \Delta t\right)^{0.29}=K\left(p^{2} \beta \Delta t\right)^{0.29},
$$

in which $K$ is a numerical constant appropriate to the particular thickness of the argon layer under consideration.

The net radiant heat transfer across the radial gas gaps was calculated with the equation:

$$
q=\frac{\sigma A_{1}\left(T_{1}^{4}-T_{2}^{4}\right)}{\frac{1}{\epsilon_{1}}+\left(\frac{D_{1}}{D_{2}}\right)\left(\frac{1}{\epsilon_{2}}-1\right)},
$$

which is applicable to infinitely long concentric cylinders. Since the gas gaps are small compared to the heights of the vertical annular gas layers, the approximation should be good. For the plane horizontal gas layers, the net radiant interchange was calculated from:

$$
q=\frac{\sigma A\left(T_{1}^{4}-T_{2}^{4}\right)}{\frac{1}{\epsilon_{1}}+\frac{1}{\epsilon_{2}}-1} .
$$

Since the physical properties were, in general, temperature dependent-especially $\rho$ and $\beta$ of the argon and $k$ and $\epsilon$ of the alumina-and since the $\Delta t$ across an argon film is dependent on the $k_{e}$ of the argon which, in turn, is dependent on $\Delta t$ (see Equation 7), an iterative solution was necessary. The general procedure was to assume a heat flow and calculate the temperature drops through the series thermal resistances until the heat sink (water coolant) was reached. The criterion of matchup was that the calculated temperature at the heat sink equal the lowest water temperature which would occur at that position, taken as $40^{\circ} \mathrm{F}$ for the se calculations. A water film coefficient of $500 \mathrm{Bru} / \mathrm{hr} \cdot \mathrm{ft} 2 .{ }^{\circ} \mathrm{F}$ was used in all cases. Since supplier representatives are designing the tungsten-mesh heating elements for an excess temperature (above that of the central argon) not to exceed 100 to $150^{\circ} \mathrm{C}$, the maximum total potential for heat transmission is a temperature difference of $\sim$ (3000 40) $=2960^{\circ} \mathrm{F}$. 
Heat Flow Vertically Upward

The temperature distribution calculated for an assumed upward heat flow of $5.86 \mathrm{kw}$ is shown in Figure 35. If the water temperature were $40^{\circ} \mathrm{F}$ rather than $141^{\circ} \mathrm{F}$, the calculated heat loss would increase to $6.1 \mathrm{kw}$. The temperature drop per unit thickness of alumina decreases with distance from the central cavity since the area normal to heat flow and the thermal conductivity of the alumina each increase with distance. Several compensating factors keep the temperature drop across the argon gaps approximately constant. Other factors resulting from the calculation are summarized in Table 7.

\begin{tabular}{cc|cc} 
Region & Material & Region & Material \\
$\mathrm{c}-\mathrm{i}$ & $0.50^{\prime \prime} \mathrm{Ar}$ & $5-6$ & $2.7 " \mathrm{Al} 2 \mathrm{O}_{3}$ \\
$\mathrm{i}-1$ & $0.060^{\prime \prime} \mathrm{Mo}$ & $6-7$ & $0.100^{\prime \prime} \mathrm{Ar}+\mathrm{O} \mathrm{O}^{\prime \prime} \mathrm{Mo}$ \\
$1-2$ & $3.8^{\prime \prime} \mathrm{Al}_{2} \mathrm{O}_{3}$ & $7-8$ & $2.5^{\prime \prime} \mathrm{Al} \mathrm{O}_{3}$ \\
$2-3$ & $0.100^{\prime \prime} \mathrm{Ar}+0.060^{\prime \prime} \mathrm{Mo}$ & $8-9$ & $1.0^{\prime \prime} \mathrm{Ar}$ \\
$3-4$ & $2.7^{\prime \prime} \mathrm{Al} \mathrm{O}_{3}$ & $9-10$ & $0.2 \mathrm{O}^{\prime \prime} \mathrm{SS}$ \\
$4-5$ & $0.100^{\prime \prime} \mathrm{Ar}+0.060^{\prime \prime} \mathrm{Mo}$ & $10-11$ & $\mathrm{H}_{2} \mathrm{O}$ Channel
\end{tabular}

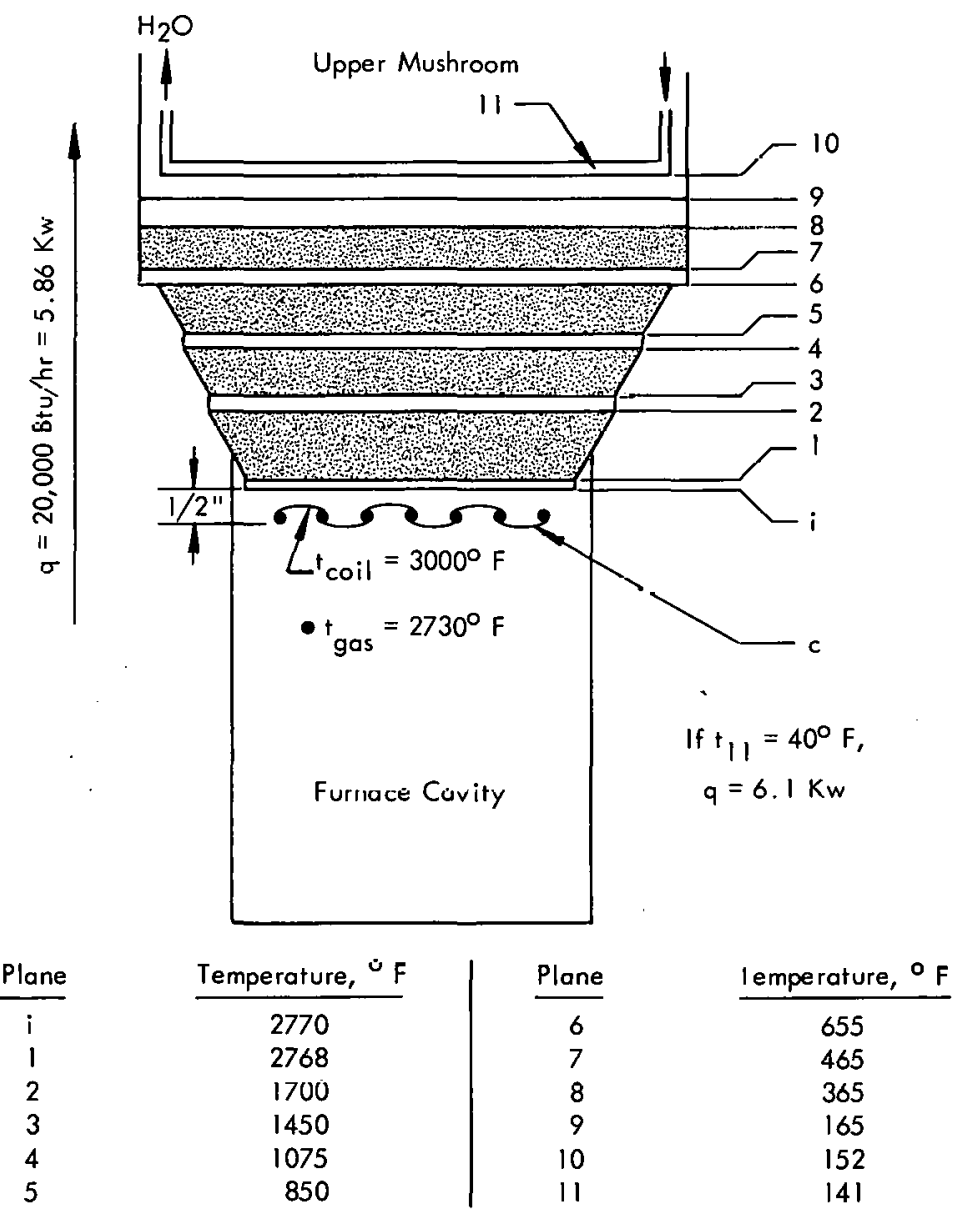

Figure 35. RESULTS OF UPWARD HEAT FLOW. 
Table 7

HEAT FLOW FACTORS

(Flow Vertically Upward)

\begin{tabular}{ccccc}
\hline Gap & $\begin{array}{c}\text { Percent } \\
\text { Radiation }\end{array}$ & NRa & $k_{e} / k$ & $\begin{array}{c}\Delta t \\
(\circ \mathrm{F})\end{array}$ \\
\hline Coil $1-\mathrm{i}$ & 100.0 & $1.8 \times 10^{7}$ & 14.0 & 230 \\
$2-3$ & 41.5 & $3.7 \times 10^{5}$ & 4.5 & 250 \\
$4-5$ & 19.4 & $7.0 \times 10^{5}$ & 5.4 & 225 \\
$6-7$ & 7.4 & $1.0 \times 10^{6}$ & 6.4 & 190 \\
$8-9(1)$ & 3.0 & $2.1 \times 10^{9}$ & 56.0 & 200 \\
\hline
\end{tabular}

(1) The large $N_{R a}$ indicates turbulent rather than laminar natural convection at this plane.

Note that the heat-conducting plate and two top blocks of $\mathrm{Al}_{2} \mathrm{O}_{3}$ (each 4.1-inches thick) which were included in the initial proposal have not been retained and do not seem necessary. The lowest alumina block (1-2) should perhaps be divided because of the large $\Delta t$ across it. The one-inch argon gap at the top (8-9) has been provided for axial thermal expansion. The temperature drop across the molybdenum canning plates never exceeded $2^{\circ} \mathrm{F}$. In Gaps 2-3, 4-5, and 6-7, the molybdenum plates were assumed to be in close contact with the lower oxide blocks, which gives a conservative result since any intermediate spacing of the plates would tend to suppress the natural convection in the argon and therefore decrease the $\mathrm{ke} / \mathrm{k}$ ratio.

\section{Heat Flow Vertically Downward}

The temperature distribution calculated for a downward heat flow of $8.43 \mathrm{kw}$ is shown in Figure 36. If the water temperature were $40^{\circ} \mathrm{F}$ rather than $116^{\circ} \mathrm{F}$, the calculated heat loss would increase to $8.65 \mathrm{kw}$. Other factors resulting from the analysis are outlined in Table 8.

A secondary conductive heat flow path exists between the coil plane and Plane 6 of Figure 36; ie, through the seven one-inch-diameter tungsten support rods; and of the total heat load absorbed at the heat sink, $~ 31 \%$ enters through these supports. The lowest alumina block (10-11) should be divided to reduce the excessive temperature drop across it $\left(622^{\circ} \mathrm{F}\right)$. The molybdenum canning plates were again assumed to be in close contact with an adjacent alumina block, and any intermediate spacing assumed by these plates would reduce the heat flow by suppression of natural convection. Although there is some indication $(10)$ that the Nusselt number for heated plates facing downward is only half that for heated plates facing upward, the same convection correlation used previously for upward heat flow (Equation 3) was used here also for conservatism.

Heat Flow Radially Outward

The final temperature distribution calculated for a radial heat flow of $65 \mathrm{kw}$ is shown in Figure 37, and other pertinent factors are tabulated in Table 9. 


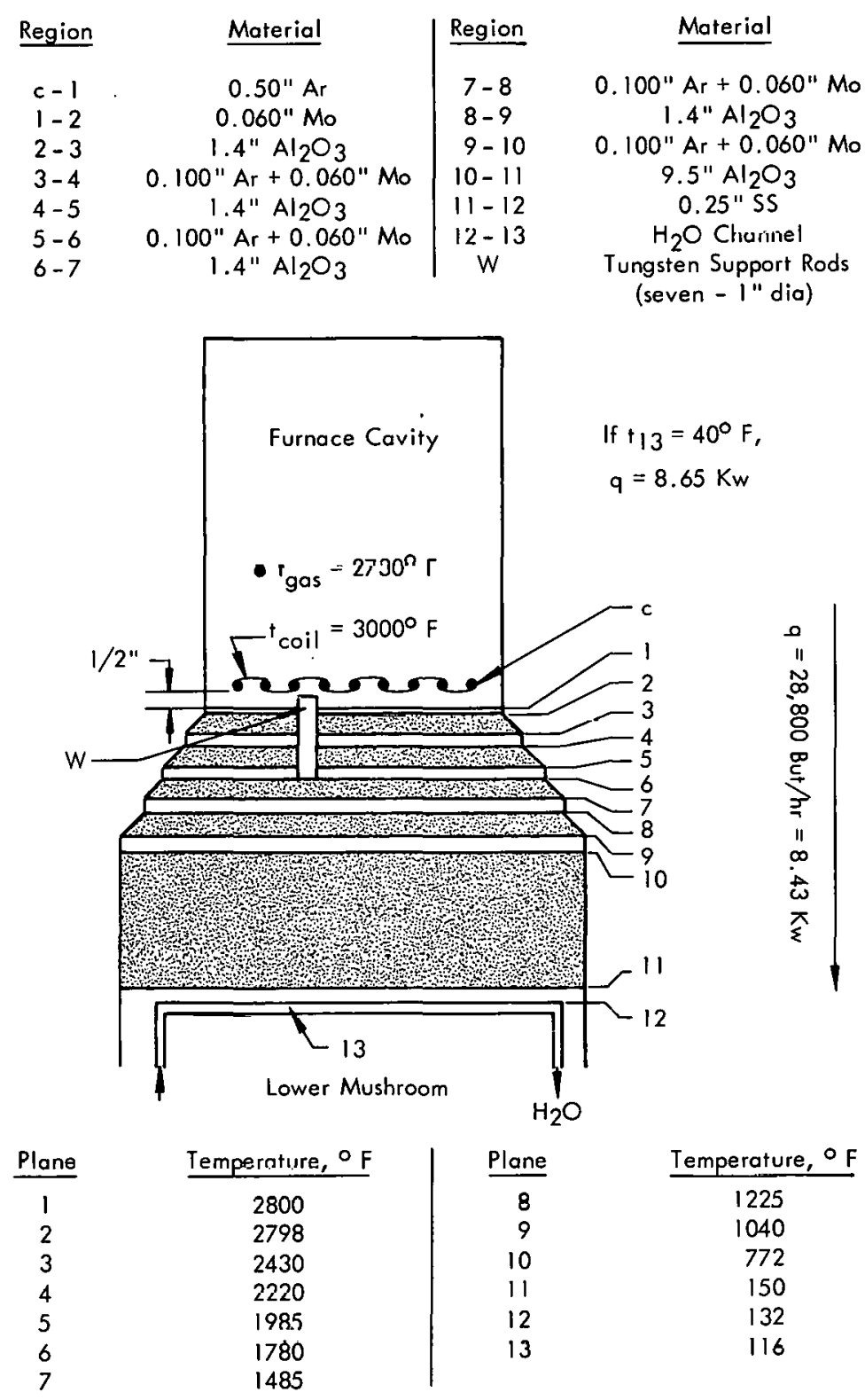

Figure 36. RESULTS OF DOWNWARD HEAT FLOW.

Table 8

HEAT FLOW FACTORS

- (Flow Vertically Downward)

\begin{tabular}{ccccc}
\hline Gap & $\begin{array}{c}\text { Percent } \\
\text { Radiation }\end{array}$ & $N_{\text {Ra }}$ & $k_{\mathrm{e}} / \mathrm{k}$ & $\begin{array}{c}\Delta t \\
\left({ }^{\circ} \mathrm{F}\right)\end{array}$ \\
\hline Coil-1 & 100.0 & $6.3 \times 10^{6}$ & 10.2 & 200 \\
$3-4$ & 67.4 & $9.6 \times 10^{4}$ & 3.1 & 210 \\
$5-6$ & 52.8 & $1.8 \times 10^{5}$ & 3.7 & 205 \\
$7-0$ & 31.2 & $5.0 \times 10^{5}$ & 5.0 & 260 \\
$9-10$ & 16.8 & $9.0 \times 10^{5}$ & 5.8 & 268 \\
\hline
\end{tabular}




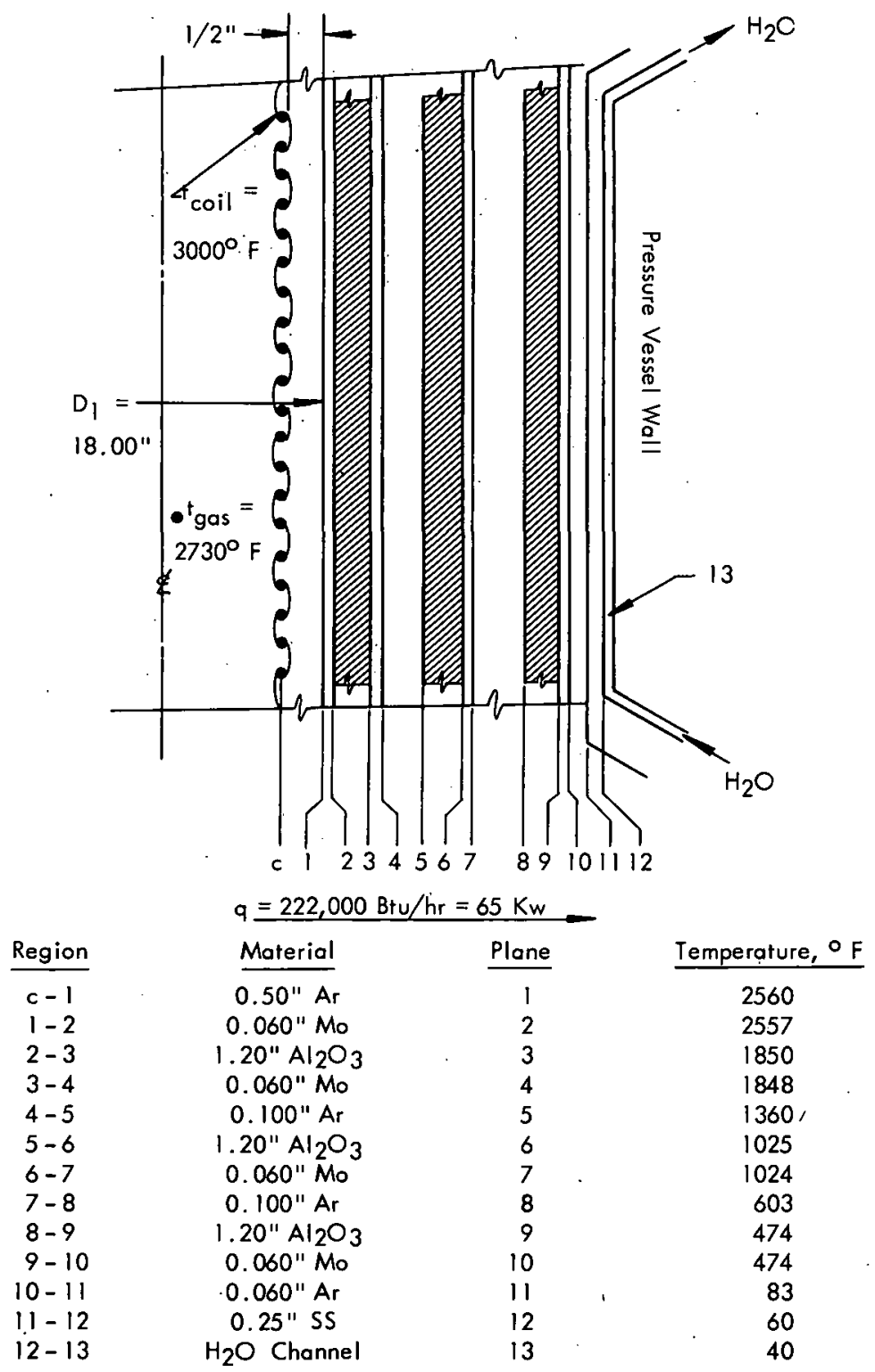

Figure 37. RESULTS OF RADIAL HEAT FLOW.

Table 9

HEAT FLOW FACTORS

(Flow Radially Outward)

\begin{tabular}{cccccc}
\hline Gop & $\begin{array}{c}\text { Percent } \\
\text { Radiation }\end{array}$ & $N_{\text {Ra }}$ & $k_{\mathrm{e}} / \mathrm{k}$ & $\begin{array}{c}\Delta t \\
(\circ \mathrm{F})\end{array}$ & $\begin{array}{c}\sim(\mathrm{V}) \mathrm{Ar}_{\mathrm{r}} \\
(\mathrm{ft} / \mathrm{sec})\end{array}$ \\
\hline Coil-1 & 93.1 & $1.5 \times 10^{7}$ & 13.1 & 440 & 0.370 \\
$4-5$ & 39.6 & $6.7 \times 10^{5}$ & 5.4 & 488 & 0.222 \\
$7-8$ & 12.2 & $1.6 \times 10^{6}$ & 6.9 & 421 & 0.244 \\
$10-11$ & 2.7 & $8.5 \times 10^{5}$ & 5.8 & 391 & 0.231 \\
\hline
\end{tabular}


The molybdenum plates were conservatively assumed to touch the alumina blocks, as shown by Figure 37. A calculation was made for Gap 7-8 (argon) with the molybdenum plate centered in the gap, and it was found that the total $\Delta t$ between Planes 6 and 8 was increased $\sim 2.7$ fold (at a constant heat loss of $65 \mathrm{kw}$ ).

The semiquantitative estimate of the velocity of the argon in the vertical annular gaps, listed last in Table 9, was made by making use of an approach to natural convection(11) from which it may be deduced that the Grashof modulus is equivalent to the square of the Reynolds modulus, that is:

$$
\begin{gathered}
N_{G r}=\frac{\delta^{3} \rho^{2} g \beta \Delta t}{\mu^{2}}=\left[\frac{\delta}{\mu}\left(\delta \rho^{2} g \beta \Delta t\right)^{1 / 2}\right]^{2} \text {, or } \\
N_{G r}=\left(N_{R e}\right)^{2}
\end{gathered}
$$

from which one may take the gas mass velocity to be

$$
G=\left(\delta \rho^{2} g \beta \Delta t\right)^{l / 2} .
$$

Since $G-p V$, the velocily is calculable from:

$$
V=(\delta g \beta \Delta t)^{1 / 2},
$$

which is the relation used to calculate the argon velocities, with $\beta$ evaluated at the mid-gap argon temperature. 
THIS PAGE

\section{WAS INTENTIONALLY LEFT BLANK}




\section{SYMBOLS}

A cross-sectional area normal to heat flow, $\mathrm{ft}^{2}$

$C_{p}$ specific heat, Btu/lb $\circ \mathrm{F}$

D diameter, $\mathrm{ft}$

g gravitational acceleration, $\mathrm{ft} / \mathrm{hr}^{2}$

$G \quad$ mass velocity of fluid, $\mathrm{lb} / \mathrm{hr} \cdot \mathrm{ft}^{2}$

k thermal conductivity, Btu/hr$\cdot \mathrm{ft} \cdot \mathrm{O}^{\mathrm{F}}$

K a numerical constant (see Equation 7)

1 height of vertical annular gas layer, $\mathrm{ft}$

L characteristic length in the Grashof modulus, $\mathrm{ft}$

$N_{G_{i}} \cdot$ Grashof modulus, $L^{3} \rho^{2} g \beta \Delta t / \mu^{2}$, dimensionless

$N_{P r} \quad$ Prandtl modulus, $C_{p} \mu / k$, dimensionless

$N_{R a}$ Rayleigh modulus, $\left(N_{G r}\right)\left(N_{P_{r}}\right)$, dimensionless

q heat-transfer rate, Btu/hr

t temperature, ${ }^{\circ} \mathrm{F}$

$\Delta t \quad$ temperature difference, ${ }^{\circ} \mathrm{F}$ 
$T \quad$ absolute temperature, ${ }^{\circ} R$

$V \quad$ molar gas volume, $\mathrm{ft}^{3} / \mathrm{lb}$ mole (in Equation 1); linear fluid velocity

z compressibility factor, PV/RT, dimensionless

$\beta$ volumetric coefficient of thermal expansion, $(O F)^{-1}$

$\delta \quad$ gas gap, $\mathrm{ft}$

$\epsilon \quad$ total normal radiant emissivity, dimensionless

$\mu \quad$ viscosity of gas, $\mathrm{lb} / \mathrm{hr} \cdot \mathrm{ft}$

p density, $\mathrm{lb} / \mathrm{ft}^{3}$

o Stefan-Boltzmann radiation constant, $0.173 \times 10^{-8} \mathrm{Btu} / \mathrm{hr} \cdot \mathrm{ft}^{2} \cdot{ }^{2} \mathrm{R}^{4}$

Subscripts

e effective value

g of gas

i inside

- outside

P at constant pressure

1 of inner surface

2 of outer surface 


\section{REFERENCES}

(1) Goldsmith, et al; "Handbook of Thermophysical Properties of Solid Materials", rev ed, Vol III: Ceramics; MacMillan Company (1961).

(2) Degussit Company Supplier Bulletin, p 10.

(3) Campbell; High Temperature Technology; John Wiley and Sons, New York (1956).

(4) Gray, ed; American Institute of Physics Handbook, pp 4-89; McGraw-Hill Book Company (1957).

(5) Lydersen, University of Wisconsin Engineering Experimental Station Reports 3 and 4 (1955).

(6) Owens and Thodos; AIChE Journal, pp 454-461; December 1957.

(7) Touloukian; Thermophysical Properties Research Center Data Books, Purdue University Research Foundation (1961, 1962).

(8) Ross and Brown; Ind Eng Chem, 49, p 2026 (1957).

(9) Grober, Erk, and Grigull; Fundamentals of Heat Transfer, pp 316-317; McGrawHill Book Company (1961).

(10) Kreith; Principles of Heat Transfer, p 311; International Textbook Company (1959).

(11) Brown and Marco; Introduction to Heat Transfer, Second Edition, pp 131-136; McGraw-Hill Book Company (1951). 
THIS PAGE

\section{WAS INTENTIONALLY LEFT BLANK}


PART 8

GAS AUTOCLAVE FACILITY DESIGN LIMITATIONS

$$
\text { C. E. Muzzall }
$$


THIS PAGE

\section{WAS INTENTIONALLY LEFT BLANK}


CONTENTS

SUMMARY ....................... 243

GAS AUTOCLAVE FACILITY DESIGN LIMITATIONS . . . . . . . . 245

General Function . . . . . . . . . . . . . . . 245

Limitations of Present Equipment . . . . . . . . . . . . . . . . . 245

Limiting Autoclave Parameters. . . . . . . . . . . . . . . 246

Temperature . . . . . . . . . . . . 246

Pressure . . . . . . . . . . . . . . 246

Size . . . . . . . . . . . . . . 246

Pressure Fluid . . . . . . . . . . . . . . 247

Vessel Design . . . . . . . . . . . . . . . 248

Furnace Design . . . . . . . . . . . . . 248

Pressure Intensifier Design . . . . . . . . . . . . 250

Pressure Vessel Containment . . . . . . . . . . . . 250

Selection of Autoclave Design Conditions . . . . . . . . . . . 251

Operating Conditions............. . . 251

Pressure Fluid . . . . . . . . . . . . . . 251

Vessel Size (pressure chamber) . . . . . . . . . 251

Furnace Size (work zone) . . . . . . . . . . . 251

Intensifier System. . . . . . . . . . . . . 251

Power Supply . . . . . . . . . . . . . . 251

General Description of Proposed Autoclave . . . . . . . . . . 252

Facility Description. . . . . . . . . . . . . 252

Process Description . . . . . . . . . . . 252 
THIS PAGE

\section{WAS INTENTIONALLY LEFT BLANK}




\section{SUMMARY}

Based on present state-of-the-art capability, the practical gas autoclave has limiting parameters of temperature, pressure, size, pressure fluid, and furnace design. The actual parameters selected for the system have been determined, and a general facility and process flow planned. 
THIS PAGE

\section{WAS INTENTIONALLY LEFT BLANK}




\section{GAS AUTOCLAVE FACILITY DESIGN LIMITATIONS}

\section{GENERAL FUNCTION}

Processing of materials and parts in a closed vessel at high pressures and at elevated temperatures is generally carried out for the purpose of densification; and, in certain applications, for bonding. A variety of materials, such as powder-metallurgy items, ceramics, and sintered metal products can be profitably treated by gas-autoclave techniques. The pressure fluid employed is normally an inert gas to prevent interaction with the workpiece, especially at higher temperatures. The pressure range for gas autoclave work may vary from a few atmospheres to 3000 atmospheres or higher, and the temperature may vary from ambient to $2000^{\circ} \mathrm{C}$.

\section{LIMITATIONS OF PRESENT EQUIPMENT}

Y-12 now has the capability for compacting large quantities of powders at high pressures and moderate temperatures. Present isostatic pressing equipment comprises four large pressure vessels: one has a pressing chamber which has a 16-inch ID and is 144 inches deep, another has a 30-inch ID and is 120 inches deep, and a third has a 60 -inch ID and is 60 inches deep. All three vessels can be operated at 30,000 psi and at a temperature of $150^{\circ} \mathrm{C}$. A fourth vessel, having a 30 -inch ID is being modified to operate at 20,000 psi and a maximum temperature of $1000^{\circ} \mathrm{C}$ as a cold-wall, inert-gas autoclave.

High-pressure processing in these four vessels is limited in temperature to a maximum of $150^{\circ} \mathrm{C}$ because of the hydrocarbon hydraulic fluid and the polyvinyl chloride plastic-bag-mold formulation which are employed in the process. To achieve temperatures even in the $150^{\circ} \mathrm{C}$ range involves preheating a layer of oil in a doublebag arrangement surrounding the preheated workpiece. The bulk of the hydraulic fluid in the vessel system remains at room temperature. Consequently, to achieve higher temperatures it will be necessary to replace the fluid with an inert gas or hydrogen since otherfluids would react with the workpiece at elevated temperatures. Since it is not feasible to modify the Bliss 60 -inch vessel (the largest of the $Y-12$ systems) for gas pressurization in the desired temperature range, a new facility has been proposed for the Y-12 Plant. The new facility will be called the "Gas Autoclave Facility".

In addition to the use of the aforementioned vessels in the manner described, highpressure technology is being expanded to include pressure-multiplying devices which utilize the pressure vessels as a first stage to achieve final pressures in the range of one to two million pounds per square inch at operating temperatures up to $2000^{\circ} \mathrm{C}$ for laboratory-scale workpieces. These vessels, with or without the pressure-multiplying devices, have many potential applications. For instance, refractory metal parts can be produced which are difficult to shape, have a fine-grained structure, are homogeneous, ductile, and close to the theoretical density. 


\section{LIMITING AUTOCLAVE PARAMETERS}

\section{Temperature}

An upper temperature limit of $2000^{\circ} \mathrm{C}$ is believed to be practical for furnace materials of construction tested under pressures of 20,000 to 30,000 psi at this temperature. Such a limit is associated with problems of heating-element support, workload support, limited void volume, electrical insulation, and thermal conductivity. Temperatures above $2000^{\circ} \mathrm{C}$ at high pressure will require additional research and development by industry.

\section{Pressure}

Gas pressure systems, designed for the 50,000 to 75,000-psi range, have been in use by the chemical process industries for several years. Battelle has an autoclave capable of operating at 50,000 psi with a 1 1/2-inch-diameter hot zone at nearly $3000^{\circ} \mathrm{C}$. The $\mathrm{Y}-12$ Plant has operated isostatic pressure vessels at 30,000 psi with mineral oil as the pressure medium for many years. However, in consideration of the size of the 48-inch-ID pressure chamber established for the project, it is recognized that an upper pressure limit of 30,000 psi becomes mandatory for safety reasons as will be observed in the safety analysis report included in this compendium (see Part 9).

$\underline{\text { Size }}$

For the given capital investment of the Gas Autoclave Facility, the selection of one 48-inch-ID vessel has been compared with an alternate choice of two vessels of smaller size; for example, one 16-inch and one 30-inch vessel. The choice of a single vessel with a 48-inch pressure cavity for the operating conditions prescribed for the Facility is preferable to a combination of smaller vessels because of the superior versatility and economy of the large unit. More extensive developmental investigations for a large variety of materials and part sizes, in addition to full production capability, can be achieved by a single 48-inch autoclave. The total capital investment of several smaller vessels wouldexceed that of a single vessel because of the necessary duplication of services and auxiliaries.

Table 10 presents an estimated capital comparison, using 1963 prices, between a single vessel and a multi-unit system.

The possibility should not be overlooked of taking advantage of the conjunctive use of existing $Y-12$ isostats (oil fluid) to increase the utilization of the gas autoclave. This step could be accomplished by prepressing the green powder compacts in the isostats to decrease shrinkage of powders in the autoclave. By this step, largerdiameter finished pieces could be produced. Since most powder compacts shrink about 30 percent in the cold isostats, large pieces could be pressed in the 60-inch isostat and then introduced into the gas autoclave to maximize the final size of the 
Table 10

COMPARISON BETWEEN TWO AUTOCLAVE SYSTEMS

\begin{tabular}{rrr}
\hline Case I & One 48-Inch Autoclave & \\
Case I Total & $\$ 2,500,000$ \\
Case II & $\begin{array}{r}\text { One 30-Inch Autoclave } \\
\text { One 16-Inch Autoclave }\end{array}$ & $\$ 2,300,000$ \\
& Case II Total & $\frac{400,000}{\$ 2,700,000}$ \\
\hline
\end{tabular}

pressed form. Specifically, some examples of maximum final sizes that could be produced by joint use of the isostats and the autoclave can be seen in Table 11 .

Table 11

UTILIZATION OF EXISTING ISOSTATS

\begin{tabular}{lcccc}
\hline $\begin{array}{c}\text { Process } \\
\text { Materials }\end{array}$ & $\begin{array}{c}\text { Green } \\
\text { Compact } \\
\text { Diameter } \\
\text { (inches) }\end{array}$ & $\begin{array}{c}\text { Cold } \\
\text { Isostat } \\
\text { Product } \\
\text { Diameter } \\
\text { (inches) }\end{array}$ & $\begin{array}{c}\text { Forty-Eight-Inch Autoclave } \\
\text { Production Diameter } \\
\text { at } 30,000 \text { psi and } \\
2000^{\circ} \mathrm{C} \\
\text { (inches) }\end{array}$ & $\begin{array}{c}\text { Forty-Eight-Inch Autoclave } \\
\text { Production Diameter at } \\
30,000 \text { psi and a Few } \\
\text { Hundred } 0 \text { C } \\
\text { (inches) }\end{array}$ \\
\hline Low Temperature & 56 & 40 & - & 40 \\
Low Temperature & 40 & - & -30 & 28 \\
High Temperature & 42 & 30 & 21 & - \\
High Temperature & 30 & - & & - \\
\hline
\end{tabular}

It should be noted that the inside diameter of the autoclave furnace is the limiting factor for the final diameter of a pressed compact. The insulation thickness and heating element size will limit the $2000^{\circ} \mathrm{C}$ furnace to about 30 inches ID and the low-temperature furnace to about 40 inches ID.

Pressurc Fluid

As stated previously, for reasons of purity and metallurgical properties the pressure medium must be an inert gas to eliminate any reaction with the product. Nitrogen is reactive with many of the process materials. Hence, the choice lies between argon and helium since the remaining inert gases are too expensive. Argon hasbeen chosen for three reasons:

1. Argon has superior insulation properties. For example, at the maximum operating temperature $\left(2000^{\circ}\right)$ the thermal conductivity of helium is almost seven times that of argon.

2. The cost of helium at the $Y-12$ Plant is about $21 / 2$ times that of argon. This cost factor is an important consideration since the quantity of gas required per run with the autoclave will be approximately 25,000 standard cubic feet. 
3. The greater solubility of helium in the workpiece with respect to that of argon under the pressure-temperature conditions of autoclave operation will have deleterious metallurgical effects. The greater diffusion rate of helium would allow deeper interstitial penetration into powder metallurgy products which are essentially granular in nature. The effect would be higher gas retention with consequent grain boundary dislocation which could adversely affect such properties as yield strength, impact resistance, and hardness. The greater diffusion of helium can be predicted from a comparison of mean-free-path data by Boltzman at $20^{\circ} \mathrm{C}$ and $75 \mathrm{~cm} \mathrm{Hg}$ :

$$
\text { Helium }=27.45 \times 10^{-6} \mathrm{~cm} \quad \text { Argon }=9.88 \times 10^{-6} \mathrm{~cm}
$$

Likewise, from a comparison of atomic diameter (from viscosity data):

$$
\text { Helium }=1.90 \times 10^{-8} \mathrm{~cm} \quad \text { Argon }=2.88 \times 10^{-8} \mathrm{~cm}
$$

$\underline{\text { Vessel Design }}$

A complete analysis of the limiting conditions and design factors of the pressure vessel are presented in another report of this compendium, Part 9, "Safety Analysis for the Gas Autoclave Facility".

Furnace Design

At the present stage of design (November 1963) it is planned that the first furnace unit for the gas autoclave will be a modified scaleup of the current preliminary furnace design for an autoclave system being engineered for the 30-inch vessel, designated as $\mathrm{PV}-2$, discussed in other parts of this compendium.

The heating element must be capable of operating at approximately $2500^{\circ} \mathrm{C}$ to lead the work-zone temperature of $2000^{\circ} \mathrm{C}$ by sufficient marg in for rapid heating. The element must be rugged and self-supporting since it is impractical to provide a ceramic support with non-slump characteristics and high electrical resistivity under the rigorous operating conditions of the autoclave. Most refractories with adequate melting points are unacceptable for other reasons. For example, many carbides have melting points above $3000^{\circ} \mathrm{C}$, such as hafnium carbide $\left(3890^{\circ} \mathrm{C}\right)$, tantalum carbide $\left(3880^{\circ} \mathrm{C}\right)$, zirconium carbide $\left(3175^{\circ} \mathrm{C}\right)$, or titanium carbide $\left(3250^{\circ} \mathrm{C}\right)$; but the electrical resistivities of these materials range from $5000 \mathrm{ohm}$ centimeters down to less than $1000 \mathrm{ohm}$ centimeters at operating temperatures. To minimize current leakage, even at the relatively low voltage of the autoclave heater, it would be desirable to use a supporting refractory with a resistivity of at least $100,000 \mathrm{ohm}$ centimeters.

The obvious solution to this problem is to design a self-supporting heating element of a refractory metal such as tungsten, molybdenum, or an alloy such as tungsten -50 rhenium. The melting point of tungsten is high $\left(3410^{\circ} \mathrm{C}\right)$, while molybdenum is questionable $\left(2625^{\circ} \mathrm{C}\right)$. Both metals became embrittled with repeated usage. The 
cost of tungsten-50 rhenium would be prohibitive. The best approach currently offered by industry for gas autoclave service is a new development by Sylvania. Sylvania now offers to furnace manufacturers a new tungsten heating element for hightemperature vacuum furnaces. Sylvania engineers indicate the new element will be adaptable forhigh-pressure argon service. The panels of the elements are fabricated from tungsten mesh consisting of interlocking. tungsten wire coils. An important characteristic of the special interlocking coil design is that the mesh furnace panels will not warp or distort with repeated heating and cooling cycles up to $3000^{\circ} \mathrm{C}$.

Another challenging feature of the autoclave furnace design is insulation. It is desirable to maintain as small a void space as possible in the furnace systembecause of the hazards considerations which are discussed in Part 9. This fact means that a nonporous insulation should be considered. There are several high-purity, near-zeroporosity refractory products available. (a) It will be necessary to clad the individual refractory insulation segments (cylindrical shells and disc shapes) with thin sheaths of high-melting-point metal to minimize convectional currents associated with a problem discussed in the next paragraph. In the hotter zones, materials such as molybdenum-titanium-zirconium can be used for cladding, and Inconel or stainless steel may be used in the cooler zones.

Autoclave experience at Battelle was limited to the use of helium as the inert gas. It was found that spun silica batting (Microquartz) was satisfactory insulation material for operation up to $1600^{\circ} \mathrm{C}$ in the helium atmosphere. The finely shredded Microquartz was tightly compacted between the heater and vessel wall to a density of about 30 pounds per cubic foot. Such a system was effective because the relatively stagnant helium in the interstices of the Microquartz contributed to the insulation. At the request of $Y-12$ engineers, Battelle substituted argon for helium in a special experimental run and found that excessive convection currents developed in the argon with the result that the upper end of the furnace overheated when the work-zone temperature reached $750^{\circ} \mathrm{C}$. Consequently, the run was prematurely terminated. There was no apparent increase in the heat-transfer rate to the vertical cooling liner. It was concluded from this run that the $Y-12$ autoclave design will need to incorporate convectional baffling and that Microquartz or an equivalent microzirconia may be inadequate. Certainly the melting point of Microquartz would be too low for the autoclave work-zone temperature of $2000^{\circ} \mathrm{C}$. It should be noted at this point that the $Y-12$ design will provide heating elements on the top and bottom zones of the furnace as well as on the side wall. The Battelle furnaces have only side-wall heating.

(a) The Liasson Company supplies excellent refractories manufactured by Degussa in Germany. Also, the Norton Company and Coors Porcelain Company are among the American sources of refractories adequate for high-temperature insulation. 
Pressure Intensifier Design

The Battelle autoclave employs five-stage Andreas Hofer 15,000 -psi piston-type gas compressors. Pressurization for free volumes of 5 to 10 cubic feet with multistage compression of the fluid in the gaseous state requires 2 to 3 hours. For free volumes as great as the $\mathrm{Y}-12$ Autoclave (25 to 100 cubic feet, depending on furnace size and design) the pressurization time with gaseous compression would be prohibitively long. Consequently, $Y-12$ engineers have chosen a scheme designated as a "cryogenic intensification" system. The method is so called because of the liquid state of the starting fluid. The system consists of storage facilities for liquid argon, a liquid argon pump, and an electric vaporizer which discharges gas directly to the pressure vessel cavity.

Since the cryogenic system rate capacity is limited only by the liquid pump rate, the intensification time is several hundred times faster than that of a gas compressor of the same relative displacement. The present state of the art for industrial cryogenic systems has advanced to the 20,000-psi level. Whether industry can successfully scale up to the 30,000-psi requirement remains to be seen. If not, it may be necessary to employ a combination of cryogenic plus multistage gas compression. This combination method would start with the cryogenic phase, and as soon as the cryogenic pump has reached its pressure capacity, the gas compressor would complete the pressurization. Otherwise, if no successful method of mechanical compression to 30,000 psi can be achieved, there is another less-flexible technique which can be applied. Using a limited cryogenic system, the pressure chamber of the vessel would be charged to the maximum pressure for which the pump would be capable (say 20,000 psi at $70^{\circ} \mathrm{F}$ ). Then the pump and vaporizer would be shut off and the final system pressure would be achieved by increasing the gas temperature. However, the latter expedient would limit the versatility of the autoclave. That is, the system pressure of 30,000 psi could be achieved only at full temperature, and the maximum cold-gas pressure would be 20,000 psi .

The foregoing intensification discussion has been limited to the use of argon as the pressure medium. Certain experimental autoclave excursions will be more successful with other media such as hydrogen or helium or mixtures of hydrogen and helium. But, the low boiling points of these gases $\left(-252.9^{\circ} \mathrm{C}\right.$ for hydrogen and $-268.9^{\circ} \mathrm{C}$ for helium) render the cryogenic method impractical. Hence, for these applications, mechanical intensification would be required.

Pressure Vessel Containment

A detailed discussion of barricade design for the Gas Autoclave will be found in the next part of this compendium (Part 9). 


\section{SELECTION OF AUTOCLAVE DESIGN CONDITIONS}

The following summary of major design parameters for the Gas Autoclave Facility is presented in itemized form. Minor auxiliary equipment and instruments are omitted.

Operating Conditions

Temperature

Pressure

Pressure Fluid

Argon

Vessel Size (pressure chamber)

Inside Diameter

Inside Height

48 inches

120 inches

Furnace Size (work zone)

Inside Diameter

Inside Height

Intensifier System

Liquid Argon Pump $5 \mathrm{gpm}$ at 30,000 psi

Vaporizer

Alternate Pump

Diaphragm Compressor

Suction Pressure

Discharge Pressure $2000^{\circ} \mathrm{C}(\max )$

30,000 psi (max)

(Note: The alternate pump and diaphragm compressor may be used if industry is unable to supply the 30,000 -psi liquid argon pump.)

Power Supply

$1000 \mathrm{kva}$ 


\section{GENERAL DESCRIPTION OF PROPOSED AUTOCLAVE}

\section{Facility Description}

Briefly, equipment for the project will consist of the pressure vessel with its integral internal cooling jacket, the furnace (mounted within the pressure cavity), pressure intensification system, coolant recirculation system (including heat exchanger, demineralizer, and de-oxo-unit), vacuum system for the purging cycle, liquid argon storage and supply, system, gaseous argon recovery system including instrumentation for analysis, equipment handling devices, process control and recording instrumentation, cooling tower, transformers, and electrical gear and a gasoline-driven motorgenerator set. There are many additional minor miscellaneous items covered in a conceptual design report and in design criteria.

The autoclave will be housed in a reinforced concrete cell adjacent to a control cubicle. The walls of the cell and cubicle will be supported by an earth layer for personnel protection.

A complete description of the facility is covered in a conceptual design report and in design criteria provided by UCC.

\section{Process Description}

The vessel will be top loaded after the top plug and mushroom are removed and after the upper insulation plug is lifted from the furnace. Depending on the nature of the work material and the atmosphere to be used (argon is the only gas planned for at present), thin metallic membranous cladding may or may not be used as a pressure envelope for the workpiece. Excessive voids in the furnace cavity will be filled with solid plugs to minimize free gas space. After loading, the vessel, chamber will be closed and the interior will be evacuated and backfilled with gas. The chamber will then be re-evacuated and backfilled repeatedly until the residual air is less than 10 parts per million. The next procedure may be performed in either of two ways: (1) pressurization to full 30,000 psi at a low temperature followed by heating the gas to temperature, allowing the excess gas pressure tobleed off into the recovery system, or (2) pressurization to an intermediate pressure and, after shutting off the intensifier, heating the gas to temperature with the pressure increasing to 30,000 psi by virtue of temperature, without further pumping. After holding the system at temperature and pressure for a suitable period, cooling will be accomplished under pressure, after which gas will be gradually bled into the gas storage cylinders. In some cases, depending on the type of product and cladding, the workpiece will be removed hot.

For certain materials, the temperature may be run to the maximum capacity of the furnace $\left(2000^{\circ} \mathrm{C}\right)$. For others, lower operating temperature settings may be used. In still other cases, cold densification will be employed without the use of the furnace heating elements. 
PART 9

SAFETY ANALYSIS FOR THE GAS AUTOCLAVE FACILITY

C. E. Muzzall 
THIS PAGE

\section{WAS INTENTIONALLY LEFT BLANK}


CONTENTS

SUMMARY .................... 257

SAFETY ANALYSIS FOR THE GAS AUTOCLAVE FACILITY . . . . . . 259

General Information ................... 259

Background Information. . . . . . . . . . . . . . . . 259

General Approach to the Safety Analysis . . . . . . . . . . . 261

Vessel Design Study . . . . . . . . . . . . . . . 261

Modes of Failure. . . . . . . . . . . . . . . . . . 265

Evaluation of Energy Release . . . . . . . . . . . . . . . . 266

Analysis of Shock Wave Produced by Energy Release . . . . . . . . . . . 273

Barricade Design. . . . . . . . . . . . . . . . . . 275

Biological Considerations . . . . . . . . . . . . . . 279

Concluding Remarks . . . . . . . . . . . . . . . 280

BIBLIOGRAPHY ....................... 283 
THIS PAGE

\section{WAS INTENTIONALLY LEFT BLANK}




\section{SUMMARY}

A study has been made of the optimum pressure vessel design based on an analysis of modes of failure. From this, the magnitude and effects of energy release from expanding gas in the event of vessel rupture were calculated, and barricade design for this facility was predicated on shock-wave physics and blast-resistance theory. 
THIS PAGE

\section{WAS INTENTIONALLY LEFT BLANK}




\section{SAFETY ANALYSIS FOR THE GAS AUTOCLAVE FACILITY}

\section{GENERAL INFORMATION}

The Gas Autoclave Facility will comprise a pressure vessel, a high-temperature furnace mounted within the vessel, auxiliary equipment such as power supply and controls, vacuum equipment, argon gas pressure intensification system, equipment for gas purging and storage, other service facilities and utilities, a containment cell for the autoclave, and cells for such auxiliary services as control, maintenance, and storage. The pressure vessel will be a yoke-type, vertical, three-element, multiwall, cylindrical unit with an integral cooling liner on the inner surface.

This autoclave system is to be used for processing materials and workpieces under pressures ranging from a few atmospheres to greater than 2000 atmospheres $(30,000$ psi maximum) at temperatures up to $2000^{\circ} \mathrm{C}$. The system is designed for the use of argon as the inert gas process medium. An operating cycle-consisting of loading, evacuation, purge, pressurization, heat up, soak, cool down, and unloading-is expected to require 24 to 36 hours.

The inherent hazards which attend the operation of a gas autoclave are related to the potential rupture of the vessel itself or other equipment components under high pressure. To evaluate these hazards it becomes necessary to assess the possible effects of vessel failure on the containment cell and other nearby structures, and the effects upon operating personnel in the control room or other areas external to the containment cell. The possible damage from blast as well as propelled fragments or missiles should be considered. It is not necessary to consider the effects of a rapid release of energy comparable to a nuclear reactor runaway or an explosive catalytic chemical reaction. The only energy source encountered in the autoclave is the energy stored in the high-pressure, high-temperature argon.

Evaluation of the potential blast and fragment damage is preliminary to the formulation of containment-cell criteria. The scope of the safety analysis which follows will include a description of shock-wave physics and missile velocities (where applicable) attending the energy release of a vessel failure which leads to the design criteria for barricading and other safety features to be incorporated in the autoclave facility design.

\section{BACKGROUND INFORMATION}

High-pressure experience in the $Y-12$ Plant has been limited to the operation of six isostatic pressure vessels (four of which are currently in operation) which employ mineral oil as the pressure fluid. These vessels operate at pressures up to 30,000 psi and at a workpiece maximum temperature of $150^{\circ} \mathrm{C}$. The existing systems are not suitable for operation with a gaseous pressure fluid, although a conversion is planned 
for an existing 30-inch-diameter vessel to permit operation with argon at 20,000 psi and $1500^{\circ} \mathrm{C}$.

Three other installations have had wide experience in the gas autoclave field, however. These laboratories, the facilities of which have been studied, are:

Battelle Memorial Institute; Columbus, Ohio Bettis Atomic Power Laboratories; Pittsburgh, Pennsylvania Lawrence Radiation Laboratory; Livermore, California

The initial approach to the gas autoclave hazards analysis included a careful study of the safety precautions in design and operation practiced by these three installations. In addition, the facilities of many other laboratories, institutions, and industries having related high-pressure experience were investigated. Some of the organizations which have yielded profitable information were:

Autoclave Engineers, Inc; Erie, Pennsylvania

Fansteel Metallurgical Corporation; Chicago, Illinois

General Electric Company; Cleveland, Ohio

High Pressure Equipment Company, Inc; Erie, Pennsylvania

Monsanto Chemical Company; St. Louis, Missouri

National Aeronautics and Space Administration

Pantex Ordnance Plant, Mason and Hanger - Silas Mason Co, Inc; Amarillo, Texas

Southwest Research Institute; San Antonio, Texas

Sylvania Electric Company; Towanda, Pennsylvania

United States Navy

Additional information on the nature of shock-wave effects and explosive-energy release was obtained by contacts with:

Aircraft Armaments, Inc; Cockeysville, Maryland

Ballistic Research Laboratories, Aberdeen Proving Ground, US Army;

Aberdeen, Maryland

Harwood Engineering Company, Inc; Walpole, Massachusetts

Illinois Institute of Technology Research Institute (formerly Armour

Research Foundation); Chicago, Illinois

Institute for Defense Analysis; Washington, DC

Union Carbide Corporation; Chemicals Division; South Charleston, West Virginia University of Tennessee; Knoxville, Tennessee

Since many of the safety considerations encountered in the current pressure vessel conversion from operation with mineral oil to argon are analogous to those of the gas autoclave, the safety analysis carried out in the conversion study was basically sufficient for the autoclave. The containment cell of the latter facility was designed on the basis of shock-resistance calculation methods employed in the modification. Reference may be made to Part 1 of this compendium, "Hazards Pertaining to the Converted Thirty-Inch Pressure Vessel". 


\section{GENERAL APPROACH TO THE SAFETY ANALYSIS}

The first consideration is to visualize the modes of rupture of the pressurized vessel or other components. The modes of rupture or failure would indicate whether the energy stored in the compressed gas would be released in a manner which would produce a violent shock wave, project a number of high-velocity missile fragments, or whether both effects would result. The next step is to evaluate the amount of stored energy in the gas in terms of commonly understood units such as foot pounds or Btus. If it were determined that both shock-wave and fragment release would be encountered, it would be necessary to calculate the relative amounts of energy applied to shock and to propelled missiles. From the velocity and mass of each projectile, the effects of penetration or impact upon the barricade structure could be computed. The magnitude and effect of the shock wave will be a more complicated determination. The theoretical and empirical shock wave analysis will be presented later in this report.

Before evaluating the possible modes of failure, it will be informative to trace the steps of analysis which were involved in the choice of pressure vessel design. The design study summary which follows covers the highlights of vessel design comparisons based on the experience of UCC-ND and various vessel experts and consultants employed by UCC-ND.

\section{VESSEL DESIGN STUDY}

In the selection of the style of vessel construction, two basic designs were considered: (1) the multiwall, threaded plug or breech type; and (2) the multiwall yoke design. These vernacular terms refer to two methods of support and closure.

The first closure design is based upon a modification of the typical breech mechanism of the 16-inch naval gun. The top plug of this vessel is provided with an interrupted thread for quick opening; the bottom plug is assembled with a continuous thread. Hence, this vessel is a three-element design consisting of a vertical cylinder and two end plugs. Plug closures are accomplished by means of "mushrooms" on the cavity side of each plug. The mushroom seats against a rubber obturator pad (neoprene or a nitrile rubber) confined against antiextrusion rings backed up by the mushroom body. The mushroom has an integral central stem section which extends through a hole in the plug and is secured by a stem nut.

The second design which was considered (and chosen for the autoclave system) is referred to as the "yoke"-type vessel. This style also is a vertical three-element vessel with a multiwall cylinder and two plug assemblies which contain short-stemmed mushrooms sealed in a manner analogous to the breech-type vessel. The plug sections are held in place by a yoke frame assembly of parallel vertical plates which fits around the pressure vessel. The lower plug and mushroom remain fixed in the bottom of the vessel. The upper plug is removable by electrically operated rods which 
retract the upperplug assembly to permit removal of the vessel from the yoke frame for loading and unloading. In the closed and operating position the upper plug assembly communicates the force of internal vessel pressure to a pair of split retainer blocks which have been inserted hydraulically between the plug and an upper load transfer block which transfers the force to the upper arch of the yoke frame. Hence, the vessel system is held in a frame of vertical plate laminations, the force of internal vessel pressure being transmitted to the frame in a manner to set the plates under tensile loading. A transfer support frame is attached to the vessel chamber at the base level. This support frame rides on the ways or wear plates of a transport table. The vessel assembly is removed from the yoke plate aperture by means of a hydraulic cylinder and the transport table assembly. Further details of vessel construction may be obtained from UCC-ND Drawings E-M-51018 and E-M-51019.

Two of the existing $Y-12$ pressure vessels fit the description of the breech-type design; namely, the 16-inch vessel (naval gun) and the 30-inch unit (PV-2). The remaining two $Y-12$ units are yoke vessels; namely, the 30 -inch and the 60 -inch vessels. All of the vessels used by Battelle, Bettis, and the Lawrence Radiation Laboratory are of the modified breech type.

$Y-12$ experienced a vessel rupture on a unit of the breech type in 1956. The defective vessel was a 30 -inch model ( $P V-1)$ of similar design to the existing 30-inch vessel $(P V-2)$. One conclusion reached by an investigating committee was that the vessel failed because of a fatigue crack at the root of the first thread of the outer vessel shell at the lower threaded closure. It was postulated that fatigue was caused by high-level, cyclic stresses. The notch caused by fatigue was the initiator for the brittle failure which followed since the metal in the outer shell was, during operation, at a temperature below the nil ductility temperature.

In addition to the $Y-12$ failure, other breech-type-vessel ruptures have been experienced. Information about other failures in this country as well as abroad was received verbally by $\mathrm{Y}-12$ representatives. Concurrent with this information, experts in the field continually cautioned about the risks involved with breech mechanisms. All of these failures occurred at the first thread root of an end closure.

From the foregoing discussion of experience with the breech-type mechanism it is apparent that the $Y-12$ decision to design the gas autoclave vessel on the yoke-closure principle has been based partially on safety considerations.

An analysis of a threaded closure for a cylindrical vessel reveals that there are serious limitations. If the ends of a vessel are closed by threaded plugs (or even by an integrally welded head), the internal pressure acting against the plug closure causes a longitudinal tension stress in the wall of the container. The result is a biaxial tension stress unfavorable to fatigue resistance. Additional bending stresses are induced in the vessel wall due to the fact that the line of action of the longitudinal tension force is not coincident with the force applied to the threads. These forces produce tension stresses which add to the longitudinal wall stress. Because the plug closure, 
no matter how deep, deflects and constrains the wall of the vessel from deflecting the same way, additional bending stresses are produced which augment the circumferential Lamé stresses. The net result is an extremely high combined stress. Furthermore, the threads of the closure are themselves subject to bending stresses because the load is assumed to act on the pitch circle. This stress is further amplified by a stress concentration factor due to the radius at the root of the thread. This factor increases the thread bending stress.

An interesting example of a plug thread failure is illustrated by the following case. There were three vessels of identical design built for a particular installation. The threaded plugs and cylinders were fabricated to close tolerances and the plugs were considered to be interchangeable. It has been conjectured that on the occasion of the failure, the plug with the least pitch diameter (still within specifications) was mated with the cylinder having the greatest pitch diameter. When the vessel approached operating pressure $(10,000$ psi), the effective pitch circle, being closer to the thread crest than normal, shifted the stress and the thread system failed in shear, allowing the plug to be ejected violently from the vessel.

This discussion on thread design illustrates at least one of the intrinsic weaknesses characteristic of threaded closures. It is clearly indicated that a design which allows complete separation of circumferential hoop stress inside the vessel from the axial stress created at the vessel ends or closures will contribute to the reduction of stress concentrations which would lead to failure in fatigue, especially in a vessel subjected to cyclic stresses induced by repeated operations. The closure system of the "yoke" design essentially accomplishes the latter stress separation.

It is difficult to visualize a catastrophic failure with a "yoke"-type vessel. Assuming that the circumferential hoop stresses are properly compensated for in the design of the cylinder, it follows that the end forces on the top and bottom plugs will be transmitted to the yoke in such manner that the frame plates will be in tension. Hence, the plates will tend to stretch. If the yield in tension is associated with sufficient strain to allow the plug seals to leak gas, the worst failure would conslst of a gas release to the atmosphere without accompanying propulsion of missile fragments. By contrast, a breech vessel rupture usually sets metal fragments in motion before the release of gas occurs. Hence, it can justifiably be stated that the yoke design is innately safer than the breech concept.

Dr. R. G. Sturm of Huntsville, Alabama has analyzed pressure vessel design in the pressure range up to 100,000 psi from the standpoint of internal diameter as related to the closure systems of yoke versus breech. His analysis indicates that it is not feasible, from an engineering point of view, to design a plug or breech vessel with an inside diameter greater than 30 inches and have adequate safety factor at 30,000 psi. This analysis establishes an upper limit of 36 inches ID as an outside consideration, regardless of economics. Economically, the yoke vessel is competitive with the breech system for diameters starting as low as 16 inches. Considering the difficulties of providing sufficient metal in the high-stress areas of a breech design 
for a 48-inch vessel, it is certain that a yoke design would be competitive for a vessel this large. The metal used in the pressure chamber and its components must be of high-yield-strength steel such as gun steel alloys used in naval guns with yield strength in the range of 100,000 to $125,000 \mathrm{psi}$. Such material in the fabricated form will cost between $\$ 1.50$ and $\$ 2.50$ per pound. However, in the case of the yoke design, the frame plates are fabricated from lower-priced alloys (about $\$ 0.23$ per pound) such as ASTM-A212. Furthermore, because of the relief of the vessel end loading contributed by the yoke frame, the vessel itself can be designed with less weight than a corresponding breech vessel. The result is that a yoke system of a given size can conceivably be designed at a lower cost than an equivalent breechtype vessel.

To illustrate the favorable economics of the yoke design, the following cost review, which was used to establish the first cost estimate for the autoclave, is presented. From preliminary designs, the 48-inch vessel was estimated to weigh 471,000 pounds for a breech design and 875,000 pounds for a yoke design. Fabricated unit cost figures per pound of vessel metal for existing breech units are:

$$
\begin{array}{cr}
\text { Y-12 30-Inch Breech } & \$ 2.08 / 1 \mathrm{~b} \\
\text { Battelle 16-Inch Threaded Plug } & 1.80 / 1 \mathrm{~b} \\
\text { Battelle 28-Inch Threaded Plug } & 1.32 / \mathrm{lb} \\
\hline & \$ 1.73 / \mathrm{lb}
\end{array}
$$

Hence, using the average unit cost, the postulated cost for the 48-inch autoclave for the breech design would be: $471,000 \times \$ 1.73=\$ 815,000$. This amount should be increased by $\$ 169,000$ for escalation to 1966 prices, giving a total of $\$ 984,000$ for a breech design.

For the yoke design, the two existing $Y-12$ yoke vessels were found to cost:

$$
\begin{array}{cc}
\text { 30-Inch Vessel } & \$ 0.82 / \mathrm{lb} \\
60-\text { Inch Vessel (adjusted) } & 0.77 / \mathrm{lb} \\
\hline \text { Average } & \$ 0.80 / \mathrm{lb}
\end{array}
$$

The estimated cost of the yoke design for the 48-inch autoclave would be $875,000 \times$ $\$ 0.80=\$ 700,000$. This number should be increased by $\$ 157,000$ for escalation to 1966 prices, giving a yoke estimate of $\$ 857,000$.

The gas autoclave will be a cold-wall system, the pressure vessel having a cooling jacket on the inner diameter. The inner vessel layer will be specially designed to receive an integrally attached cooling liner fabricated from a corrosion-resistant alloy. A preferred method of fabrication for the cooling liner would be a seamless extrusion from the corrosion-resistant alloy. If the liner should be rolled from plate stock and welded longitudinally (and circumferentially if fabricated in sections), the 
assembly would have to be annealed and heat treated to restore some of the original properties to the heat-affected zone. Of course, the molten zone could not be restored to the original conditions of the parent metal. The vessel designer should bear in mind the relative merits of the as-fabricated conditions of whatever metal is chosen for the cooling system, whether it be stainless steel, steel, or aluminum.

\section{MODES OF FAILURE}

As indicated in the foregoing study, the most probable mode of failure for the yoke vessel design would result from undue stretching or failure in tension of the frame plates-an action which would allow the plug seals to leak gas. The most severe effect of such a gas release would be a shock wave in the surrounding atmosphere.

The next most probable failure mode would be a rapid rupture along one side of the vessel, which would release the internal gas pressure quickly, generating a shock wave. Since no "gun action" can occur in such a failure, and since the duration of any reactive force on the vessel will be very short, it appears unlikely that the vessel would be accelerated appreciably or become a hazardous missile. Maximumblast effect would be realized in such a failure since the shock wave would be driven by all the energy of expansion of the gas from the initial conditions to atmospheric pressure.

The possibility of fragmentation failure of this pressure vessel, which is subjected to rapid internal energy release, appears to be quite incredible. The maximum energy potential exists in the form of stored energy prior to rupture: By contrast, sudden release of chemical or nuclear energy within a pressure vessel can cause the yield strength to be exceeded at many points nearly simultaneously, thus causing fragmentation. This situation cannot occur in the gas autoclave.

Rupture of the argon pressure intensifier and related interconnecting piping and fittings is a possibility; but, considering the low mass of the potential fragments and small amounts of energy in the low-volume piping and pressurizing system, no serious hazard is expected from such relatively low-impact missiles. The impact resistance of the barricade, which will be necessary for shock-wave protection, will be quite adequate for such fragments.

In summary, the principal hazard presented by rupture of the gas autoclave is the blast effect. Prior to determining the shock-wave effect on the reinforced concrete cell it was necessary to describe the physics of the wave in terms of duration, peak pressure, and impulse. Before such a description could be provided, the energy level had to be established. An evaluation of the energy of expansion of the compressed argon follows. 


\section{EVALUATION OF ENERGY RELEASE}

The basic assumption employed in the energy calculations for shock-wave analysis is that the gas expansion following rupture would be a reversible adiabatic process, assuming that no change in entropy occurs. It is believed that the assumption of an isentropic expansion tends to maximize the calculation of total energy available for catastrophic release in the vessel-failure process. Other accepted assumptions for the calculations included taking argon as a perfect gas. in its behavior and properties. For example, the ratio of specific heats (gamma) was taken to be $5 / 3$, the value of a perfect monatomic gas. The latter assumption, likewise, should tend to maximize the energy calculations. It is recognized that the actual expansion process will not be truly isentropic, nor will the argon satisfy exactly the perfect gas assumption. However, the actual expansion will occur in a very short time; that is, the process will be of an explosive nature and there will not be sufficient time to transfer enough heat to the surroundings to grossly invalidate these basic assumptions.

On this basis, the amount of work done by the gas in expanding from the initial state (1) to a final state (2) can be calculated from:

$$
W_{1-2}=M_{1} \int_{1}^{2} p d v=\frac{M_{1}}{k-1}\left(p_{1} v_{1}-p_{2} v_{2}\right)
$$

which was based on the relation:

$$
p v^{k}=\text { constant },
$$

where:

$$
\begin{aligned}
& k \quad \text { gives the ratio of specific heats, } \\
& M_{1} \quad \text { is the mass of argon, } \\
& p_{1} \text { and } v_{1} \text { are the initial pressure and specific volume, and } \\
& P_{2} \text { and } v_{2} \text { are the final conditions. }
\end{aligned}
$$

For example, suppose it is assumed that the free volume in the autoclave is 100 cubic feet with a pressure of $30,000 \mathrm{psi}$ and a temperature of $2000^{\circ} \mathrm{C}$. The work of expansion, using Equation 57, would be (using the following constants):

$$
\begin{aligned}
& \mathrm{p}_{1}=(30,000)(144)=4.32 \times 10^{6} \mathrm{lbs} / \mathrm{ft}^{2}, \\
& \mathrm{p}_{2}=(14.7)(144)=2.12 \times 10^{3} \mathrm{lbs} / \mathrm{ft}^{2}, \text { and } \\
& \mathrm{T}_{1}=4092^{\circ} \mathrm{R}=\frac{4092-492}{1.8}=2000^{\circ} \mathrm{C} .
\end{aligned}
$$




$$
\begin{gathered}
\left(\frac{p_{1}}{p_{2}}\right)^{1-k}=\left(\frac{T_{2}}{T_{1}}\right)^{k} \text {, or } \\
{\left[\frac{4.32 \times 10^{6}}{2.12 \times 10^{3}}\right]^{1-\frac{5}{3}}=\left[\frac{T_{2}}{4092}\right]^{\frac{5}{3}} .} \\
T_{2}=194^{\circ} \mathrm{R}
\end{gathered}
$$

$$
\mathrm{pv}=\mathrm{RT}=\frac{1544 t}{M}\left(M, \text { the mol wt of } \mathrm{Ar}=40 ; \mathrm{p} \text { is in } \mathrm{lbs} / \mathrm{ft}^{2} ; v=\mathrm{ft}^{3} / \mathrm{lb} ; \mathrm{T}=0 \mathrm{R}\right) \text {. }
$$

So:

$$
\begin{gathered}
v_{1}=\frac{1544 \mathrm{~T}_{1}}{40 \mathrm{p}_{1}}=\frac{1544(4092)}{40\left(4.32 \times 10^{6}\right)}=0.0366 \mathrm{ft}^{3} / \mathrm{lb} \text {, and } \\
v_{2}=\frac{1544 \mathrm{~T}_{2}}{40 \mathrm{p}_{2}}=\frac{1544(194)}{40\left(2.12 \times 10^{3}\right)}=3.63 \mathrm{ft}^{3} / \mathrm{lb} . \\
M_{1}=\frac{v_{1}}{v_{1}}=\frac{100}{0.0366}=2730 \mathrm{lbs} \text { (argon). }
\end{gathered}
$$

(Note: $V$, represents the free volume in the autoclave in cubic feet.)

Hence:

$$
\begin{aligned}
& w_{1-2}=\frac{2730}{\frac{5}{3}-1}\left[\left(4.32 \times 10^{6}\right)(0.0366)-\left(2.12 \times 10^{3}\right)(3.63)\right], \text { or } \\
& W_{1-2}-617 \times 10^{6} \mathrm{fl} \mathrm{llus}(1 \mathrm{ft} \mathrm{lb}=0.001285 \mathrm{Bru}) \text {, or } \\
& w_{1-2}=\left(617 \times 10^{6}\right)(0.001285)=793 \times 10^{3} \text { Btus. }
\end{aligned}
$$

To simplify the energy calculations for repetitive operations, Equation 57 can be manipulated as follows to solve the work function in terms of pressure alone: 


$$
\begin{aligned}
& W_{1-2}=\frac{M_{1}}{k-1}\left(p_{1} v_{1}-p_{2} v_{2}\right), \\
& M_{1}=\frac{v_{1}}{v_{1}} \text { or } M_{1} v_{1}=v_{1} \text {, and } \\
& M_{1}=\frac{v_{2}}{v_{2}} \text { or } M_{1} v_{2}=v_{2} .
\end{aligned}
$$

Hence:

$$
W_{1-2}=\frac{1}{k-1}\left(p_{1} v_{1}-p_{2} v_{2}\right)
$$

Dividing Equation 6 by $\vee_{1}$ gives:

$$
\frac{W_{1-2}}{V_{1}}=\frac{1}{k-1}\left[p_{1}-p_{2}\left(\frac{V_{2}}{V_{1}}\right)\right]
$$

From the relations, $p_{1} V_{1}^{k}=c$ and $p_{2} V_{2}^{k}=c$, it can be shown that:

$$
\frac{v_{2}}{v_{1}}=\left(\frac{p_{1}}{p_{2}}\right)^{1 / k}
$$

Therefore:

$$
w_{1-2}=\frac{v_{1}}{k-1}\left[p_{1}-p_{2}\left(\frac{p_{1}}{p_{2}}\right)^{1 / k}\right]
$$

Assuming $k=\frac{5}{3}$ :

$$
w_{1-2}=1.5 v_{1}\left[p_{1}-p_{2}\left(\frac{p_{1}}{p_{2}}\right)^{0.6}\right]
$$


To verify the use of Equation 10 in solving for the expansion energy, the example used to illustrate Equation 1 is recalculated from Equation 10 as follows:

$$
\begin{aligned}
& W_{1-2}=1.5(100)\left[4.32 \times 10^{6}-2.12 \times 10^{3}\left(\frac{4.32 \times 10^{6}}{2.12 \times 10^{3}}\right)^{0.6}\right] \text {, or } \\
& W_{1-2}=617 \times 10^{6} \mathrm{ft} \mathrm{lbs,} \mathrm{or} 793 \times 10^{3} \text { Btus. }
\end{aligned}
$$

In the early stages of exploring the possible theoretical methods for approximating the amount of releasable energy from a rapidly expanding gas, another more sophisticated technique was considered. This method will be explained in the discussion that follows. The question of whether the expanding gas follows a purely reversible adiabatic isentropic thermodynamic path is debatable. In an adiabatic expansion, the gas temperature drops as the pressure decreases, as shown in Equation 3. It can be observed in the calculated example that the temperature dropped from 4092 to $194^{\circ} \mathrm{R}$ (or $-266^{\circ} \mathrm{F}$ ) as the pressure decreased from $30,000 \mathrm{psi}(2,000$ atmos) to one atmosphere. It is conceivable that the expansion could follow another path. For instance, it could follow a reversible adiabatic isentropic to a point where the gas temperature reaches room temperature, then follow a reversible isothermal path until the pressure is reduced to atmospheric. The latter path would assure the achievement of maximum work, although the actual path might entail less work. The total work path involving the isentropic followed by an isothermal would be reversible and theoretically maximum. Dr. Stanley H. Jury, The University of Tennessee, has suggested this dual-path method.

The procedure for calculating the energy of expansion is as follows: Values would be determined for the specific volume of argon at various pressures starting at rupture pressure and proceeding down to one atmosphere. The specific-volume values for the isentropic path would be taken in the pressure range between rupture pressure and that pressure which corresponds to room temperature $\left(293^{\circ} \mathrm{K}\right)$. The specificvolume values for the isothermal path would be traced on the latter constant temperature line to atmospheric pressure. Next, the specific-volume values for both thermodynamic paths would be plotted on a semilog graph as one continuous curve with specific volume as the abscissa and pressure as the ordinate. A smooth curve would be drawn connecting the points. The area under the curve and above the line parallel to the abscissa through the pressure point corresponding to one atmosphere would yield the pv product summation equivalent to the total energy of expansion in foot-pound units. The area under the curve between the limits of initial and final specific volume can be obtained by graphical integration or by writing an equation obtained by any of several numerical curve-fitting methods and integrating the equation between limits.

Use of this duo-thermodynamic path procedure requires the knowledge of specific volumes at several pressures throughout the full range of expansion. Empirical data 
for argon can be obtained from Drawing A-401509, Union Carbide Corporation, Linde Division, Tonawanda Laboratories. This drawing was based upon the "TemperatureEntropy Diagram for Argon", prepared by F. Din, British Oxygen Company, Limited, Research and Development Department, London. Unfortunately, this chart is limited to the temperature range of 70 to $600^{\circ} \mathrm{K}$. This means that the initial specific volume at $2273^{\circ} \mathrm{K}$ must be calculated from critical argon values and using the compressibility factor to adjust for deviation from ideality. Use of the T-S chart also implies that the entropy value must be established for the initial pressure and temperature. This relative entropy level is calculated by employing the method of entropy differences between two thermodynamic states, an equation for which may be derived as follows:

Starting with a definitive relationship,

$$
\begin{aligned}
& d S=\frac{d Q_{R}}{T} \text { and taking the ideal gas property: } \\
& d Q_{R}=C_{P} d T \text { - vdp then }
\end{aligned}
$$

dividing by T gives:

$$
\begin{gathered}
\frac{d Q_{R}}{T}=C_{p} \frac{d T}{T}-\frac{v}{T} d p \text {, or } \\
d S=C_{p} \frac{d T}{T}-n R \frac{d p}{p}(\text { where } p v=n R T) \text {, then }
\end{gathered}
$$

integrating between $T_{s}, P_{s}$ and $T, P$,

$$
\begin{aligned}
& \Delta S=\int_{T}^{T} C_{p} \frac{d T}{T}-\int_{P_{S}}^{P} n R \frac{d p}{p^{\prime}} \text { or } \\
& \Delta S=\int_{T_{S}}^{T} C_{p} \frac{d T}{T}-n R \ln \frac{p}{P_{S}}=S_{f}-S_{i} .
\end{aligned}
$$

In order to clarify the preceding principles, an example will be taken from the hazards analysis of the proposed pressure vessel modification mentioned previously in the background information. The normal operating conditions for this vessel analysis are: 20,000 psi, a bulk gas average temperature of $1000^{\circ} \mathrm{C}$, and a free volume of 20 cubic feet: First, the specific volume at maximum or rupture conditions is calculated. 
From basic argon data,

$$
\begin{aligned}
& T_{c}=150.7^{\circ} \mathrm{K}, \\
& P_{c}=48 \text { atmospheres, and } \\
& \rho_{c}=0.510 \mathrm{~g} / \mathrm{cc} .
\end{aligned}
$$

At $1100^{\circ} \mathrm{C}$ and 20,000 psia,

$$
\begin{aligned}
& T_{r}=\frac{1273.1}{150.7}=8.45 \text {, } \\
& P_{r}=\frac{20,000}{(14.7)(48)}=28.4 \text {, } \\
& Z=1.35 \text { (from Hougen and Watson's generalized charts), } \\
& R=\frac{P_{0} v_{0}}{T_{0}}=\frac{(14.7)(359)}{273.1} \frac{(\mathrm{lb})\left(\mathrm{ft}^{3}\right)}{\left(\mathrm{in}^{2}\right)(\mathrm{lb} \text { mole })\left({ }^{\circ} \mathrm{K}\right)}, \\
& \frac{v}{n}=\frac{(1273.1)(1.35)(14.7)(359)}{(20,000)(273.1)}=1.66 \mathrm{ft}^{3} / \mathrm{lb} \text { mole. }
\end{aligned}
$$

From Linde data:

$$
\begin{gathered}
C_{p}=0.124 \mathrm{Btu} / \mathrm{lb} \cdot{ }^{\circ} \mathrm{F} \text { which is independent of temperature in the equation: } \\
\qquad S_{f}-S_{i}=\int_{i}^{f} C_{p} \frac{d T}{T}-n R \ln \frac{p}{P_{s}} .
\end{gathered}
$$

Taking the point $1000^{\circ} \mathrm{C}$ at one atmosphere and a convenient point in the upper region of the T-S diagram:

$$
\begin{aligned}
{\left[S_{1000^{\circ} \mathrm{C}}-S_{5700 \mathrm{~K}}\right] } & =(0.124)(40)(2.303) \log \frac{\mathrm{T}_{f}}{\mathrm{~T}_{\mathbf{i}}} . \\
\mathrm{P} & =1 \text { atmos }
\end{aligned}
$$

(Note: The second term vanishes with $p=1$; the entropy taken from the T-S diagram, at $570^{\circ} \mathrm{K}$ and one atmosphere is 168 joules per gram mole per ${ }^{\circ} \mathrm{K}$; the conversion factor to Btu per lb mole per ${ }^{\circ} \mathrm{F}$ is 0.2389 .) 


$$
\begin{aligned}
& \mathrm{S}_{1000^{\circ} \mathrm{C}, 1 \text { atmos }}=168(0.2389)=(0.124)(40)(2.303) \log \frac{1273.1}{570} \text {, and } \\
& \mathrm{S}_{1500^{\circ} \mathrm{C}, 1 \text { atmos }}=40+3.98=43.98 \mathrm{Btus} / \mathrm{lb} \text { mole } \cdot{ }^{\circ} \mathrm{F} \text {. }
\end{aligned}
$$

Next, take the points at 20,000 psia and one atmosphere with each at the same temperature $-1000^{\circ} \mathrm{C}$ :

$$
S_{1000^{\circ} \mathrm{C}, 20,000 \text { psia }}-S_{1000^{\circ} \mathrm{C}, 1 \text { atmos }}=-\frac{R}{J} \ln \frac{P_{f}}{P_{i}} .
$$

(Note: The first term of the basic equation vanishes since the temperature is constant:)

Determine $R$ for the units in Btus/lb mole ${ }^{\circ} \mathrm{F}$ :

$$
\begin{gathered}
R=\frac{\mathrm{P}_{\mathrm{o}} \mathrm{v}_{\mathrm{o}}}{\mathrm{T}_{\mathrm{o}}}=\frac{(14.7)(144)(359)}{(492)(778)} \mathrm{Btus} / \mathrm{lb} \text { mole } \cdot{ }^{\circ} \mathrm{F}, \\
\mathrm{S}_{1000^{\circ} \mathrm{C}, 20,000 \text { psia }}=43.98-\frac{(14.7)(144)(359)(2.303)}{(492)(778)} \log \frac{20,000}{14.7}, \\
\mathrm{~S}_{1000^{\circ} \mathrm{C}, 20,000 \text { psia }}=43.98-14.35=29.63 \mathrm{Btus} / \mathrm{lb} \mathrm{mole} \cdot{ }^{\circ} \mathrm{F}, \text { or } \\
\mathrm{S}_{1000^{\circ} \mathrm{C}, 20,000 \text { psia }}=\frac{29.63}{0.2389}=124 \text { joules } / \mathrm{gm} \mathrm{mole} \cdot{ }^{\circ} \mathrm{K} .
\end{gathered}
$$

This treatment establishes the entropy level on the T-S diagram for the isentropic expansion. For the specific volumes on the isentropic portion of the curve, the vertical 124 entropy line is followed down the chart taking the values of " $v$ " for arbitrary temperature isotherms at the intersection of each pressure isobar chosen. The constant entropy process is interrupted at the horizontal isotherm, $T=293^{\circ} \mathrm{K}$. For the isothermal portion of the curve, the specific volumes are chosen at each pressure value as the horizontal $293^{\circ} \mathrm{K}$ isotherm is traced to the right on the chart, stopping at $p=1$ atmosphere.

With the $p-v$ plot complete, the area under the curve is graphically integrated. In the case of this example, large graph paper sheets (Dietzgen 3400-L112, semilog) were joined together for a four-cycle plot in order to provide a large area in the upper region for greater accuracy. The $p-v$ area under the curve was calculated to be $6.93 \times 10^{6}$ foot pounds per pound mole, since the pressure was expressed in pounds per square foot and the specific volume in cubic feet per pound mole. Dividing this energy value by the initial specific volume gives:

$6.93 \times 10^{6} \mathrm{ft} \mathrm{lb} / \mathrm{lb}$ mole $\div 1.66 \mathrm{ft}^{3} / \mathrm{lb}$ mole $=4.17 \times 10^{6} \mathrm{ft} \mathrm{lb} / \mathrm{ft}^{3}$ of free volume 
Since the free volume was 20 cubic feet,

$$
W_{1-2}=4.17 \times 10^{6} \mathrm{ft} \mathrm{lb} / \mathrm{ft}^{3} \times 20 \mathrm{ft}^{3}=83.4 \times 10^{6} \mathrm{ft} \mathrm{lbs} .
$$

The thermodynamic process of the foregoing procedure may be visualized by the schematics shown in Figure 38.
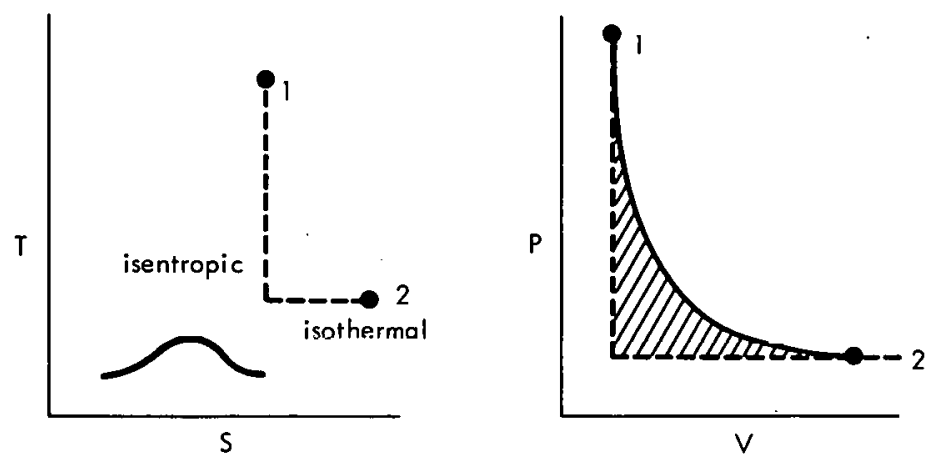

Figure 38. T.S AND T.V CURVES FOR THE DUAL THERMODYNAMIC PATH PROCEDURE.

The example just calculated can be compared to the simplified adiabiatic isentropic process embodied in Equation 67 derived previously.

$$
\begin{aligned}
& w_{1-2}=1.5 \quad v_{1}\left[p_{1}-p_{2}\left(\frac{p_{1}}{p_{2}}\right)^{0.6}\right] \text {, or } \\
& w_{1-2}=1.5(20)\left[2.88 \times 10^{6}-2.12 \times 10^{3}\left(\frac{2.88 \times 10^{6}}{2.12 \times 10^{3}}\right)^{0.6}\right] \text {, or } \\
& w_{1-2}=81.6 \times 10^{6} \mathrm{ft} \mathrm{lbs} .
\end{aligned}
$$

Hence, the purely isentropic process yields essentially the same value $(98 \%)$ as the more elaborate dual-path method.

\section{ANALYSIS OF SHOCK WAVE PRODUCED BY ENERGY RELEASE}

Having established a simple and accurate method for calculating the energy of expansion, the next step is to interpret the energy in terms of shock-wave effect. Attention at this point should be drawn to the basic difference between a shock wave 
and a normal sound wave. The propagation of normal sound waves occurs at a "natural "velocity characteristic of the medium in which the transmission takes place. The wave form is normally, for pure frequencies, that of a sine wave. Shock waves, by contrast, being generated by a much more violent source, have a distorted form with a flat-faced front as shown in the following sketches:

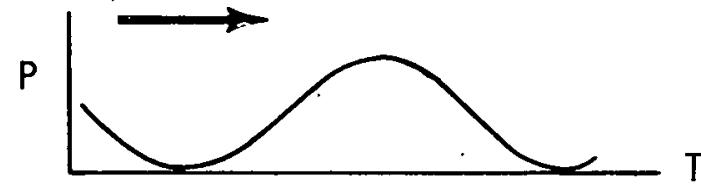

Normal Sound Wave

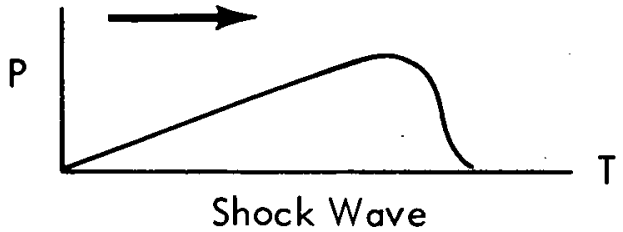

Shock Wave

The velocity of sound in air is about 1000 feet per second compared to about 5500 feet per second for shock waves expected from the pressure vessel rupture. When the flat, discontinuous shock-wave front strikes a wall, the impact is abrupt. A few microseconds prior to the impact, the overpressure at the wall surface is zero. At impact, the. full-peak pressure is imposed instantaneously. The effect is to compress a dense layer of air in a spring-like fashion at the wall surface. If the wall resists' the shock-wave impulse, the pressure at the surface builds to a maximum which is several times (about six times in our case) the initial or incident shock-wave pressure, and the wave is reflected in the opposite direction. Hence, the wall must withstand the magnified or reflected pressure.

Unfortunately, knowledge of the magnitude of the gas expansion energy alone is insufficient to determine the shock-wave properties. It is conceivable that, by application of gas-kinetics principles and atomic mechanics, the shock-wave effect could be predicted. However, such methods were considered impractical and an analogy was drawn between the gas release by vessel rupture and a high-energy explosivespecifically pentolite. It has been observed that the practice is widespread in industry to translate the expansion energy of a ruptured pressure vessel into the HE equivalent for interpretation.

There are indications that the assumption that a gas expansion, equated to a highexplosive equivalent in terms of energy units such as Btus, does not produce as powerful a shock wave as the high explosive. The Institute of Aerophysics, University of Toronto, in a 1958 experiment, shattered a series of glass spheres containing air, helium, and other gases under high pressure. Shock-wave measurements indicated that the shock overpressures for air spheres at 22 atmospheres were less than those produced by comparable TNT charges at the same distance. In a recent telephone conversation with Dr. F. A. Loving of EI Du Pont's Eastern Laboratory, Gibbstown, New Jersey, he expressed the strong opinion that test data on shock-wave damage from pentolite blasts reflect energy effects beyond the energy of detonation (1980 Btus per pound). This suggests that some of the after-burning energy of the oxygendeficient explosive contributes to the blast effect. It is well established, however, 
that the after-burning energy (about 2000 Btus per pound) does not contribute to the shock-wave front itself, since after burning follows the shock wave by several hundred microseconds. Considering the phenomenon suggested by $\mathrm{Dr}$. Loving, it follows that high-explosive conversions using 1980 Btus per pound for the gas-expansion equivalent would render the estimate conservative. That is, the actual peak shock pressure would be less than the calculated value.

In any case, for the shock-wave analysis at hand, the expansion energy expressed in Btus is divided by 1980 Btus to obtain the high-explosive equivalent. For the first example, calculated by the two methods described previously (EVALUATION OF ENERGY RELEASE), the equivalent is:

$$
793 \times 10^{3} \text { Btus } \div 1980 \text { Btus } / \mathrm{lb}=400 \text { lbs of pentolite }
$$

The next step is to determine the peak pressure, impulse, and duration of the shock wave created by a given amount of pentolite. The 400-pound quantity just calculated represents the maximum energy for the Gas Autoclave Facility. These three shock-wave characteristics can be obtained from experimental data by the Ballistic Research Laboratory recorded in BRL Report 1092, "Compiled Free-Air Blast Data on Bare Spherical Pentolite", by H. J. Goodman. Conversion charts showing the relationship between TNT or pentolite weights and shock-wave data are given in Figures 39-41.

\section{BARRICADE DESIGN}

The Ballistic Research Laboratory has compiled data from a vast number of highexplosive experiments conducted to measure the resistance of reinforced concrete to blast. A nomograph relating this experience is presented in Figure 5, Page 31 . On the basis of this nomograph and personal communication by Dr. W. E. Baker of Aircraft Armanents, Inc, the barricade design established for the gas autoclave has been checked and found to be within the region of safety.

A second method of establishing the optimum thickness of concrete for blast resistance has been employed as an independent verification of the BRL nomograph. This technique consists of a calculation method based on a procedure developed by Dr. N. M. Newmark, Research Professor of Structural Engineering, University of Illinois. This method, as applied through the use of TNT shock-wave data, is summarized in the discussion that follows.

The US Atomic Energy Commission's Manual, Chapter 6306, Structural Design-021, states in part:

"To achieve a uniformly balanced blast-resistant design for a building, the blast loadings can only be approximated by simple static loads. Blast is a 
w

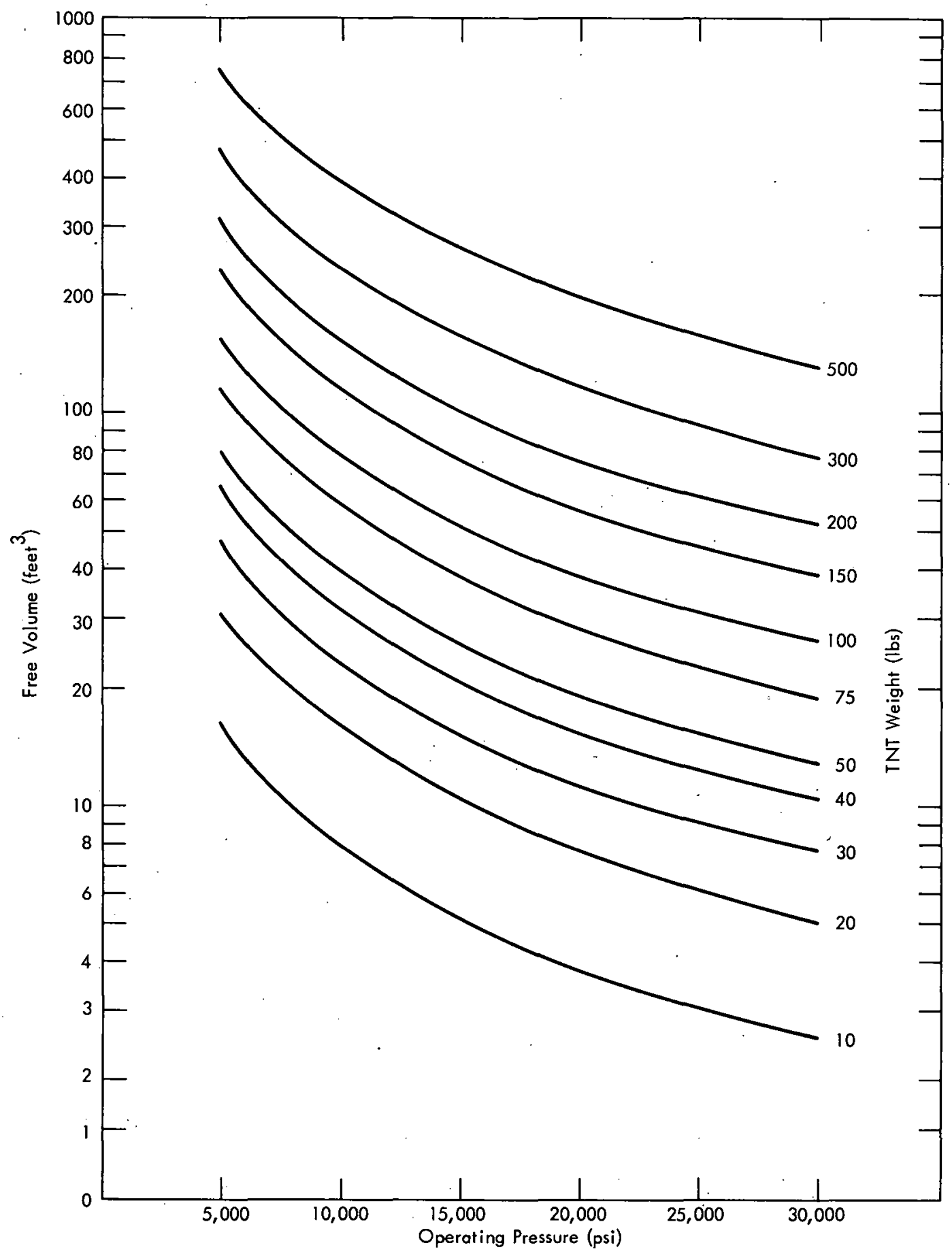

Figure 39. EQUIVALENT EXPLOSIVE WEIGHT.

dynamic loading and the behavior of a structure under this loading depends on the strength, size, shape, and mass of the structure and upon the elastic and plastic properties of the materials of construction". 


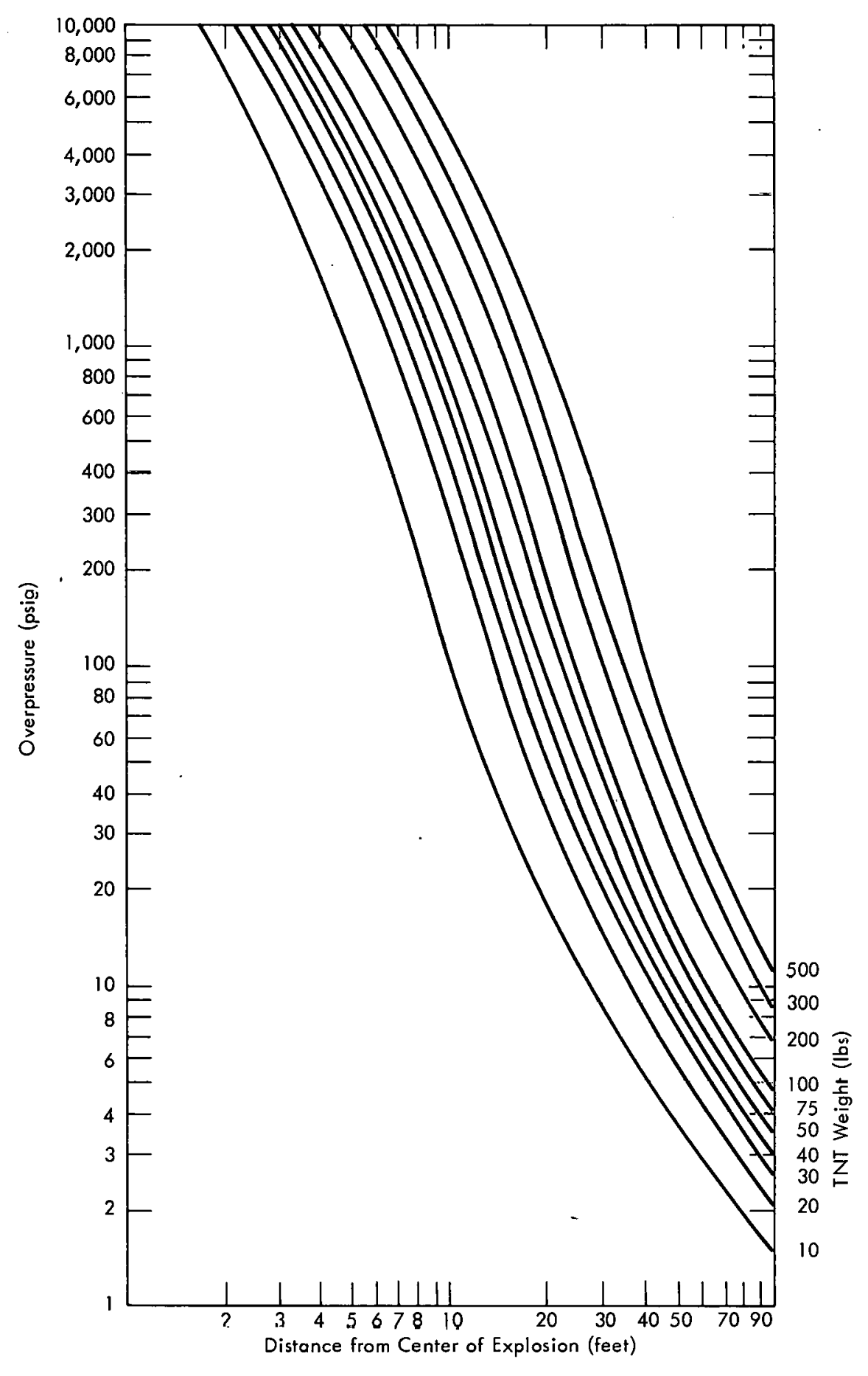

Figure 40. PEAK REFLECTED OVERPRESSURE்.

The design procedure which most nearly fulfills the requirements based on the work of Dr. Newmark involves: (1) the use of a simplified type of resistance-deflection curve in the elastic and plastic ranges; (2) substitution of a load pulse, decaying linearly with time in place of the actual load-time relation, and (3) provision for a 


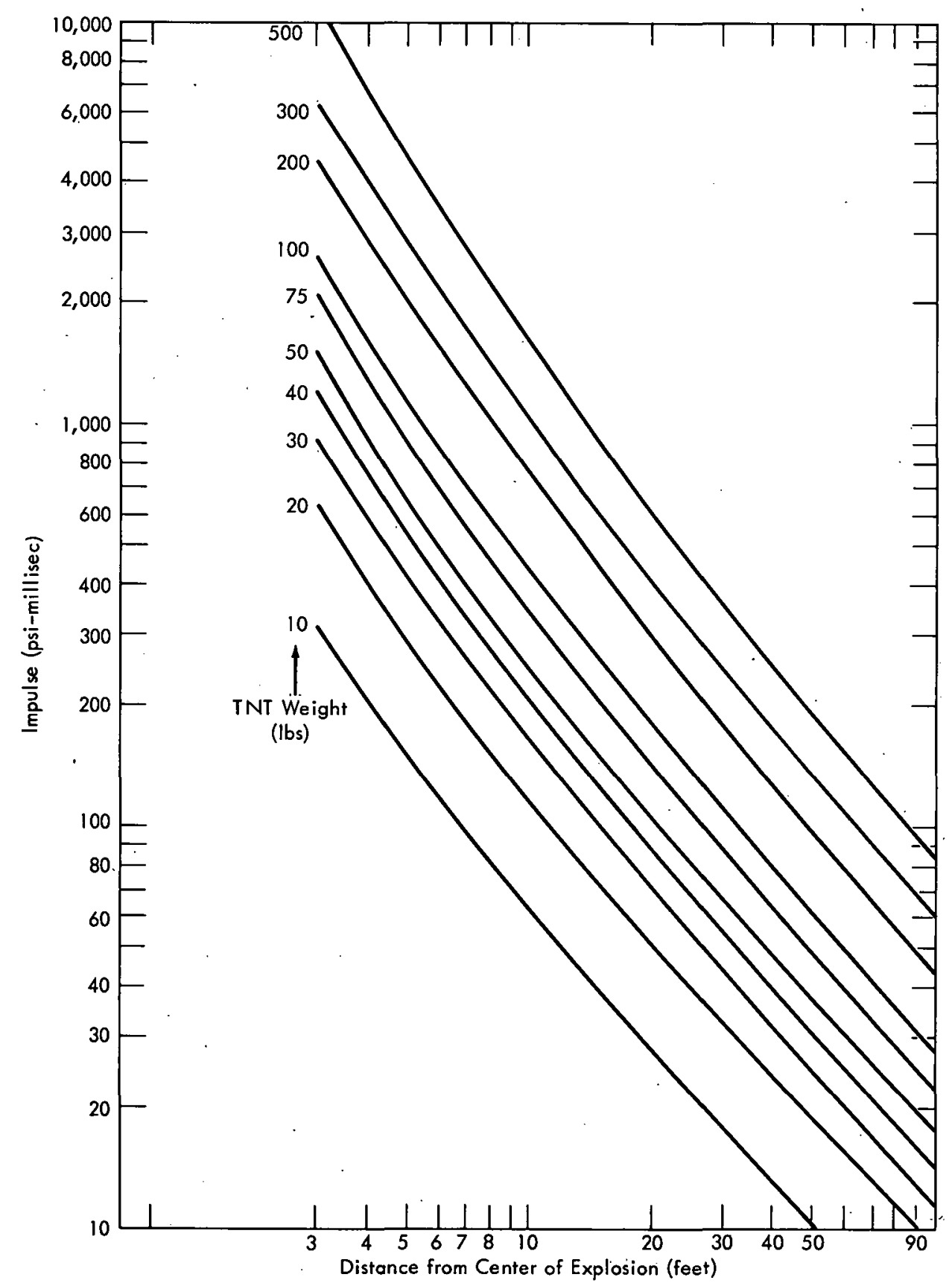

Figure 41. REFLECTED IMPULSE.

rapid means of determining dynamic response. The design procedure consists of estimating: (1) the natural period of vibration of the member and the effective duration of the blast load on the member; (2) the ductility factor or the ratio of the desired limiting deflection to the yield-point deflection, and (3) from these estimates determine the yield resistance or equivalent static load for which the design must be made. After the preliminary design is made, more accurate values of the period of the structure and of its ductility factor can be computed. 
The design parameters for computation are available as follows:

Duration of the shock wave, $t$, is equal to $2 \mathrm{~V} / \mathrm{P}$, where $I$ represents the impulse and $P$ is the pressure. Both $I$ and $P$ are functions of distance from the center of explosion and weight of TNT, as shown in Figures 39-41. The natural period of vibration, $T$, for the member in its initial elastic state if found using standard analytical or numerical procedures.

The deflection does not need to be estimated accurately, but can be selected for the material where the ductility factor, $\mu$, for a completely brittle structure equals 1.0 . For moderately brittle structures, $\mu$ ranges from 3 to 5 ; for moderately ductile structures, $\mu$ ranges from 10 to 30 ; for very ductile structures, $\mu$ is greater than 40 .

The required static resistance or equivalent static load is found from the relation:

$$
P=\left[\frac{T}{\pi t} \sqrt{2 \mu-1}+\frac{1-\frac{1}{2 \mu}}{1+0.7 \frac{T}{t}}\right] P_{s} .
$$

The design procedure as previously described was used in the preliminary design of the cell structure to determine equivalent static loads. The structure must be designed to resist the equivalent explosive weight of TNT, as determined by the operating condition of the gas autoclave. The ductility of structure and duration of the load pulse have been considered in determining the equivalent static load. The remainder of the design is essentially like the ordinary routine for static loads.

\section{BIOLOGICAL CONSIDERATIONS}

The best available information on the biological aspects of blast phenomena has been compiled by the Lovelace Foundation for Medical Education, Albuquerque, New Mexico. A report issued by the Defense Atomic Support Agency, DASA-1271, "Biological Effects of Blast", by Clayton S. White, MD, represents a selective summary of the current status of knowledge in this field.

Even though the Gas Autoclave Facility is provided with adequate barricade structure to withstand blast and with a blow-out panel wall to relieve overpressure, there is the potential danger of reflected, deflected secondary shock waves from the surroundings of the facility which could penetrate openings in the operating cubicle. It is expected that the cubicle design will eliminate the hazard and attenuate such secondary shock waves below the biologically "safe" criteria recommended by the Lovelace Foundation. The lungs and ears are man's most sensitive organs. The safe limits for lungs indicated in the DASA report are "15 psi maximal incident overpressure with a classical wave form and a 6 psi incident reflecting instantaneously to 15 psi 
maximal". For the ears, the limit is quoted at "5 psi incident and maximal overpressure and 2.5 psi incident reflecting to 5 psi maximal".

Quoting from the report on gross pathological aspects:

"It is definitely true-that damage to the animal from fast-rising overpressures occurs at those areas in the body where the variations in tissue density are the greatest. The special target organs are those containing air; eg, the paranasal sinuses, the ears, the GI tract, and particularly, the lungs. In addition, there are signs and symptoms which occur at a distance from these organs which are due to air emboli. Any organ in the body may be involved".

"In air blast, rupture of the ear and bleeding from the sinuses is not an immediate threat to the organisms. Rupture of the abdominal viscera is relatively rare, unless displacement and impact occur. However, abdominal pathology is more prominent in underwater casualities. Bleeding into and edema of the lungs are common and very dangerous, but most hazardous of all are ruptures of the walls between the alveoli and the pulmonary vein which allow air emboli to reach the heart and general circulation".

\section{CONCLUDING REMARKS}

It is apparent that the potential amount of energy which could be stored in the compressible argon gas fluid under operating conditions would be formidable: With.a pressure of over 2000 atmospheres and an average temperature of $1500^{\circ}$ : C, there would be: over 2700 pounds of argon, equivalent to nearly 25,000 standard cubic feet, confined in a space of 100 cubic feet under maximum conditions. If a mechanical failure of the vessel occurred during the operating cycle there would be an abrupt gas release, possibly accompanied by explosively propelled missile fragments, creating a shock wave in the vessel area. Assuming the gas release to be essentially instantaneous, the amount of work exerted by the blast wave can be estimated from an isentropic expansion using pure gas laws. The intensity and duration of the blast wave at various distances from its source can then be estimated conservatively by computing an equivalent weight of explosive, using data obtained from detonation of chemical explosives in air. The energy from isentropic expansion under the maximum conditions previously stated is equivalent to that of approximately 400 pounds of pentolite. The incident peak shock pressure for such an explosion is about 400 psi with a wave duration of approximately 600 microseconds. If a concrete barrier or containment barricade wall were at a distance of 12 feet from the vertical centerline of the vessel, the incident shock wave would be reflected by the wall creating a resultant reflected shock wave with a peak pressure of 2700 psi and a duration of about 650 microseconds. The duration of that portion of the wave in which the pressure is in excess of 2000 psi is estimated to be between 25 and 50 microseconds, which means that the wall would be under the impact of a $2000-2700$ psi pressure 25 to 50 microseconds. The total impulse of the shock wave would be 475 psi- 
millisec. These conditions define the barricade requirements for shock-wave resistance.

Geometry of the barricade design should exclude 90 degree or angular corners because of reflected shock magnification generated by intersecting flat wall sections. This restriction dictates the use of curved-surface geometries such as hyperbolic, elliptic, or circular arches and contours.

Full advantage should be taken of the use of earth embankments, recessment in compacted earth, and other features provided by natural terrain in order to minimize the amount of reinforced concrete required to withstand missile fragments and blast waves. The vessel containment should be designed on a conservative basis in full support of the precautionary measures recommended in this hazard analysis.

Another important requirement of the containment cell design is a frangible wall on the side of the building facing the natural earth walls of the ravine in which the facility will be constructed. The purpose of the "blow-out" wall is to relieve overpressure associated with the shock wave following a potential vessel failure. The frangible wall might consist of a light frame supporting two panels of thin plastic film with an intermediate dead-air space for thermal insulation. Without a blow-out panel, a secondary overpressure would be created with in the 40,000-cubic-foot cell if the 25,000 standard cubic feet of gas were released, assuming the shock wave would fail to rupture the cell wall. This secondary overpressure would probably be around 10 psi, which could be sufficient to collapse the cell structure since the duration of the overpressure from gross gas release would probably be several seconds. It should be borne in mind that the shock wave, being propagated in air at about 5500 feet per second, would precede the slower gas release which would fill the cell at something less than sonic velocity. 
THIS PAGE

\section{WAS INTENTIONALLY LEFT BLANK}




\section{BIBLIOGRAPHY}

Newmark, N.M.; "An Engineering Approach to Blast-Resistant Design", ASCE Transactions, Paper 2786; October 1953.

Jury, Stanley H.; An Investigation of Argon Expansion to Determine Maximum Work, Chemical Engineering Department, The University of Tennessee; July 1963.

Browne, Howard C., Hileman, Harold, and Weger, Lowell, C.; "Barricades for High Pressure Research", I and E Chemistry, 53 (10), p 52A; October 1961.

Loving, F. A.; "Barricading Hazardous Reactions", I and E Chemistry, 49, pp 17441746; October 1957.

White, Clayton S.; "Biological Effect of Blast", Defense Atomic Support Agency Technical Progress Report, DASA-1271; December 1961 .

Boyer, D. W., Brode, H. L., Glass, I.I., and Hall, J. G.; Blast from a Pressurized Sphere, UTIA Report 48; University of Toronto Institute of Aerophysics; January 1958.

Flynn, P. D.; Elastic Response of Simple Structures to Pulse Loading, BRL Memorandum Report 525; November 1951.

Tolch, N. A. and Bushkovitch, A. V.; Penetration and Crater Volume in Various Kinds of Rocks as Dependent on Caliber, Mass, and Striking Velocity of Projectile, BRL Report 641; October 1947.

Allen, F. J. and Rally, F.; A Plastic-Rigid Theory of the Response of Beams to Air Blast Loading, BRL Memorandum Report 811; July 1954.

Goodman, H. J.; Compiled Free-Air Blast Data on Bare Spherical Pentolite, BRL Report 1092; February 1960.

Hougen, O.A. and Watson, K. M.; Chemical Process Principles, Part Two, Thermodynamics; John Wiley and Sons, New York (1947).

Porzel, F. B.; Comments on Explosive Rupture of Union Carbide Autoclave; Institute of Defense Analyses, Washington, DC; November 6, 1963.

Kaplan, M. F.; "Crack Propagation and the Fracture of Concrete," Journal of the American Concrete Institute, November 1961.

Concrete Reinforcing Steel Institute Handbook, Revised 1957. 
Urquhart, O'Rourke, and Winter; Design of Concrete Structures, Sixth Edition; McGraw-Hill Book Company, Inc, New York (1958).

Weber, J. P., Savitt, J., Krc, J., and Browne, H. C.; "Detonation Tests Evaluate High Pressure Cells", I and E Chemistry, 53 (11), pp 128A-133A; November.1961.

Shortley, G. and Williams, D.; Elements of Physics, Second Edition; Prentice-Hall, Inc (1955).

Baker, W. E.; Evaluation of Shock and Missile Hazards from a Bursting Pressure Vessel; Aircraft Armanents, Inc, Cockeysville, Maryland; August 14, 1963 (hand-written report).

Baker, W. E.; Evaluation of Shock and Missile Hazards from a Bursting Pressure Vessel, ER-3192; American Armaments, Inc, Cockeysville, Maryland; August 1963.

Baker, W. E.; Evaluation of Shock and Missile Hazards from a Bursting Pressure Vessel, Addendum to AAI ER-3192; Cctober 1963.

Rouse, H.; Fluid Mechanics for Hydraulic Engineers; McGraw-Hill Book Company, Inc, New York (1938).

Zemansky, M. W.; Heat and Thermodynamics, Fourth Edition; McGraw-Hill Book Company, Inc, New York (1957).

Mooney, D. A.; Introduction to Thermodynamics and Heat Transfer; Prentice-Hall, Inc (1956).

Getman, F. H. and Daniels, F.; Outlines of Physical Chemistry; John Wiley and Sons, Inc, New York (1943).

Courant, R. and Friedrichs, K. O.; Supersonic Flow and Shock Waves, l; Interscience Publishers, Inc, New York (1948).

Zeldovich, B. and Kompaneets, A. S.; Theory of Detonation; Academic Press, New York (1960).

Lewis, G. N. and Randall, M.; Thermodynamics and the Free Energy of Chemical Substances, First Edition; McGraw-Hill Book Company, Inc, New York (1923). 